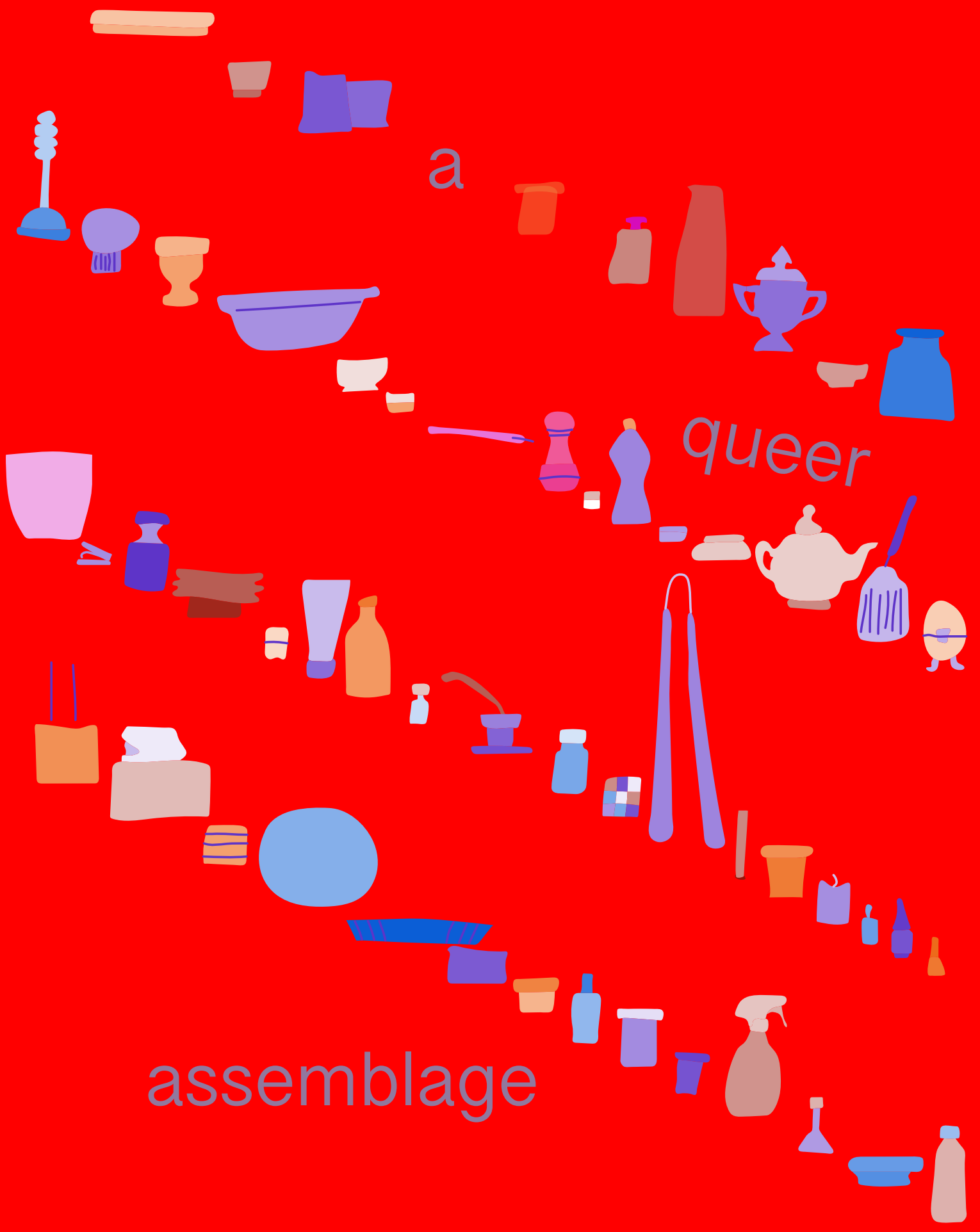

a thesis by Michelle Ashurov 



\title{
A QUEER ASSEMBLAGE
}

\author{
by \\ Michelle Ashurov \\ Bachelor of Architectural Science, Ryerson University, \\ 2016 \\ A thesis presented to Ryerson University in partial \\ fulfillment of the requirements for the degree of Master \\ of Architecture in the Program of Architecture
}

Toronto, Ontario, Canada, 2019

(c) Michelle Ashurov 2019 


\section{author's declaration}

I hereby declare that I am the sole author of this thesis. This is a true copy of the thesis, including any required final revisions, as accepted by my examiners.

I authorize Ryerson University to lend this thesis to other institutions or individuals for the purpose of scholarly research.

I further authorize Ryerson University to reproduce this thesis by photocopying or by other means, in total or in part, at the request of other institutions or individuals for the purpose of scholarly research.

I understand that my thesis may be made electronically available to the public.

Michelle Ashurov 



\title{
abstract
}

\author{
A Queer Assemblage \\ Master of Architecture 2019 \\ Michelle Ashurov \\ Ryerson University
}

The tradition and reproduction of heteronormativity is evident in all aspects of social life, extending to nationality, culture, law, commerce, medicine, intimacy, leisure, and beyond. Speculations at the intersection of queer space and architecture began in the 1980s, focusing on a resistance to the hegemony of heterosexuality. Architecture is not safe from the ideologies that assemble and enforce this hegemony. By way of recounting and marking up history through a queer lens, a queer assemblage is formed, disorienting and subverting [hetero]normative constructs at the confluence of sociality and architectural space. The destabilization of oppressive advances that (im/ex)plicitly target singular or intersecting social locations not only unveils the engendering of heteronormativity in all facets of life, but promises to delineate space for a proper queer occupation. 


\section{acknowledgments}

The following individuals helped me in forming a queer assemblage.

Firstly, I would like to thank my supervisor, John Cirka, for spending countless hours at our meetings which typically resembled a reading club, rich with tangents that led my imagination to grasp concepts that kept trying to slip away.

Thank you to my second reader, Christine Leu, for her consistent enthusiasm and support of my work.

Thank you to my program representative, Colin Ripley, for his knowledge and familiarity in the act of queering.

Thank you to P Elaine Sharpe for bringing to light what was in the dark.

Thank you to Nahal Rahnamaei for entertaining all of my ramblings, making sense of my scatter, and nurturing a stimulating creative environment which we will continue to share.

Thank you to all my loved ones for your endless positivity and encouragement.

Finally, thank you to the individuals who have shaped how I make sense of life. 
contents

author's declaration iii

abstract v

acknowledgments vii

contents viii

list of figures $\quad \mathrm{x}$

introduction $\quad 001$

$\begin{array}{ll}\text { sexual purification } & 011\end{array}$

Q

pop-ups 023

balls 039

washrooms 043

ix

$\begin{array}{ll}\text { closetses } & 067\end{array}$

objects in digital space 083

$\begin{array}{ll}\text { chairs } & 105\end{array}$

$\begin{array}{ll}\text { elements } & 117\end{array}$

$\begin{array}{ll}\text { stored in house } & 127\end{array}$

$\begin{array}{ll}\text { towards } & 175\end{array}$

$\begin{array}{ll}\text { references } & 181\end{array}$ 
figure

$001 \quad$ Untitled, Neal Boenzi, The New York Times/ Redux, 1986, Source: www.cnn.com/2016/04/18/ us/80s-times-square-then-and-now/index.html

$002 \quad$ Untitled, Andreas Feininger, Getty Images, 1983, Source: www.cnn.com/2016/04/18/us/80stimes-square-then-and-now/index.html

003 SHE NEEDS A STEAK... OR A SWEATER, Robert Presutti, The New York Times, 2007, Source: www. nytimes.com/2007/02/28/dining/reviews/28rest.html

$004 \quad$ Untitled, Benjamin Lowy, Reportage by Getty Images for CNN, 2016, Source: www.cnn.com/2016/04/18/ us/80s-times-square-then-and-now/index.html

$005 \quad$ Untitled, Benjamin Lowy, Reportage by Getty Images for CNN, 2016, Source: www.cnn.com/2016/04/18/ us/80s-times-square-then-and-now/index.html

$006 \quad$ Boom staff and friends hang after hours, Sofie Weber, Source: www.thenandnowtoronto. com/2014/09/then-now-boom-boom-room/

007 The Palladium: Nightclub in Manhattan, Edie Lee Cohen, Interior Design, October 1, 1985, 230, Source: An Organism of Hedonistic Pleasures: The Palladium, Ivan. L Munuera, Log 41, Fall 2017, 102

$008 \quad$ march 172018 00:27 444 dufferin street, Michelle Ashurov, 2018

009 march 172018 01:09 444 dufferin street, Michelle Ashurov, 2018

$010 \quad$ march 172018 01:20 444 dufferin street, Michelle Ashurov, 2018

$011 \quad$ march 172018 02:39 444 dufferin street, Michelle Ashurov, 2018

012 march 172018 03:15 444 dufferin street, Michelle Ashurov, 2018

013 march 172018 03:16 444 dufferin street, Michelle Ashurov, 2018

014 june 242017 00:34 the great hall, Michelle Ashurov, 2017

Untitled, Andre Vautour, 2017, Source: still

015 from personal video shot by friend

$016 \quad$ june 32018 00:40 500 keele street, Michelle Ashurov, 2018 


\section{list of figures}

017 november 262017 00:36 191 geary avenue, Michelle Ashurov, 2018

018 december 12017 00:17 luanda house, Michelle Ashurov, 2017

019 october 82017 00:34 500 keele street, Michelle Ashurov, 2017

020 september 102017 02:39191 geary avenue, Michelle Ashurov, 2017

021 Untitled, Twitter user @communistbabe, Twitter, 2018, Source: www.twitter.com/communistbabe/ status/956948479984750592

022 Untitled, Instagram user @adamjosephmusic, Instagram, 2018 Source: www.instagram.com/p/BgFRsWuHBRU

023 series of bathroom passage conditions, Michelle Ashurov, 2017

024 series of bathroom stalls, Michelle Ashurov, 2017

025 "The ladies' parlor at the Willard Hotel in Washington, shown during Inauguration Week in 1861.

Presumably, men were welcomed inside during an inauguration party", Library of Congress, 1861, Source: www.citylab.com/design/2018/12/historywomens-bathroom-design-lounge/576742/

026 “The gentlemen's parlor, reading, and sitting room at the Willard, also shown during 1861's inaugural celebrations, with no women visible", Library of Congress, 1861, Source: www.citylab.com/design/2018/12/ history-womens-bathroom-design-lounge/576742/

027 still of tv series Popular s02e07 5:44, 2000, Source: www.youtube.com/watch?v=qEg4ytvDo9o

028 still of tv series Popular s02e07 35:45, 2000, Source: www.youtube.com/watch?v=qEg4ytvDo9o

029 still of tv series Popular s02e07 20:37, 2000, Source: www.youtube.com/watch?v=qEg4ytvDo9o

030 still of tv series Popular s02e07 20:34, 2000, Source: www.youtube.com/watch?v=qEg4ytvDo9o

031 still of tv series Popular s02e07 35:55, 2000, Source: www.youtube.com/watch?v=qEg4ytvDo9o

032 Table 3.7.4.3.A. Water Closets for Assembly Occupancies, Adapted from Ontario Regulation 332/12 Building Code, Government of Ontario, 2018, Source: www.ontario.ca/laws/regulation/120332 
033 Table 3.7.4.3.C. Water Closets for Assembly Occupancies, Adapted from Ontario Regulation 332/12 Building Code, Government of Ontario, 2018, Source: www.ontario.ca/laws/regulation/120332

034 Stabian Baths in Pompeii based on Figure 75 by Inge Nielsen in Thermae et Balnea: The Architecture and Cultural History of Roman Public Baths, 1990, Roy Bowen Ward, Source: Women in Roman Baths, The Harvard Theological Review, (85) 2, April 1992, 129

$035 \quad$ Capito Baths in Miletus based on Figure 229 by Inge Nielsen in Thermae et Balnea: The Architecture and Cultural History of Roman Public Baths, 1990, Roy Bowen Ward, Source: Women in Roman Baths, The Harvard Theological Review, (85) 2, April 1992, 130

036 Afternoon tea at sketch, The Swelle Life, Source: www.theswellelife.com/swelle life/2013/12/afternoon-tea-at-sketch.html

037 Sketch Washrooms during the holidays, Instagram user@sketchlondon, Source: www.secretldn. com/sketch-beautiful-mayfair-restaurant/

038 Sketch Washrooms during Easter, Instagram user @sketchlondon, Source: www.secretldn. com/sketch-beautiful-mayfair-restaurant/

039 Untitled, Instagram user @theryanjude, Instagram, 2019

$040 \quad$ Untitled, Instagram user @shea.daspin, Instagram, 2019

$041 \quad$ Untitled, Instagram user @shea.daspin, Instagram, 2019

042 Untitled, Instagram user @1missannabel, Instagram, 2019

$043 \quad$ Untitled, Instagram user @zzhongji, Instagram, 2019

$044 \quad$ Untitled, Instagram user @tmyuzu_6, Instagram, 2019

045 Untitled, Instagram user @tmyuzu_6, Instagram, 2019

$046 \quad$ Untitled, Instagram user @ddehardt, Instagram, 2019

$047 \quad$ Untitled, Instagram user @talkramer, Instagram, 2019

$048 \quad$ Untitled, Instagram user @ allthestuffineed, Instagram, 2019

$049 \quad$ Untitled, Instagram user @ tiffanyarment_6, Instagram, 2019

$050 \quad$ Untitled, Instagram user @ tiffanyarment_6, Instagram, 2019 
$051 \quad$ Untitled, Instagram user @

tiffanyarment_6, Instagram, 2019

052 Untitled, Instagram user @sgmi7, Instagram, 2019

$053 \quad$ Untitled, Instagram user @sgmi7, Instagram, 2019

$054 \quad$ Untitled, Instagram user @sgmi7, Instagram, 2019

055 Untitled, Instagram user @sgmi7, Instagram, 2019

056 Untitled, Instagram user @sgmi7, Instagram, 2019

057 Untitled, Instagram user @sgmi7, Instagram, 2019

$058 \quad$ Untitled, Instagram user @sgmi7, Instagram, 2019

059 Untitled, Instagram user @abbiwebsterr, Instagram, 2019

060 Untitled, Instagram user @abbiwebsterr, Instagram, 2019

$061 \quad$ Untitled, Instagram user @

katfernandez28, Instagram, 2019

$062 \quad$ Untitled, Instagram user @

katfernandez28, Instagram, 2019

$063 \quad$ Untitled, Instagram user @

primalaprincess, Instagram, 2019

$064 \quad$ Untitled, Instagram user @chhwyn, Instagram, 2019

065 Untitled, Instagram user @chhwyn, Instagram, 2019

$066 \quad$ Untitled, Instagram user @chhwyn, Instagram, 2019

$067 \quad$ Untitled, Instagram user @chhwyn, Instagram, 2019

$068 \quad$ Untitled, Instagram user @chhwyn, Instagram, 2019

069 Untitled, Instagram user @jo_withthe_fro, Instagram, 2019

$070 \quad$ Untitled, Instagram user @nadialba_, Instagram, 2019

$071 \quad$ Untitled, Instagram user @idca13, Instagram, 2019

072 Untitled, Instagram user @therauldelara, Instagram, 2019

073 Untitled, Instagram user @jgee, Instagram, 2019

074 Untitled, Instagram user @smcdnyc, Instagram, 2019

$075 \quad$ Untitled, Instagram user @arthur_ amsterdam, Instagram, 2019

076 Untitled, Instagram user @cloudluxury, Instagram, 2019 
077 Untitled, Instagram user @jazzkata, Instagram, 2019

078 Exterior view of Don't Miss a Sec', Monica Bonvicini, 2004, Source: www.monicabonvicini. net/work/dont-miss-a-sec-2004/

079 “Interior” view of Don’t Miss a Sec', Monica Bonvicini, 2004, Source: www.monicabonvicini. net/work/dont-miss-a-sec-2004/

080 Still from BOXTRUCKSEX - SHY HOT CHICK FUCKS IN A ONE-WAY MIRRORED TRUCK IN THE PUBLIC at 5 41, Box Truck Sex, Pornhub, 2017, Source: www.pornhub. $\mathrm{com} /$ view_video.php?viewkey=ph58ad87e589b07

$081 \quad$ Pollee, UiWE, 2011, Source: www.dezeen. com/2011/07/15/pollee-by-uiwe/

082 Pollee, UiWE, 2011, Source: www.dezeen. com/2011/07/15/pollee-by-uiwe/

083 Pollee, UiWE, 2011, Source: www.dezeen. com/2011/07/15/pollee-by-uiwe/

084 Brasserie washroom, Diller Scofidio + Renfro, 1999, Source: www.dsrny.com/project/brasserie

Urinal, Bureau A, 2015, Source: www.dezeen. com/2015/08/18/bureau-a-fountain-2017-pinkmarble-urinal-pissoir-zurich-car-park/

$086 \quad U$ Urinal, Bureau A, 2015, Source: www.dezeen. com/2015/08/18/bureau-a-fountain-2017-pinkmarble-urinal-pissoir-zurich-car-park/

087 Urinal, Bureau A, 2015, Source: www.dezeen. com/2015/08/18/bureau-a-fountain-2017-pinkmarble-urinal-pissoir-zurich-car-park/

$088 \quad$ Urinal, Bureau A, 2015, Source: www.dezeen. com/2015/08/18/bureau-a-fountain-2017-pinkmarble-urinal-pissoir-zurich-car-park/

$089 \quad$ National Coming Out Day logo, Human Rights Campaign Fund, 1993, Source: Closets, Clothes, Disclosure, Henry Urbach, Assemblage (30), 1996, 67

$090 \quad$ Plans of clothes storage cupboards, Wooster Bard Field, House Planning, 1940, Source: Closets, Clothes, Disclosure, Henry Urbach, Assemblage (30), 1996, 66

091 Expulsion of the Money-Changers from the Temple, Giotto di Bondone, 1304-6, Source: www.wga.hu/ html_m/g/giotto/padova/3christ/chris11.html 
092 Bedroom closet for one person, Maud M. WIIson, Closets and Other Storage Arrangements for the Farm Home, 1934, Source: Closets, Clothes, Disclosure, Henry Urbach, Assemblage (30), 1996, 66

093 diagram of the ante-closet, Michelle Ashurov, 2018

$094 \quad$ Experimental hybrid storage furniture by Kata Monus, Reka Hegyhati, 2012, Source: www. katamonus.blogspot.com/p/furniture.html

095 Alexander Girard: An Uncommon Vision, Unknown, Herman Miller Reach, Source: hermanmillerreach.com/en/Post/Story/47

$096 \quad$ Experimental hybrid storage furniture by Kata Monus, Reka Hegyhati, 2012, Source: www. katamonus.blogspot.com/p/furniture.html

097 Coiffeuse, Eileen Gray, 1926, Source: www.madparis. $\mathrm{fr} /$ francais/musees/musee-des-arts-decoratifs/ editions/arts-decoratifs/francais/musees/museedes-arts-decoratifs/parcours/art-nouveau-artdeco/l-art-deco-modernite-et-tradition/coiffeuse

098 Coiffeuse, Eileen Gray, 1926, Source: http://www. madparis.fr/francais/musees/musee-des-artsdecoratifs/editions/arts-decoratifs/francais/musees/ musee-des-arts-decoratifs/parcours/art-nouveau-artdeco/l-art-deco-modernite-et-tradition/coiffeuse

099 Untitled, Unknown, Apartment Therapy, Source: www. apartmenttherapy.com/closet-offices-121399

$100 \quad$ Untitled, Unknown, Apartment Therapy, Source: https:// www.apartmenttherapy.com/closet-offices-121399

101 Untitled, Unknown, Apartment Therapy, Source: www. apartmenttherapy.com/closet-offices-121399

$102 \quad$ La Tournette by Freaks Architecture, David Foessel, 2018, Source: www.freaksarchitecture. com/wordpress/portfolio/la-tournette/

103 La Tournette, Freaks Architecture, 2018, Source: www. freaksarchitecture.com/wordpress/portfolio/la-tournette/

104 Stanza per un uomo, Franco Albini, VI Triennale di Milano, 1936, Source: www.socks-studio.com/2015/09/30/ franco-albinis-a-room-for-a-man-1936/

105 Furniture House 1, Shigeru Ban Architects, 1995, Source: www.shigerubanarchitects.com/ works/1995_furniture-house-1/index.html 
106 Home Storage, Herbert Gehr, Life, 1945, Source: www.harvarddesignmagazine.org/issues/43/ before-billy-a-brief-history-of-the-bookcase

107 Hakama House, Jun Tamaki, 1998, Source: Michael Freeman, www.michaelfreemanphoto. $\mathrm{com} / \mathrm{media} / 3 \mathrm{~d} 4 \mathrm{ecae0}-4439-11 \mathrm{e0}-810 \mathrm{c}-$ fd75e0eb609f-hakama-house

108 Hakama House, Jun Tamaki, 1998, Source: Michael Freeman, www.michaelfreemanphoto. $\mathrm{com} / \mathrm{media} / 3 \mathrm{~d} 4 \mathrm{ecae0}-4439-11 \mathrm{e0}-810 \mathrm{c}-$ fd75e0eb609f-hakama-house

109 Untitled, Instagram user @sixat21, Instagram, 2019 Source: www.instagram.com/p/BsQH3ZOF720

$110 \quad U n t i t l e d$, Instagram user @sammytunis, Instagram, 2018, Source: www.instagram.com/p/BpCp6DqBMtD

111 Untitled, Instagram user @poooooookie, Instagram, 2018, Source: www.instagram.com/p/BrMuWvbnHXe

112 Untitled, Instagram user @justcozyy, Instagram, 2018, Source: www.instagram.com/p/BrOIDdfF88z/

113 Untitled, Unknown, Instagram, 2018, Source: www.instagram.com/p/BrNE58fBHOu

114 Playboy Townhouse, Humen Tan and R. Donald Jaye, Playboy Magazine, 1962, Source: www.apartmenttherapy. com/the-1962-playboy-townhouse-pos-125687

115 Playboy Townhouse, Humen Tan and R. Donald Jaye, Playboy Magazine, 1962, Source: www.apartmenttherapy. com/the-1962-playboy-townhouse-pos-125687

$116 \quad$ Untitled, Duncan Rawlinson, Source: www. hallaminternet.com/desire-lines-and-blogging/

117 straights and oblique, Michelle Ashurov, 2018

118 Arne Split chair, Martino Gamper, Anna Arca, 2007, Source: www.martinogamper.com/get-it-louder/

119 Upside down chair, Martino Gamper, 2012, Source: www.themoderninstitute.com/artists/ martino-gamper/works/chairs/154/

120 Kolho chair, Matthew Day Jackson, 2019, Retrieved from: www.dezeen.com/2019/04/10/matthew-dayjackson-kohlo-formica-furniture-milan-2019/

121 Mutant, Chair, Helmut Palla, 2005, Source: www. designboom.com/design/helmut-palla/ 
122 Bobbin Chair, Eva Fly, 2015, Source: www. evafly.dk/?work=bobbin-chair

123 MingMu, Chair, Martino Gamper, Anna Arca, 2007, Source: www.martinogamper.com/get-it-louder/

124 L'Echasuffesuse sofa, Louis Durot, 1978, Source: www.wright20.com/auctions/2015/06/design/236

$125 \quad$ Hubert le Galle seats, Instagram user @ musingselles, Instagram

126 Sit yourself down, Jamie Isenstein, 1998, Source: www.reed.edu/reed magazine/march2012/ articles/alumni_profiles/isenstein.html

127 Sit yourself down, Jamie Isenstein, 1998, Source: www.reed.edu/reed magazine/march2012/ articles/alumni_profiles/isenstein.html

128 Tissue Box, Coat Hook, Hygienic Paper Roll, Dunne and Raby, 2000, Source: www. dunneandraby.co.uk/content/projects/277/0

129 Steps, Dunne and Raby, 2000, Source: www. dunneandraby.co.uk/content/projects/277/0

130 Series of adult furniture, Dunne and Raby, 2000, Source: www.dunneandraby.co.uk/content/projects/277/0

131 Low Table and Hygienic Paper Roll, Dunne and Raby, 2000, Source: www.dunneandraby. co.uk/content/projects/277/0

132 Kar A Sutra, Axonometric, Mario Bellini, 1972, Source: www.designboom.com/design/mariobellini-kar-a-sutra-concept-car-01-20-2017/

133 Kar A Sutra, Mario Bellini, 1972, Source: www. designboom.com/design/mario-bellini-kara-sutra-concept-car-01-20-2017/

134 Kar A Sutra, Mario Bellini, 1972, Source: www. designboom.com/design/mario-bellini-kara-sutra-concept-car-01-20-2017/

135 Kar A Sutra, Diagram, Mario Bellini, 1972, Source: www.designboom.com/design/mariobellini-kar-a-sutra-concept-car-01-20-2017/ 
$136 \quad$ L'Odalisque Brune, Francois Boucher, 1745, Retrieved from: www.commons.wikimedia.org/ wiki/File:Francois Boucher - Brown Odalisque (L\%270dalisque_Brune)_-_WGA2879.jpg

137 Uno torna a casa stanco per aver lavorato tutto il giorno e trova una poltrona scomoda, Bruno Munari, Domus (202), 1944, Source: www.domusweb. it/en/from-the-archive/2012/03/31/searchingfor-comfort-in-an-uncomfortable-chair.html

series of chairs occupied, Michelle Ashurov, 2017 beaded chair, plan, front, side, iso, Michelle Ashurov, 2017

140 tying chair, plan, front, side, iso, Michelle Ashurov, 2017

141 bubble chair, plan, front, side, iso, Michelle Ashurov, 2017

142 split chair, plan, front, side, iso, Michelle Ashurov, 2017

143 spank chair, plan, front, side, iso, Michelle Ashurov, 2017

144 spank chair seat, Michelle Ashurov, 2017

145 saddle chair, plan, front, side, iso 1:20, Michelle Ashurov, 2017

wall as cabinet and doors as tiles, Michelle Ashurov, 2018

147 wall as closets and closets as door and corridor, Michelle Ashurov, 2018

wall as bookcase, Michelle Ashurov, 2018

window as shelf, Michelle Ashurov, 2018

door as window/window as door, Michelle Ashurov, 2018

door as negotiator, Michelle Ashurov, 2018

door as [pseudo-]negotiator, Michelle Ashurov, 2018

wall as door and display, Michelle Ashurov, 2018

wall as door and door in door, Michelle Ashurov, 2018

156 wall and ceiling as room and bench, Michelle Ashurov, 2018 
161 stair as wall, Michelle Ashurov, 2018

162 stair as wall and corridor, Michelle Ashurov, 2018

163 wall as fluid corridor, Michelle Ashurov, 2018

164 wall and aperture as scalable object and signifier of space, Michelle Ashurov, 2018

165 wall as fluid corridor 2, Michelle Ashurov, 2018

166 The upside-down room designed by Hildi Santo-Tomas, Trading Spaces, Source: www. hookedonhouses.net/2015/10/29/6-of-thescariest-trading-spaces-makeovers/

house 1 plan, Michelle Ashurov, 2016

168 house 1 from bed to bed through garden, Michelle Ashurov, 2016

169 One Room Apartment, First wall, Cornelius Meijer, 1969, Source: www.socks-studio.com/2017/11/12/ the-one-room-apartment-by-cornelius-meyer-1689/

170 One Room Apartment, Second wall, Cornelius Meijer, 1969, Source: www.socks-studio.com/2017/11/12/ the-one-room-apartment-by-cornelius-meyer-1689/

171 One Room Apartment, Third wall, Cornelius Meijer, 1969, Source: www.socks-studio.com/2017/11/12/ the-one-room-apartment-by-cornelius-meyer-1689/

172 One Room Apartment, Fourth wall, Cornelius Meijer, 1969, Source: www.socks-studio.com/2017/11/12/ the-one-room-apartment-by-cornelius-meyer-1689/

173 Furniture House 1 isometric, Shigeru Ban Architects, 1995, Source: www.shigerubanarchitects. com/works/1995_furniture-house-1

174 Furniture House 1 interior, Shigeru Ban Architects, 1995, Source: www.shigerubanarchitects. com/works/1995_furniture-house-1

175 Furniture House 1 construction, Shigeru Ban Architects, 1995, Source: www.shigerubanarchitects. com/works/1995_furniture-house-1 
$176 \quad$ Housewife overcome by her things, Tomorrow's House, George Nelson and Henry Wright, 1945, Source: Spigel, L. (2012). Object Lessons for the Media Home: From Storagewall to Invisible Design. Public Culture. 24, (3 68). 547.

177 The Nelson kitchen has cupboard units that resemble office storage and reduce the visibility of kitchen appliances and plumbing. Advertisement, 1952, Source: Spigel, L. (2012). Object Lessons for the Media Home: From Storagewall to Invisible Design. Public Culture. 24, (3 68). 561.

178 Storagewall, Tomorrow's House, George Nelson and Henry Wright, 1945, Source: Spigel, L. (2012). Object Lessons for the Media Home: From Storagewall to Invisible Design. Public Culture. 24, (3 68). 561.

179 Eames Storage Unit (ESU) Bookcase, Charles Eames and Ray Eames, 1949, Source: www.archiproducts. com/en/products/vitra/laminate-highboard-with-slidingdoors-eames-storage-unit-bookcase_278360

180 Eeames-designed room, Detroit Institute of Arts, An Exhibition for Modern Living, 1949, Source: Monica Obniski, Playful Domesticity, Serious Play: Design in Midcentury America 2018, 32

XX 181 Shelving system designed by Alexander Girard for the Alcoa Forecast campaign, Charles Eames, 1957, Source: www.greg.org/archive/2011/12/22/alexandergirard-shelves-alcoa-forecast-throwback.html house 2 plan (small), Michelle Ashurov, 2019

183 Storefront for Art and Architecture by Steven Holl Architects and Vito Acconci, , Paul Warchol, 1993

$184 \quad$ Untitled, Rozana Montiel, 2018, Source: Rozana Montiel, Commons Spaces in Housing Units, 2018, 33

185 set of closet doors for rooms with low roof, Michelle Ashurov, 2019

186 set of closet doors for rooms with high roof, Michelle Ashurov, 2019

187 closet unit with possible rod positions, Michelle Ashurov, 2019

188 closet unit with possible shelf positions, Michelle Ashurov, 2019

189 bare closet unit, Michelle Ashurov, 2019 
190 distinctions of interior and exterior spaces in house 2, Michelle Ashurov, 2019

191 layers of inflection, Michelle Ashurov, 2019

192 house 2 plan, Michelle Ashurov, 2019

193 house 2 stripped plan, Michelle Ashurov, 2019

194 house 2 section 1, Michelle Ashurov, 2019

195 house 2 section 2, Michelle Ashurov, 2019

196 house 2 elevation a, Michelle Ashurov, 2019

197 house 2 elevation b, Michelle Ashurov, 2019

198 house 2 elevation c, Michelle Ashurov, 2019

199 house 2 elevation d, Michelle Ashurov, 2019

200 segment of house 2, Michelle Ashurov, 2019

201 segment of house 2, Michelle Ashurov, 2019

202 segment of house 2, Michelle Ashurov, 2019

203 things through the courtyard, Michelle Ashurov, 2019

204 curb alert, Michelle Ashurov, 2019

205 framed objects and bodies, Michelle Ashurov, 2019 


binary refers to something of a dual nature; where there is involvement of two things

sex refers to birth sex, typically understood as male and female, but also intersex; it can also reflect intimate relations between one or more individuals

gender refers to a term that arose when the distinction between gender and sex was made; it is socially constructed through notions of the feminine and masculine, of woman and man, of norms, roles, and relations, of non-binary individuals

cisgender/cis refers to the state of identity and gender that corresponds with sex

transgender/trans refers to the state of identity and gender that may not correspond with sex; it can refer to one or more of the following: transgender, transman, transwoman, transmasculine, transfeminine, genderqueer, gendervariant, genderfluid, gender non-conforming, agender, non-binary, bigender, dual gender, Two-Spirit, third gender, androgynous, any other term that describes an individual who is not cisgender

sexuality refers to sexual orientation, not to be derived from norms of gender; it refers to an individual's romantic, physical, emotional, or other form of attraction to another individual, group or thing, can can be one or more of the following: heterosexual or straight, homosexual, gay, lesbian, asexual, demisexual, bisexual, pansexual, queer...

heteronormative refers to the positioning of heterosexuality as compulsory and as cultural norm

cis-heterosexism refer to systemic prejudice that only favors the cisgender heterosexual individual 


\section{introduction}

A Queer Assemblage is an attempt to reconcile queer occupation in architectural space. Identifying the socially divisive nature of architecture brings to question the contributions its material or immaterial facets make in the execution of oppression and repression. The governance of architecture (through lawmaking, codifying and normalization), the formal elements (walls, floors, doors, windows...), and the occupation of space are all at the mercy of ideologies and relations of social locations (sexuality, gender, class, race, religion, ability, age...). With the influx of divisive politics and leaders exemplifying regressive fear-mongering tactics that fuel a rebirth of hate groups, queering, or acts of protest, needs to take up space wherever it can - in literature, medicine, architecture, media, fashion, things outside of formal governance. Vigilance needs to be widespread, at the very least, to cultivate discussion and resist erasure.

The Queer Nation Manifesto

"I hate that in twelve years of public education I was never taught about queer people. I hate that I grew up thinking I was the only queer in the world, and I hate even more that most queer kids still grow up the same way. I hate that I was tormented by other kids for being a faggot, but more that I was taught to feel ashamed for being the object of their cruelty, taught to feel it was my fault. I hate that the Supreme Court of this country says it's okay to criminalize me because of how I make love. I hate that so many straight people are so concerned about my goddamned sex life. I hate that so many twisted straight people become parents, while I have to fight like hell to be allowed to be a father. I hate straights." (1990)

Representation of queerness, the components it is made up of, and the role of architecture as a vehicle in oppression has been rendered unclear if not invisible in architecture school. In hindsight, this comes at no surprise, as contemporary architecture has long abandoned its social-centric politics, 
*this term is a reformulation of Judith Butler's heterosexual matrix, which refers to the norm that everyone is heterosexual until proven otherwise. Appearing as a natural state, the heterosexual matrix delineates one form of living from all others, subjecting those who break from the norm as deviant and/ or invisible. The prefix "cis" is added here to specify not only norms that pertain to sexiordig, but also 4 gender identity. exploited by the mechanisms of capitalism (in labour, commodity). During my time in the undergraduate program, social locations were not highly discussed, let alone an implication of a cisheterosexual matrix* on architectural space, and I do not know who is to be held accountable. Sustenance of power and influence of the architects, designers, and theorists we were taught, male, cisgender, and white, is made possible through the presentation of pristine, white-washed, immaculate histories as fact. This rendered women, queers, and people of colour as nearly, if not entirely, invisible as these narratives underrepresented major fragments of reality. I wish I left my lectures filled with queer rage like I am while I write this in reactive solidarity to the Queer Nation Manifesto, a document that circulated in 1990 which described the transgressions made against queers by the heteronormative majority, differing from ones made in present in that they were explicit, unwaveringly developed to be implicit in the present. This shift further complicates the identification of heteronormative rule, as power struggles have become disguised and institutionalized.

My work continues a discourse started in the 1980s at the intersection of queer space and architecture, bringing a buried background, easily missed through a repetition of erasure, to the foreground. I am interested in how heteronormativity sets up camp in the built world, how it resides in architecture without appearing exclusionary, and how it can be queered. When looking to how space becomes the medium for hostility and manipulation, the fittings need to be considered. How is that space occupied, how is it malleable in light of other spaces, physical, digital or imagined? To queer is to subvert a cultural cis-heterosexist hegemony that is dynamic, as the social is wrapped in performance.

Queerness has a strong aversion to binarism. Binaries of male-female, heterosexual-homosexual, and separate 
spheres spatially manifest in other oppositions - insideoutside, public-private, city-suburb, architecture-interior, and structure-ornamentation. While some of these do not appear to be oppositions in nature, they are framed as such within a cisheterosexual patriarchal matrix.

$\begin{array}{ll}\text { here } & \text { there } \\ \text { outside } & \text { inside } \\ \text { right } & \text { left } \\ \text { clean } & \text { dirty } \\ \text { order } & \text { disorder } \\ \text { above } & \text { below } \\ \text { on top } & \text { underneath } \\ \text { parallel } & \text { perpendicular } \\ \text { parallel } & \text { oblique } \\ \text { he } & \text { she } \\ \text { male } & \text { female } \\ \text { uncloseted } & \text { closeted } \\ \text { heterosexual } & \text { homosexual } \\ \text { subject } & \text { object } \\ \text { public } & \text { private } \\ \text { city } & \text { suburb } \\ \text { structure } & \text { ornament } \\ \text { architecture } & \text { interior } \\ \text { hard } & \text { soft } \\ \text { west } & \text { east } \\ \text { front** } & \text { back** }\end{array}$

This study of architecture and the objects and bodies that populate it is deeply concerned with representation and interpretation, acknowledging representation of the thing as possibly more important and complex than the thing itself. From representation, intent is constructed, abstracted, disseminated. It is an indication of something otherwise unstated. Media, vocabulary, and digital space play an important role here as they possess a malleability or mobility, caught in a loop of immaterial processes and frameworks emerging materially, collapsing into something immaterial once more.

Objects also possess a mobility that buildings do not, typically operating at a more intimate scale with the body. The idea

** this refers to a multiplication of rooms in house plans that located spaces of women's domain (kitchens, bedrooms, boudoirs) in the back of the house or anywhere but the main floor, nestled from street view. 
of permanence is at odds with queerness, not because it is undesirable but because queerness has been expelled from countless realms and conditions, forced into mobilization in order to survive. The text following this introduction begins to depict the ephemeral state of queerness through the sexual purification of physical (page 11) and digital (page 19) space. The former refers to a review of zoning laws that restrict motions and displace bodies through the eradication of queer settlement, an erasure of queer imprints (page 13).

Digital networks mitigate this sort of erasure, allowing queer culture to form community and live elsewhere. The connectivity the digital realm presents becomes especially crucial when and where it may not be possible to openly and comfortably live queerly. To do so is a "middle-class prerogative" (Betsky \& Kolb, 2017, 86), as queer liberation exists sporadically through social, political and geographical locations, typically where there is density and wealth (but not necessarily). The sexual purification of digital space takes form in bills depicted to eradicate sexual exploitation, but instead have led to the dismantling of online queer communities amongst other things, undermining queer sustenance as it is predicated on sexual pleasure. "The literal workings of queerness [at its root is] a choice to reorganize the body and its environs for sex and pleasure," (Holder, 2017, 155).

Regulations and censorship also take place when looking at the history of the gendered washroom (page 43), a space of ubiquity in its type. Turmoil is investigated in tighter space, through the blatant separation of men from women in light of the implications of industrialization. Building codes uphold and conceal bias, and the distinctions between sex and gender become blurred, casting further otherness onto non-normative bodies. The inscription of gendered and sexualized conduct in spatial forms appears less blatantly in domestic space. Division of activities and objects and sexuality is explored through the history of closets (in every 
sense of the word) (page 67), and the collapse of collective domestic space (page 70), distancing concepts of private and public.

In recent years, digital intimacy and image culture has obscured a division between public and private information - in turn breaking down these boundaries when they are more tangible or spatially accessed (page 83). The performance involved in expression through social media, where this blurring is most dominant, pulls our objects closer to ourselves, as they take on other lives in new networks. Their ability to orient the body make them curious subjects when exploring orientations, sexual or otherwise. The nuances of orientation are investigated with a queered reading of phenomenology (page 88 ), starting in metaphor but concluding in very spatial practice to comprehend orientation through sex preferences, spatial occupation and designed objects, utilizing their ubiquity to establish non-normative ends. Through such a lens, objects (page 111) and identifiable elements of architecture (page 117) are queered, exhibiting deviations from norms of how things appear, how they operate, how they impress. Engagements with beds (page 84) and chairs (page 105) and storage walls (page 134), their conceptions, promotion and reception, are made to visualize how heteronormativity is given a voice in spatial terms or how this is overcome, suggesting sites at which architecture can be queered.

How do bodies and objects, or traces of life, gather in houses? In attempts to strip the house from its title of a machine for living and its goal of productivity (or reproductivity), of labour - since when did living become interchangeable with work (doing $x x x$ for a living)? - a queer assemblage of the house is proposed (page 144). Imbued with references and responses to the research it follows, the house is used as a vehicle to interrogate how architectural space can support a queer occupation. 
My red marking up of histories through words and designs culminate at a series of points that stipulate ways in which architecture can be effectively queered. "Queerness may feel different here (slow, quiet, diffuse), but its formula remains: to interrogate how normative culture produces desire, to expose the constructedness of that desire, and to expand the possibilities of desire through strategic acts of critique and reformulation," (Kolb, 2017, 66). 


\section{on bodies and buildings}

the very colour of paint that sits atop the nails and lips and strands of hair that linger in promiscuity,

and of illumination that grazes and blurs skins in precincts of pleasure, and of ink giving indications of error or slowness or stillness, authoritative, and of our insides when we are punctured, scratched or split is rather assertive and arresting 




\section{sexual purification}

In 'Five Points Toward a Queer Architecture; Or Notes on Mario Banana No. 1', Andrew Holder states that "there is no queer architecture in the way there is classical or modern or deconstructivist architecture, or any of the regional vernaculars," (Holder, 2017, 155). Buildings may be identified as queer, but they were not conceived of as queer. I would suggest that queer architecture has not been defined like an era of architectural style for a few reasons.

1 Our existing methods of translating abstract to 'physical' are confined to a heteronormative logic. The system that designers are operating in, the steps to produce objects and architecture, are conducive to the production and reproduction of heteronormative things. Architecture is affiliated to: capital, confining production of universality and repetition (Mangold, 2011); competitions, demanding unpaid labour for a statistically slim opportunity for reward (Deamer, 2015); and unpaid internships offered by the

011

* Adam Nathaniel Furman, @ adamnathanielfurman on Instagram, has recently taken to collecting alleged emails from leading architecture practices that solely offer unpaid or insufficiently paid positions as an initial step to investigating the exploitative conditions of the practice of architecture. leading practices in the field*. Customization is offered by manufacturers, retailers, contractors, all actors in this process, at a premium (otherwise mass produced and standardized), driven by "capitalist profit seeking" (Mangold, 2011, 76), bestowing only the wealthiest consumers with such opportunity. Promoting universality or a one size fits all model is conducive towards a heteronormative system in its assumption that there is a universal body, casting everything outside itself into otherness. Participation in architecture falls under a familiar power dynamic with a normative social order, and a tradition of exploitation and invisibilization. Architecture (in its built state), its composing parts (the very materials it is made of, extracted of earthly matter), and those who conduct varying types of labour in its production (physical or otherwise) are all commodity, and "the commodification of architecture [lays] the groundwork [for] other means of exploitation," (Mangold, 2011, 75).

2 The production of architectural space fails to keep up in a timely manner with queerness, which constantly "must 
identify and respond to new structures that attempt to encode and enforce evolving forms of cultural normativity," (Kolb, 2017, 63). Institutionalized heterosexism buries itself in obscurity.

3 The instability and flightiness of queerness does not lend itself to the "static contour[s]" (Munuera, 2017, 109) that architecture in its built state considers or forms. Queerness has developed a "knowledge in mobile sites of drag, youth culture, music, dance, parades, flaunting, and cruising sites whose mobility makes them possible but also renders them hard to recognize as world making because they are so fragile and ephemeral," (Berlant \& Warner, 1998, 561).

Heteronormative culture is supported and disseminated through the institutions of marriage, family law, in the architecture of the domestic, in the realms of work and politics. On the other hand, queer culture has lived with the absence of such institutions (Berlant \& Warner, 1998) that validate a sexual citizenship up until quite recently.

"There's no place for the state in the bedrooms of the nation."*

While Pierre Elliott Trudeau's introduction of Bill C-150** assembled a path towards the decriminalization of homosexuality, Section 159 of the Canadian Criminal Code is only said to be repealed once Bill C-75 is passed, a process initiated in 2016 and is currently in Senate committee (Bill C-75, 2019). C-75 is a lengthy document that modernizes sections of the Criminal Code, one of which being Section 159 (see following page). This section is concerned with who is able to perform anal intercourse and under what conditions. Exempted from the criminalization of anal intercourse are specifically heterosexual married couples or any two consenting individuals above the age of 18,2 years above Canada's current age of consent and 4 years above the close-in-age exception (Age of Consent to Sexual

012

* this phrase was popularized

by Trudeau, but coined by Martin

O'Malley from

The Globe and

Mail (Trudeau: 'There's no

place for the

state in the

bedrooms of the nation, n.d.)

** a process

which was

halted in

1967-1968

when Lester B.

Pearson was

in office, and

reintroduced

and adopted

in 1969 once

Trudeau

was in office

(Chambers, 
Activity, 2017), so long as it takes place in private. In the code's sense of the word, what is deemed not private is if acts are performed in public, and with or in the presence of more than two individuals.

This renders sex between bodies that produce sperm as disadvantaged through discrimination on the basis of age. The criminalization of non-normative and possibly queer sex acts grants sexual citizenship unequally, excluding desire for non-monogamous or anonymous/public encounters. However progressive the famous phrase and following political action seemed during an aggressively anti-queer political climate, the state never intended to remove itself from the bedrooms of the nation, or more specifically through sites of sexual pleasure.

The ephemeral state of queerness and queer sites of resistance comes from a cultural hegemony that inserts itself at every point of engagement with the body and ostracizes queerness. I refer to this ephemerality in our built condition as transient queer space. Transience can be explained through the contentious battle, initiated in October 1995, between New York City Council and the city's adult entertainment industry (Berlant \& Warner, 1998, 551) - a zoning law that outlined rules adult businesses must abide by in order to remain or open.

Stated by J Fahey of the New York State Law Reporting Bureau in the case For the People Theatres of N.Y. Inc. versus the City of New York: "In 1994, the New York City Department of City Planning (DCP) completed a study of sexually focused businesses, namely 'adult video and bookstores, adult live or movie theaters, and topless or nude bars,' and identified significant negative secondary impacts, including increased crime, diminished property values, reduced shopping and commercial activity, and a perceived decline in residents' quality of life. After public hearings, the City's Planning Commission issued a report, adopting 
Anal intercourse

159

(1) Every person who engages in an act of anal intercourse is guilty of an indictable offence and liable to imprisonment for a term not exceeding ten years or is guilty of an offence punishable on summary conviction.

\section{Exception}

(2) Subsection (1) does not apply to any act engaged in, in private, between
(a) husband and wife, or
(b) any two persons, each of whom is eighteen years of age or more, both of whom consent to the act.

(3) For the purposes of subsection (2),

(a) an act shall be deemed not to have been engaged in in private if it is engaged in in a public place or if more than two persons take part or are present; and (b) a person shall be deemed not to consent to an act

(i) if the consent is extorted by force, threats or fear of bodily harm or is obtained by false and fraudulent misrepresentations respecting the nature and quality of the act, or
(ii) if the court is satisfied beyond a reasonable doubt that the person could not have consented to the act by reason of mental disability.

(Criminal Code, 2018). 


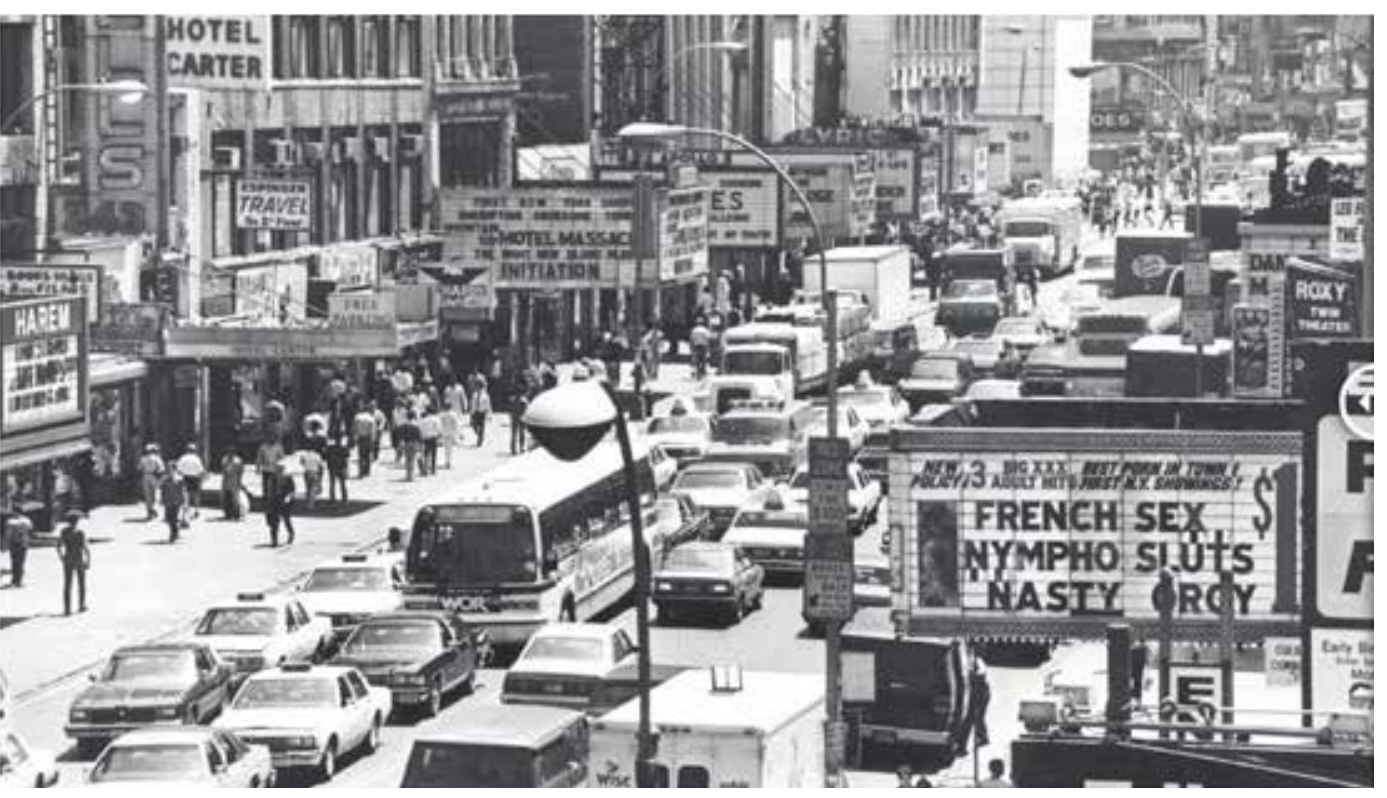

fig. 1: Times

Square in 1980s the findings and conclusions of the study and noting that by Neal Boenzi, the businesses with adverse secondary impacts had 'a New York Times

015 predominant, on-going focus on sexually explicit materials or activities,"' (For the People Theatres of N.Y. Inc. v. City of New York, 2017).

Limitations included business locations in specified nonresidential zones, along with a minimum of 500 feet distance that must be maintained from schools, daycares and places of worship, and other adult businesses. To separate adult businesses from one another destructs any formation of queer and pleasure districts. Signage is limited in its placement, size and illumination. This pervasive law has been questioned and modified time and time again by the council, judges of the state court, business owners, anticensorship groups and queer organizations.

The law was modified, permitting adult businesses to remain open as long as no more than 40 percent of their gross floor space was devoted to adult materials, referred to as the 60-40 test. In 2017, it has been reinstated in its original form, as the 60-40 rule provided business owners 


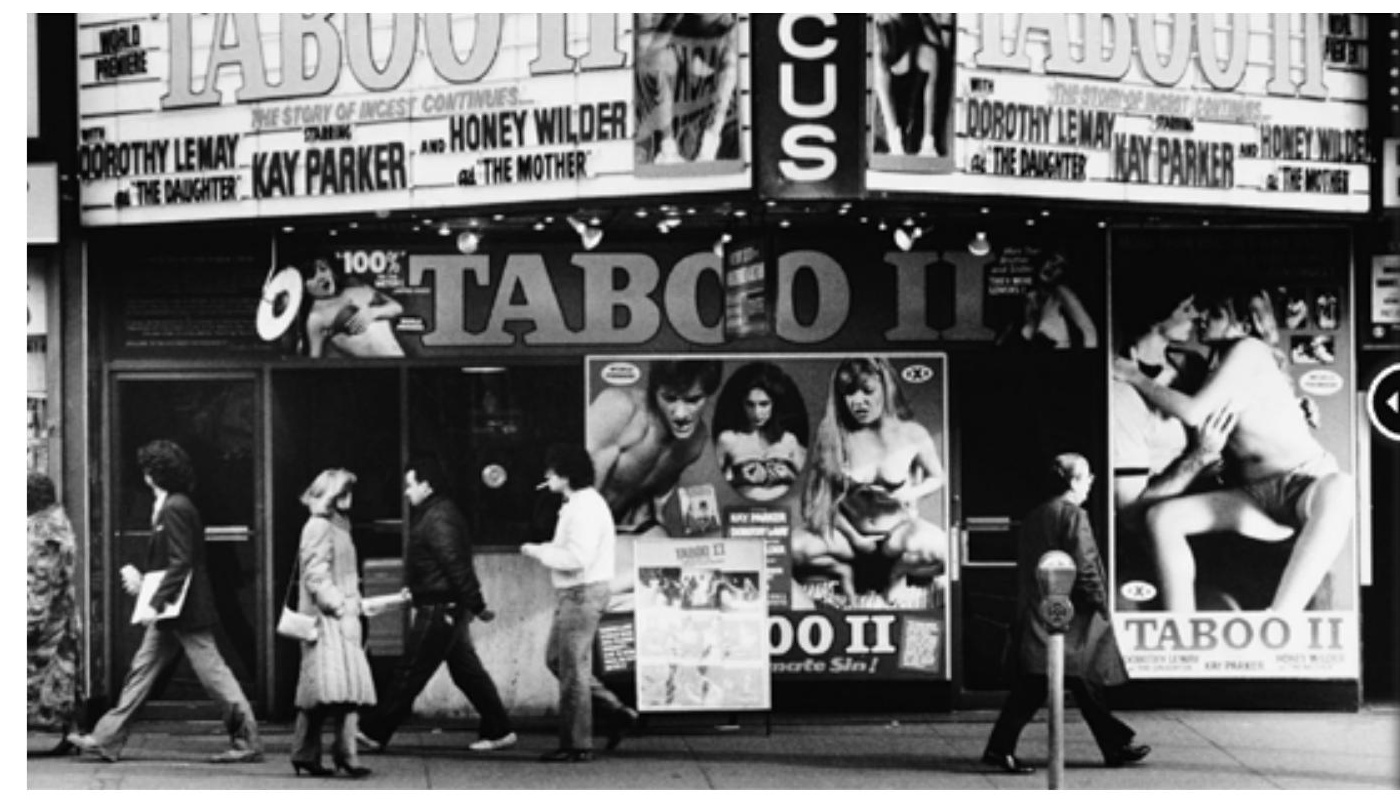

with a sort of loophole. The report continues, "As the City began to enforce the 1995 Ordinance, it concluded that adult establishments were achieving technical compliance with the 60/40 test, but without altering their predominant focus on sexually explicit activities or materials. As the City saw it, the 60/40 businesses were engaged in a "sham." In one case, the City sought to shut down a store that complied with the test, insofar as just $24 \%$ of its stock consisted of adult videos, but where the non-adult videos were offered only for sale, not for rent, did not sell profitably, had been supplemented very modestly, and were located in a back room," (For the People Theatres of N.Y. Inc. v. City of New York, 2017). For example, the stage at the Penthouse Executive Club in Manhattan is a steakhouse and strip club that adhere to their respective area limitations (see fig, 4).

Lauren Berlant and Michael Warner (1998) spoke of the first stages of this law in their essay Sex in Public to illustrate the displacement of queer individuals to less safe and less catered locations to seek alternative forms of queer community and sexuality. More specifically, the impact of the sexual purification of New York fell unequally on those who 


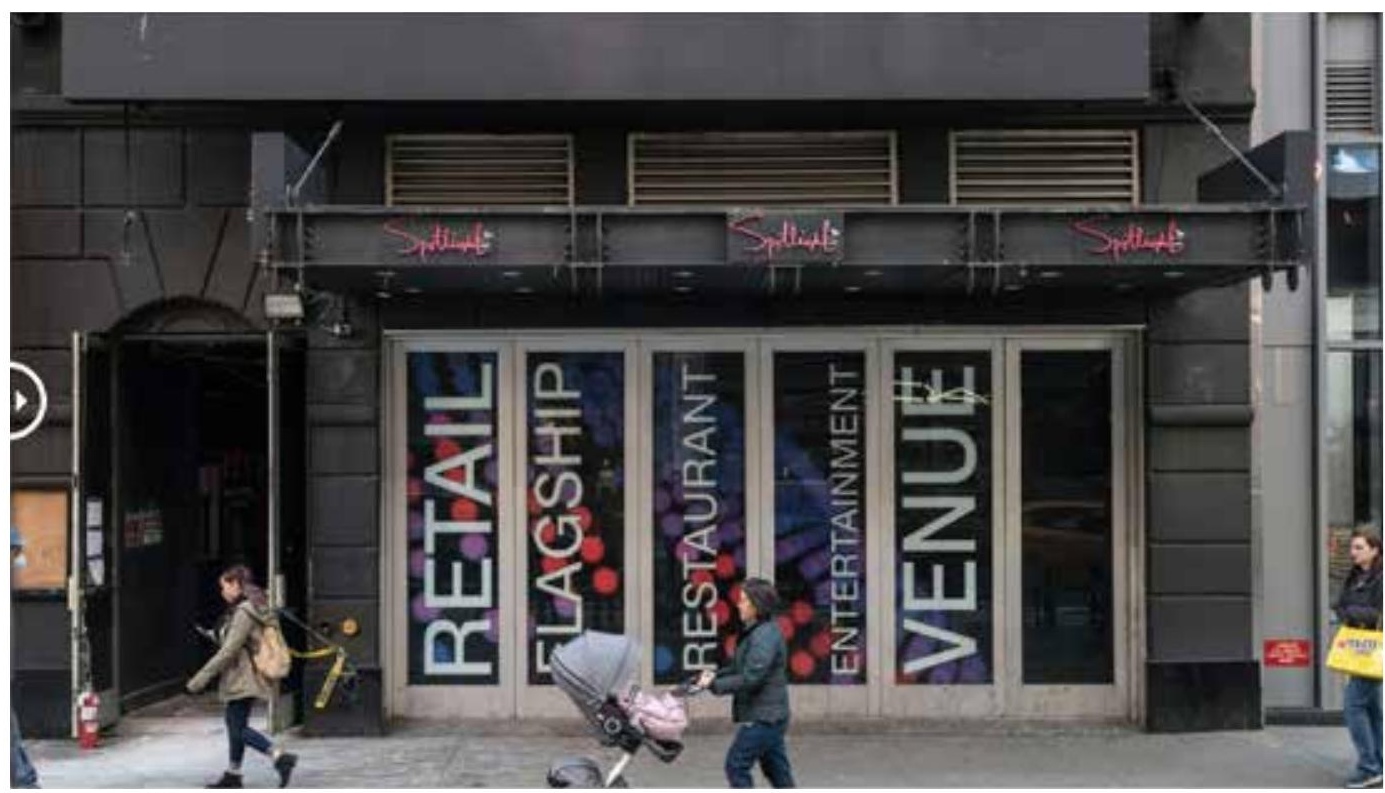

Court of Appeals.

fig. 5: Times

Square in 2016

by Benjamin

Lowy, Getty

A feature on Resident Advisor titled 'An alternate history of sexuality in club culture' presented eras and types of dance Images 8 - 8 NN music with respect to historical political ongoings - more specifically the marginalisation of queer and racial groups - to highlight the imperative role these groups held in the formation of music genres, promoting "ideals of community, equality and diversity that were so crucial to dance music's DNA from the beginning," (Garcia, 2014, quote of Loren Granic). The sexual purification of New York is cited here as well. "The ' 90 s was a time of crisis for many of the city's outcasts. Under the mayorship of Rudolph Giuliani, Midtown Manhattan underwent a program of 'Disneyfication': a wave of inner-city gentrification, often aggressively enforced by police violence and bureaucratic pressure. 'It was so bizarre,' reflects [Terre] Thaemlitz, [a deep house DJ who performed in midtown]. 'Around 1997, Disney just came in and bought 42nd Street. Literally. The sex district was gone within just a few months. I remember Disney had one of their fucking electric parades down 42nd, and they had so much political clout that the city actually turned off all 
the streetlights for them. I mean, that may not sound like a big deal, but to anyone who did activist work and had heard endless bullshit from cops and city officials about safety regulations, fire codes and all kinds of crazy shit to limit the movement of protestors, it really laid bare the relations between commerce, politics and the construction of mobility within 'public spaces'," (Garcia, 2014).

The censorship of sexuality is prevalent in the present day. In March of 2018, the Trump administration passed a bill that combined the Fight Online Sex Trafficking Act (FOSTA) and the Stop Enabling Sex Traffickers Act (SESTA). In the days following the bills passing in Congress, public platforms such as subculture dating sites, like Pounced, and forums for sex trade and advertisement of such, and sections of Craigslist, like Seeking Arrangements, were shut down, and companies like Google and Facebook began to rigorously enforce terms of service regarding sexual speech. These digital spaces had enabled sex workers to leave exploitative work conditions through self representation and administration. With their erasure, workers are pushed back into the street, increasing the likeliness of sex trafficking and violence against them, (Cole, 2018).

The sexual purification of the web endangers the lives of sex workers, a group composed largely of marginalized and intersecting groups, like trans individuals and people of colour. It displaces work that could be performed individually, administered in a safe space, perhaps domestically located, into the heteronormative public realm that threatens. It censors queerness altogether, as a distinct community predicated on sexual pleasure. 


With the emergence of technologies that enabled digital communications in the 21 st century, or more specifically the creation of and access to social media networks and location-based sex applications, transience of queer space has shifted in its sites, methods, and engagements. Media representation of domestic and public space on public platforms intersects with the movement of queer bodies. The "atomization of public space" (Betsky \& Kolb, 2017, 88) for queer use through these mediums engages with a contemporary obsession with immediacy and quickness.

In an interview with Aaron Betsky, Jaffer Kolb describes his experience in Copenhagen: "Last year I was doing research in Copenhagen. I kept hearing about how friendly but closed off Danish culture is; how expats living there for five years had only been to the homes of two or three Danes. I went on Grindr to see what the gay scene there was like, and immediately had dozens of invitations into various bedrooms around the city from Copenhagen natives. It felt like hitting a fast-forward button that gave me unlimited cultural access in an instant; intimacy and the most private facets of a social interior suddenly visible. This moment made our community feel so important and unique. We seem to be building a new kind of queer culture - one that has a more complex relationship to space itself - both real and imagined,"

This outlook through social media and "pop-up sites" (Betsky \& Kolb, 2017, 88) informs a reasoning behind the decentralization of queer activity from the established queer pleasure district in Toronto, aside from the oppressive hierarchies within the Gay Village and queer community or a lack of rights to be openly queer.

For example, Flash on Church is a male members only club that has been open since 2010. For example, most major clubs in the village revolve around male same sex desire. For example, Slacks, Church Street's flagship lesbian bar, 


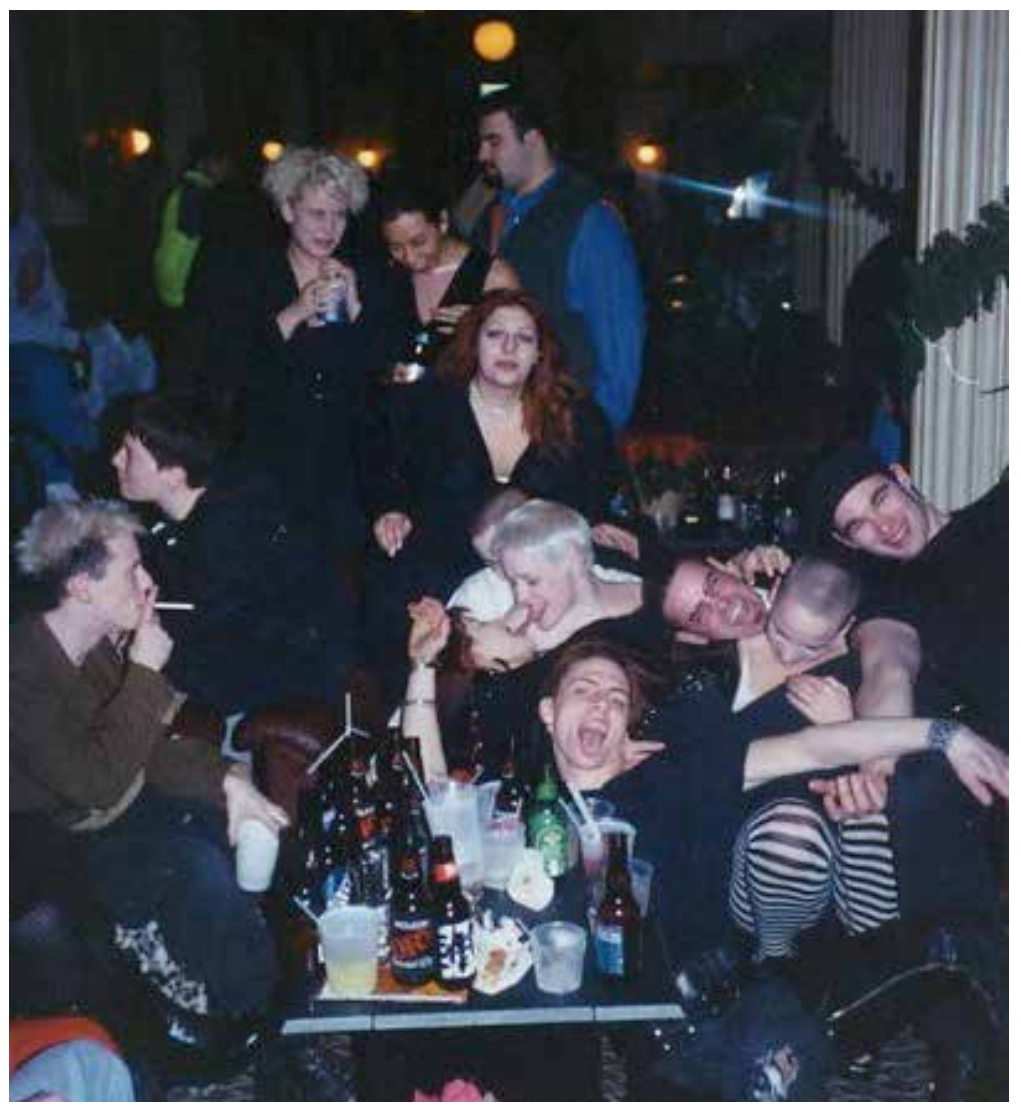

fig. 6: Boom staff and friends hang after hours, Sofie Weber

closed in 2013. For example, profiles on gaycentric dating apps still read no fats, no femmes, no Asians, no blacks, and the list goes on. Queer people, primarily women or trans individuals and people of colour, have departed from the old queer haven of the Village to newer permanent establishments primarily in the West End, but also to pop-up queer events dispersed through the city led by organizations rather than club owners, and self-initiated queer spaces.

Boom Boom Room (see fig. 6) was a club that was operated between 1988 to 1993 by Lon, Stephen, Douglas, and Peter Ballinger following their overwhelming success in their conversion of the Holiday Tavern at Queen and Bathurst into The Big Bop, a three level rock club. The Boom Boom Room became a place for subcultural exchange, which included queers, and celebrated diversities of ethnicity, 
orientation, gender expression, music, politics, fashion, everything. Queer DJs brought in queer people through dedicated nights, like Boys Night Out on Thursdays, and Dyke Nite on Fridays, along with music oriented events, like industrial on Sundays, (Benson, 2014).

The club supported and featured early evening events, such as experimental film screenings, readings by queer novelists and activists, community fundraisers, concerts, hot-tub parties and the like. In other words, events that took place there did not solely accommodate party culture and chemical regimes - it was a cultural institution born of nightlife. "The club's catwalk and cubbyholes were put to good use," (Benson 2014). Steel cages were suspended in space to host dancers, but once they left, partygoers could occupy them. Inadvertently, the club's success in attracting queer groups initiated the transformation of Queen West to Queer West (Benson, 2014).

The flight of the queer scene contrasts a very different reality than that of the early 1800s, when the Gay Village and nearby Allen Gardens became gay destinations, and the 1950s and 60s, when large numbers of queer people moved to flats in the area due to a close proximity to popular gay hangouts and cheaper rents than others on nearby streets (Teitel, 2017). Within the last few decades, queer individuals, primarily women and trans individuals and people of colour, have sought out alternative venues and neighborhoods that do not overwhelmingly cater to white queer men, quite unlike the village.

The persistence of digital social networks has both contributed to the scattering of queer bodies throughout Toronto, and reconnected bodies through their needs for mutual spaces and emotional connection, constructing networks of 'pop-up sites' - and a less oppressive city landscape, where queerness is more normalized, allows queer individuals to decentralize. Pop-up sites for queerness 
occur in public or domestic realms, borrowing from existing locations, whether located in a historic building in a gentrified neighborhood, an industrial site, or a private bedroom.

The collection of photos presented on the following pages, are examples of self-organized queer pop-up sites, some of which are located at addresses rather than established businesses. These photos begin to illustrate transience through spatial configurations and interventions, something that cannot be fully explained without immersing the body at the designated time and place. Events pictured represent

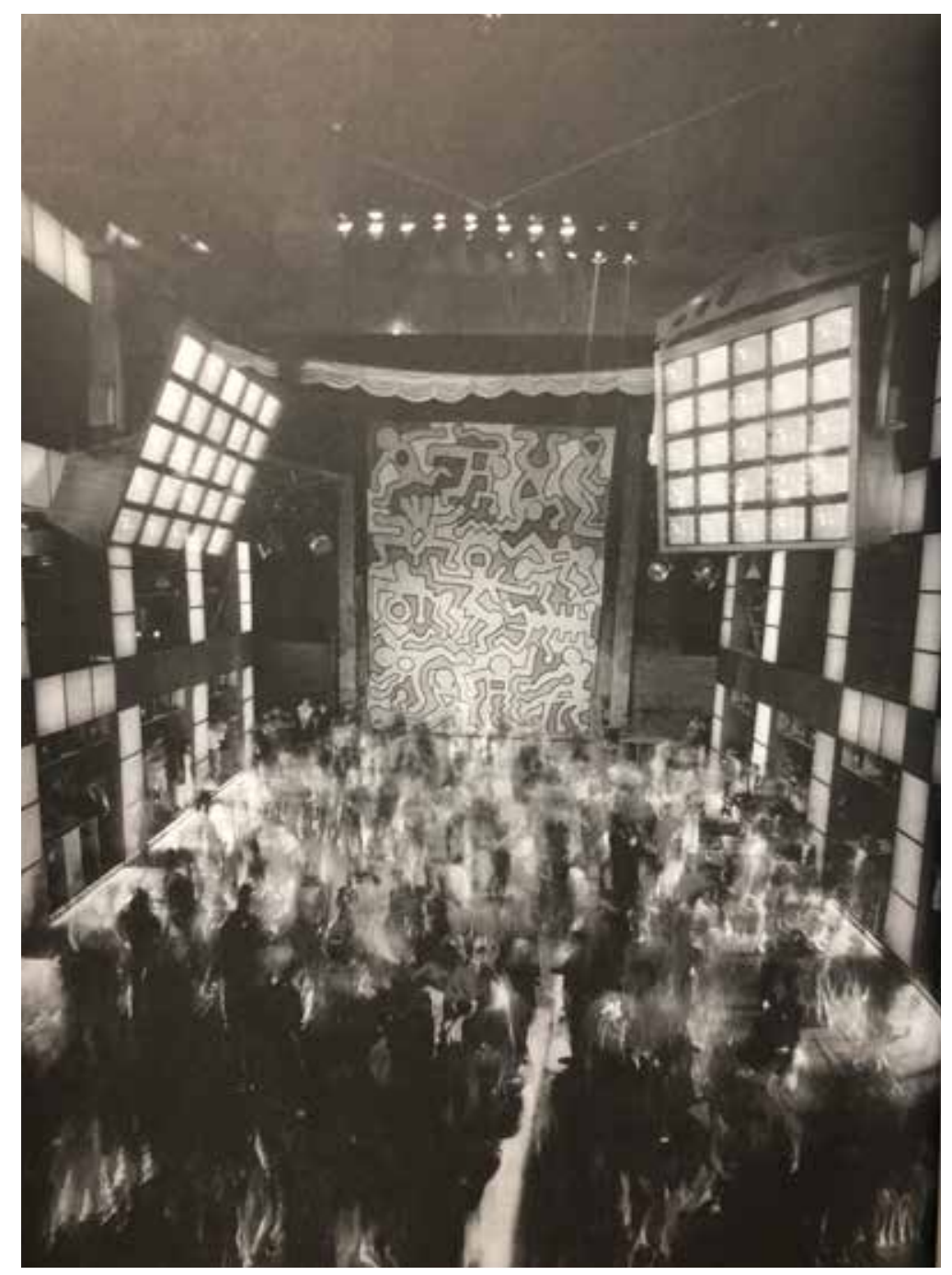

026

fig. 7 : the palladium nightclub in manhattan, interior design, 1985, by edie lee cohen 
only a small fraction of queer gathering, but one that exists out of the typical setting of club or bar and for five or six hours at a time. While this type of mobility can exist for different purposes (pop up shops, one night only art shows, parades), it almost complements the ephemeral qualities of queer culture. This series depicts methods of occupation through an assemblage of seemingly simple parts (sounds, lights, projections, vapours, installations, bodies, and other miscellaneous objects).

While Ivan L. Munuera referred to the Palladium dance club, designed by Arata Isozaki in mid 1980s Bushwick in the following description (see fig. 7), the assortment of agents are the same: the events captured "[contain, shape and propagate] a specific understanding of architecture as an event in which chemical regimes, music and acoustics, media, artistic interventions, bodies and subjects, politics and activisms, connections to the urban planning and lighting systems (to name only a few of its diverse agents) together [create] an environment that [challenges] the definition of architecture as a discipline," (Munuera, 2017, 103-104). 
028 

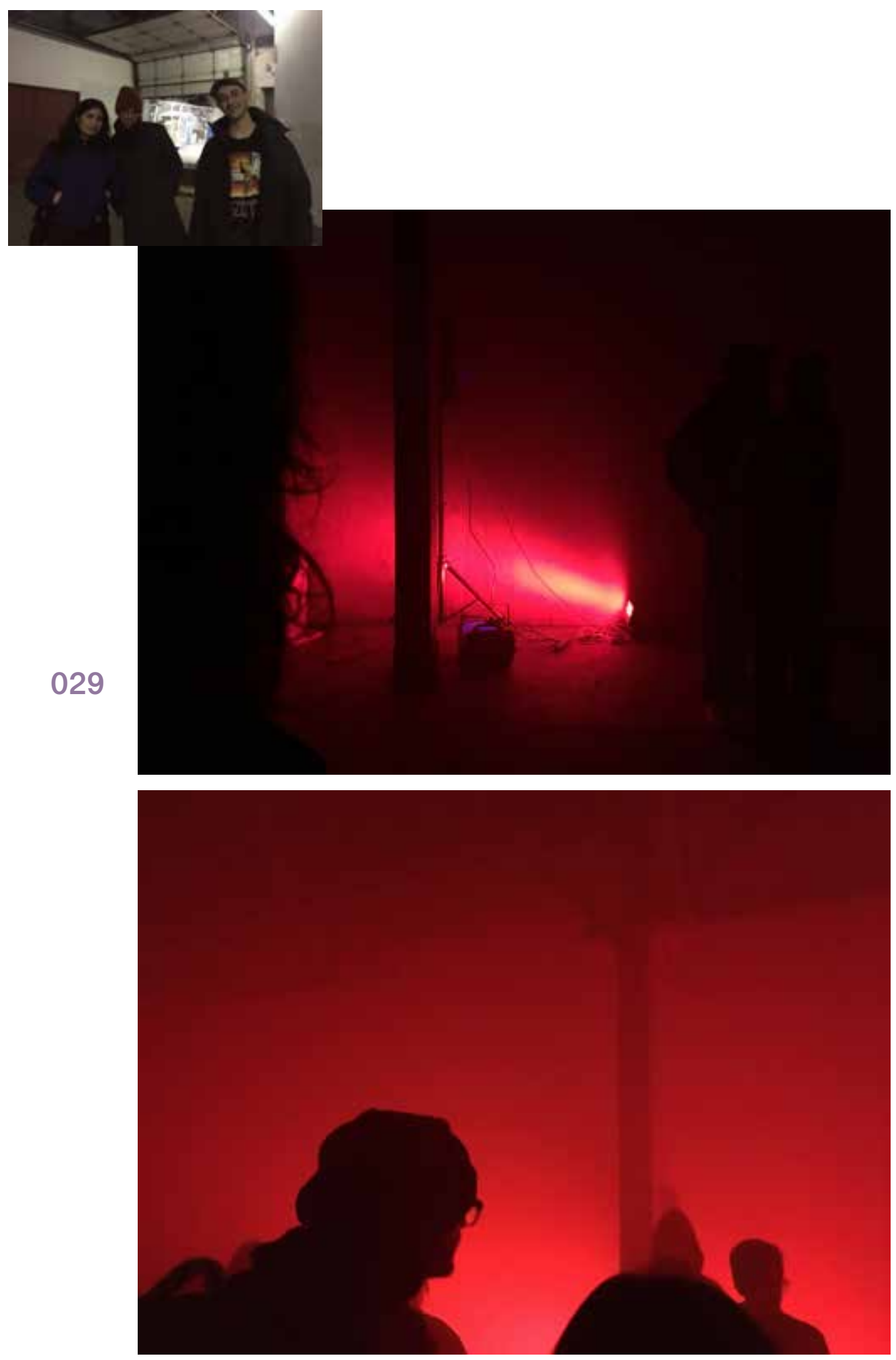
facing page:

fig. 8: march 172018 00:27 444 dufferin street, entry through back, a party that took place during the last week of 444 dufferin's life, Michelle Ashurov, 2018

fig. 9: march 17 2018 01:09 444 dufferin street, Michelle Ashurov, 2018

fig. 10: march 172018 01:20 444 dufferin street, Michelle Ashurov 2018 030

fig. 11: march 172018 02:39

444 dufferin street, Michelle Ashurov, 2018

current page:

fig. 12: march 17 2018 03:15 444 dufferin street, view walking home from the back door entry, Michelle Ashurov, 2018

fig. 13: march 172018 03:16 444 dufferin street, view to entry, obscured through industrial lighting parts, Michelle Ashurov, 2018 
pop-ups

fig. 14: june 24 2017 00:34 the great hall, the great hall queer event during Toronto pride 2017, located in the west end, also known as Queer west. Toronto pride was typically celebrated within the demarcation of the gay village neighborhood up until recent years, taken by Michelle Ashurov, 2017

fig. 15: december 12017 00:17 luanda house, luanda House queepehent in annce studio, hosted by Phile Magazine, still from personal film taken by Andre Vautour, 2017

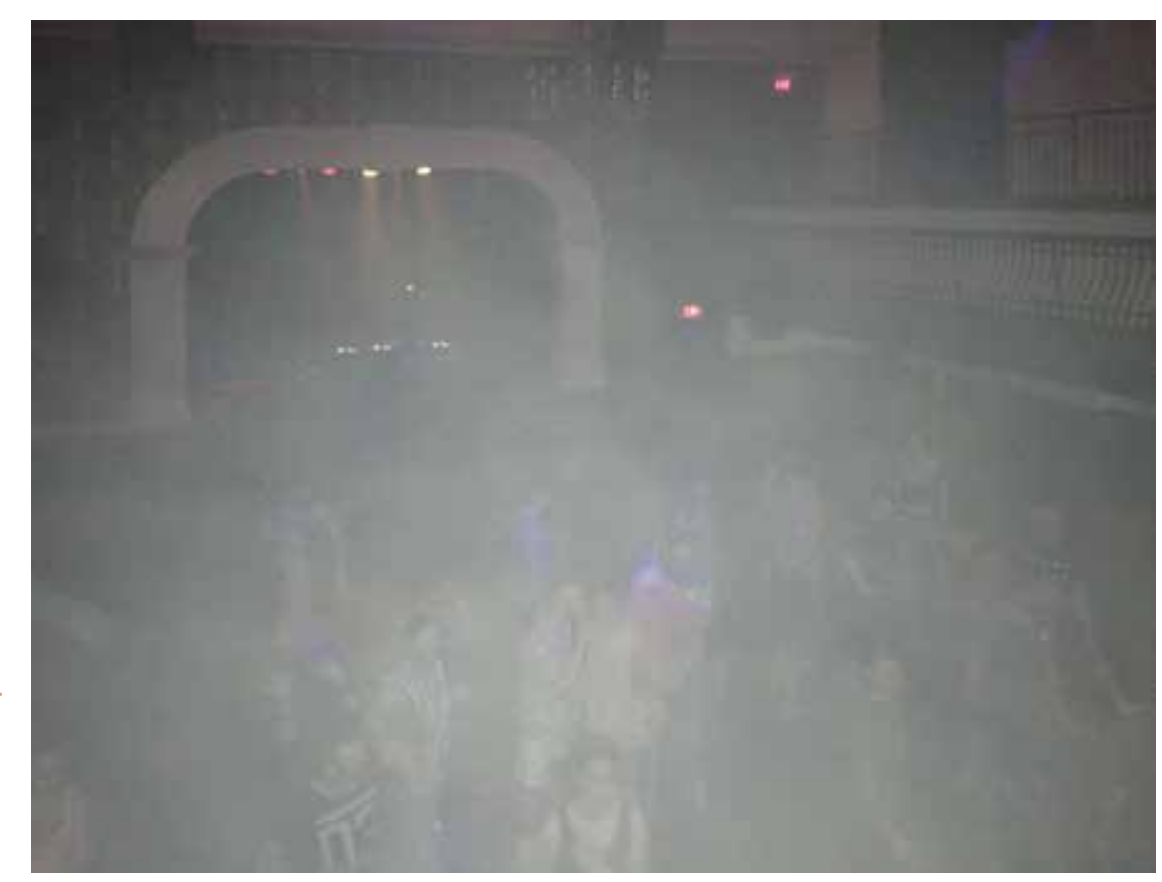

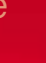




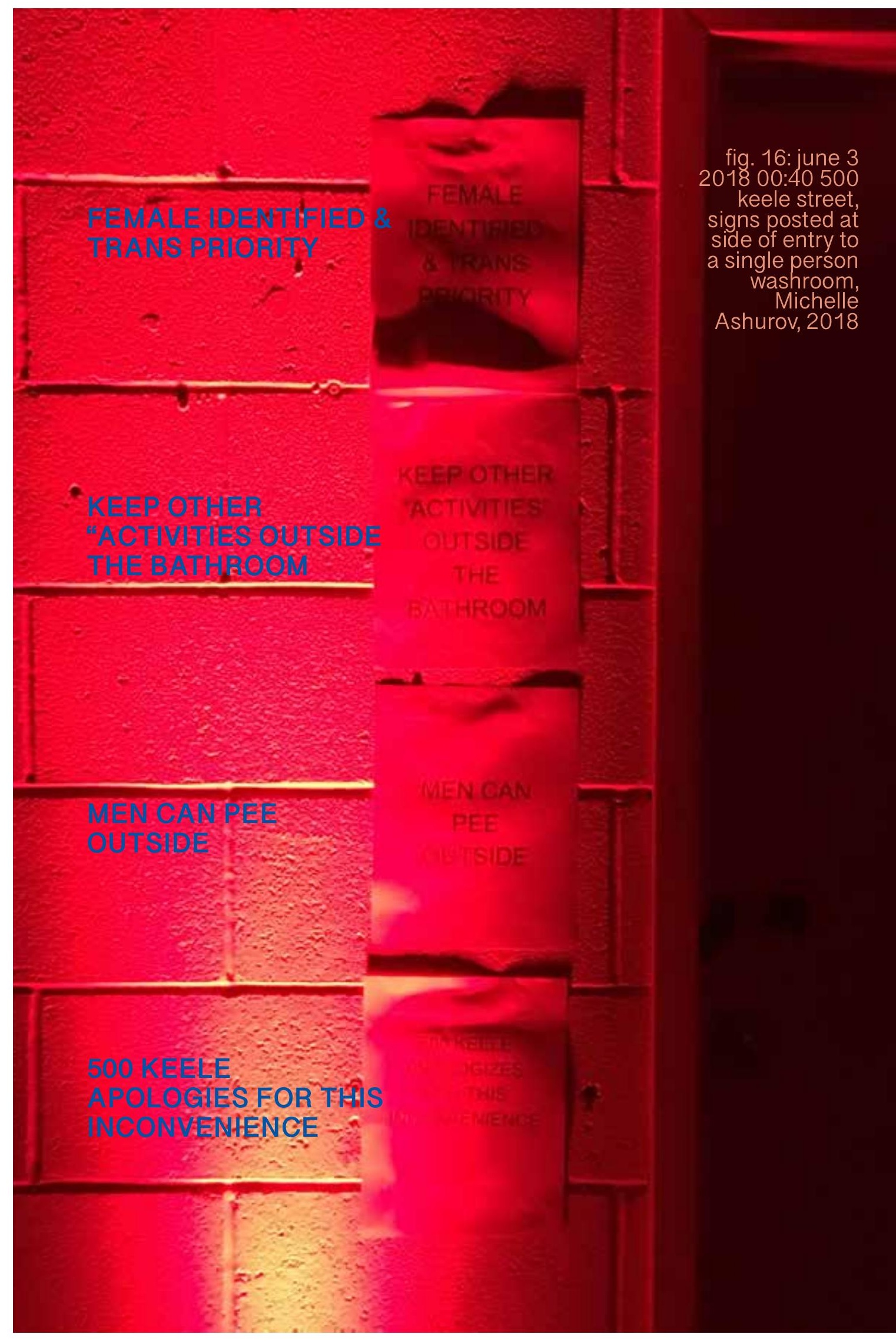


fig. 17:

november 26 2017 00:36 191 geary avenue, queer event in industrial space. hosted by the Rude Collective temporary signage outlines rules of conduct for the event, also described on the event page on Facebook, Michelle Ashurov, 2017

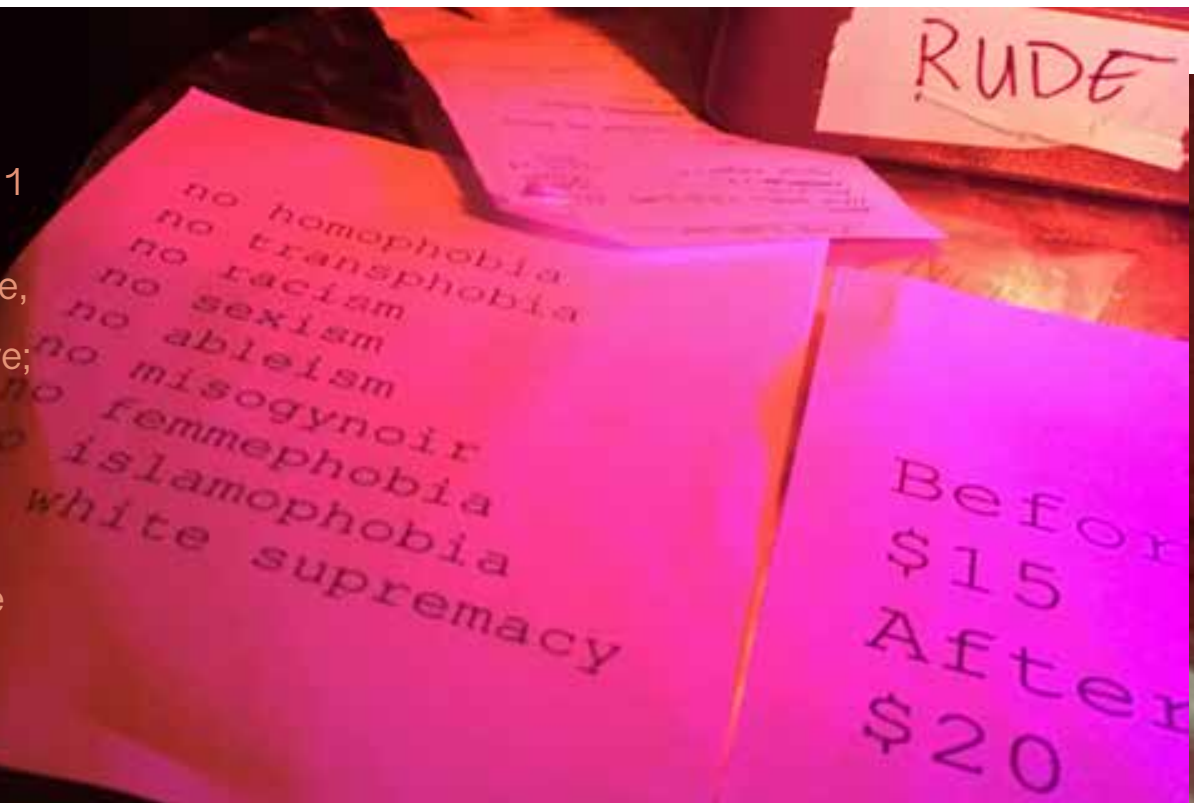

fig. 18: 12:17 AM /December 1, 2017 / Luanda House Queer event in dance studio, hosted by Phile Magazine. Lighting installations and smoke machines transform a generic dance studio, located below an RBC. Taken by Michelle Ashurov. 
fig. 19: october

82017 00:34

500 keele street,

queer event in

industrial space;

temporary

objects are

strategically

placed to

transform the

flows of space; transience

can be seen

not only in the

action, but also

in the material

qualities and projections; behind where this photo is shot stood

metal fencing

that separated industrial

equipment

and materials

from the event

space, Michelle

Ashurov, 2017 
pop-ups

fig. 20:

september 10 2017 02:39 191 geary avenue, queer event in industrial space; prior to the entry of police, bottles of liquor behind the bar werg 2 mptied into $4 \mathrm{Se}_{\text {sinks }}$ and cash tills were removed and hidden from sight, pictured is a discussion between two officers and the individual running the bar, which revolved around a document.

Unlike a previous event, the event continued, Michelle

Ashurov, 2017 

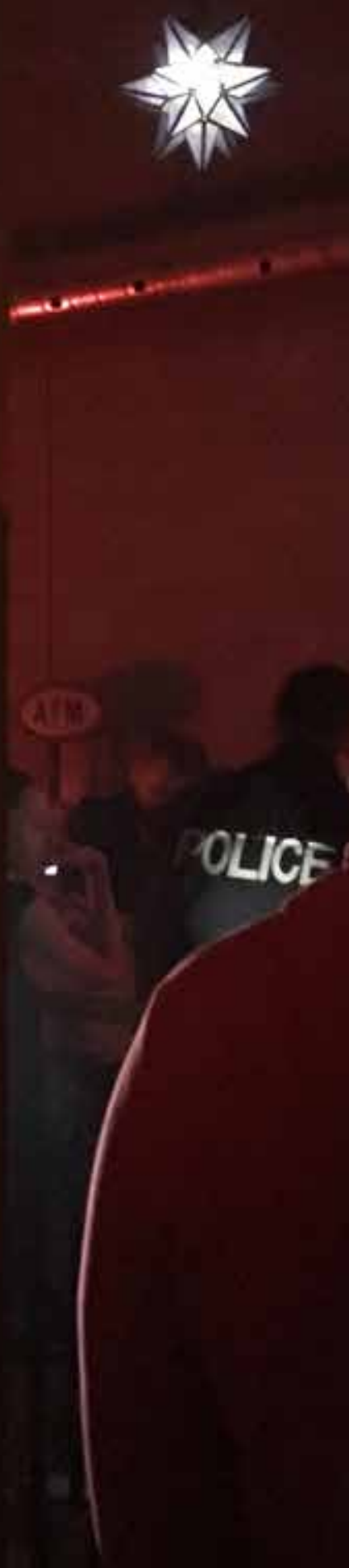

5

1 


Ballroom culture in the queer world is a mixture of music, dance, performance art, fashion and self expression. They are reappropriations of debutante balls, beauty pageants, fashion runways, and dance competitions of the domain of queer people of colour, but at the root, it was space carved out out for transgender people of colour. This subculture for queer people was a place to "walk", which entailed bodily movement on the runway, pregnant with references to the ways in which humans perform gender and status (categories to walk for included executive, thug, and realness amongst many others). Much like in all sorts of drag subcultures, exploration of social nuances indicate an understanding of gender as performance. Drag balls are breaks in the thickness of a heteronormative landscape, where individuals who face mild to extreme marginalization can "enjoy a degree of social prominence and cultural authority," (Garcia, 2014).

The proliferation of queer representation in media can be represented with the drag ball. Rupaul's Drag Race, a reality television show that invites drag queens across America to compete in hopes of becoming the next Drag Race Superstar, has gained popularity in the last few years amongst a nonqueer audience. The format of show, familiar in many reality TV shows (think Project Runway meets America's Next Top Model, but remixed), makes queer culture accessible to those who are queer, who are interested in queer history, drag, fashion, music, art, and/or reality. It gives a voice to a group of individuals who are heavily involved in the formation of queer social life, and represents them in a non-derogatory fashion, unlike the historic portrayal of drag queens and transgender individuals in media as a punch line. In the majority of seasons, the second to last challenge that the queens are faced with is the Ball challenge, one of the most rigorous tasks on the show (requiring drag looks for three themes, plus a choreographed dance routine). In the process, challenges throughout the seasons have promoted fragments of the queer liberation movement. And 
overall, other references such as the film Paris Is Burning, Divine the drag queen, Club Kid culture, are scattered throughout the show, sparking interest in queer and nonqueer individuals alike.

However, the promotion of queerness is put in quite a bind. On the premiere of season 3 of Rupaul's Drag Race: All Stars, Aja, a contestant in the race, performed a jawdropping voguing routine, and in reply, guest judge Vanessa Hudgens exclaims, "I'm so into voguing right now so that gave me life," (Bailey et al., 2018). This spurred a large collections of memes, of critiques, and the scene in .gif format became the face of the problem of straight queer consumption. Situating culturally queer tradition as trend, this statement exemplified the detriments of a proliferation of queer things, the appropriation and commodification of language and culture of marginalized groups, the erasure of roots with popularity - heterosexuals barging into queer nightclubs, and deteriorating the safe spaces queer bodies have built up. Boundaries of queer space are constantly in flux in light of such infringement, sped up through the proliferation of queer things in the digital age.
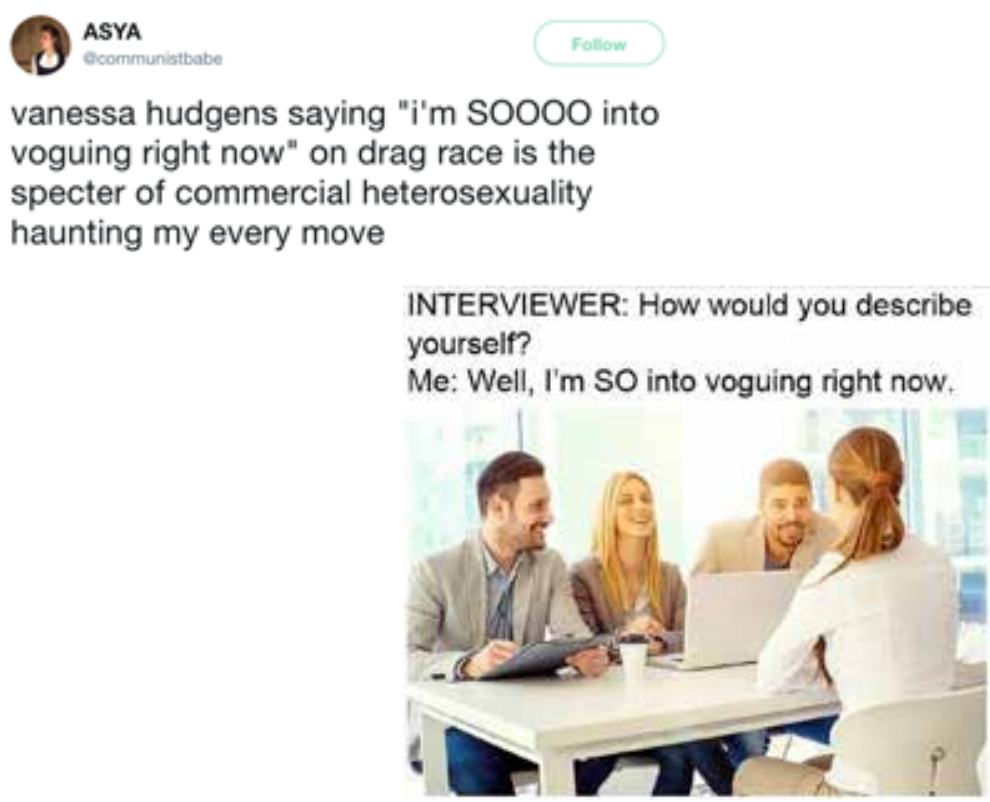

fig. 21: untitled, twitter user @communistbabe, 2018

fig. 22: untitled, instagram user @adamjosephmusic, 2018 




\section{washrooms}

Gendered space* is a result of negotiations of space derived from the social construction of gender. It is an architecturally grounded translation of gender politics that interferes with how individuals use and access space. It is also a translation of gender politics that is imposed upon space. One is designed with meaning ascribed to it from its conception, while the other is realized prior to its stamp. For example, the gendered public washroom is architecturally grounded, while the gendered train compartment is imposed.

To investigate how gendered space architecturally operates

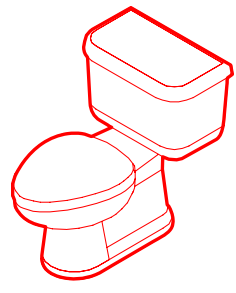

043 in contemporary society, I identified the gendered public washroom as a common space that extends beyond its traditional meaning - it is donned with a utilitarian purpose by user, by designer, by law, however it sees the materialization of diverse use beyond elimination and maintenance due to its normatively inherent qualities. As an auxiliary space, its frequency and type of use is contingent on the occupation of its adjacent space. Its repetition throughout the built world allows for us to deem it as familiar and banal, something that fades in the background and suffers from a "loss of place," (Ahmed, 2006, 165).

* this term is not to say that gender and sex are synonymous, but rather is a term used in reference to theoretical literature that identifies space denoting to a heteronormative conception of gender
In the second year of my undergraduate studies, penultimate studio presentations took place, with the townhouse as the typology of study. Following a few presentations that included renderings of washrooms, a professor hastily pointed out how this was unnecessary since it was just a washroom, and the affirmative nods of a dozen complacent students frantically attempting to prove their ability to learn followed. The washroom, public or private, is neglected, suffering from a loss of place, and was it through its image of ubiquity, or through a shared humiliation of the physical body and its processes, or through presentation without consideration, or something else?

The confinement and seclusion provided by an arrangement of opaque walls into stalls, separating plumbing fixtures 
and semi-nude bodies, can comfortably house a series of other acts that may be more difficult or uncomfortable to do within a more public and visible space. In washrooms, people talk to each other and on their phones, they argue or police or assault, they groom and pluck, they consume or produce illicit materials, they commit consensual and non consensual acts, they express emotions and reflect, they sexually propose and engage.

The separation of the washroom from the space it services requires an entryway that typically doubles as an exit $-a$ single opening that accommodates the flow of fluctuating numbers of individuals. Varying numbers of occupants result in multiple social atmospheres within the washroom. High traffic confines many, and sometimes too many, proposing multiple types of interaction, from exchanging glances to exchanging detailed anecdotes. Few occupants include these types, but also raise the likelihood of non-consensual interaction, that include verbal, physical and/or sexual assault. The lack of public presence and policing becomes an ideal condition for one party, and a highly vulnerable condition for the other. One entry can become one blocked

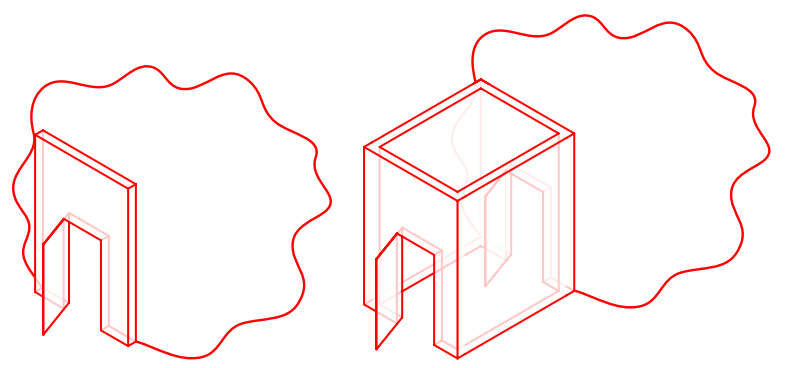
cons 
fig. 24:

translating

qualities of

the public

washroom

identified (from

left to right,

top to bottom):

regular stall,

accessible stall,

cannot stand

with door closed

stall, vanity

stall, duchamp

door stall

045
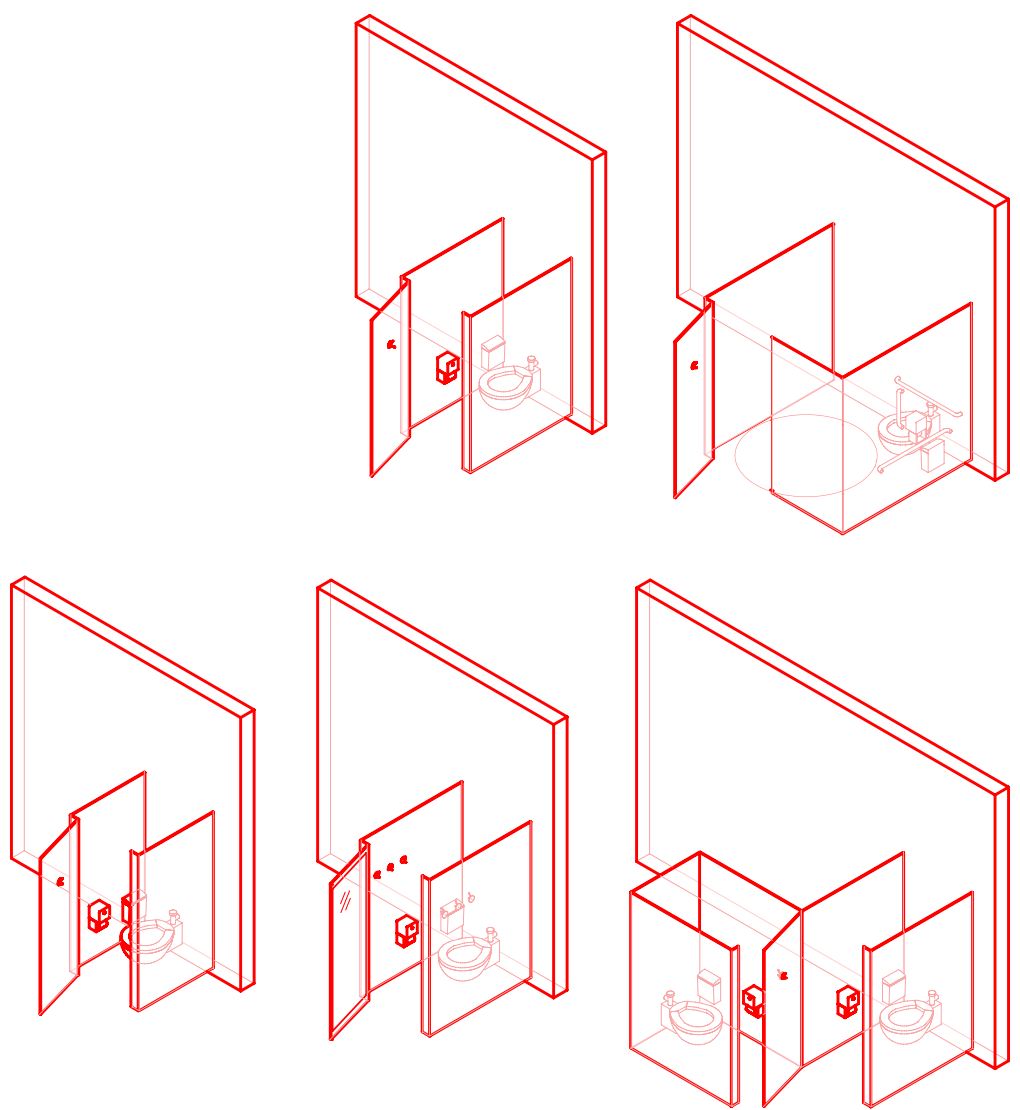

exit.

Historically, the public washroom is typically overlooked as a politically and emotionally charged space within an architectural project. The introduction of what was called sex segregation in the 19th century provides a reflection of a social ideology of that time period. The first ever example of gender segregated washrooms was in a Parisian restaurant in the 18th century. However the focus is on 1887, when Massachusetts enacted the first ever state law that required workplace facilities to provide a separate female washroom for female employees only (Kogan, 2007). This followed the 1850s, when plumbing and sewage technology was able to facilitate multi-user washrooms (Yuko, 2018). The Act reads: "Whenever male and female persons are employed in the same factory or workshop, a sufficient number of 
separate and distinct water-closets, earth-closets or privies shall be provided for the use of each sex and shall be plainly designated, and no person shall be allowed to use any such closet or privy assigned to persons of the other sex."

Other states followed suit, New York being one of them that adopted a similar law, including a provision that water closets are to be separated by sex (Kogan, 2007, 15):

An Act to secure proper sanitary provisions in factories and workshops:

Act of Mar. 24, 1887, chapter 103, 1887 Mass. Acts 668 "Every person employing five or more persons in a factory, or employing children, young persons or women five or more in number in a workshop, shall provide, within reasonable access, a sufficient number of proper water-closets, earthclosets, or privies for the reasonable use of all persons so employed; and whenever male and female persons are employed in the same factory or workshop, a sufficient number of separate and distinct water-closets, earth-closets or privies shall be provided for the use of each sex and shall be plainly designated, and no person shall be allowed to use any such closet or privy assigned to persons of the other sex," (Kogan, 2007, 15, emphasis by Ashurov).

To contextualize this act, the Separate Spheres ideology must be introduced:

"During the nineteenth century, the genteel elite - as well as an emergent middle class - developed an ardent faith in the civilizing power of moral women. Females were widely assumed to be endowed with greater moral sensibility and religious inclinations than men. Such pedestaled notions of women helped nourish a powerful 'cult of domesticity' which assigned to women the role of self-denying guardians of the hearth and soul. As the more complex economy of the nineteenth century matured, economic production was 
increasingly separated from the home, and the absence of men who left to work long hours in the city transformed the middle-class home into a "separate sphere" governed by mothers," (Shi, 1995, 17).

This ideological supposition of women locked to their domestic sphere failed to represent the reality of women's daily experiences or the progression of social reality. Women left their "spheres" for the public world, participating in workplace and civic life. Prior to the Civil War, semi-public spaces were of a masculine domain, but by the second half of the 19th century, the presence of women become generally more acceptable, but followed with conventional concerns of breaching what womanhood meant in society (Kogan, 2007).

The widespread adoption of gender segregated washrooms in places like department stores, hotels, theatres, libraries also unveiled the lounge or parlour. These pseudodomestic rooms typically served the women's washroom throughout history as a space to apply makeup or smoke cigarettes, something deemed inappropriate for publicity, to rest the fRaGiLe FeMaLe BoDy, to shed and reassemble cumbersome Victorian garments, to breastfeed and to tend to other biological processes. These spaces were designed to appear like living rooms or parlours, perpetuating the separate spheres ideology - a woman's true place was something within the domestic realm, her virtue protected (Yuko, 2018). Interestingly enough, depictions of the women's lounge show men welcomed (perhaps during social functions) (see fig. 25), while the less commonly found men's lounge solely occupied by men despite the inflexible titles of such spaces (see fig. 26). Who is being protected, and from what? Additional to the heteronormative conception of washroom, parlours or lounges exist due to Victorian ideals, divisions of class and race, and presumptions made by men of what women need when entering the public sphere. In some parts of the US, the divisions of space continued to 

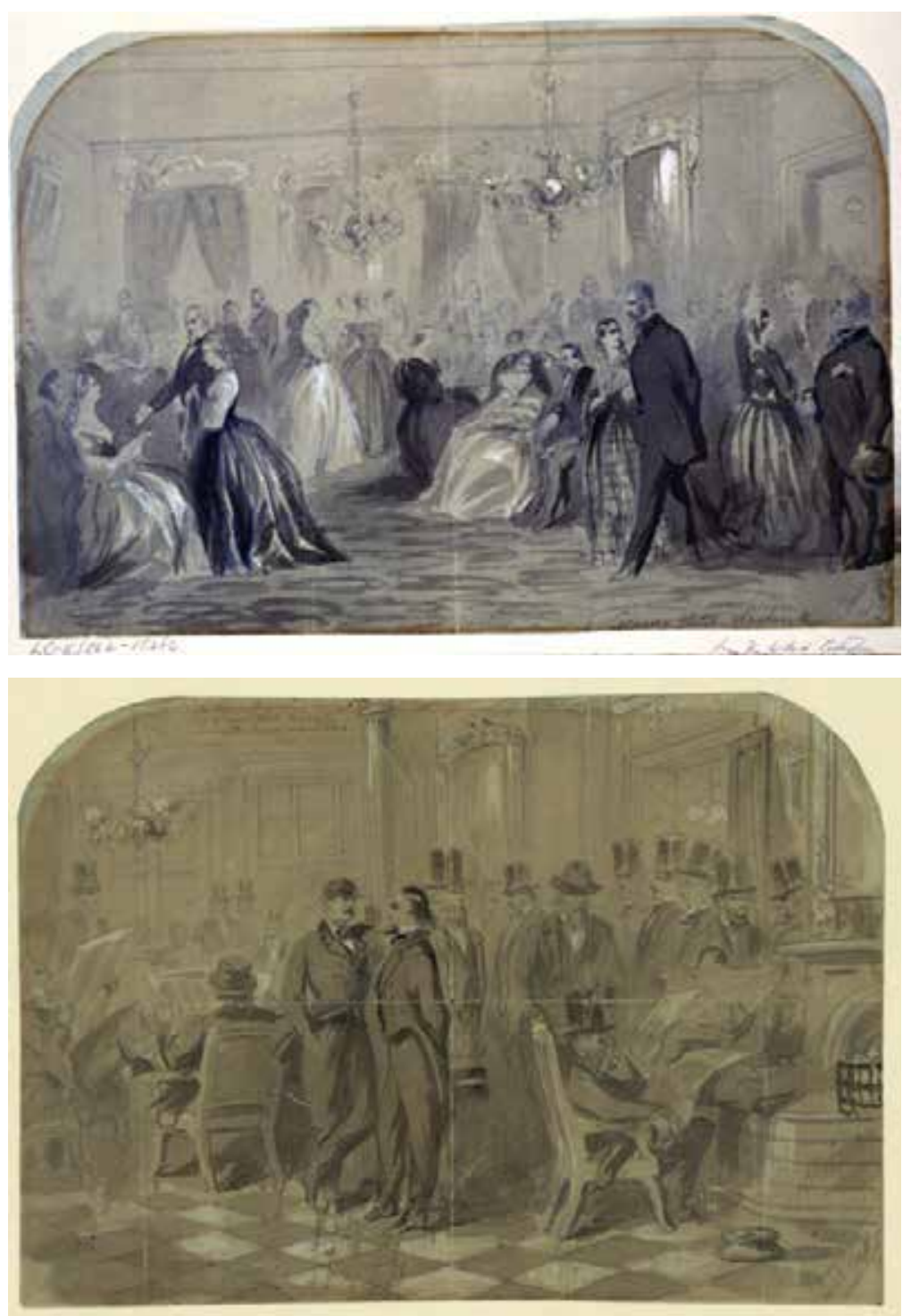

separate white from black, with special attention made to the spaces meant to be occupied by white women above all (Yuko, 2018).

In Popular (1999-2001), a teenage comedy-drama TV series that took place in an American high school, the prized women's washroom located on the ground level resembled a lounge with lush textures and deep warm tones, a Hollywood vanity mirror, and ample space for activity to fig. 25: "The ladies' parlor at the Willard Hotel

in Washington, shown during Inauguration Week in 1861. Presumably, men were welcomed

inside during an inauguration party", Library of Congress, 1861

fig. 26: "The gentlemen's parlor, reading, and sitting room at the Willard, also

shown during 1861's inaugural celebrations, with no women visible", Library of Congress, 1861

048 

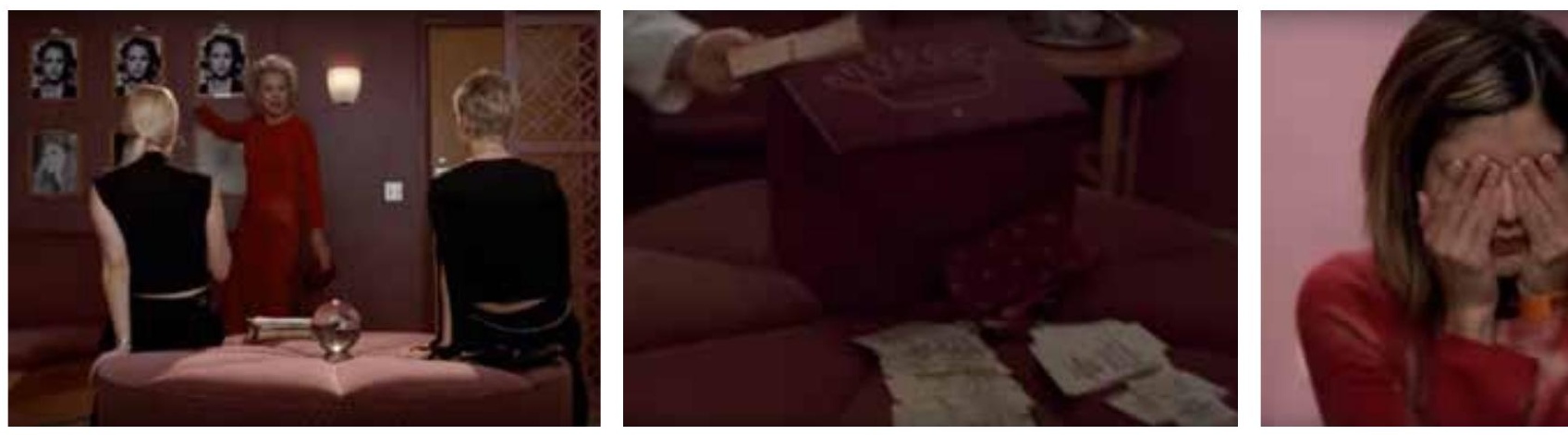

take place. The most jarring and pivotal moments within the series generally took place in this psuedo-domestic space, like when two out of the six main female characters inserted hundreds of fake ballots during a school election to sway the results in their favour (see fig. 27-28). The inner workings of character relationships, female or not, were most visible in this particular washroom. Here, the washroom transcends its utilitarian purpose, its value in the support of intricate social function plainly shown as a sublime stage.

049

* see Alex

Verman's article titled "It's about time we ask why men aren't funny" Verman, A. (2019). It's about time we ask why men aren't funny. A.Side. Retrieved from www.ontheaside. com/culture/itsabout-time-weask-why-menarent-funny/
The emergence of realism in science during the midnineteenth century stressed sex differentiation and hierarchy, with particular focuses on race and sex. Scientists stated distinctions in anatomy, physiology, temperament, and intellect, whereas gender roles previously defined the differences of men and women. It is noteworthy that these assertions are adopted and still used to this day, informally within social circles or through daily microaggressions, but also publicly broadcasted and endorsed (consider the common tropes of comedy routines performed by cisgender men*). These findings were used to affirm the Separate Spheres ideology, and legislators derived from them that women must be protected, as they are viewed as vulnerable once they departed from their domestic spheres. Every nook of the public realm occupied by women became a potential target for regulation. Legislation translated a weaker body argument into a banning of women from dangerous industries, or a set of restrictions on what women can and cannot do in a workplace. Literal gendered designations of 

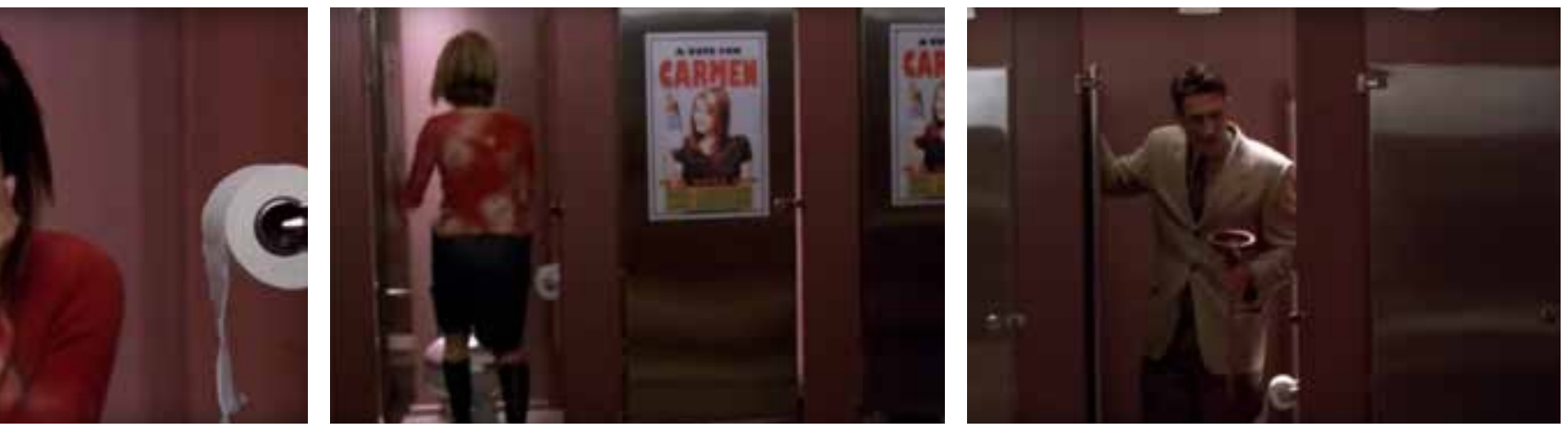

space were next.

At this point, I would like to note that these acts are to be understood as gender segregation as they were born from a sociological distinction between binary gender. Separation of reproductive organs is not the underlying driver of this act, rather an extension from those as a point of referral. The reason this point in time is of focus is that laws can surpass their period of relevancy, while societal values evolve, however, laws shift in a much slower fashion. They interfere through their grandeur, and act as affirmation of behaviours that are seen as controversial, undermining, or dangerous - unconstitutional. They can become socially and culturally ingrained, even harder to shake off in their absence. The majority of new architectural projects continue the tradition of gendered washrooms, simple to execute and practically suggested by building codes.

Up to this day, the Ontario Building Code refers to sex, male, and female when addressing water closets for all occupancies, specifically identifying numbers of individuals that fall either under one or the other. All tables besides those that engage with barrier-free design follow one of two formats (see fig 32 and fig 33). The following excerpt on page 47 is sentence 3.8.3.12., which describes the "universal washroom", and holds the universal washroom to the standards of barrier-free design, unlike gendered washrooms.

fig. 27 : still

of tv series

Popular s02e07

$5: 44,2000$

fig. 28: still

of tv series

Popular $502 \mathrm{e} 07$

35:45, 2000

fig. 29: still

of tv series

Popular s02e07

20:37, 2000

fig. 30: still

of tv series

Popular s02e07

20:34, 2000

fig. 31: still

of tv series

Popular s02e07

35:55, 2000 


\subsubsection{Universal Washrooms}

(1) A universal washroom shall,

(a) be served by a barrier-free path of travel,

b) have a door that is capable of being locked from the inside and released from the outside in case of emergency and that has,

(i) a graspable latch-operating mechanism located not less than $900 \mathrm{~mm}$ and not more than $1000 \mathrm{~mm}$ above the finished floor,

(ii) if it is an outward swinging door, a door pull not less than 140 $\mathrm{mm}$ long located on the inside so that its midpoint is not less than $200 \mathrm{~mm}$ and not more than $300 \mathrm{~mm}$ from the latch side of the door and not less than $900 \mathrm{~mm}$ and not more than 1100 $\mathrm{mm}$ above the finished floor, and

(iii) if it is an outward swinging door, a door closer, spring hinges or gravity hinges, so that the door closes automatically,

(c) have one lavatory conforming to Sentences 3.8.3.11.(1), (3) and (4),

(d) have one water closet conforming to Article 3.8.3.9. that is located in accordance with Clause 3.8.3.8.(2)(a) or (b),

(e) have grab bars conforming to

(i) Sentence 3.8.3.8.(3), if the water closet is located in

accordance with Clause 3.8.3.8.(2)(a), or

(ii) Sentence 3.8.3.8.(4), if the water closet is located in accordance with Clause 3.8.3.8.(2)(b)

(f) have no internal dimension between walls that is less than $1700 \mathrm{~mm}$

g) have a coat hook that conforms to Clause 3.8.3.8.(1)(e) and a shelf that is located not more than $1100 \mathrm{~mm}$ above the finished floor and projects not more than $100 \mathrm{~mm}$ from the wall,

(h) be designed to permit a wheelchair to turn in an open space not less

than $1700 \mathrm{~mm}$ in diameter,

(i) be provided with a door equipped with a power door operator if the door is equipped with a self-closing device,

(j) be provided with a mirror,

(i) installed above a lavatory described in Clause (1)(c), and (ii) mounted with its bottom edge not more than $1000 \mathrm{~mm}$ above the finished floor or inclined to the vertical to be usable by a person in a wheelchair, and

(k) have lighting controlled by a motion sensor conforming to Sentence 12.2.4.1.(2).

(2) A universal washroom shall have,

(a) an emergency call system that consists of audible and visual signal devices inside and outside of the washroom that are activated by a control device inside the washroom, and

(b) an emergency sign that contains the words IN THE EVENT OF AN

EMERGENCY PUSH EMERGENCY BUTTON AND AUDIBLE AND

VISUAL SIGNAL WILL ACTIVATE in letters at least $25 \mathrm{~mm}$ high with a 5 $\mathrm{mm}$ stroke and that is posted above the emergency button.

(3) A clear space not less than $810 \mathrm{~mm}$ wide and $1830 \mathrm{~mm}$ long shall be provided in each universal washroom for an adult-size change table.

(4) Where the clear space provided for an adult-size change table is adjacent to a wall, reinforcement shall be installed in the wall to permit the future installation of the change table.

(5) Where an adult-size change table is installed, it shall,

(a) when fully loaded, have a surface height above the finished floor that can be adjusted from between $450 \mathrm{~mm}$ and $500 \mathrm{~mm}$ at the low range to between $850 \mathrm{~mm}$ and $900 \mathrm{~mm}$ at the high range,

(b) be designed to carry a minimum load of $1.33 \mathrm{kN}$,

c) have a clear floor space parallel to the long side of the table not less

than $760 \mathrm{~mm}$ wide and $1500 \mathrm{~mm}$ long, and

(d) in the case of a fold-down table,

(i) be installed so that it does not encroach into a clear transfer space described in Clause 3.8.3.8.(2)(a) or (b), and

(ii) have no operating mechanisms higher than $1200 \mathrm{~mm}$.

(6) A universal washroom need not conform to Sentences (3) and (4) if,

(a) it is located in an individual suite that

(i) is used for an assembly occupancy, a business and personal services occupancy, a mercantile occupancy or an industrial occupancy, and

(ii) meets one of the following requirements,

(A) it is located in a bulding that is less than $300 \mathrm{~m} 2$

in building area, or

(B) it is less than $300 \mathrm{~m} 2$ in area, if located in a

building that is at least $300 \mathrm{~m} 2$ in building area, or

(b) another universal washroom conforming to this Article is provided on the same floor level within $45 \mathrm{~m}$.

(O. Reg. 332/12: BUILDING CODE, 2018). 
"(2) Except as provided in this Subsection, water closets shall be provided for each sex assuming that the occupant load is equally divided between males and females, unless the proportion of each sex expected in the building can be determined with reasonable accuracy.

(3) Except as provided in Sentence (4), urinals are permitted to be substituted for water closets required by this Subsection for males and may be counted as water closets provided the number of urinals is not more than,

(a) one-fifth of the required number of water closets in hospitals and long-term care homes, and

(b) two-thirds of the required number of water closets in any other occupancy.

(7) The water closet and lavatory provided in the universal washroom described in Sentence 3.8.3.12.(1) may be counted as part of the plumbing fixtures required for males and females in this Subsection if,

(a) more than one water closet is required for males, and

(b) more than one water closet is required for females.

(8) Where one water closet is required for males and one water closet is required for females, the following may be provided in lieu of the water closets otherwise required by this Subsection:

(a) one universal washroom conforming to Sentence 3.8.3.12.(1), and

(b) one washroom containing one water closet that is permitted to be used by both sexes provided the door to the room can be locked from the inside.

(9) Both sexes are permitted to be served by a single water closet if the occupant load is not more than 10 persons in an assembly occupancy referred to in Article 3.7.4.3. except for,
(a) elementary and secondary schools,
(b) child care facilities,
(c) places of worship, and
(d) undertaking premises."

(O. Reg. 332/12: BUILDING CODE, 2018). 
(from left

to right)

fig. 32: Table

3.7.4.3. A

Water Closets

for Assembly

Occupancies,

Adapted

from Ontario

Regulation

332/12

Building Code,

Government of

Ontario, 2018

fig. 33: Table

3.7.4.3.C.

Water Closets

for Assembly

Occupancies,

Adapted

from Ontario

Regulation

332/12 Building

Code

053
Table 3.7.4.3.C.

Water Closets for Assembly Occupancies

Forming Part of Sentences 3.7.4.3.(3) and 3.11.9.1.44)

\begin{tabular}{|c|c|c|}
\hline Item & $\begin{array}{l}\text { Column } 1 \\
\text { Number of Persons of Each Sex }\end{array}$ & $\begin{array}{l}\text { Column } 2 \\
\text { Minimum Number of Water } \\
\text { Closets for Each Sex }\end{array}$ \\
\hline 1. & 1 to 50 & 1 \\
\hline 2. & 51 to 150 & 2 \\
\hline 3. & 151 to 250 & 3 \\
\hline 4. & 251 to 375 & 4 \\
\hline 5. & 376 to 500 & 5 \\
\hline 6. & over 500 & $\begin{array}{l}6 \text { plus } 1 \text { for each additional } \\
\text { increment of } 150 \text { persons of each } \\
\text { sex in excess of } 500\end{array}$ \\
\hline
\end{tabular}

Table 3.7.4.3.A.

Water Closets for Assembly Occupancies

Forming Part of Sentence 3.7.4.3.(1)

\begin{tabular}{|c|c|c|c|}
\hline Item & $\begin{array}{l}\text { Column } 1 \\
\text { Number of Persons } \\
\text { of Each Sex }\end{array}$ & $\begin{array}{l}\text { Column } 2 \\
\text { Minimum Number of } \\
\text { Water Closets for } \\
\text { Males }\end{array}$ & $\begin{array}{l}\text { Column } 3 \\
\text { Minimum Number of } \\
\text { Water Closets for } \\
\text { Females }\end{array}$ \\
\hline 1. & $1-25$ & 1 & 1 \\
\hline 2. & $26 \cdot 50$ & 1 & 2 \\
\hline 3. & $51 \cdot 75$ & 2 & 3 \\
\hline 4. & $76-100$ & 2 & 4 \\
\hline 5. & $101-125$ & 3 & 5 \\
\hline 6. & $126-150$ & 3 & 6 \\
\hline 7. & $151-175$ & 4 & 7 \\
\hline 8. & $176-200$ & 4 & 8 \\
\hline 9. & $201-250$ & 5 & 9 \\
\hline 10. & $251-300$ & 5 & 10 \\
\hline 11. & $301-350$ & 6 & 11 \\
\hline 12. & $351-400$ & 6 & 12 \\
\hline 13. & Over 400 & $\begin{array}{l}7 \text { plus } 1 \text { for each } \\
\text { additional increment } \\
\text { of } 200 \text { males in } \\
\text { excess of } 400\end{array}$ & $\begin{array}{l}13 \text { plus } 1 \text { for each } \\
\text { additional increment } \\
\text { of } 100 \text { females in } \\
\text { excess of } 400\end{array}$ \\
\hline
\end{tabular}

Under sentence 3.7.4.2. Plumbing Fixtures, General, the following clauses give hint to gender neutral washrooms, but with much less clarity than all other sex-based data (see page 48). This language maintains a divisive status quo through plumbing fixtures and occupancy, emphasizing occupant loads only after a filter of sex is applied.

The gendered washroom that emerged in the nineteenth is not the first of its kind. Possibly due to a likeness in a gendered state of affairs and program revolving around hygiene, the history of Roman bathing reveals a similar history to one 
that is presently developing. Literary evidence suggests baths were initially built for male use only, but growing desire in public bathing from women resulted in spatial separations. The Stabian baths of Pompeii are among the earliest pieces of archeological evidence for Roman baths, and it is theorized that the separate entrances and facilities were built for gender segregation (Ward, 1992).

In the early empire, Roman bath architecture shifted to single sets of bath rooms. One of the first examples are the Capito baths at Miletus in Asia Minor. Research on gender and Roman baths have at first suggested a more sexual function to these spaces, noting that women who frequented bath rooms were promiscuous and were there to serve men, however other research suggests this is not the case (Ward, 1992). Perhaps this is an example of gendered process in itself, and researchers fail to divorce their bias from what should be objective.

We have replicated a similar process with our approach to a more stripped down and utilitarian vision of the Roman bath. Such a simplistic approach to permitting access to
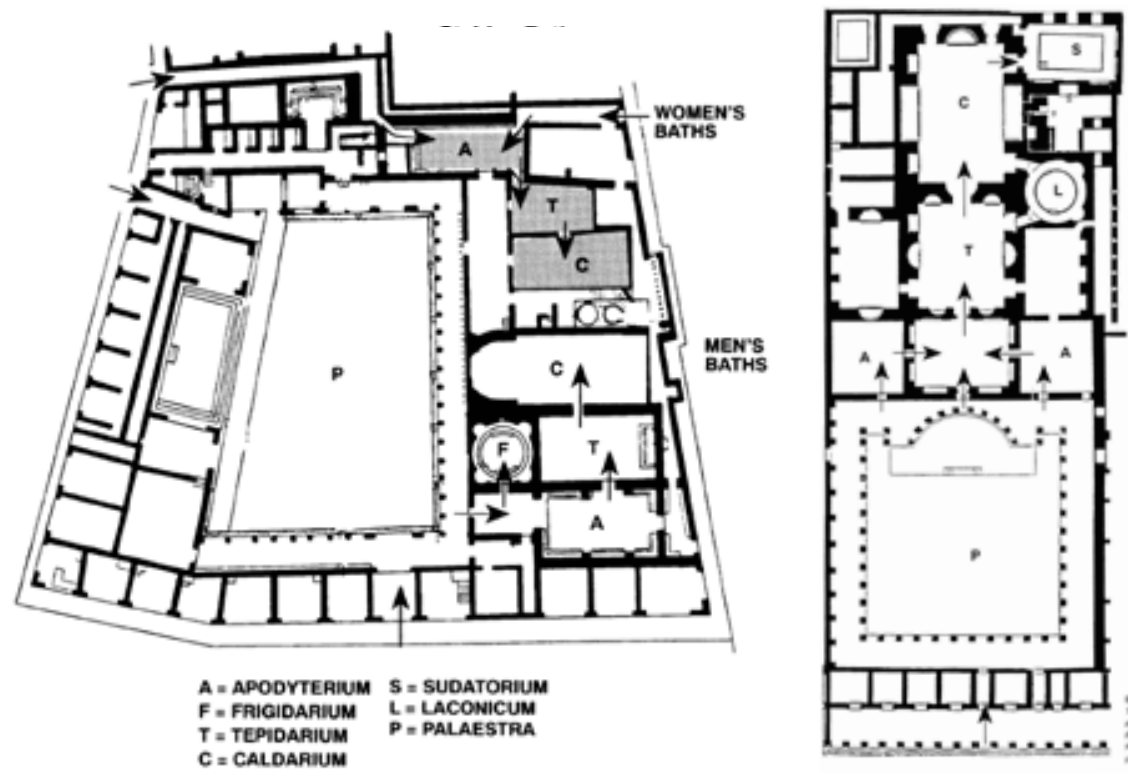

fig. 34: Stabian Baths in Pompeii, based on figure 75 by Inge Nielsen, Thermae et balneal: the architecture and cultural history of roman public baths, reproduced

by Roy Bowen Ward

fig. 35 Capito Baths in Miletus, based on figure 229 by Inge Nielsen, Thermae et balneal: the architecture and cultural history of roman publ054ths reproduced by Roy Bowen Ward

(from left t) , , 
space has generated discussions on how public washrooms do or do not accommodate trans people. The nineteenth century legislation affirms and perpetuates an ideology of gender binarism - increasingly rejected by contemporary society - that compromises the safety and comfort of many trans individuals. The majority of new architectural projects of public use continue what has become the tradition of gendered washrooms, while discussion in multiple disciplines begin to question how a washroom can accommodate all individuals. These discussions revolve primarily on gender-neutrality as a solution, but typically fall short of identifying the architectural implications of gender variance.

Sketch restaurant, trending on social media for its reimagining of dining space design with the proliferation of millennial pink and other elements, contains a non-gendered washroom hall complete with tunnel vaulted ceiling. Rather than nestled away into the depths of the restaurant, its position is emphasized through grand entry from two sets of sculptural curving staircases set atop the cocktail bar (see fig. 36). Toilets are contained in freestanding egg-like domes scattered throughout the washroom level, allowing for alternative movement around stalls that would otherwise be unsupported in space with a traditional adjacent stall configuration. The absence of colour (reserved for lighting) and texture with a touch of kitsch serves users with a clear and porous backdrop for selfies (taken to be shared on social media), transforming the publicity of the washroom through the production of an experience. Sketch's washroom is a destination rather than an auxiliary space, subverting its normative place within architectural space. During specific times of year, the space is occupied with festive garb, further branding otherwise anonymous or placeless space (see fig 37 and 38). 

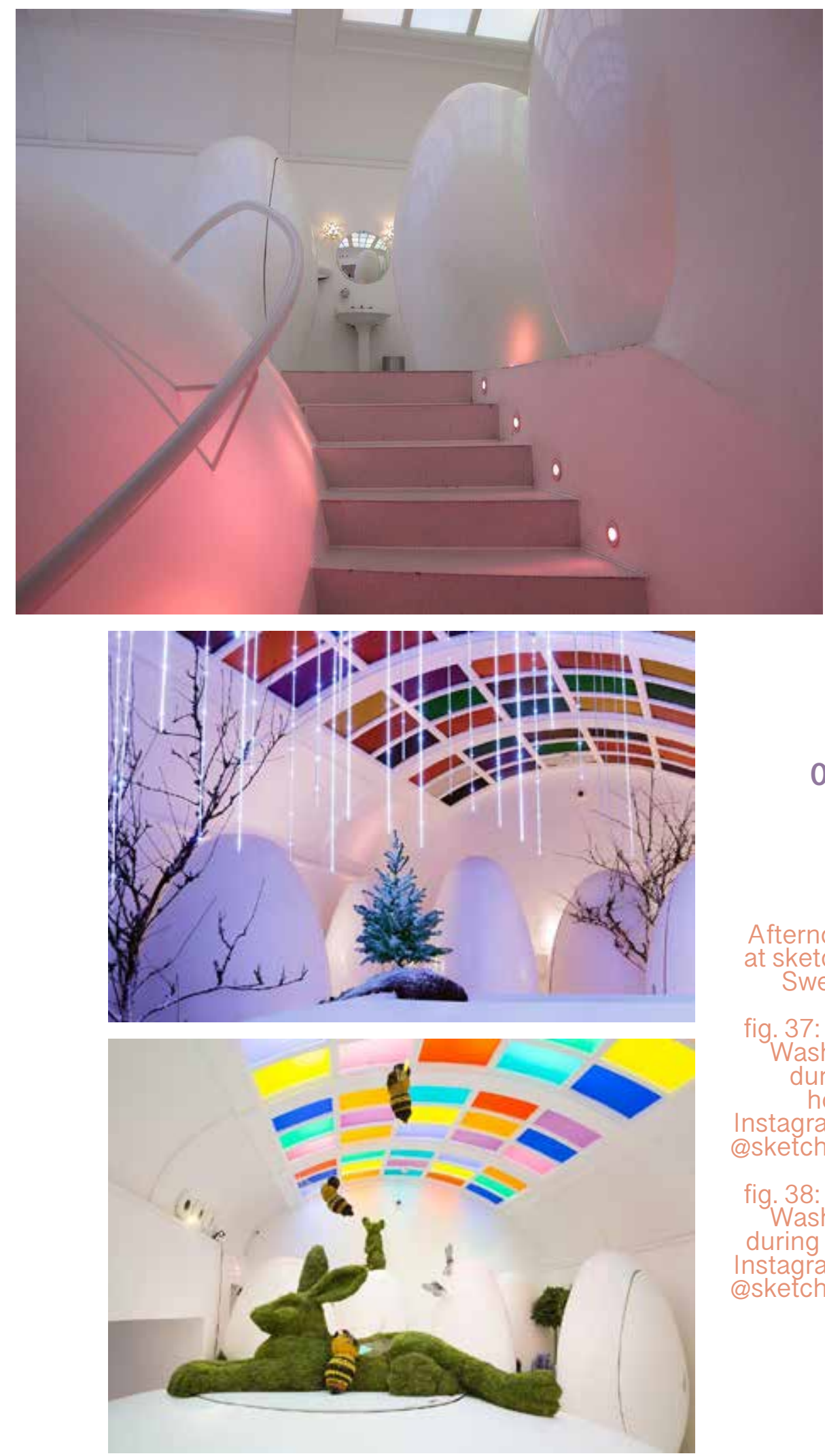

056

fig. 36:

Afternoon tea at sketch, The Swelle Life

fig. 37: Sketch Washrooms during the holidays, Instagram user @sketchlondon

\section{fig. 38: Sketch} Washrooms during Easter, Instagram user @sketchlondon 
washrooms

(from top to bottom, left to right)

fig 39: Untitled, Instagram user @theryanjude, Instagram, 2019

fig. 40-41:

Untitled,

Instagram user @shea.daspin, Instagram, 2019

fig. 42: Untitled, Instagram user @1missannabel, Instagram, 2019

fig. 43: Untitled, Instagram user @zzhongji, Instagram, 2019

fig. 44-45:

Untions\%

Instagram user @tmyuzu 6,

Instagram, 2019

fig. 46: Untitled, Instagram user @ddehardt,

Instagram, 2019

fig. 47: Untitled, Instagram user @talkramer,

Instagram, 2019

fig. 48: Untitled, Instagram user @allthestuffi-

need, Instagram, 2019

fig 49-51:

Untitled,

Instagram

user@

tiffanyarment 6 , Instagram 2019
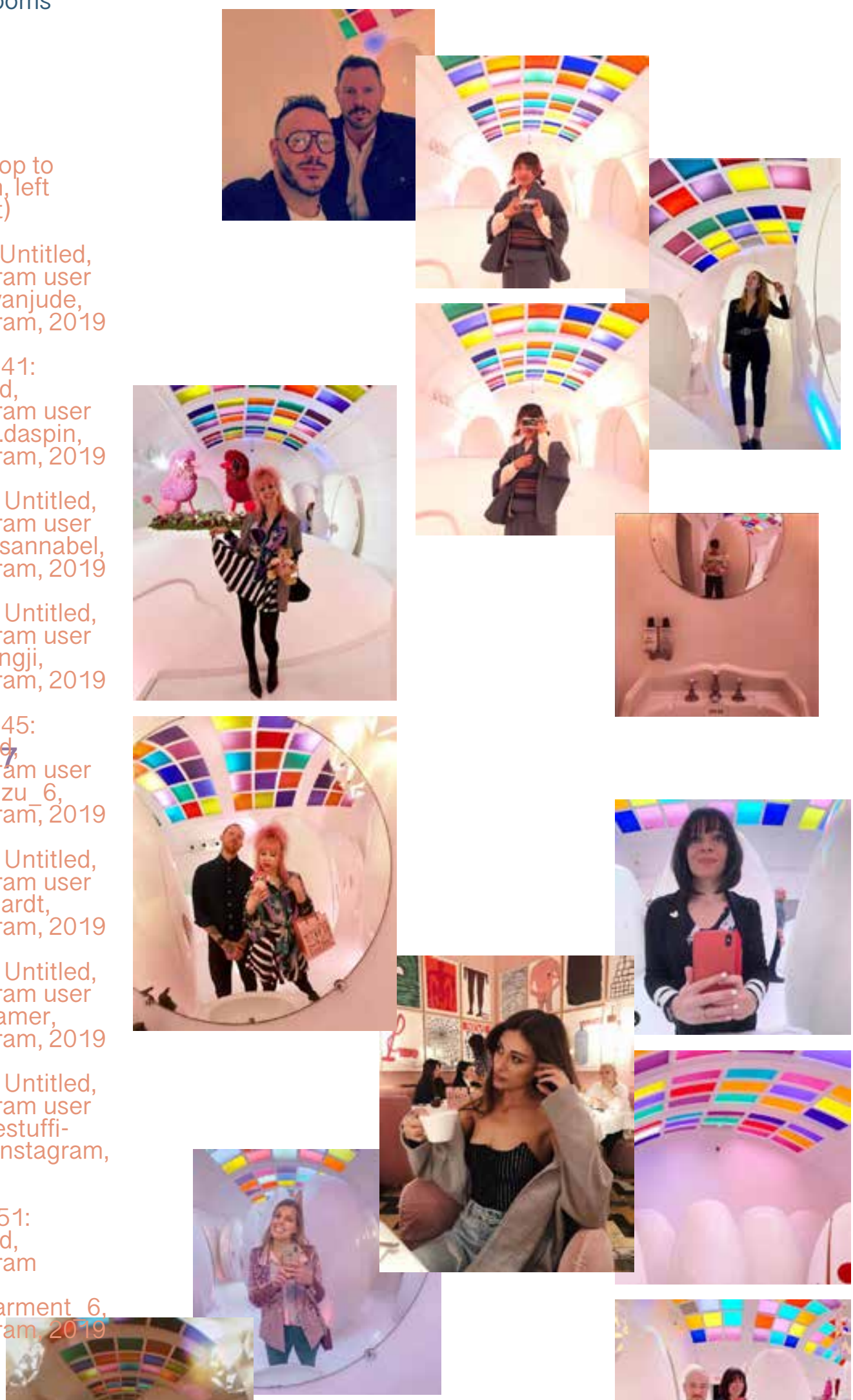


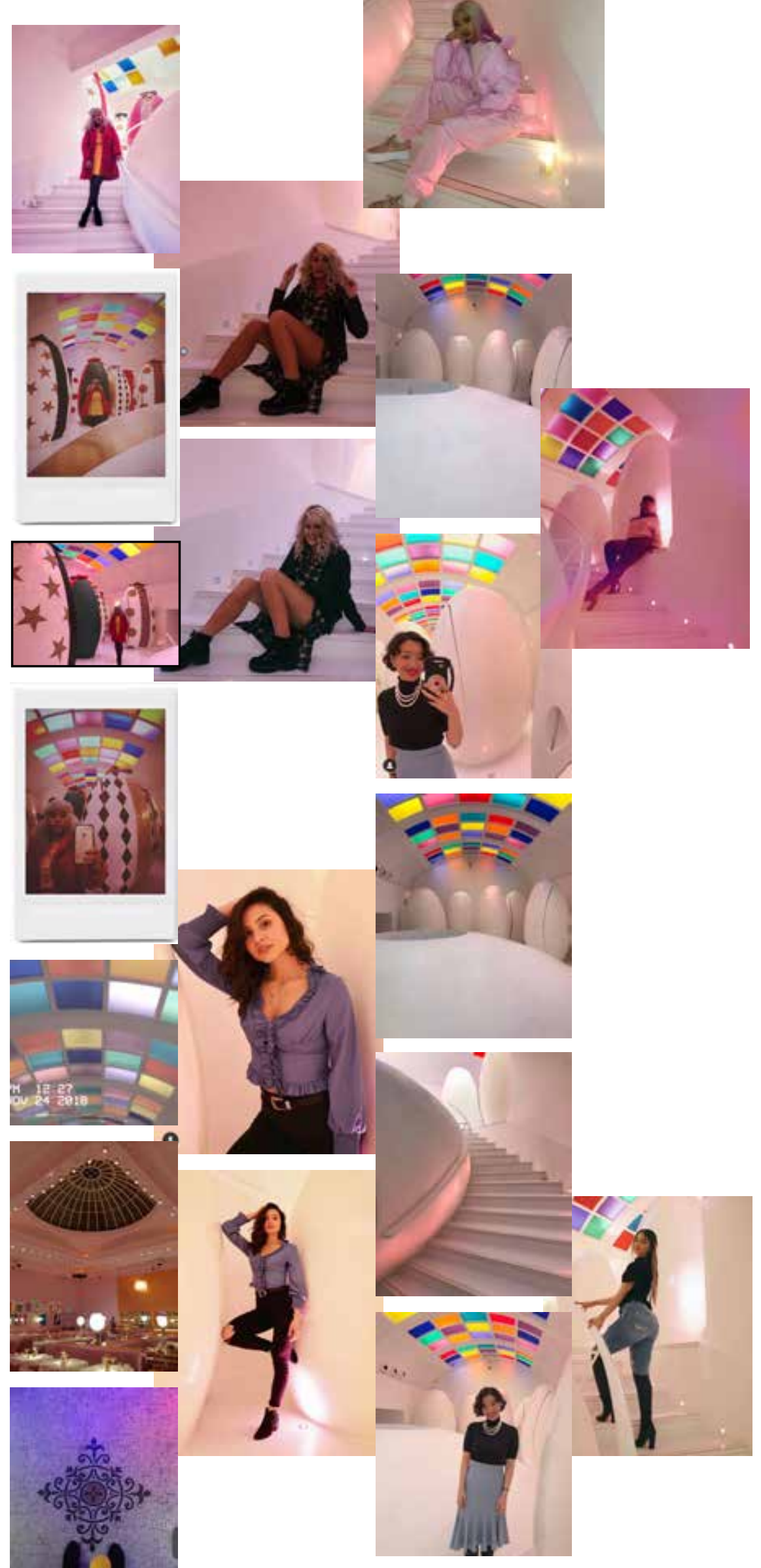

(from top to bottom, left to right)

fig. 52-58: Untitled, Instagram user@sgmi7, Instagram, 2019

fig. 59-60: Untitled, Instagram user @abbiwebsterr, Instagram, 2019

fig. 61-62: Untitled, Instagram user @katfernandez28, Instagram, 2019 058

fig. 63: Untitled, Instagram user @primalaprincess, Instagram, 2019

fig. 64-68: Untitled, Instagram user@chhwyn, Instagram, 2019

fig. 69: Untitled, Instagram user @jo withthe fro, Instagram,

fig. 70: Untitled, Instagram user @nadialba, Instagram, 2019 
washrooms

*William

Camfield,

the author

of "Marcel

Duchamp,

Fountain",

included a letter

Duchamp had

written to his

sister Suzanne,

on April 11,

1917 which

included the

following: "One

of my female

friends under

a masculine

pseudonym,

Richard Mutt,

sent in a

porcolain urinal

as a 059 glpture;

it was not at

all indecent

- no reason

for refusing it.

The committee

has decided to

refuse to show

this thing. I have

handed in my

resignation and

it will be a bit of

gossip of some

value in New

York,' (Howarth,

2000). This may

indicate that

Duchamp was

not the artist,

but is widely

credited for this

work. It has also

been suggested

that by

Baroness Elsa

von Freytag-

Loringhoven is

the artist behind

Fountain.

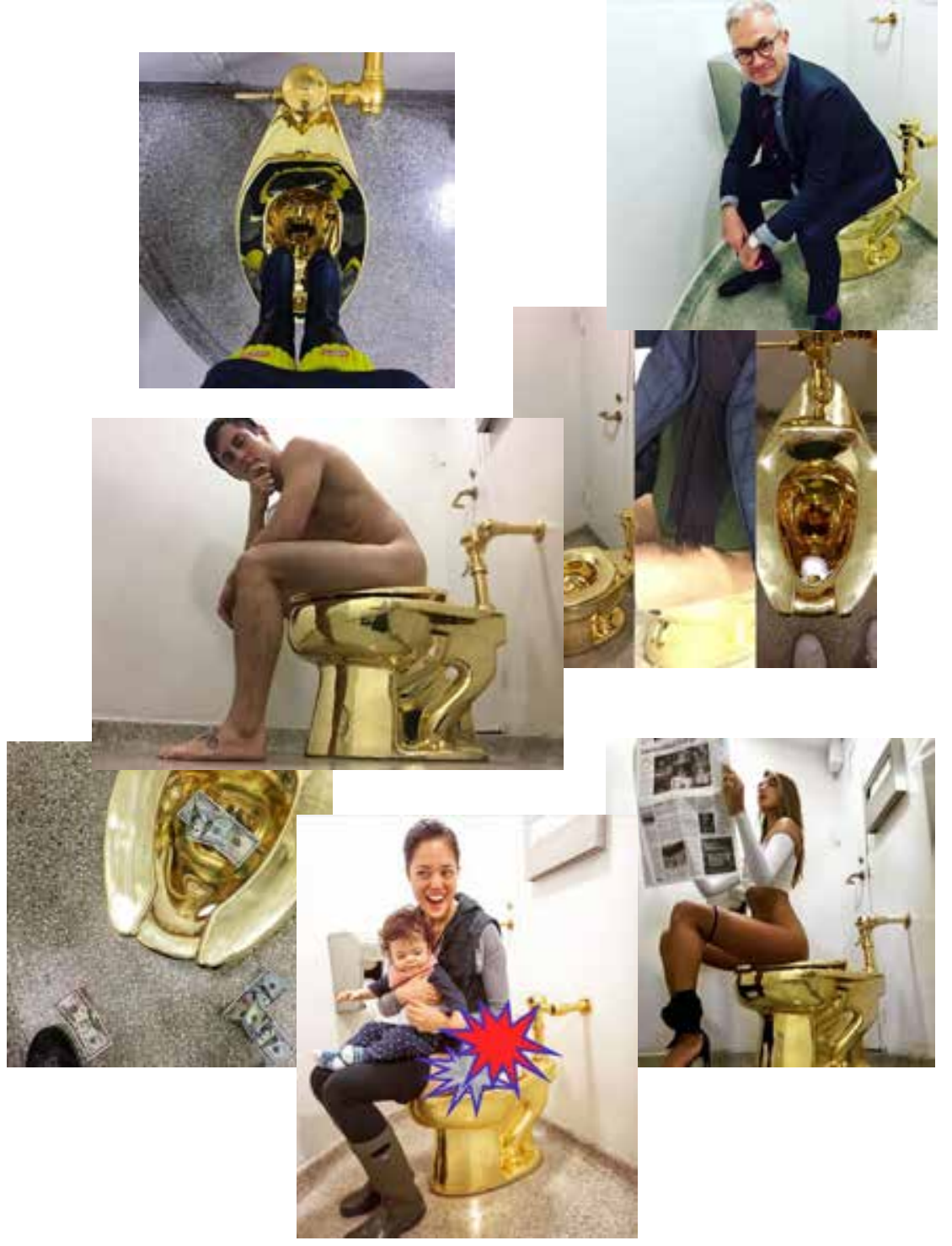

Engaging more intimately with the digitally public washroom, Maurizio Cattelan's "America" made the toilet seat a well documented phenomenon. Unlike contemporary luxury toilets that feature seat warming, spraying and drying functions amongst other things, America is an eighteen karat gold version of a standard plumbing part that is widely found in places of public access, a reference towards "the vanity of wealth" (Kennicott, 2018). And unlike R. Mutt's (a pseudonym for Marcel Duchamp or perhaps an anonymous female artist*) Fountain, this plumbing fixture is functional. Visitors of the museum are able to individually and in private make use of the toilet, inciting alternative relations between viewer and artwork. In turn, slews of images of individuals on the throne are found when searching \#goldentoilet on 
Instagram (see fig. 71-77), a curious and intimate case of private publicity.

Monica Bonvicini's "Don't Miss a Sec"' (2004) is an installation that takes the form of a public washroom enveloped in layers of varying glass panels that effectively act as a two-way mirror (see fig. 78). Within the space, situated on a sidewalk near Rotterdam's City Hall, sits a stainless steel toilet unit with a built-in sink and toilet roll holder (see fig. 79). Otherwise the space is clear, and once occupied, allows a clear view in any direction. This interplay of relief and privacy thrusted into public plays on the sense of publicity, not unlike the the Box Truck Sex pornography (see fig. 80). These videos are shot around but mostly within a truck's two-way mirrored cargo box, featuring people having sex while driven around or parked in highly populated areas around major European cities. Through particular camera angles and covert materials that treats unequally, the act of public sex and elimination is subverted.

In more recent years, the United States has released variations of bathroom bills by state that defined access to public washrooms by trans individuals, which were sparked by a series of cases involving trans individuals, mainly children, that were denied access to the washrooms that aligned with their gender identity in schools (Sanders \& Stryker, p. 779). The complex chain of events revealed social opinions, primarily the ignorance of identifying trans individuals with their appropriate gender, articulating the dangers trans individuals face in gendered washrooms.

This can be broken down into two realities where bathroom bills mandate that individuals may use the appropriate gendered washroom and individuals may only use the gendered washroom that aligns with their birth sex. In both cases, the deemed correct or incorrect uses to the facing page

(from top to

bottom, left to right):

fig. 71: Untitled, Instagram user @idca13. Instagram, 2019

fig. 72: Untitled, Instagram user @therauldelara Instagram, 2019

fig. 73: Untitled,

Instagram user@igee, Instagram, 2019

fig. 74: Untitled, Instagram user @smcdnyc. Instagram, 2019

fig. 75: Untitled, Instagram user @arthur amobolam Instagram,2019

fig. 76: Untitled, Instagram user @cloudluxury, Instagram, 2019

fig. 77: Untitled, Instagram user @jazzkata, Instagram, 2019 

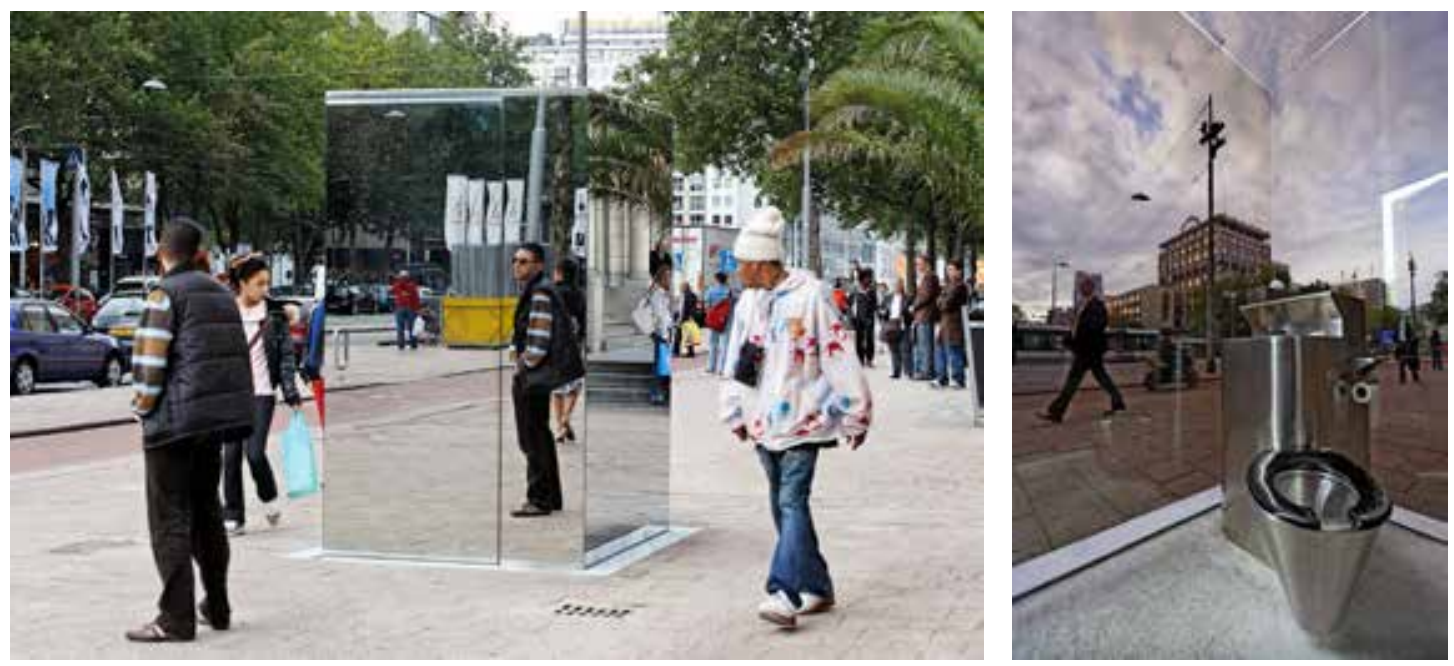

061

fig. 78: Exterior view of Don't Miss a Sec', Monica
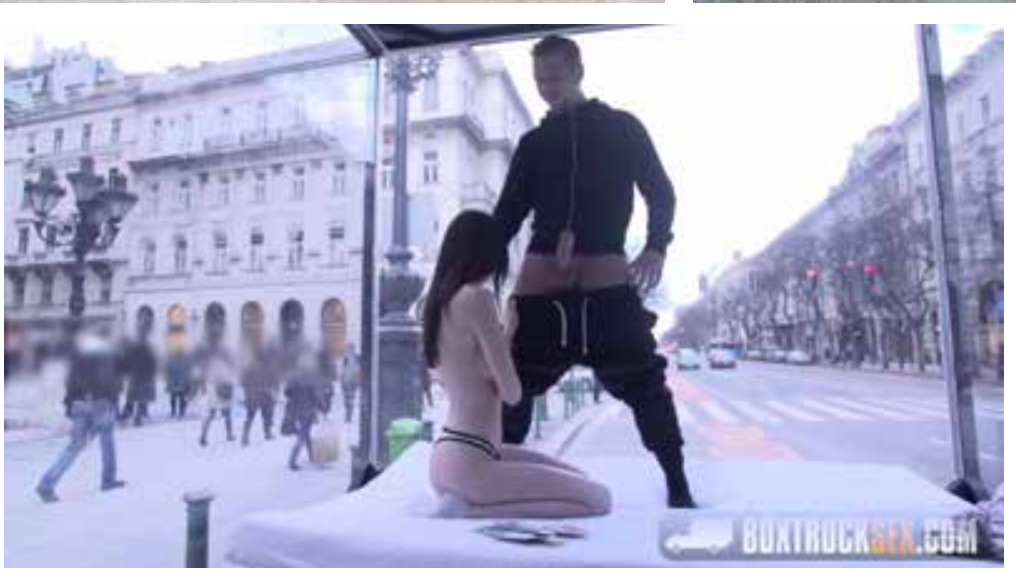

\section{Bonvicini, 2004}

fig. 79:

"Interior" view of Don't Miss a Sec', Monica Bonvicini, 2004

fig. 80: still from BOXTRUCK-

SEX - SHY HOT CHICK FUCKS IN A ONE-WAY MIRRORED TRUCK IN THE PUBLIC at 541 , Box Truck Sex, Pornhub, 2017 washroom takes the form of moral policing from other users who disagree with a transness in varying levels of violence, from verbal harassment to physical and sexual assault. However, with 'incorrect' uses, legislating supports this moral policing, and can be harnessed to wrongfully penalize.

The debate on trans access to public washrooms utilizes a lack of safety for one group or another as an argument in asserting their position. "While advocates cite high rates of violence faced by trans people, and trans women of colour in particular, opponents claim that trans women pose a threat to cis women, portraying trans women as predatory men masquerading in dresses to stalk prey in the ladies' room. Beneath this unsubstantiated fear lurks longstanding 
societal anxieties about human embodiment that bathrooms have historically harbored, including abjection, misogyny, homophobia, and ableism. However, a perhaps even deeper threat is the notion of gender ambiguity," (Sanders, 2017, 148). What supporters of North Carolina's proposed bathroom bill use as justification for removing the rights of trans individuals is the safety of cis women and children. The labeling of transgender people as perverted or criminal resembles a social opinion with respect to gay men in public washrooms during the AIDS crisis, who were also seen as a threat due to widely accepted homophobic rhetoric.

In these instances, "the public restroom stages the transformation of an abstract concern into a tangible threat, by virtue of it being a physical space in which so-called normal citizens are brought into intimate physical proximity with precisely those presumably non-normal people whose expulsion from or invisibilization within the body politics underpins and enables our society's norms of embodied personhood," (Sanders \& Stryker, 2017, 779-780). The qualities of the public washrooms outlined earlier begin to gain new meaning in this controversy, as severely opposing politics carry into small segmented spaces.

Gendered washrooms blatantly articulate their divisive nature through their titles and arrangements of space, but what about spaces in which cis-heterosexism operates more subtly, spaces and arrangements that install gendered, sexualized, racialized positions? And more importantly, how can diversions from such normalized paths and spatial practice that uphold cis-heterosexist ideals be achieved? 
washrooms

fig. 81: Pollee urinals for those who produce eggs, UiWE, 2011 fig. 82: Pollee, UiWE, 2011

fig. 83: Pollee, UIWE, 2011

fig. 84: Brasserie washroom,

Diller Scofidio + Renfro, 1999

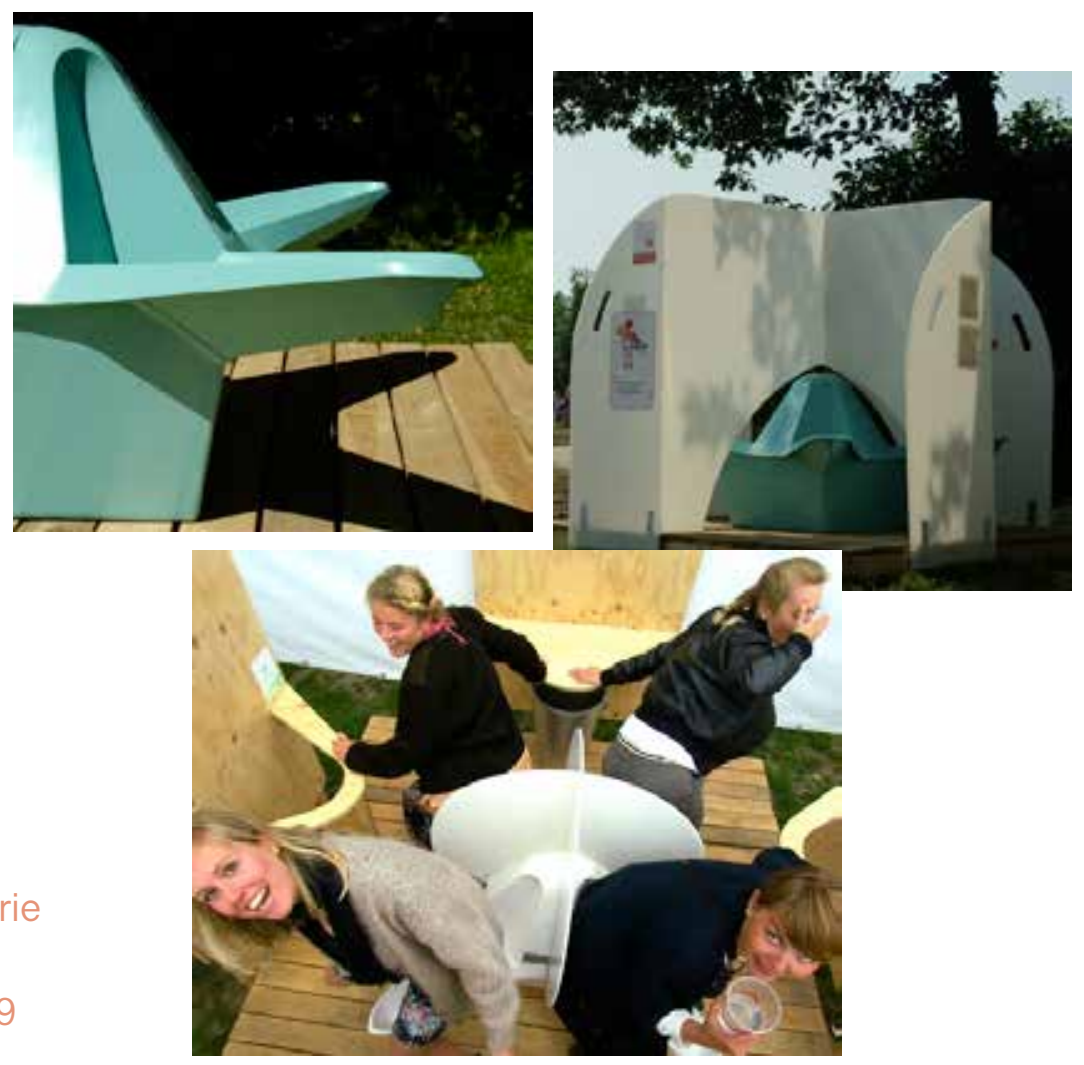

063

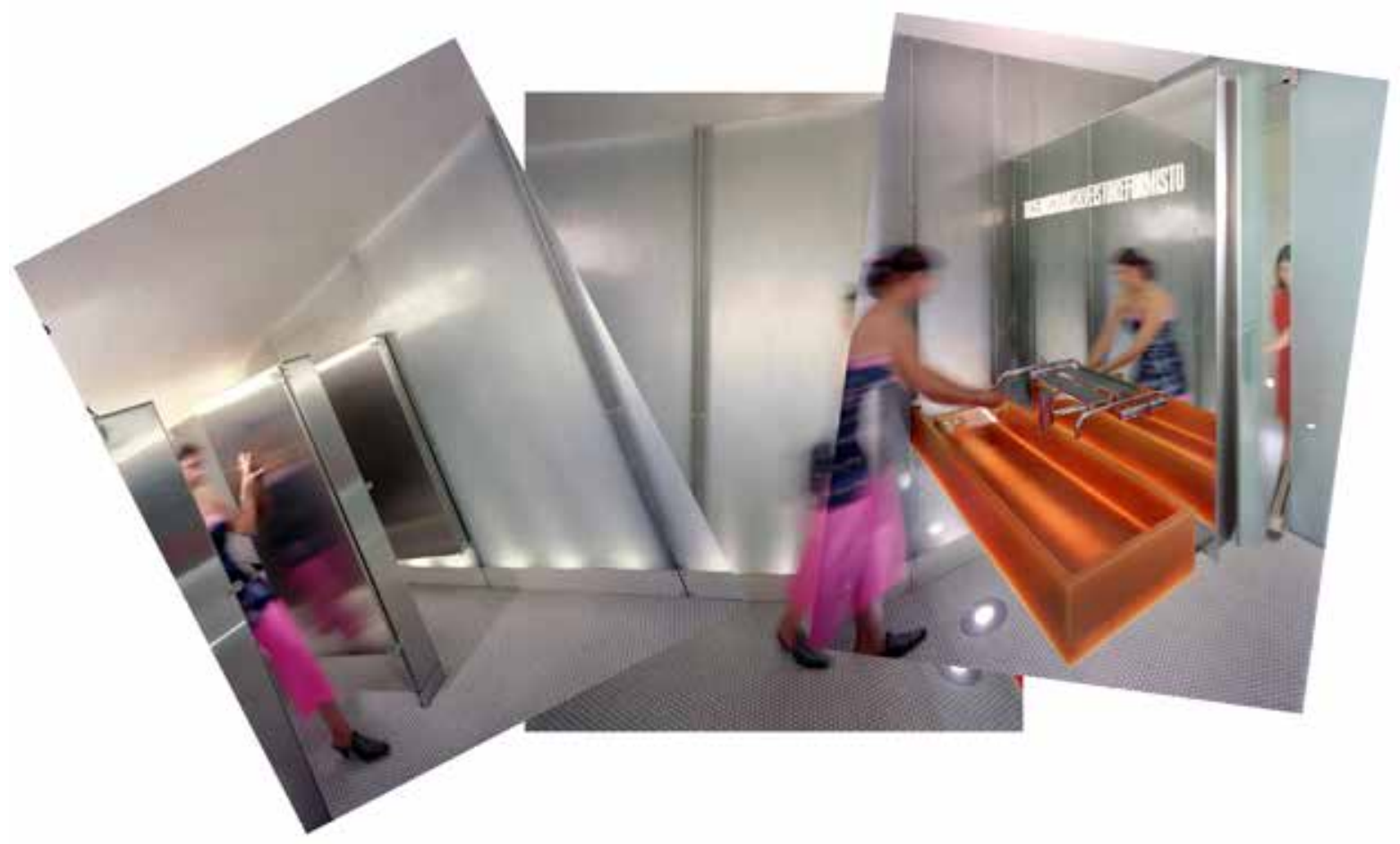



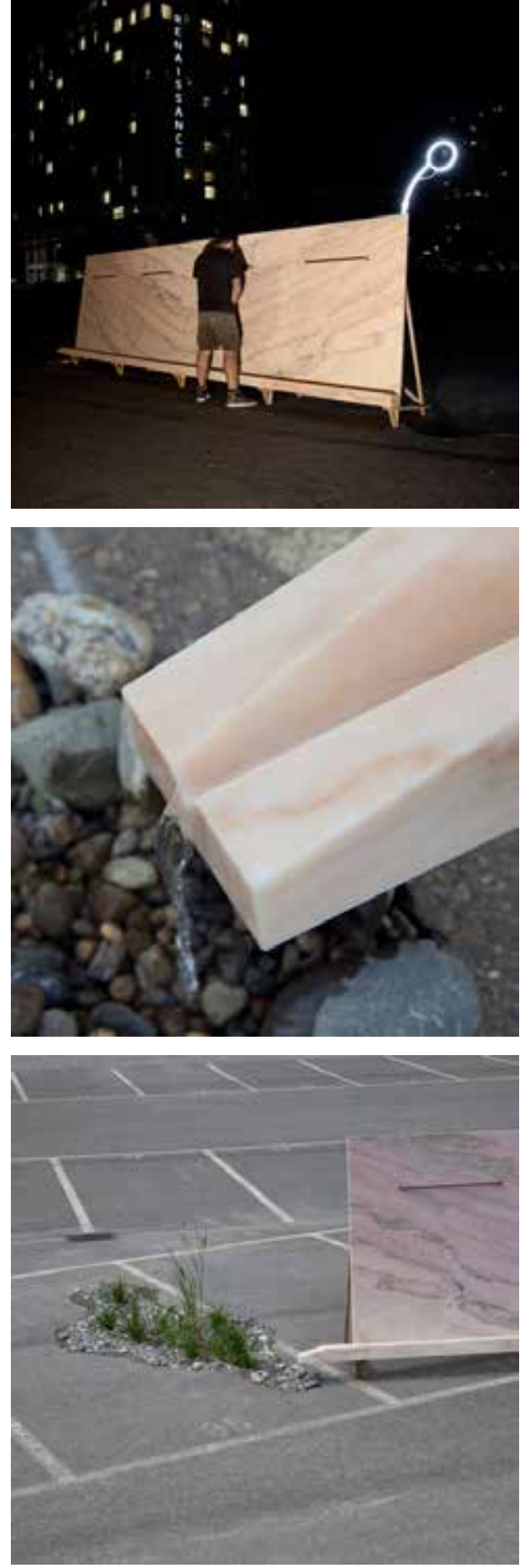

fig. 85: Urinal, pink marble urinal at Zurich car park, Bureau A, 2015

fig. 86: Urinal, Bureau A, 2015 fig. 87: Urinal, Bureau A, 2015 fig. 88: Urinal, Bureau A, 2015

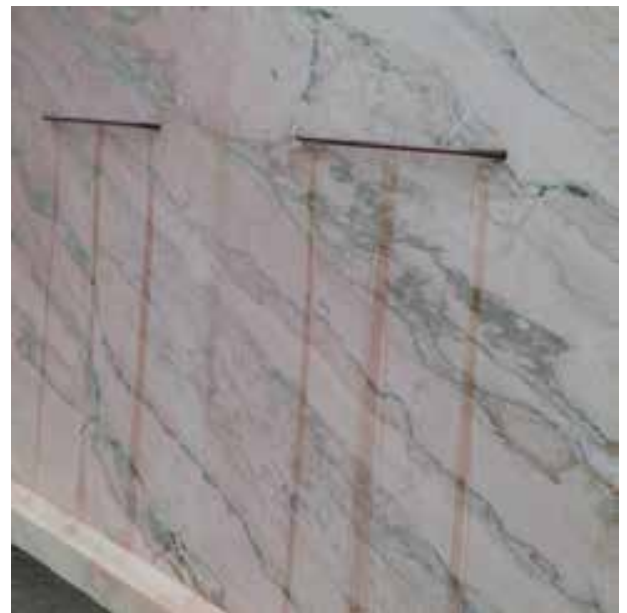




fig. 89: National

Coming Out

Day logo, 1993,

figure 7 from

Closets, Clothes,

Disclosure by

Henry Urbach,

in Assemblage,

No. 30 (Aug.

1996), pp. $62-73$

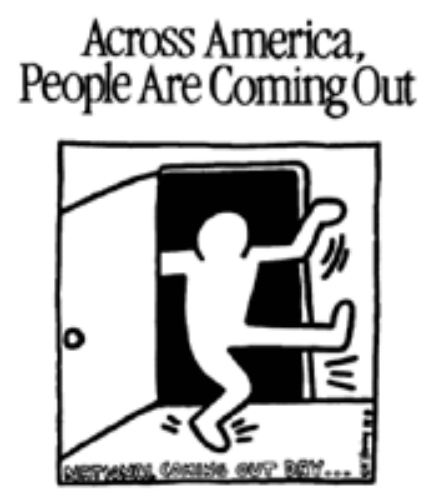

The closet is typically defined as two types of constructions. The first one is physical, existing as a void carved out of a wall plane in a room, and given the sole function of storing an accumulation of physical objects. The second one, borrowing from the qualities of the former, is immaterial, and exists in a heteronormative organization of gender and sexuality. These two closets share in common a way of "defining and ascribing meaning to space" through the function of dedicated storage separated from non-storage, or "display" (Urbach, 1996, 342). The contents of the closet, whether it is withheld expression of desire and gender, or physical objects, are placed/left/stored there to not disrupt a social or hygienic order. In 'Closets, Clothes, disClosure', Henry Urbach presents an account of both closets, concentrating their qualities to uncover their operations and inform possibilities of subversion through a queer lens.

The built-in closet, conceived of in mid-nineteenth century America, was a new type of space that emptied the contents of a room's furniture of storage - armoires, chests, wardrobes - along with garments that hung from walls, and stored them in a wall cavity that lives beyond the perimeter of a room. And rather than existing as a free-standing object, commanding attention through an overall form with decorative elements, the closet hinted at its presence through a slip in the surface of a wall, a door's surface. "From 


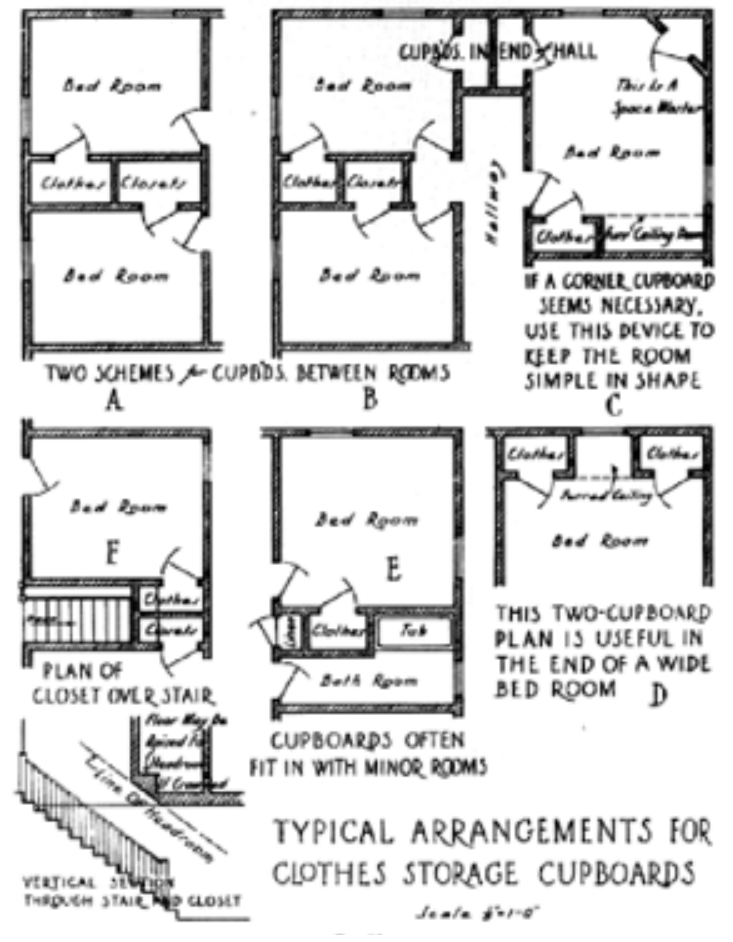

about 1840 onwards, the closet offered, instead, diminished architectural expression. The storage of clothing had been respatialised as a kind of shameful secret. The closet not only concealed the things it contained but, significantly, it also promised to hide itself," (Urbach, 1996, 343).

The built-in closet expresses passivity, as it was expressed through drawing - evident only in plan, but no further elaboration provided elsewhere. The details of its height, ventilation, lighting, surface treatment and other spatial qualities were omitted from texts produced during the period of its dissemination (Urbach, 1996). Crudely stuffed into strips of volume separating rooms, closets maintained no relation to one another despite any adjacency, and became an extension of the cavity of the wall.

Besides the aperture of the door that grants access to the interior, the perimeters of a closet are rarely broken up with other doors or windows that would otherwise allow the closet to present itself beyond the room it is in. This establishes an exclusive, "monogamous relation," between, "the closet and its room," (Urbach, 1996, 345). Urbach cites an excerpt fig. 90: Plans of clothes storage cupboards, ca. 1940, figure 4 from Closets, Clothes, Disclosure by Henry Urbach, in Assemblage, No. 30 (Aug., 1996), pp. 62-73

\section{8}


closets

from a domestic planning manual from the 1940s: "closets should not interfere with [the] main areas of activity in a house. They should be accessible but inconspicuous," (Wilson, 1865, 1). But as moderately as it displays itself, hinges, seams, handles, and slips in the surface and furniture arrangements that remain clear facing its access betray its concealment (Urbach, 1996).

Parallel to the insertion of the closet as element, for Americans, "encountering an expanding industrial economy alongside the resurgence of Christian [or Victorian] morality, wealth had come to represent both virtue and decadence. It could be amassed but not comfortably shown," (Urbach, 1996, 344). Moral obligations to sustain prudery and gender and sexual norms came to be represented in the built form. Social codes of conduct were forming ways in which elements and spaces of homes were arranged in relation to one another. To illustrate, Urbach cites the splitting of domestic space and program typically joined together quarantined to discrete rooms.

During the rise of industrialization in Switzerland, alterations to agreeable minimum standards for dwelling units for the working classes reshuffled boundaries of private, collective,

fig. 91: Expulsion of the Money Changers from the Temple by Giotto di Bondone, 1304-06

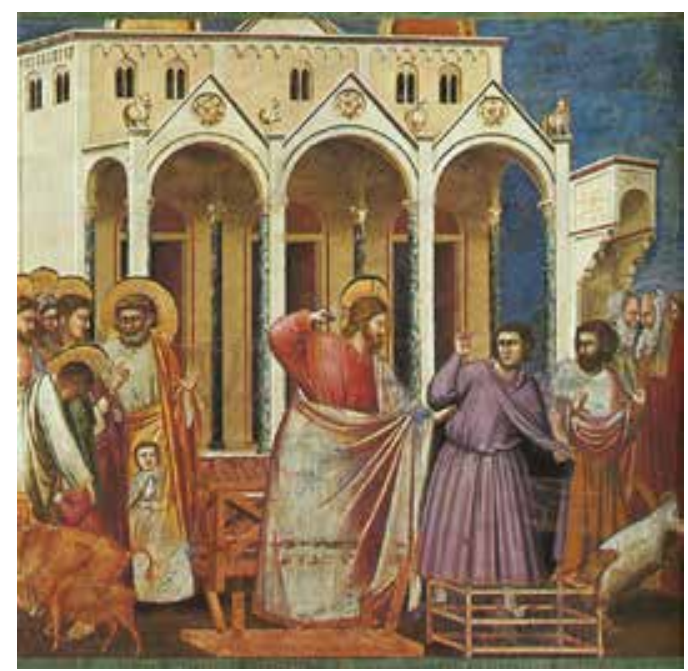


and public spaces, and elongated divisions between private and public realms. Technical developments such as the elevator and the delivery of public utilities facilitated major transformation of logics in the built form. The mid-nineteenth century marks the increase in size of urban housing units and a decrease in the number of individuals per household. Areas considered to be collective space - namely the corridor, the staircase, the lobby - were reduced in size, ornamentation, and light quality. The corridors became a dark passage to get from the public street to the private unit, not for entertainment or socializing. Other collective spaces, such as facilities for laundry, cooking, grooming and elimination, were privatized in stages, reducing a sense of community by providing every domestic service a tenant needed within the confines of their units (Lawrence, 1996).

This reduction and redistribution of collective space was to decrease maintenance costs, but also to intervene in the patterns of living, separating residents from one another during their fulfillment of domestic tasks. The privatization of such facilities also burdened the tenant with responsibility for maintenance and repair, alongside increases in rent. Codes of conduct were established in order "to regulate conceptual, behavioural and temporal boundaries that defined where and when the daily activities of tenants should occur," such as restriction in performing domestic activities in shared building space (Lawrence, 1996, 37). Domesticity came to be a severely private act, treated like a shameful secret rather than a mutual experience.

During the last decade of the nineteenth century and onwards, residential buildings were commonly set back from rather than aligning with a street, the latter typical of buildings in Swiss towns. This external space of transition inadvertently separated private from public, failing to feel and serve as collective space to residents as it was not quite an extension of the public realm of the street but did not visually express a separation in domain (Lawrence, 1996). 
Effectively, this strip became an unlively buffer zone filled with cars and plants. This creates a volumetric anonymous expression of a separation of spheres and reiterates a similar logic to the built-in closet.

Moderation of display, of wealth and objects and actions, is impressed into normative patterns in the built form, and are suppressed from public legitimacy. And the suppression of these items is a suppression of the self. "If a person's various garments offer a repertory for self-representation, the closet served to ensure, instead, that only those garments worn at any particular moment would be visible," (Urbach, 1996, 345). What is worn in the present is given a singular validity, thrusting multiple representations, forms of drag, further into the depths of privacy.

The room offloads objects that create disorder, that "threaten to soil the room," (Urbach, 1996, 342) into the dead end space of the closet, and in turn constitutes itself as clean through this relation. Similarly, in a heteronormative

fig. 92: Bedroom closet for one person, ca. 1934, figure 5 from Closets, Clothes, Disclosure by Henry Urbach, in Assemblage, No. 30 (Aug. 1996), pp. 62-73

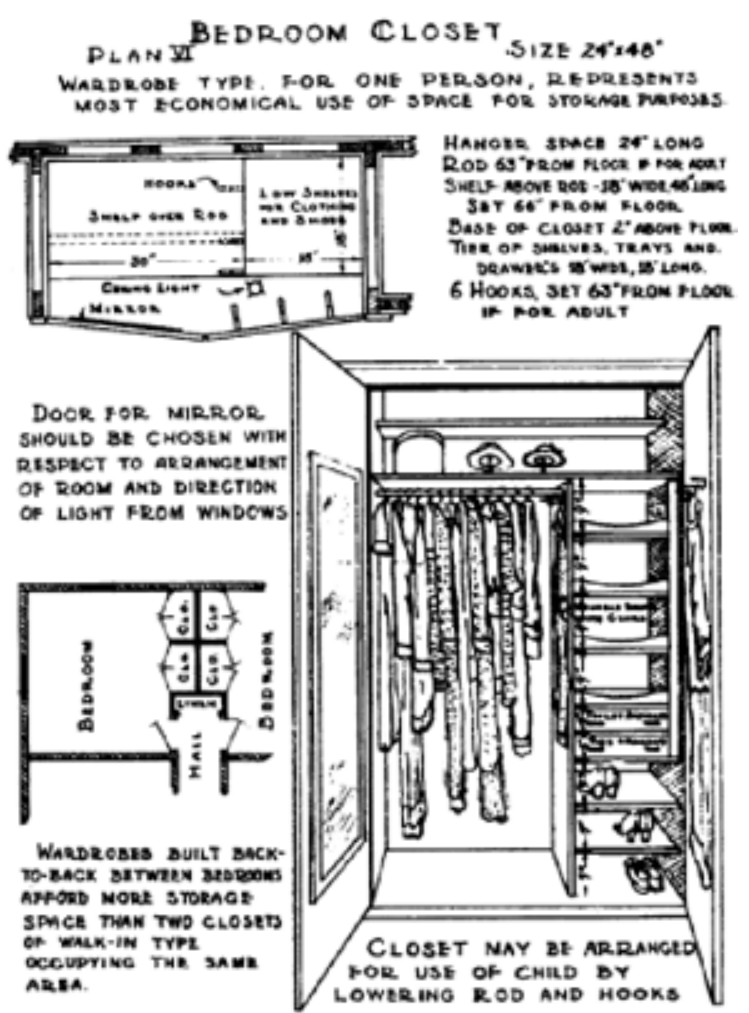


society that cannot divorce itself from archaic conceptions of morality, manifestations of queerness are the disorderly objects that threaten to soil the world through its perversions and debauchery.

"The closet organised [queer] identity as an open secret, a telling silence. Like the wall seams and door pulls that betray the closet, the absence of wedding bands and other positive assertions of heterosexuality would raise the spectre of gay identity even without forthright disclosure. One could neither be fully legible nor fully invisible; instead, dissemblance would serve to reveal a condition otherwise unstated," (Urbach, 1996, 346). As Wilson stated of a builtin closet's performance, accessible but inconspicuous is how queerness resides in the closet.

Prior to the 1960s, the homosexual, and by extension queer, closet had not existed as a metaphor to express self disclosure. "The nascent gay rights movements identified the closet as a tool of homophobic heterosexism and advanced a new battle cry: 'Out of the closets! Into the streets!'” (Urbach, 1996, 347). The closet's room is a heteronormative public. Rather than 'coming out' denoting to a woman 'coming out' to debutante balls as a formal introduction into society, and later appropriated to describe a queer individual's 'coming out' to a drag ball or other established forms of queer society (Chauncey, 1995), the introduction of the closet of queer identity took ownership of coming out. Rather than coming out to join a social collective, the closet positioned it as coming out of a place of disclosure.

"As [Eve] Sedgewick has argued, the sustenance of [queer] identity (where straight identity is presumed) depends upon continuous acts of declaration," (Urbach, 1996, 347). Remaining in or coming out of the sexual closet, is a recurring act at every new occasion. In a heteronormative society, or "a regime of (almost) compulsory heterosexuality," (Urbach, 
1996, 347) queer individuals inherit this closet through their existence. The binaries formed by closet and room, in and out, storage and display, constrain the formation of queer identity from being an ongoing performance rather than a simplification of sexuality in acts of disclosure (Urbach, 1996).

The oppositions of all senses of the closet neglect the interstitial space between the two volumes, where door planes dance to reveal the contents of the closet and its interior. This temporal space pops up to facilitate states of change (dress/undress) and motion. The act of dressing, the planning of a performance of the self, assembles acquired objects that possess a plenitude of references to form a narrative of representation. Urbach labels this space as the "ante-closet", a subtle unfolding of the closet.

"The ante-closet has a curious status in architectural drawings, conventionally rendered as a kind of graphic interruption. The notation for 'door swing' is an arc that traces the passage of the unhinged edge from open to shut. Whether drawn as a light solid line or a series of dashed segments, this arc does not indicate, as other lines do, 'cut' material. Instead, it registers the possibility of movement and spatial manipulation. At once conventional and abnormal, a moment of graphic folding, the door swing draws attention to the possibility of making and remaking space," (Urbach, 1996, 350). The ante-closet is positioned as place of possibility, expanding the division between room and closet enough to make it habitable.

Between the late-fourteenth to nineteenth centuries, the closet, or the French grand cabinet and its female counterpart, the boudoir, referred to a room designated for the storage and display of dear objects, study, prayer, contemplation, and rest. Closets were versatile through habitable volume. The closets of royal residences extended their collection of program to include the gathering of 


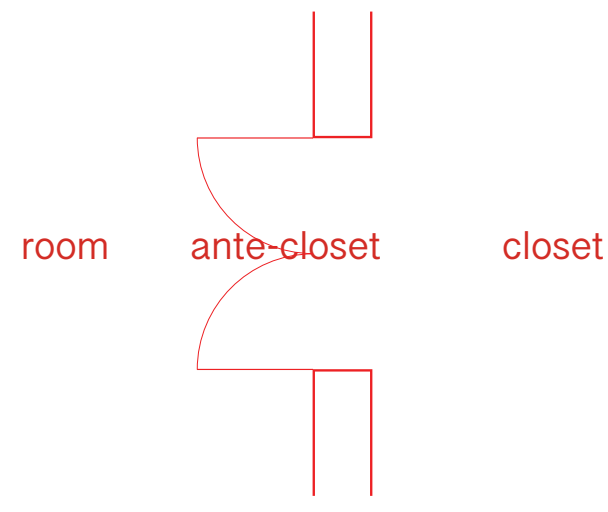

guests for social, political and spiritual purposes (Urbach, 1996). These rooms are examples of full expansions of a later division between room and closet.

The closet has hosted many occupations: non-normative gender and sexuality, an excess of objects, collections of garments, guests of a household, thinking, studying, retreating, and resting. When the closet was reduced to a unit of accompaniment, and developed to have a distinct binary relationship to its host (the room) it was adopted through operation of metaphor to describe, spatialise, and affirm other precarious binaries of queer experience. For these reasons, the closet is a site that demands a destabilization of boundaries, materials, and relations that otherwise continue to vilify a queer existence. The following chapters present a narrative to situate the object within a queer and contemporary discourse, and conclude with the queer assemblage of a house. 
closets
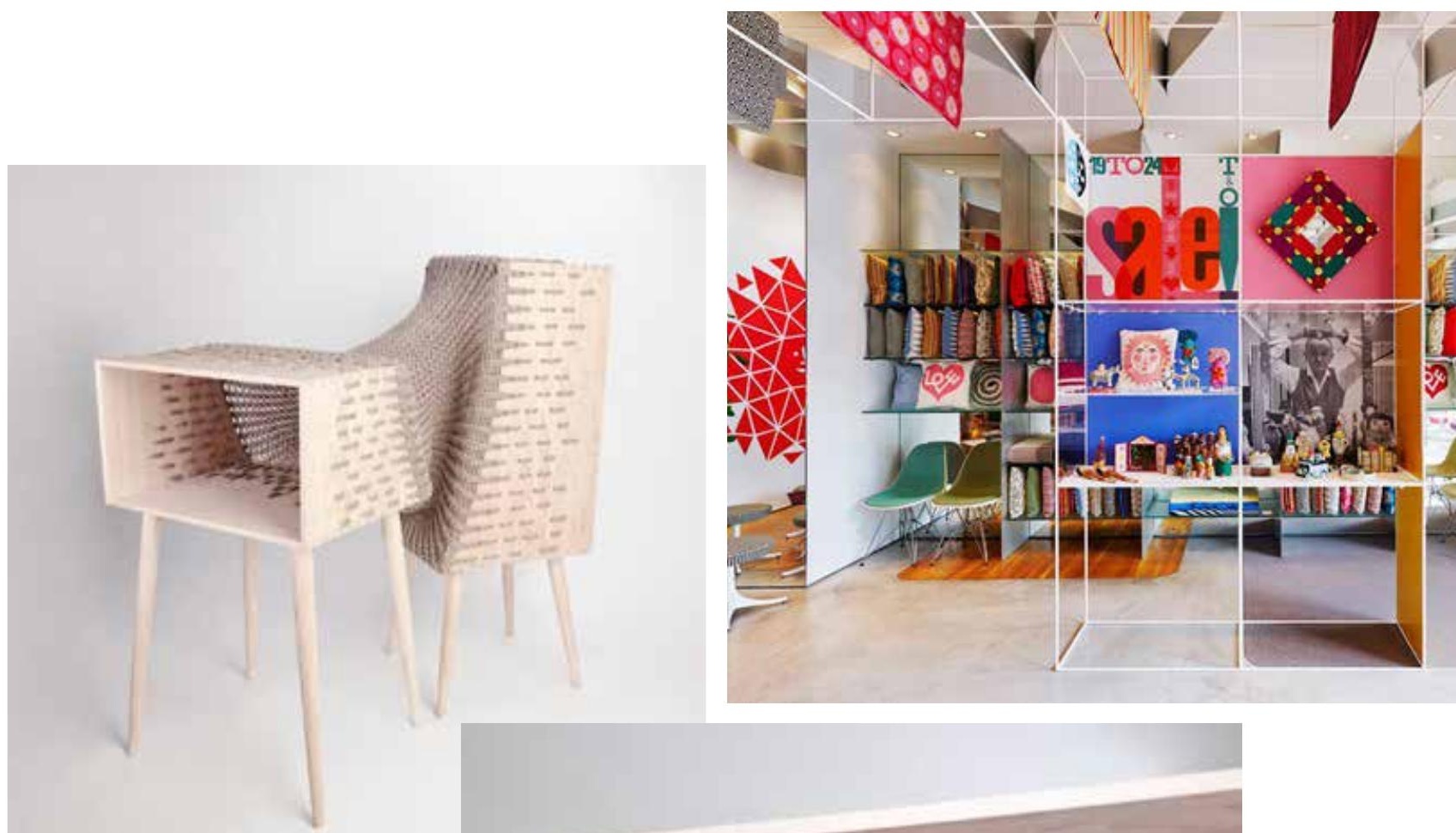

from left to right, top to btoom

fig. 945

Experimental hybrid storage furniture by Kata Monus, Reka

Hegyhati, 2012

fig. 95:

Alexander

Girard: An

Uncommon

Vision,

Unknown,

Herman Miller

Reach

fig. 96:

Experimental hybrid storage furniture by Kata Monus, Reka Hegyhati, 2012

fig. 97-98

Coiffeuse, Eileen Gray, 1926
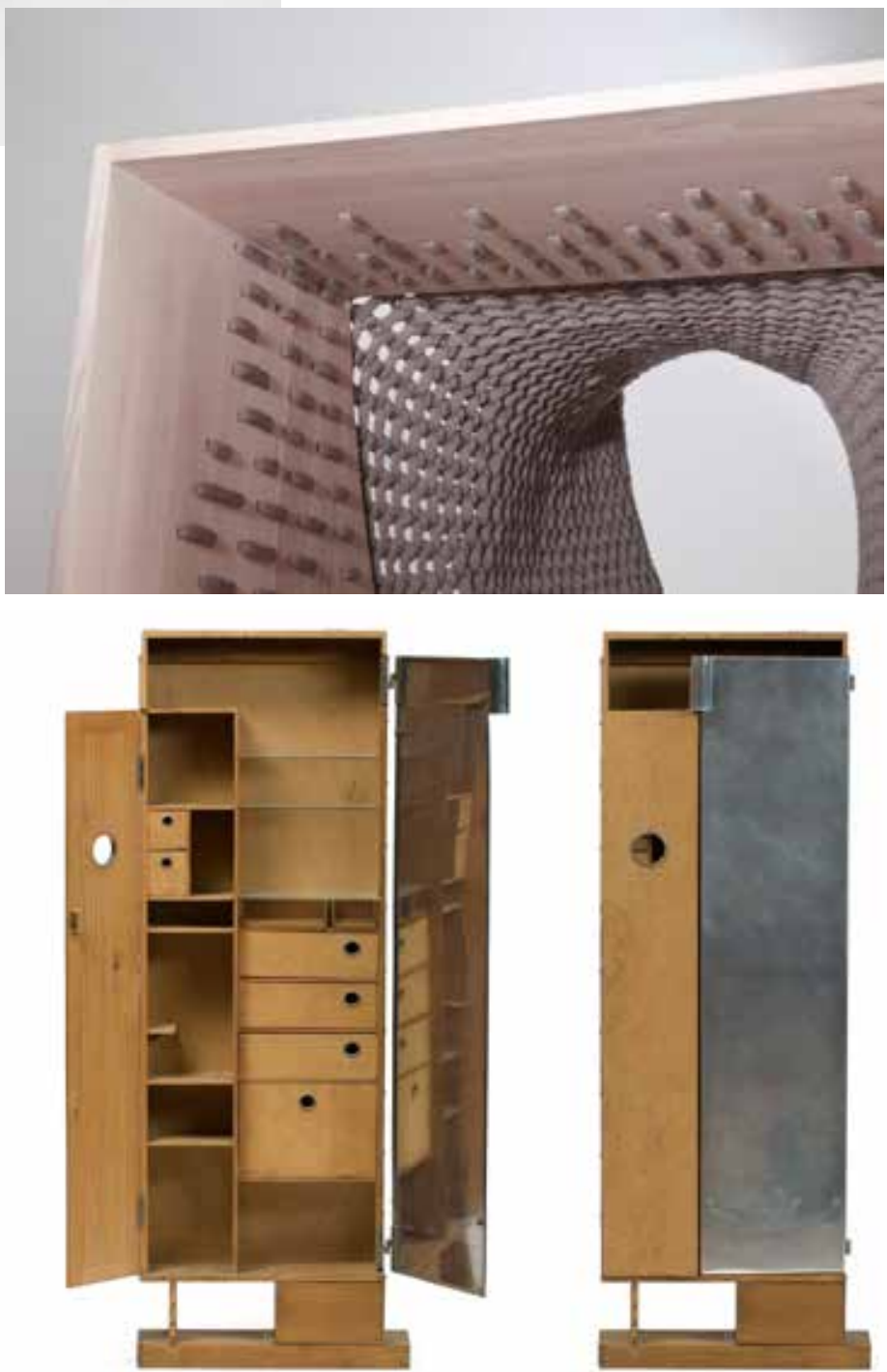


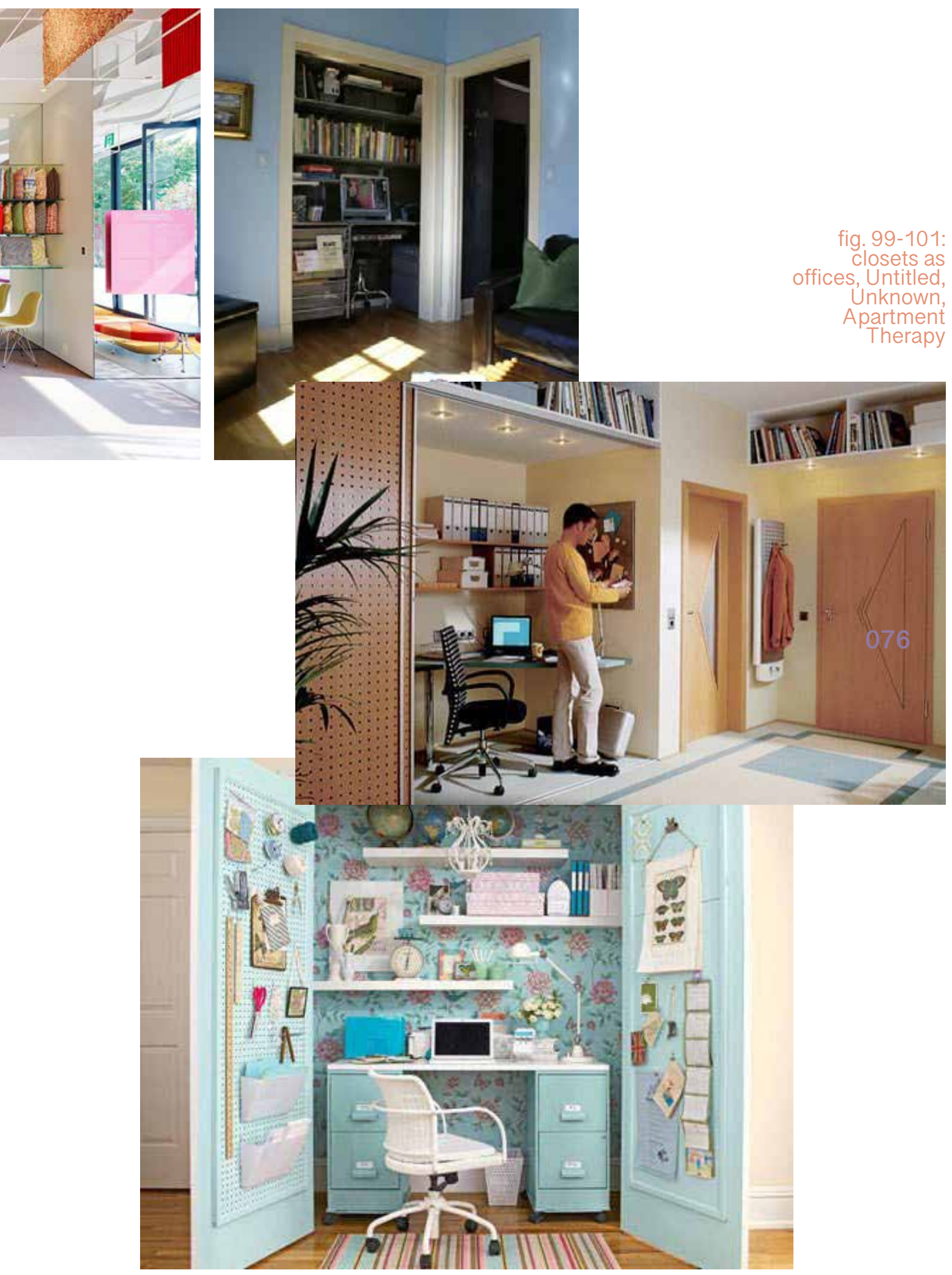


closets

fig. 102: La

Tournette

by Freaks

Architecture,

David Foessel, 2018

fig. 103: movable storage wall, La Tournette,

Freaks

Architecture, 2018
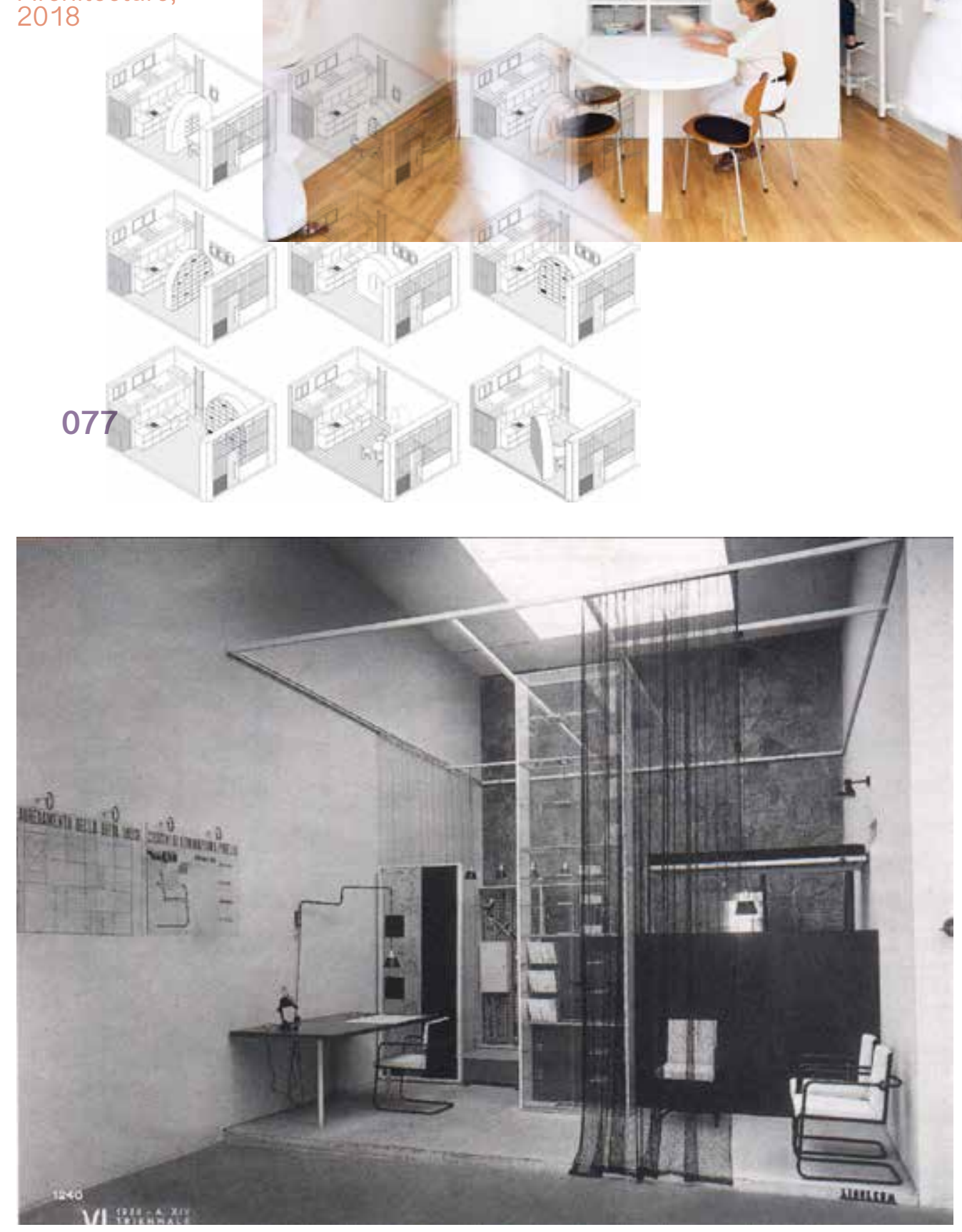

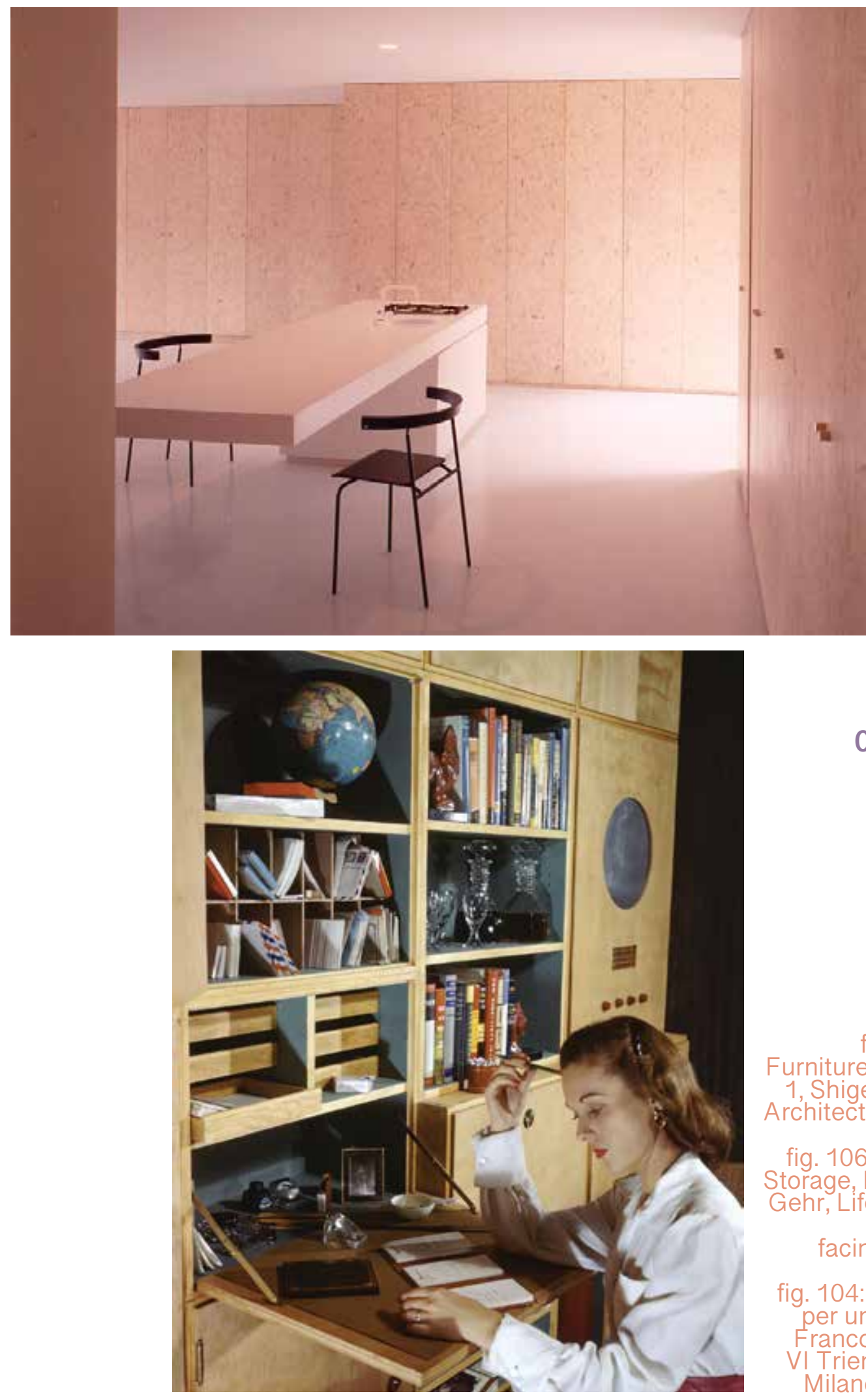

078

fig. 105:

Furniture House 1, Shigeru Ban Architects, 1995

fig. 106: Home Storage, Herbert Gehr, Life, 1945

facing page

fig. 104: Stanza per un uomo, Franco Albini, VI Triennale di Milano, 1936 


\section{closets}

fig. 107-108: Hakama House, Jun Tamaki, 1998

\section{9}

The curtain of the Hakama House reveal the many interiors hidden within, like the kitchen and dining rooms, the mezzanine, and living room.
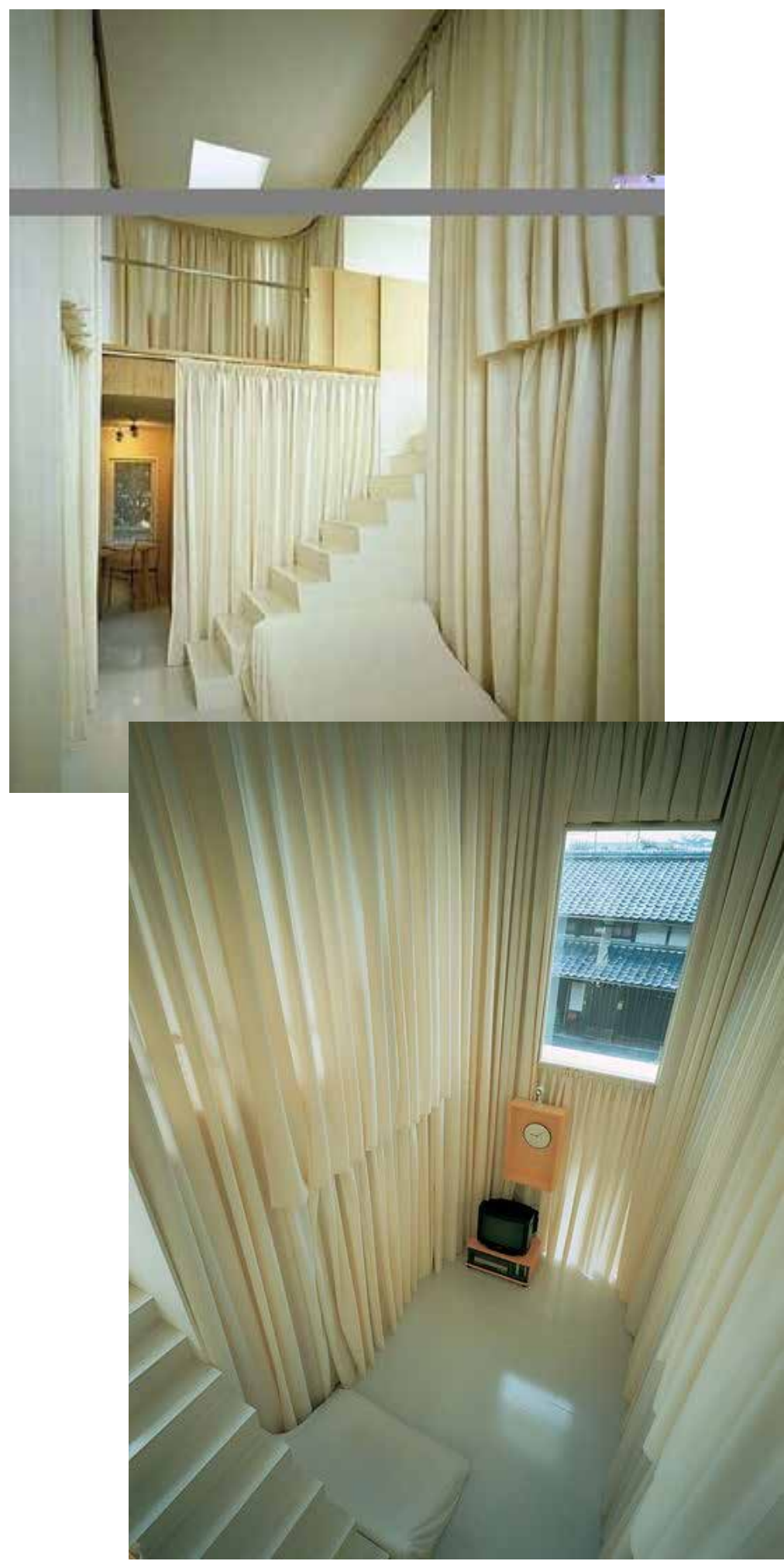


The present undoing of burying domestic interiors and personal possessions born of Victorian morals takes place in digital space. "Digital intimacy and the image culture of social networks have blurred the division between public and private space and public and private information," (Blanchfield and Lotfi-Jam, 2018, 130). The representation of domestic space on public platforms, through recurring acts and transformations in these platforms, has normalized domestic publicity and its nuances. In turn, the depths of our interiors and the objects contained, previously concealed through the demarcation of the private, are propelled to the forefront of self expression, and form new networks and "spatial and material hierarchies" that direct modes of living and representing (Blanchfield and Lotfi-Jam, 2018, 129).

the following

figures are a series of Instagram posts found under the \#bed

\section{3}

fig. 109: Untitled, Instagram user@sixat21. Instagram, 2019

fig. 110: Untitled, Instagram user @sammytunis, Instagram, 2018,

fig. 111: Untitled, Instagram user @poooooookie, Instagram, 2018

fig. 112: Untitled, Instagram user @justcozyy,

Instagram, 2018

fig. 113: Untitled, Unknown, Instagram, 2018
In the essay titled 'The Bedroom of Things', Caitlin Blanchfield and Farzin Lotfi-Jam use the bed as an agent to explore new meanings through the proliferation of its image in digital public platforms. Consider the digital commons of sites and, by extension, applications like Instagram, Facebook, Myspace, Airbnb, Craigslist, Grindr and Tinder. The bed can convey lifestyle, sales of service or space, and desires for intimacy or rest through a composition of
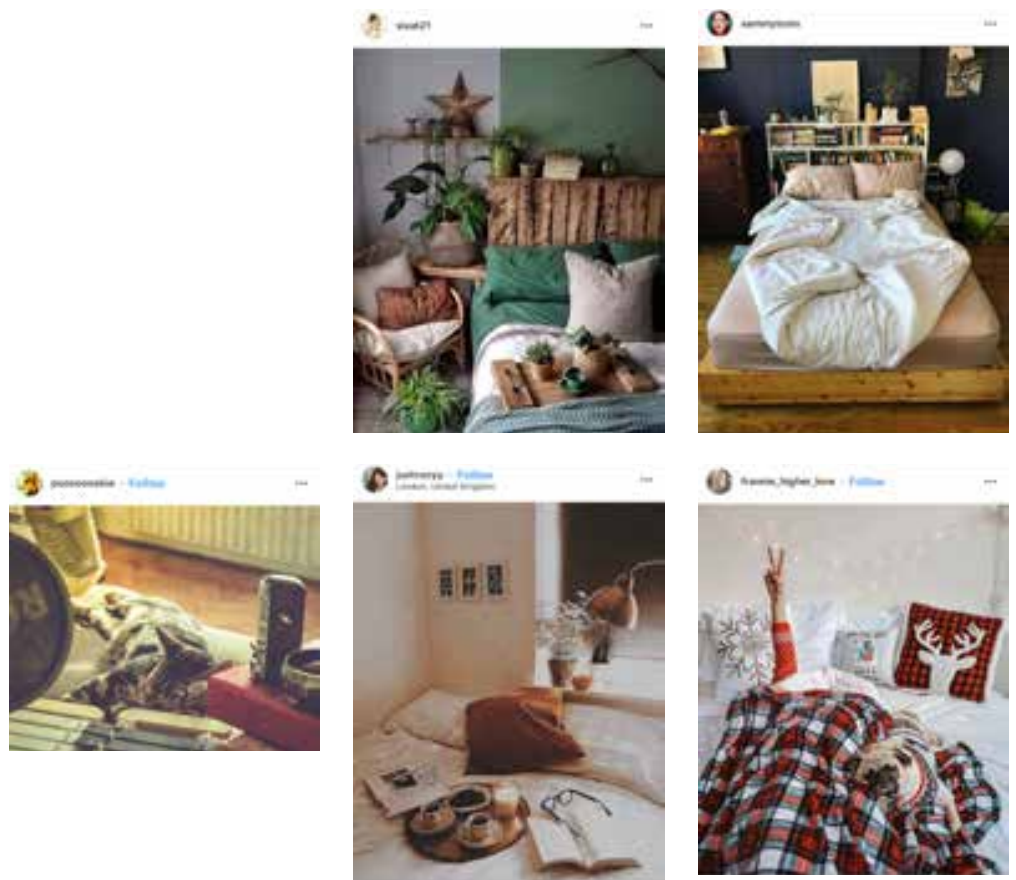


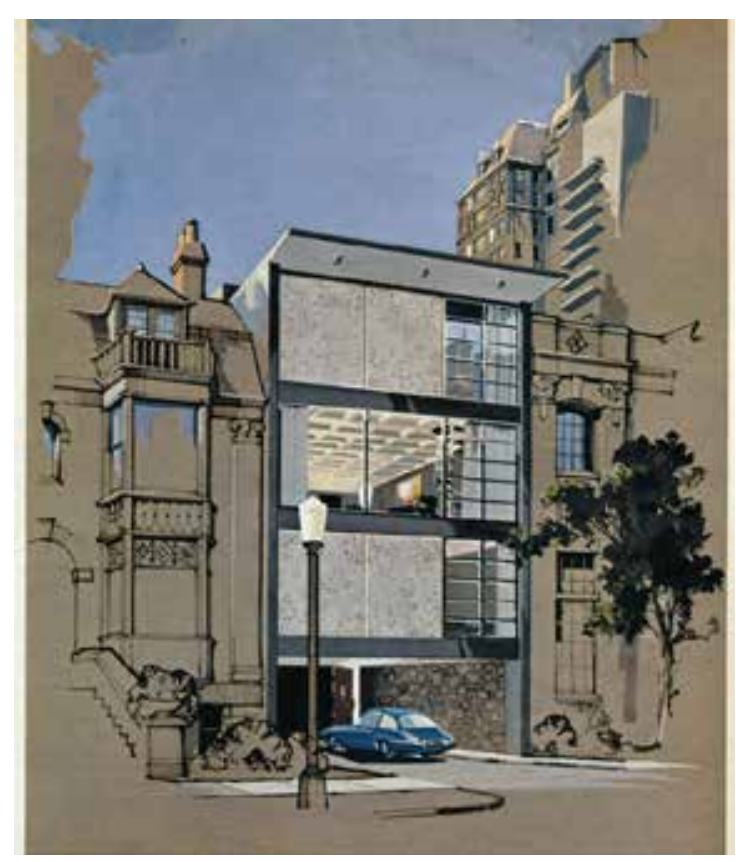

fig. 114: Playboy Townhouse, design by $R$. Donald Jay, rendering by Humen Tan

texture, colour, organization, and relations to other objects, spaces and time (Banchfield and Lotfi-Jam, 2017). Not only is the bed distributed as a signifier, but it becomes a site of production and reproduction in the wake of postindustrialization (Colomina, 2014).

Playboy magazine has been filled with rich depictions of domestic space that utilized material arrangements to convey desire and lifestyle. From the beginning, design was the tool to promote and assert the bachelor. In the second issue of the magazine, an article began with: "some say you can judge a man by the way he furnishes his home," which eventually became a mantra for the magazine (Colomina, 2012). The dissemination of "self is assembled through material means," (Blanchfield and Lotfi-Jam, 2017, 133). Praises of modern architecture and furnishings carefully staged and constructed a sexual and consumer identity for the straight cisgender man.

Through successive issues, Playboy devised an architecture of seduction and interiority, prioritizing and linking the urban centre by situating the Playboy home in the penthouse or 
fig. 115: Playboy

Townhouse, design by $R$. Donald Jay, rendering by Humen Tan
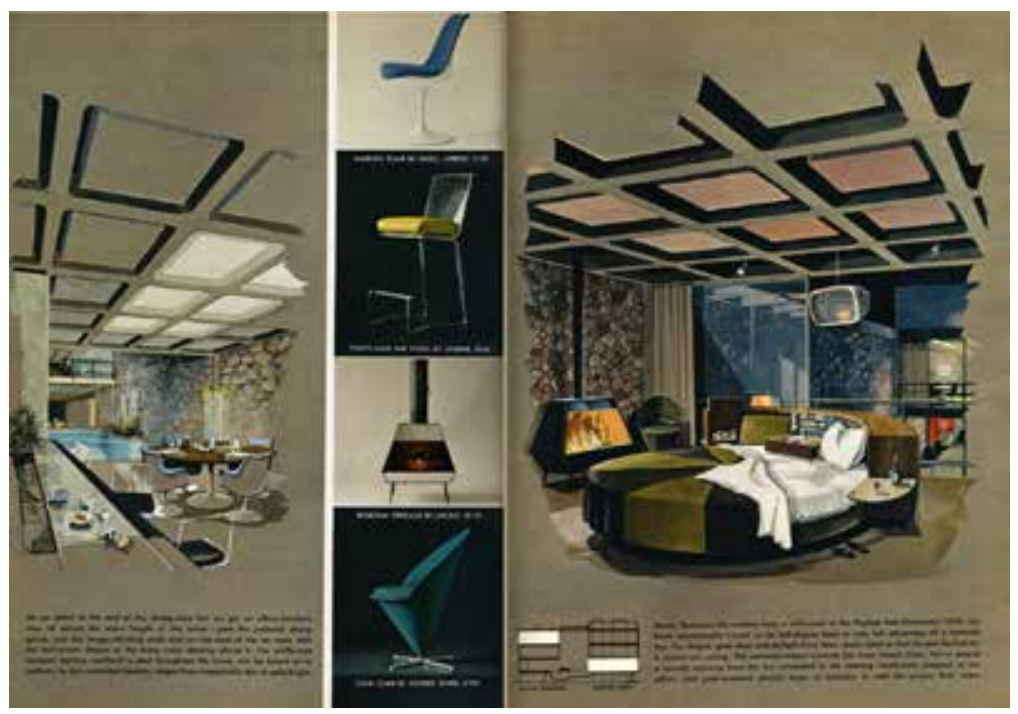

the townhouse (see fig 114 annd 115). Selected designer furniture and the latest electronics arguably became the features of spreads, with details of designer, manufacturer and pricing provided. "In a canny seduction, the magazine describes the most advanced interior architecture design for 'a man perhaps very much like you,'” (Colomina, 2012). In response to letters from readers requesting elaboration of the house in the form of plans and where featured objects could be acquired, the magazine started a popular series that featured different 'playboy pads', such as the Weekend Hideaway, the Playboy Townhouse, the Playboy Patio Terrace, and the Playboy Duplex Penthouse (Colomina, 2012). These constructed a spatial setting that privileged the bachelor, a new notion of occupation of the house that did not centre around the normative family. "Beyond simply offering refuge, the goal of the house [had] always been to create the possibility of frictionless cohabitation in which people can reproduce themselves. This is why the subject of the house becomes the family. The term 'family' comes from the Latin familia, which means servile. The house is thus a congregation of famuli, of servile person whose lives are dedicated to reproduction," (Aureli and Tattara, 2015). In a rather queer fashion, Playboy pushed an assemblage of space that made no promises to accommodate the nuclear 
family, but instead prioritized nonreproductive sexual intimacy.

The bed eventually became the ultimate Playboy house, suited with entertainment and communication devices, casting it in a place of authority. Hugh Hefner's famous round bed was introduced in the 1962 Playboy Townhouse, which was primarily commissioned to be his own house. In the end, the only part of the townhouse realized was the bed, which consolidated so many features of the home into itself, the bachelor would never have to leave. The rotating and vibrating bed was fitted with a small fridge, a bar, various media and communication devices, a breakfast table along with work surfaces, and filing cabinets to fulfill a wide spectrum of program (Colomina, 2012). The round bed effectively was a room for sex, work, rest, and leisure. While the common bed of the present day is most likely not built as a machine for living, they perform similarly to the Playboy bed, and entertain the various types of work we perform in the name of productivity (Colomina, 2014). Digital space grants a possibility of working from the home, or from the bed. Smartphones and laptops nestle their way into beds through ease of mobility, and enable the individual to communicate globally and work remotely, order necessities and pleasures to their doors, host sexual partners, consume and produce text, image, audio, video. The bed is a dense site of activity through its connection to digital space.

The recent shift of the twentieth century in how we access materials and how we encounter publicity destabilizes the division of private and public space and information. Our personal devices and modes of consuming media link us to a public that was otherwise unavailable, sometimes with little to no consent as at times it is written into structure. Considering the proliferation of electronic media, New York Times columnist William Safire wrote with much urgency: "Your right to privacy has been stripped away. You cannot walk into your bank, or apply for a job, or access your personal 
computer, without undergoing the scrutiny of strangers... Isn't it time to reverse that terrible trend toward national nakedness before it replaces privacy as an American value?" (The Un-Private House, 1999). The notion of privacy in the post-digital age is obsolete, and the built world can do very little about it beyond signal attenuation of barriers. When referring to the unbuilt Spartan Villa project situated in the Hague, Bernard Tschumi wrote "the borders of the living room and work space, devoid of ornamental camouflage, expand beyond the property line just as they are undermined by the electronic devices of everyday use (TV, fax, etc.) that they contain," (Spartan Villa, n.d., emphasis by Ashurov).

*ISO is an acronym for "in search of", typically used in classified ads on Bunz, Craigstlist, Kijiji, Facebook, and others.
The reach of digital networks, in the ease of communication and use for a spectrum of sociality, broke down a prudishness of sharing personal information - "What's on your mind, Michelle?" confronts me on my Facebook home page, "What's happening?" Twitter asks. Digital platforms initially provided a space to take up with personal divulgence, and now they demand it. The increasing intricacies in platforms parallel the ways individuals convey narratives through image currency. Blanchfield and Lotfi-Jam describe the proliferation of the selfie that took place when Myspace formed, photos taken specifically from above, which provided an effective stage behind the subject to exhibit their space, subtle cues of personal interests, actions, opinions and the like. Following the era of Myspace, the selfie cultivated a culture that brought background into the foreground through manipulation/curation. Sites and applications devised for individuals ISO* sexual encounters demonstrate a "circuit of desire and self-representation", and the staging of profiles, projections of the self, are curated to advertise a promise of emotional or physical connection and solicit a reciprocation from another party or parties (Blanchfield and Lotfi-Jam, 2017, 132). Similar to Playboy's representation and promotion of lifestyle, assertions of gender and sexuality 
are formed through material means and projections of domestic space, but rather than exist within the spreads of a magazine, they exist in complex digital platforms. Objects, and the absence of, in digital space perform alongside us to more efficiently portray subtleties or abstractions than words could.

"The customizable background of the Myspace page was succeeded by the more rigid template of Facebook, limiting how users imagined capturing their interior life. Now social networking sites celebrate their constraints and norms - 140 characters, square proportions, a filter, a hashtag - and place even more pressure on peripheral objects to perform for and as us," (Blanchfield and Lotfi-Jam, 2017, 133). Contrary to such regularity and staticism, the evolutions of sites for social media have put emphasis on sharing ephemerally. Snapchat's introduction of the 24 hour disappearing story erases any evidence or accountability of shares that took place, obscuring the publicity in the digital commons, beginning to resemble a relationship before digital access became nearly ubiquitous. Events that take place are only experienced by those in proximity, physical or digital.

In Queer Phenomenology: Orientations, Objects, Others (2006), Sara Ahmed presents a queering of phenomenology, through a focus on objects and orientations, sexual and spatial, which are not mutually exclusive. "Orientations, shape not only how we inhabit space, but how we apprehend this world of shared inhabitance, as well as who or what we direct our energy and attention toward," (Ahmed, 2006, 3). By extension, sexual orientation becomes a spatial matter, and the lines of direction are not negligible. Orientation relies on objects, familiar points of reference, to establish or strengthen a sense of direction. "Phenomenology can offer a resource for queer studies insofar as it emphasizes the importance of lived experience, the intentionality of 
fig. 116: image

by Duncan

Rawlinson, depicting desire lines through a sliver of grass

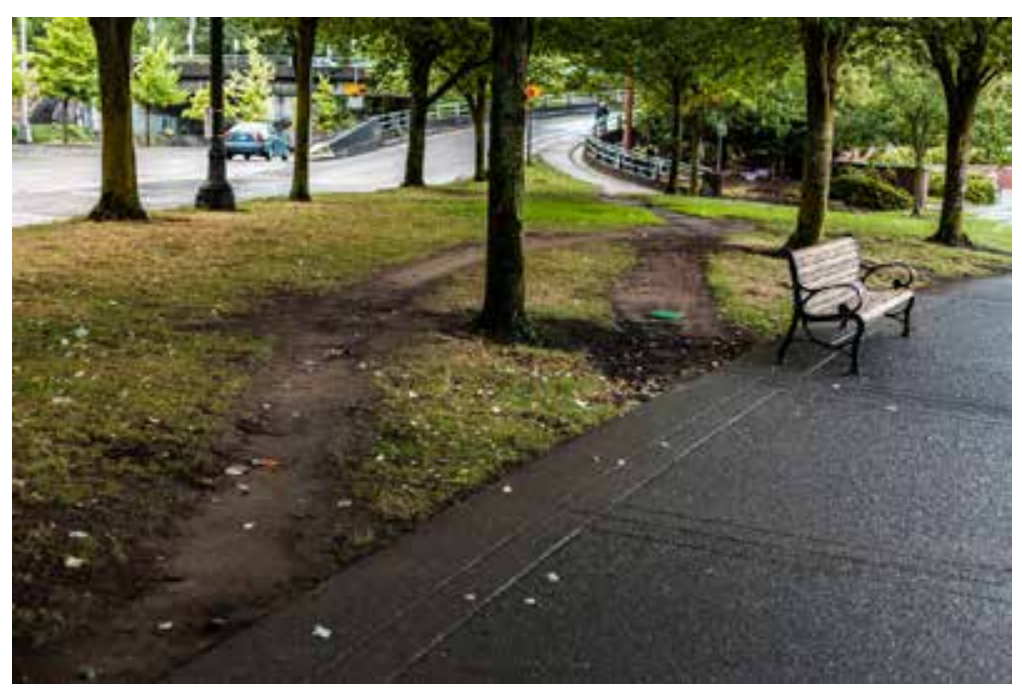

consciousness, the significance of nearness or what is ready-to-hand, and the role of repeated and habitual actions in shaping bodies and worlds," (Ahmed, 2006, 2). Queer phenomenology begins to operate by way of a redirection of attention towards objects that "deviate or are deviant," appearing slantwise (Ahmed, 2006, 3). This deviation occurs when lines of direction in an orientation toward something are strayed from.

In the context of this discussion, direction must not lose its meaning and connotations. Direction is not a matter of going one way or another, but is also something that is given. It is established through a need for a construction of a line that is then to be engaged with. "The etymology of 'direct' relates to 'being straight' or getting 'straight to the point,"' (Ahmed, 2006, 16) Following lines of direction is a method to straighten.

The paradox of the formation and following of lines is illustrated with "a path well trodden" (Ahmed, 2006, 16). A path is formed through spatially overlapping repetitive acts of traversing. To follow a path implies there is a path to follow, marked through a "repetition of norms and conventions," (Ahmed, 2006, 16). "Lines are both created by being 
followed and are followed by being created," (Ahmed, 2006, 16). Reproductions of lines involves an investment of will, time, resources, in turn implying a return that potentially sustains a will to continue without diversion. To follow a line implies a selected choice of direction to acquire something (thing or experience), and when the results are unexpected or not what was desired, there is a moment of crisis, an anxiety or doubt that revolves around the placed (social) pressure to arrive (Ahmed, 2006).

In landscape architecture, 'desire lines' are a term used to describe unofficial paths taken when individuals deviate from intended paths (see fig. 116). To contextualize this within queerness, bodies are oriented through lines set by and for the normative heterosexual couple, and desire lines are the redirection that disorientates in the process. "Internalized societal norms and actions orientate our bodies toward heterosexual objects, which then create a field where certain objects are pulled closer, while other objects become non-perceivable," (Kojima, 2008, 89) Queer bodies, when not in line with the established straight lines of direction, are considered deviant through deviation from repeated acts. Crisis and deviation form the sensation of disorientation, when "you lose one perspective, but the 'loss' itself is not empty or waiting; it is an object, thick with

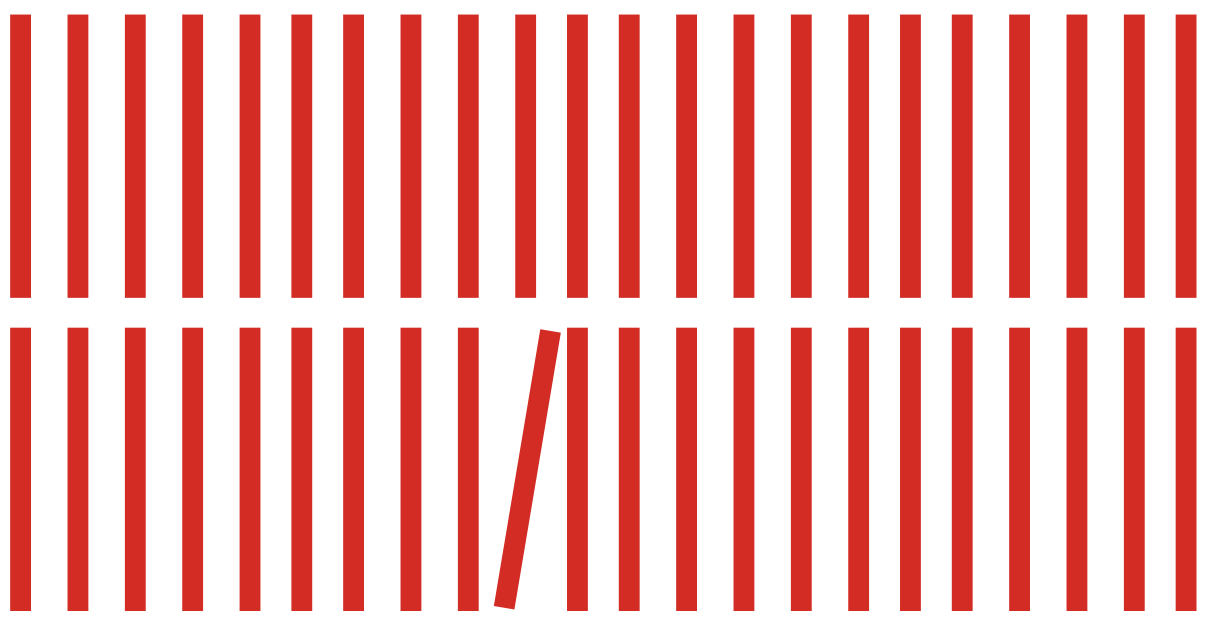


presence," (Ahmed, 2006, 158).

DISORIENTATION: One night, I took a break from writing about closets to go to a grocery store to buy dinner with my friend, as we were planning to stay at school late. The route we took is a mere three blocks, however in the middle, I experienced spatial disorientation. The route I had walked hundreds of times before, and the blistering cold temperature I had felt thousands of times before. My head was nestled as far into the layers of scarf wrapped around the top fourth of my body, my face and eyes were pointed straight down, absently watching my oxfords slip in and out of view along the texture of the paved sidewalk, and I was lost in thought - shoes, closets, closeted, orientation, sex, drag. The first block we walked with urgency and in silence, and then my friend spoke. It was not until then that I realized that I had no conception of the present, and I was startled to be brought back. I had forgotten where I was, who I was with. What I perceived was situated in a different reality, a site temporal and imagined. The discrepancy between bodily motion and an imagined spatial cognition I could feel in my chest.

Non-normative bodies are faced with many moments of crisis when the conventional lines of direction do not support their intentions, and to come to such a realization and divert to a desire line is rather disorienting. "Disorientation is unevenly distributed: some bodies more than others have their involvement in the world called into crisis. This shows us how the world itself is more 'involved' in some bodies than in others, as it takes such bodies as the contours of ordinary experience. It is not just that bodies are directed in specific 
ways, but that the world is shaped by the directions taken by some bodies more than others," (Ahmed, 2006, 159).

Ahmed references Jean-Paul Sartre's Nausea, where he describes a story of disorientation, "of a man losing his grip on the world," (Ahmed, 2006, 162). In an excerpt, Sartre describes a growing strangeness or awkwardness or queerness, and a sensation of touch between his hands and familiar objects, like a fork or a doorknob. "Just now, when I was on the point of coming into my room, I stopped short because I felt in my hand a cold object which attracted my attention by means of a sort of personality. I opened my hand and looked: I was simply holding the doorknob," (Sartre, 1938, 13). The object was perceived as strange, however the object was not strange, in fact very familiar as he had repeated the act many times (entering his bedroom). "What is so compelling to me about this account of 'becoming queer' is how the strangeness that seems to reside somewhere between the body and its objects is also what brings these objects to life and makes them dance... When objects come to life, they live their impressions," (Ahmed, 2006, 163). The sensation he describes pulls the doorknob out of the expanses of ubiquity without wavering in its thingness.

Queerness is described as something that does not reside within objects but registers how the object can impress upon us and what we can "borrow from the contingency of its life," - a queerness that brings objects to life in their loss of place, when they are registered as familiar and as background (Ahmed, 2006, 164). The primary example Ahmed uses to illustrate this is the table, an object that is an object in itself, but also supports other objects. It supports the experience of other objects.

This loss of place can refer to the objects in homes - the chair, the couch, the coffee table, the light switch, the door 
handle, the plate, the bowl. The familiarity of our objects allow us to disengage with them, to use them without acknowledging their elements - surface temperatures, solidity, forms.

"Queer becomes a matter of how things appear, how they gather, how they perform, to create the edges of spaces and worlds." Furniture's condition of movability lends itself to this cacophony of queer function, and it is given its own connotations. For example, the bed is an object located in the bedroom, except that it does not have to be, nor should it have to be. Furniture stores reproduce norms in domestic arrangement, distancing furnishing objects from their own being, and so the bed typically (is the daybed a queer object?) remains within the precinct of the bedroom. If the bed was placed in a study, for use as a table due to its likeness in its expansive horizontal support, the softness makes itself known, and the bed performs queerly.

093

This reading of furniture was the entry point to develop the following projects that engage with domesticity and the objects we adorn our homes with, emphasizing how objects impress on us and how they can be queer or perform queerly. I use the chair as the object of focus, and turn it "materially deviant," a concept explained by material culture and gender theory scholar Scott Herring which refers to the conduct of an object refusing proper social and normative relations (Blanchfield \& Lotfi-Jam, 2017,131). Ahmed suggests plurality of meaning to the term straightness, synonymous with heteronormativity, but also as the vertical direction, and bodies straightening upwards or queer or oblique bodies forced to straighten themselves to participate in normative life. 
094 
objects in digital space

fig. 118: Arne Split chair, found wooden and metal chair elements. a fake Arne Jacobsen 2107 chair mixed with another found in a furniture warehouse, Martino

Gamper, Anna Arca, 2007

fig. 119: Upside down chair, reclaimed chair with reupholstered wool, Martino Gamper, 2012

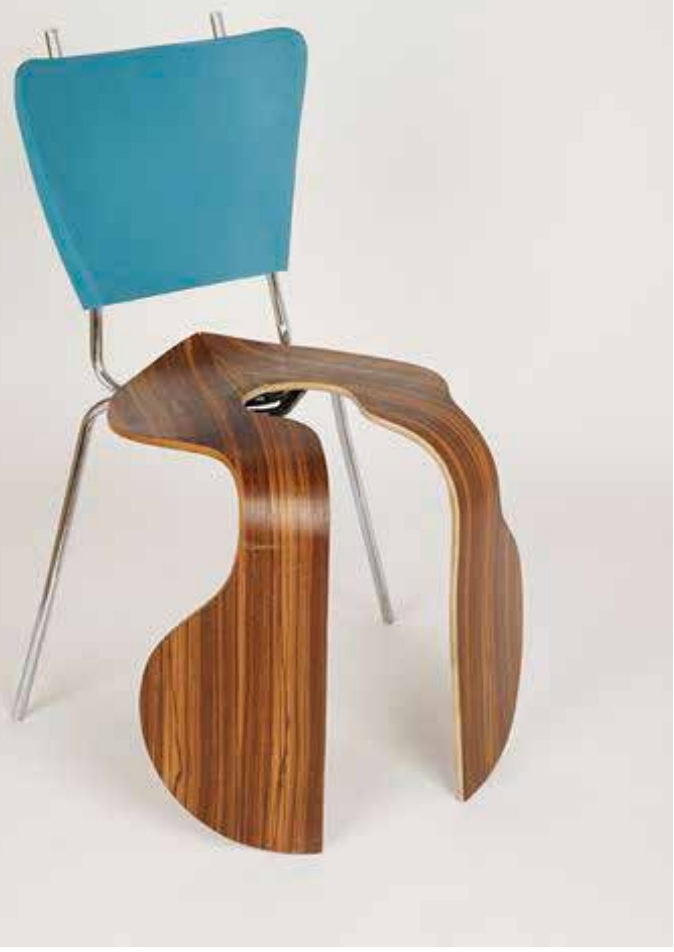

095

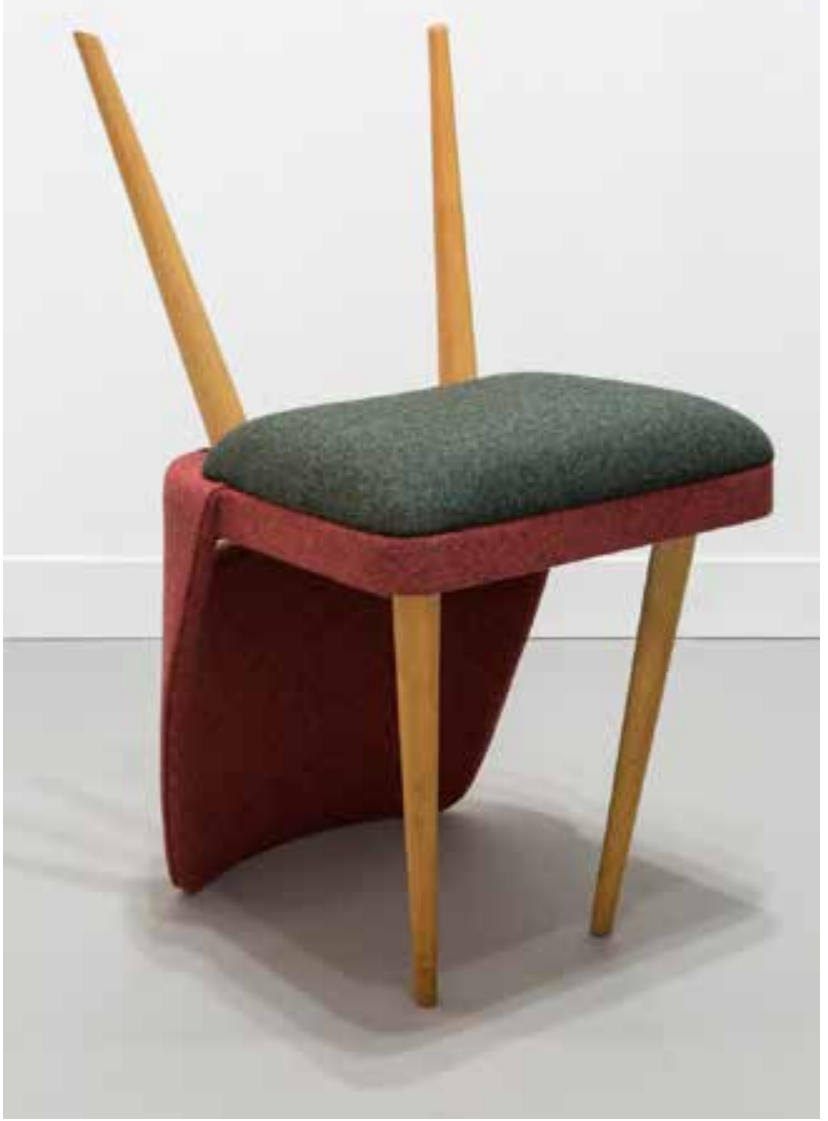




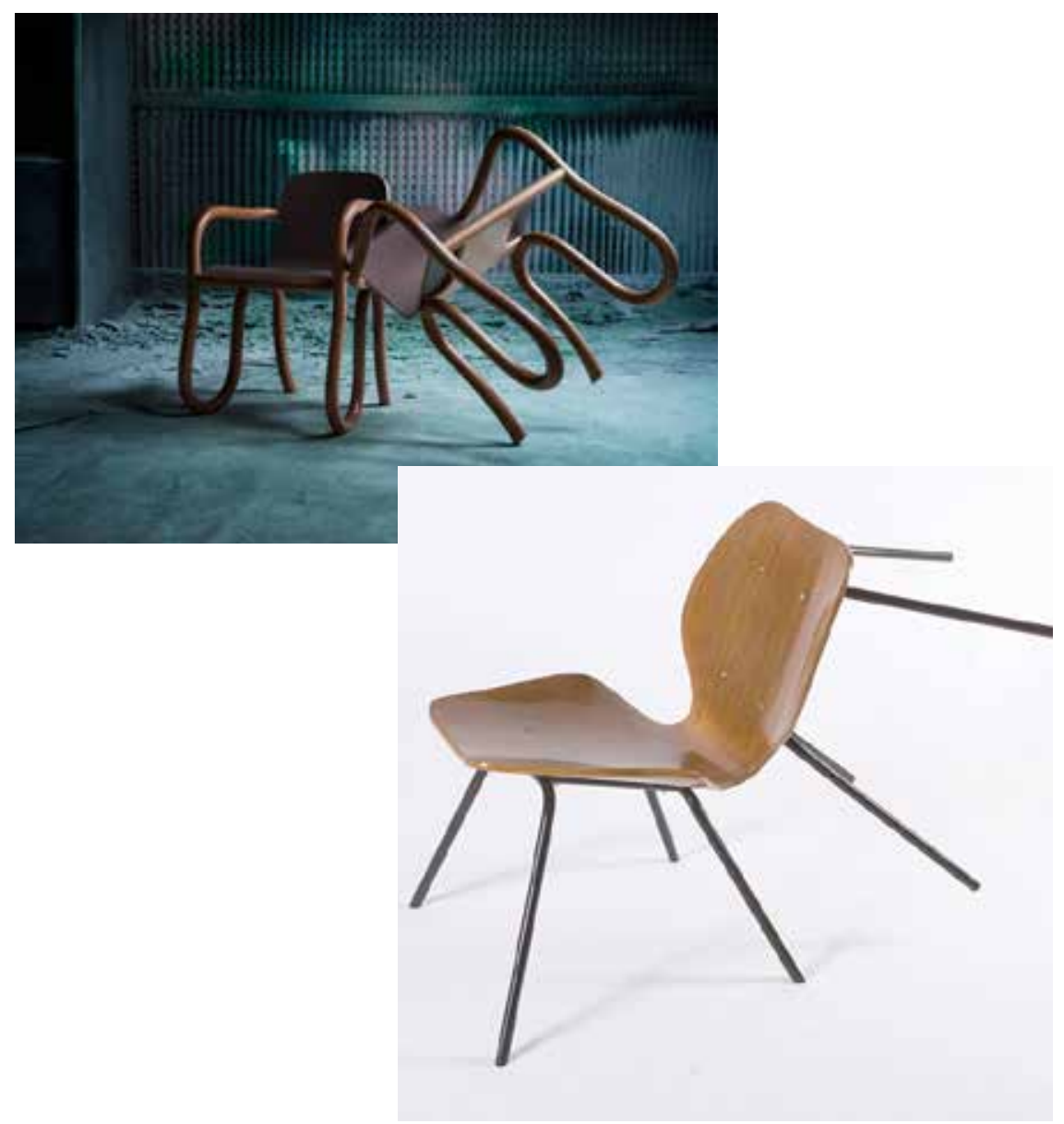

fig. 120: Kolho chair, Matthew Day Jackson, 2019

fig. 121: Mutant, Chair, Helmut Palla, 2005

fig. 122: Bobbin Chair, Eva Fly, 2015

fig. 123: Ming Mu, Chair, found wooden and metal chair elements; chair copied from Ming Dynasty period sliced together, Martino Gamper, Anna Arca, 2007
096
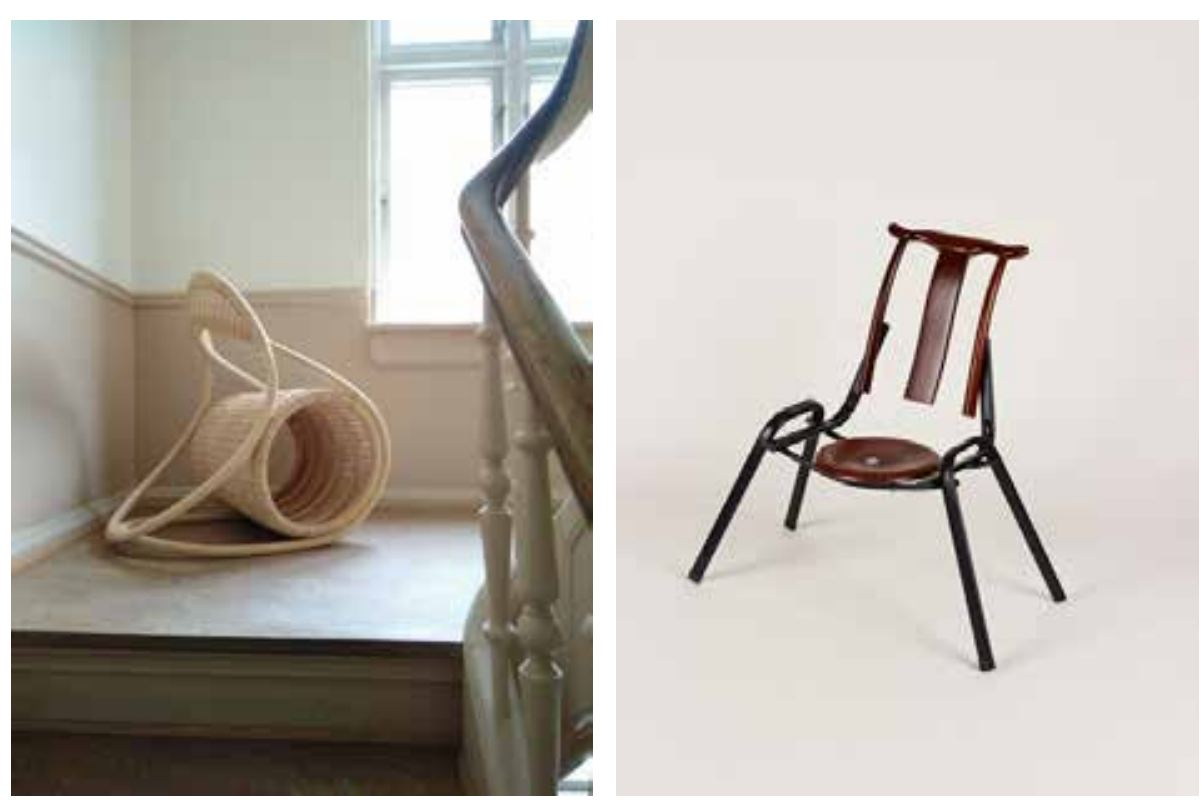
objects in digital space

fig. 124:

L'Echasuffesuse sofa, Louis

Durot, 1978

fig. 125: Hubert le Galle seats, Instagram user @musingselles, Instagram

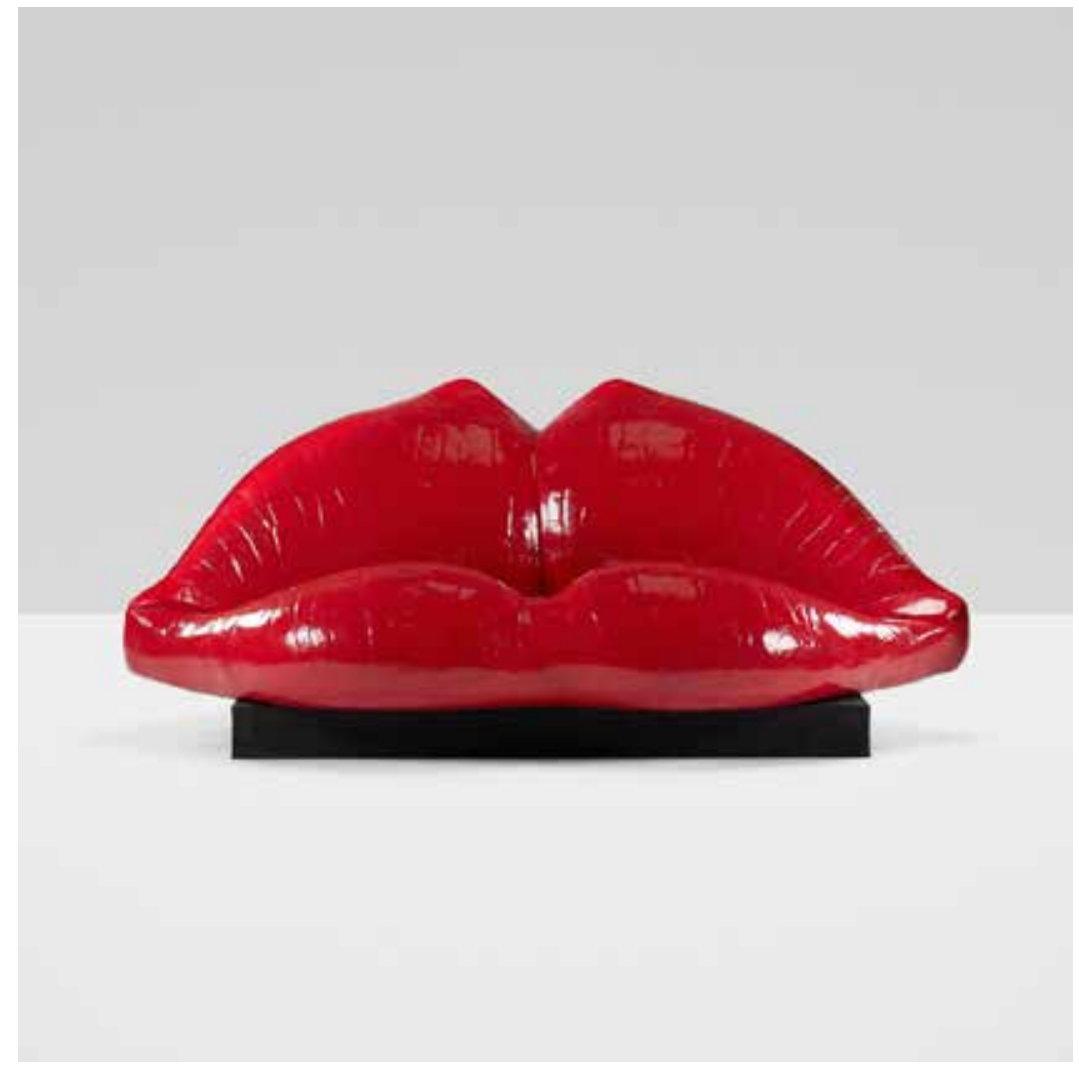

097

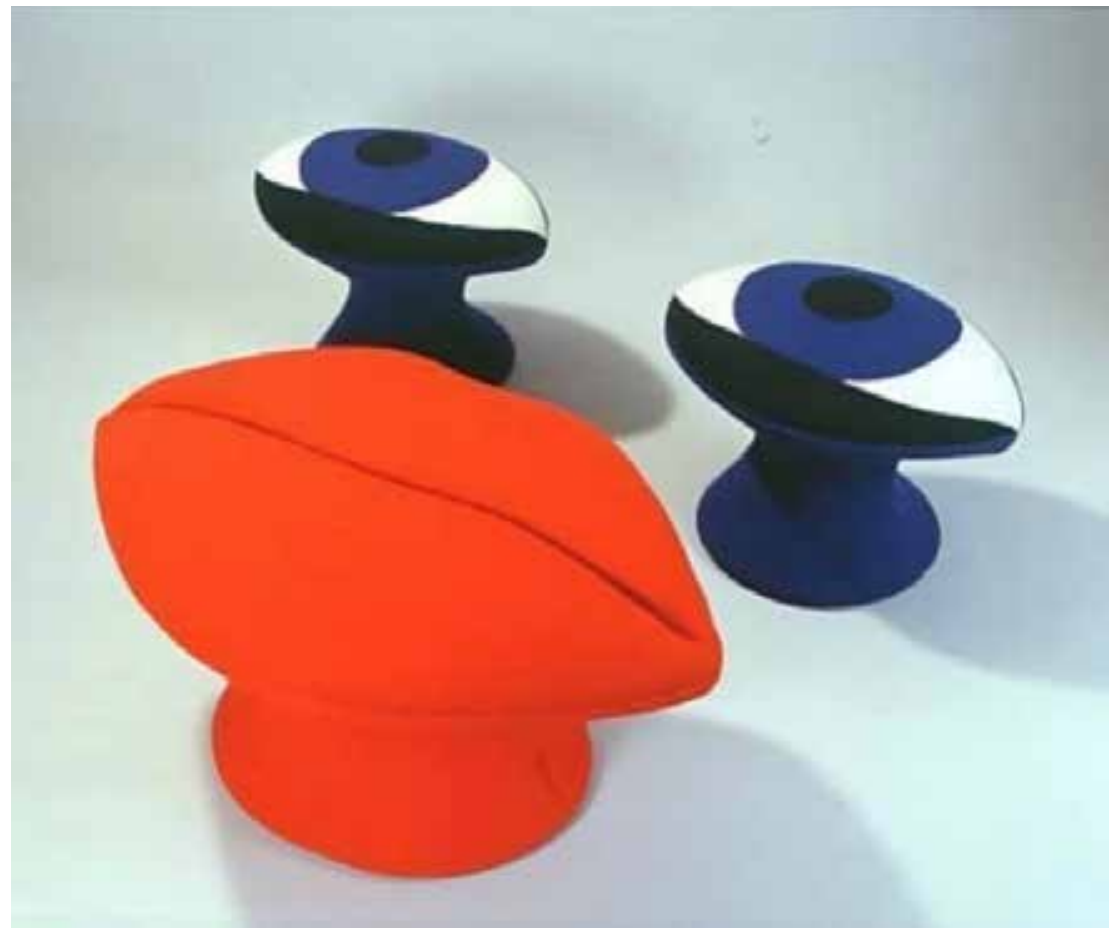



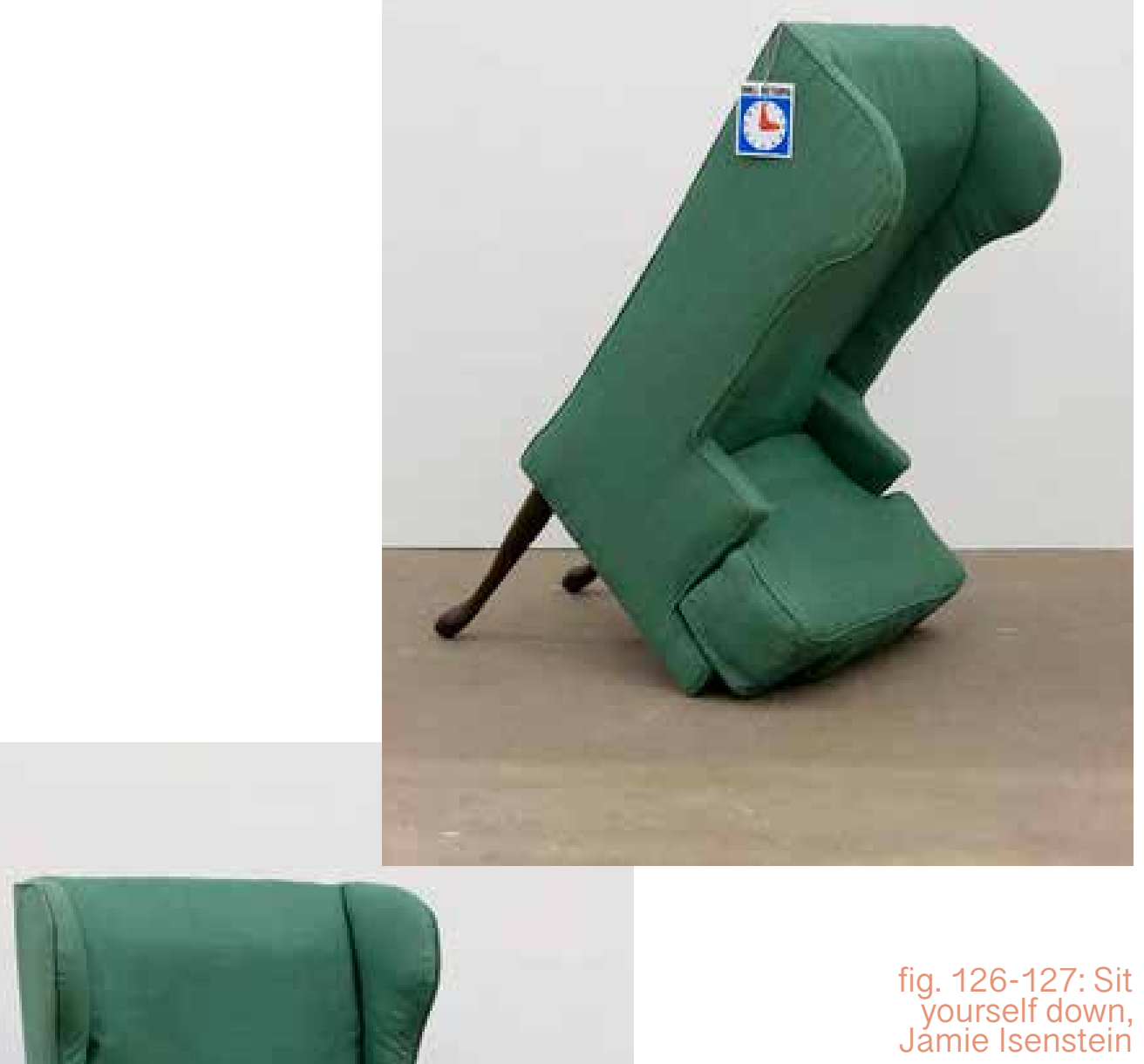
objects in digital space

099

fig. 128: Tissue Box, Coat Hook, Hygienic Paper Roll, Dunne and Raby, 2000

fig. 129: Steps, Dunne and Raby, 2000 facing page:

fig. 130:

Series of adult furniture, Dunne and Raby, 2000

fig. 131: Low Table and

Hygienic Paper Roll, Dunne and Raby, 2000

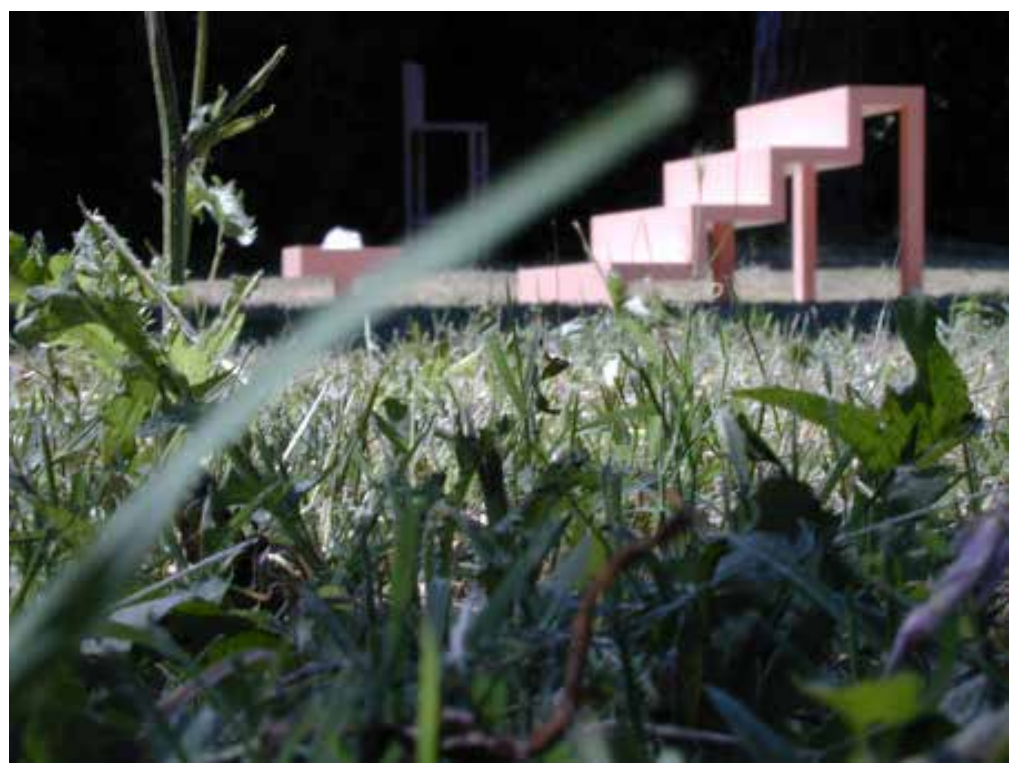



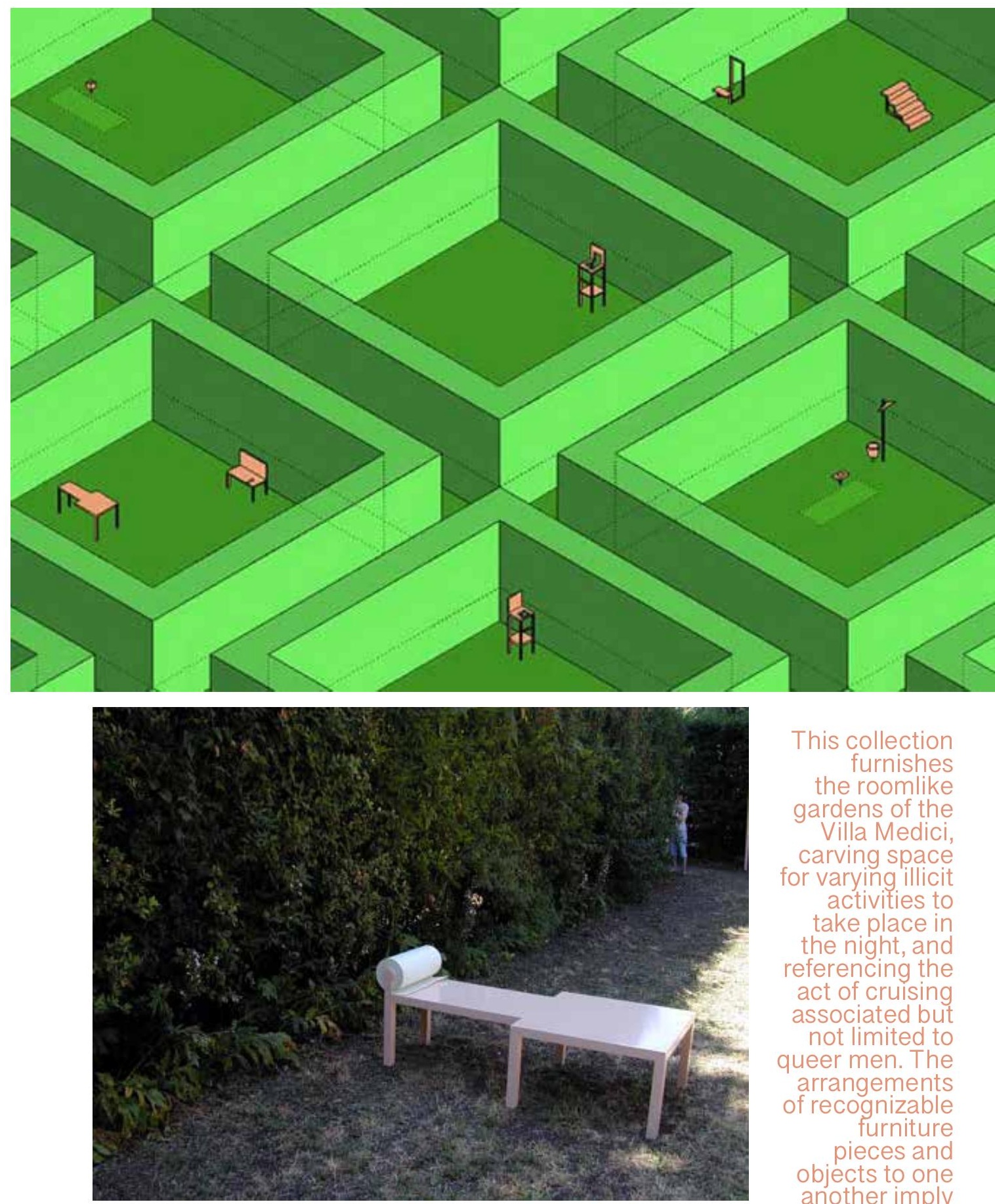

This collection furnishes the roomlike gardens of the Villa Medici, carving space for varying illicit activities to take place in the night, and referencing the act of cruising associated but not limited to queer men. The arrangements of recognizable furniture pieces and objects to one another imply narratives that both conduces and supports sexual acts. 
objects in digital space

fig. 132: Kar

A Sutra,

Axonometric, Mario Bellini

fig. 133: Kar A

Sutra, Mario

Bellini, 1972

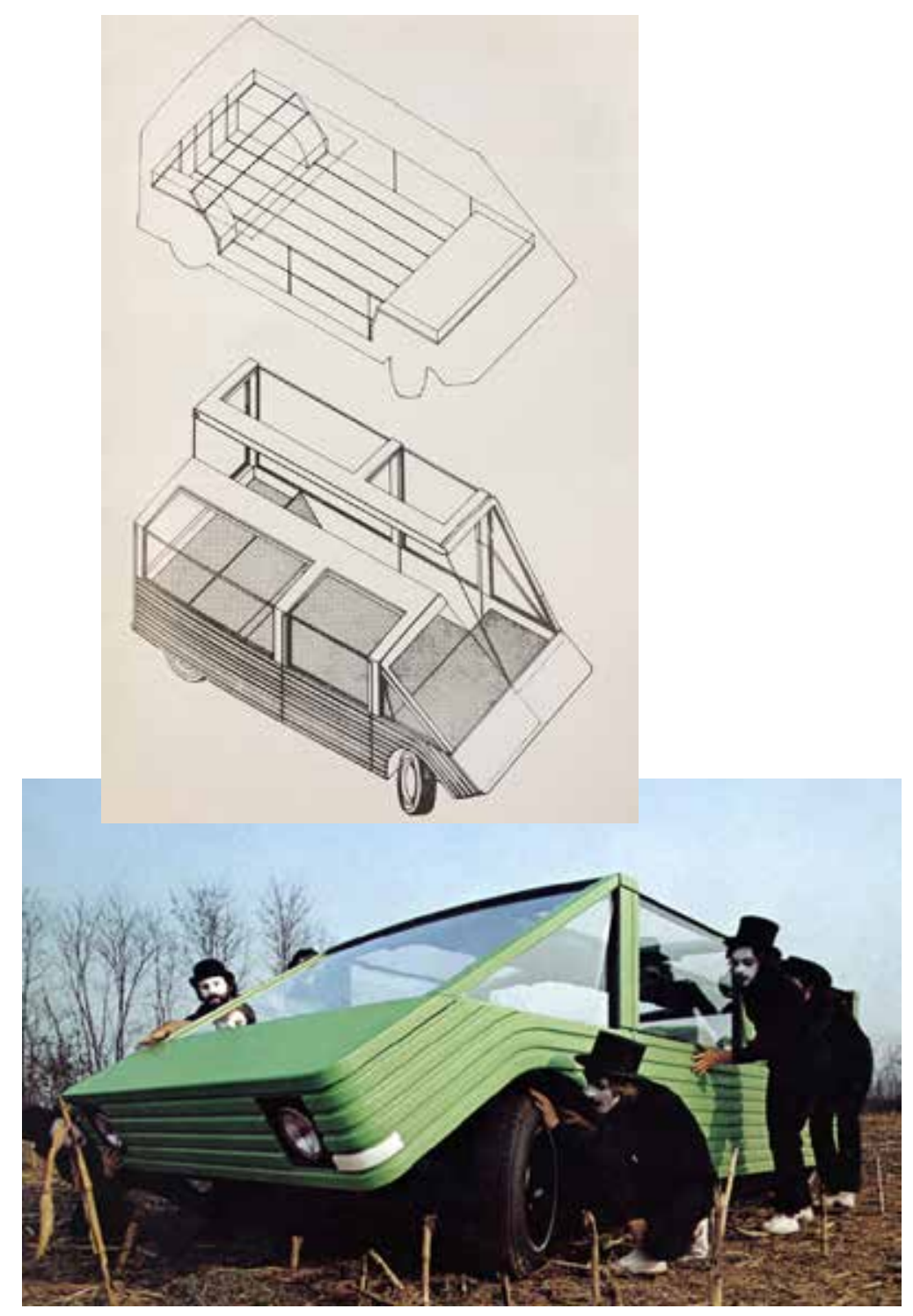



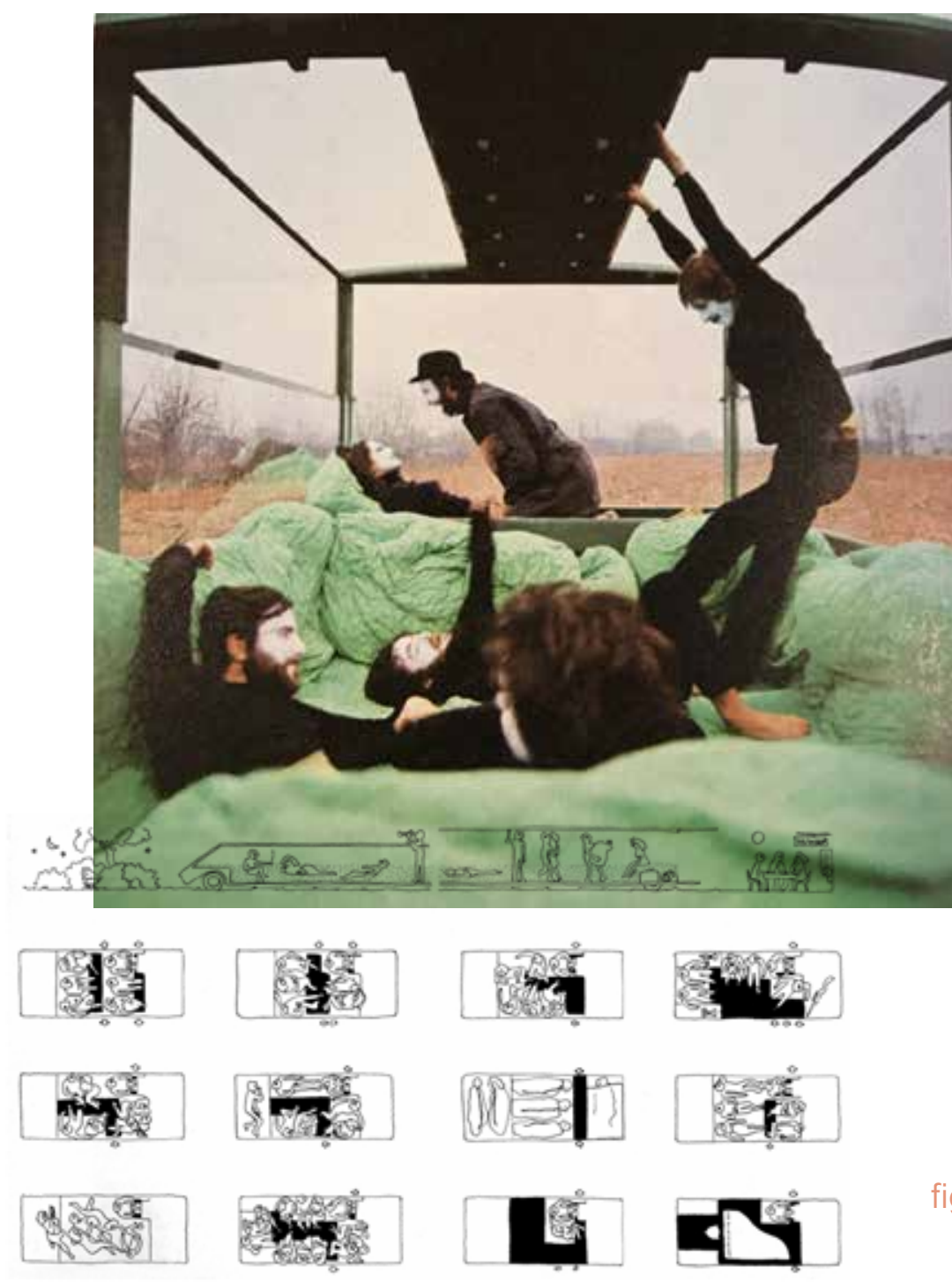

fig. 134: Kar A
Sutra, Mario
Bellini, 1972

fig. 135: Kar A Sutra, Diagram Mario Bellini 


"ici, on ne brode pas des coussins"

("we don't embroider cushions here")

(Drury \& Fopp, 2019, 86)

The series of chairs for lounging, for dining, for congregating found in the following pages enable or suggest the body to orient itself to the object itself and to other bodies in a nonnormative fashion. The chair is used as a point of reference for its ubiquity and recognizable features. Models of social convention broaden and specialize the forms of such objects (Drury \& Fopp, 2019), like the angles of support that a chair can provide, dictating a use or motion within or around them.

In Pictures, Porn and Fantasy, Holland Drury and Damian Fopp depict a history of the chaise longue, or long seated chairs that "introduced new levels of comfort into the homes of the elite, and came to stand as signs of wealth and fashion," (Drury \& Fopp, 2019, 82). A variety of seating types, with names that dictated explicit uses, were the vehicles to accommodate etiquettes of domestic space, and the chaise longue is rich in its many prescriptions. In L'art du Menuisier en Meubles (The Art of the Carpenter in Furniture, 1772), Andre-Jacob Roubo produced a catalogue of chaise longue types, varying from seating that supported more than one body, or seating that supported varying forms of rest. Their many classifications featured some racialized and gendered, specifically feminine, titles and references to specific female individuals. The chaise longue's many depictions in art throughout history were also gendered and sexualized, positioning female bodies with flushed cheeks in scenes lush with luxurious fabrics, or descriptions of non normative lovemaking in literature. Claude Prosper Joloyot de Crebillon wrote exactly that in Le Sopha (1742), where a young married woman engaged in intimate immoral sex with a slave following a lackluster sexual encounter with her husband. These acts, which were specifically situated outside of the marital bed, were spectated by the male 


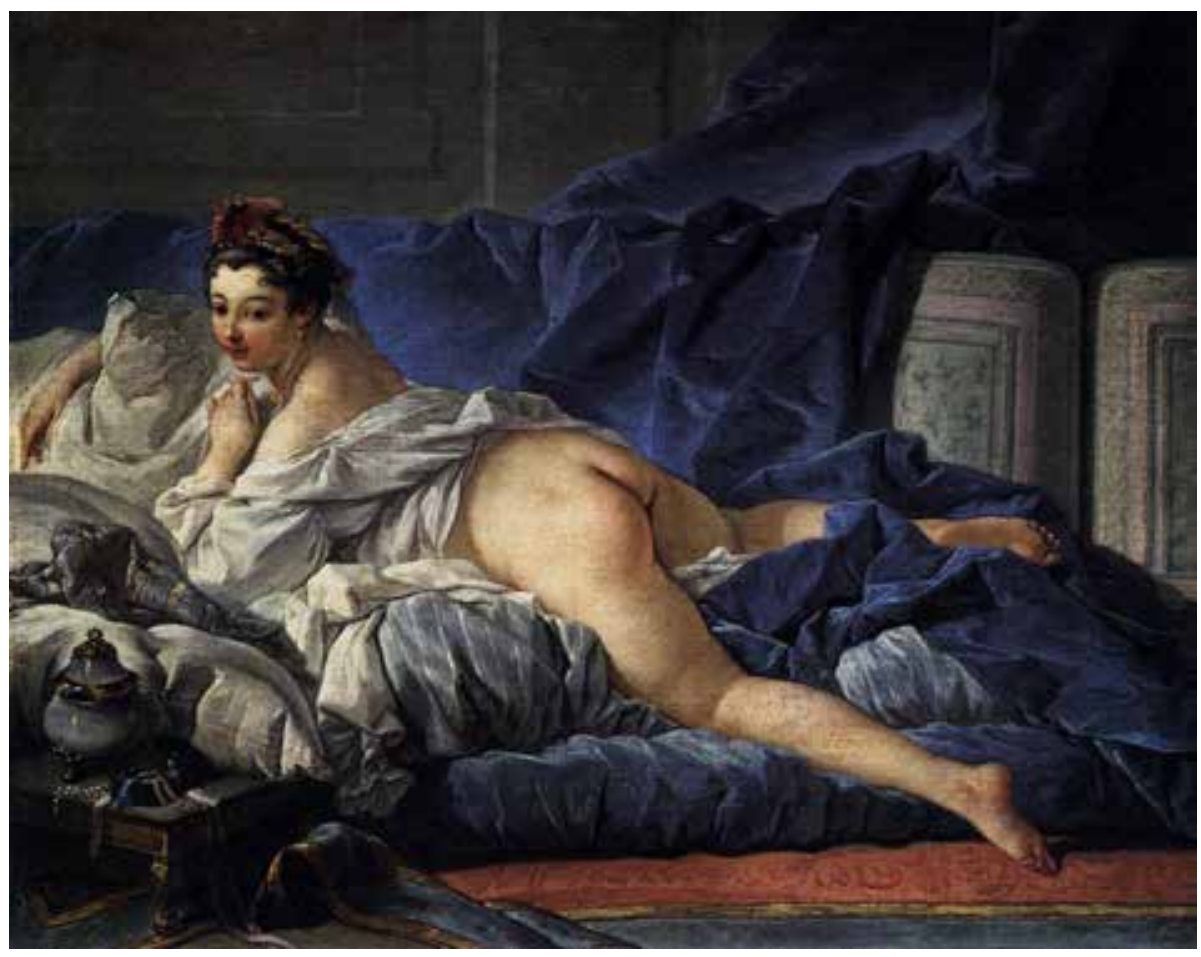

protagonist of the story who took the form of that very fuck 106 chair, following the casting of a spell that would transform him into one type of sofa after another. The publicization of 'her' pleasure recontextualized the chair for sexual pleasure, and subverted a widely accepted notion that while men could regularly take up affairs without scrutiny - with their petite maîtresse, a term that publicly acknowledges a lover through its definition and very existence - women were unable to openly take up the same practice (Drury \& Fopp, 2019).

Three years following the publication of Le Sopha, Francois Boucher painted the Brown Odalisque, which featured a young white nude woman tangled in sheets, lain over her body in such a way that ensured her backside reveals bare skin (see fig. 136). Her pose, replicated in subsequent works, and the transfigured protagonist and voyeur in Le Sopha centered the female body in the heterosexual male gaze, in "the commoditization of women," (Drury \& Fopp, 2019, 
chairs

fig. 137: Uno torna a casa stanco per aver lavorato tutto il giorno e trova una poltrona scomoda (One comes home tired from working all day and finds an uncomfortable chair), Bruno Munari, 1944
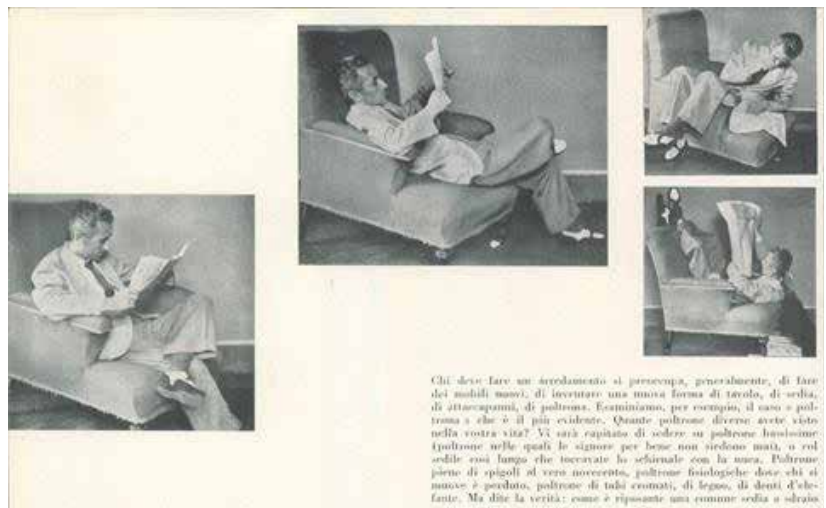

UNO TORNA A CASA STANCO PER AVER LAVORATO
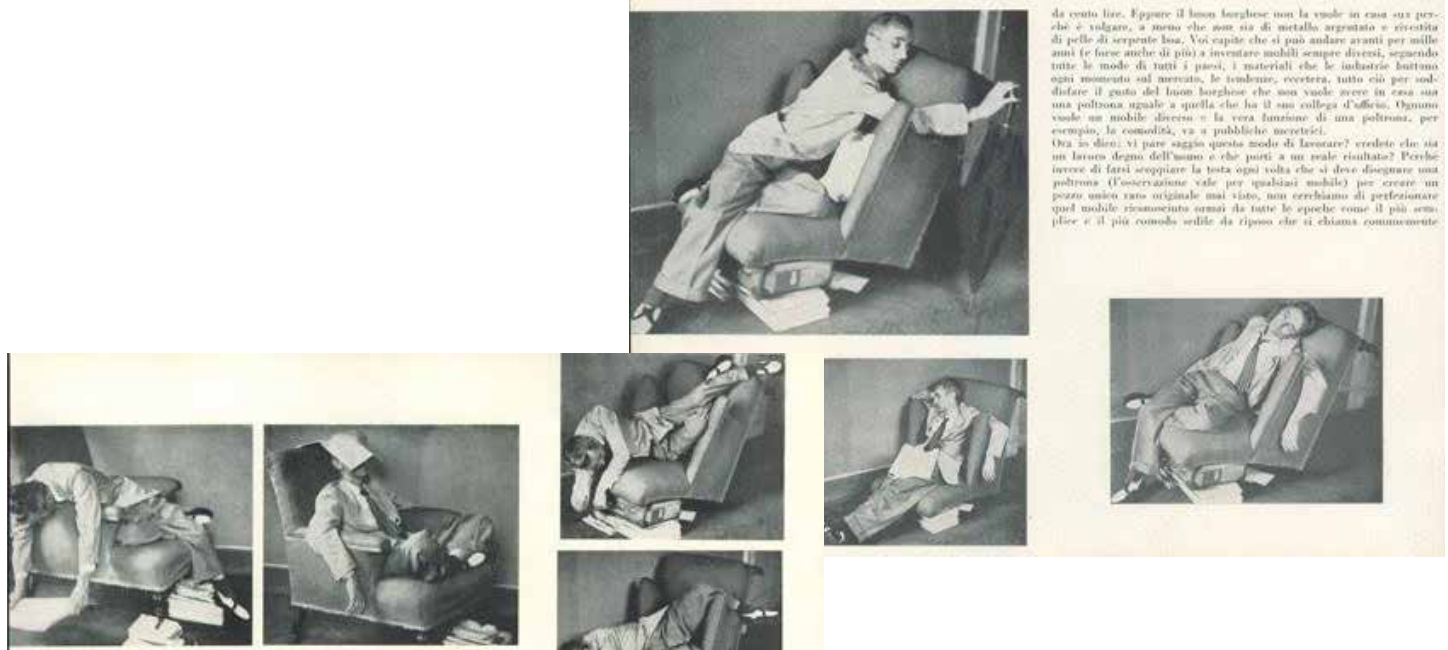

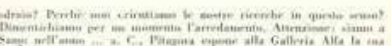

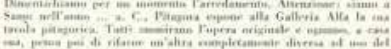

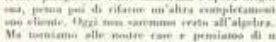

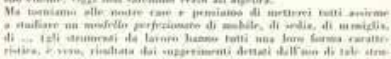

\section{TUTTO IL GIORNO E TROVA UNA POLTRONA SCOMODA}
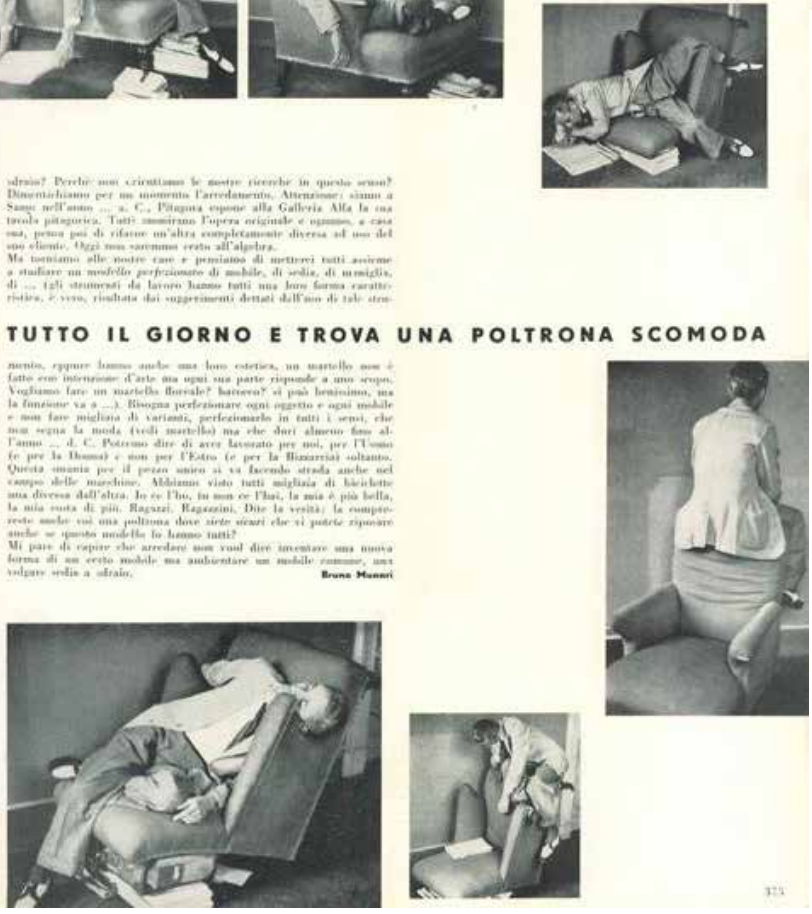
85). The woman in Boucher's Blonde Odalisque captured the attention of King Louis XV so much that upon request to Boucher, she, Miss Louise O'Murphy was brought to him to verify "her beautateous likeness" (85), and become his petite maitresse. "So, is it fair for us to argue that the way in which it was fashionable - or fantasized about - that women reposing on sofas and chaises longues offered them the potential to 'market themselves' in sexually liberating scenarios?" (85). This act reveals a curious condition, where women's sexuality and objectification locks their status as beneath the man of power. However it allows for a climb in social class, as O'Murphy went from model to royal mistress.

Designer Charlotte Perriand first met Le Corbusier in 1927 when she applied for a position in his studio, and was faced with a rejection of misogynist rhetoric: "ici, on ne brode pas des coussins" ("we don't embroider cushions here") (Drury \& Fopp, 2019, 86). Later that year, the two encountered each other following Perriand's chrome-plated ensemble Bar in the Attic at the Salone d'Automne in Paris" (87), acclaimed to be the best and most innovative in the whole salon. Following the retraction of his rejection, the pair designed the LC4 lounge chair, a widely recognized chaise longue that has since been featured in over 800 pornographic films, "juxtaposing the unequal working relationship under which the chair was conceived with the visual objectification of the female pornstars," (89). In 1929, the journal The Studio advertised the LC4 lounge chair for the first time alongside an article written by Perriand titled 'Wood or Metal'. The photograph, shot by Corbusier, exhibited Perriand in recline looking away from the camera, "her skirt falling from her upstretched legs highlighting them as objects of desire," (88).

Since the 18th century, the chaise longue has developed a vast visual economy of facets of female sexuality, "a recognisable visual language of feminine sexuality that was proffered to the viewer, readily available," (88). It is the 
vessel in which the objectification of the body takes place, instructing through the proliferation of its imagery and its form a way to occupy it. The chairs on the following pages make reference to chair types through scale, form, texture, dimensions and other discernible characteristics, however proposes an alternative occupation.

They suggest bodies to mimic through their humanized forms (see fig. 142), or they can support the experience of other objects that come to life in their loss of place, like ropes or chains (see fig. 139-140). Through angles of support, they can imply comfort or tenseness (fig. 141). Through their surfaces, rather than discourage, they can accommodate multiple forms of occupation, perhaps not typical for the average chair (see fig. 143-144). Ultimately, the chairs work to support and encourage motions of nonnormative intimacy, and publicizing sexual acts through reference to where these chairs would typically sit and be used for.

This practice of turning physical objects materially deviant can be translated to larger forms, like houses or storefronts or bars or offices. "Queer objects support proximity between those who are supposed to live on parallel lines, as points that should not meet," (Ahmed, 2006, 169). Applied to how space and place are defined or composed, how can methods of generating architecture support proximity between points that should not meet? How can repetitive normative patterns in the built world be broken through a method of queering the elements of architecture? By elements, I do not mean to say that a wall is simply a wall, that it is limited to a singular purpose or function, that each one does not bleed into the other. A wall can be a door, as a floor can be a window, and these overlaps or fluid exchanges from multiples acting as one and breaking their distinctions, a binary of it is or it is not, becomes crucial to queering architecture. 


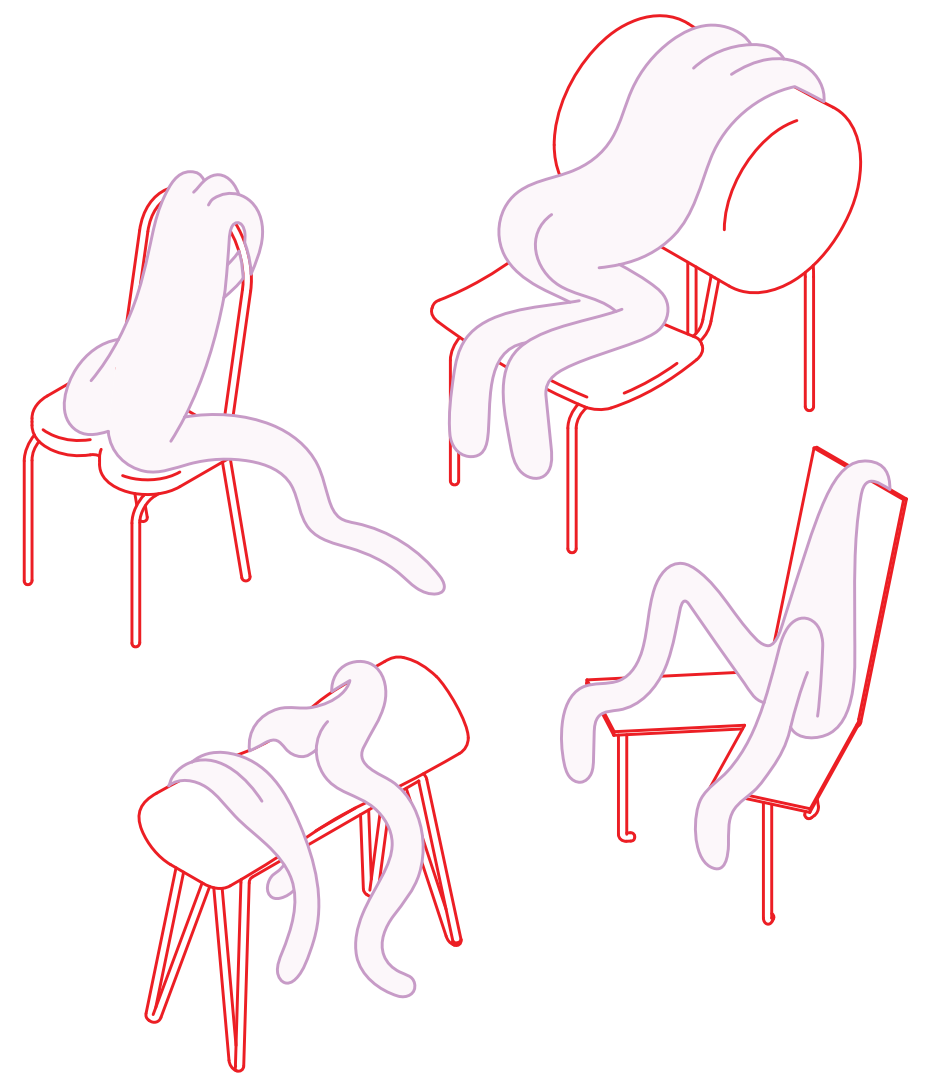

fig. 138: series of chairs occupied, Michelle
urov, 2017

Ashurov, 2017 
chairs

columns from
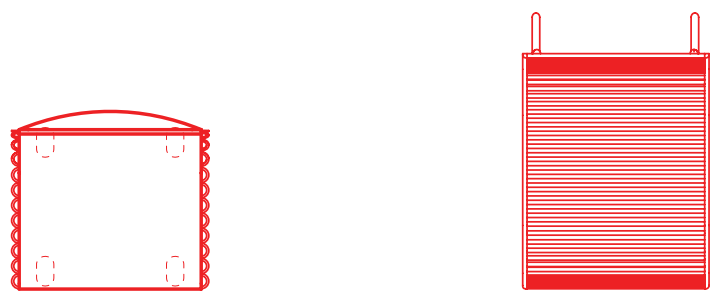

left to right

fig. 139: beaded

chair (top to

bottom) plan,

front elevation,

side elevation,

isometric, 1:20

fig. 140: tying

chair (top to

bottom) plan,

front elevation,

side elevation,

isometric, 1:20
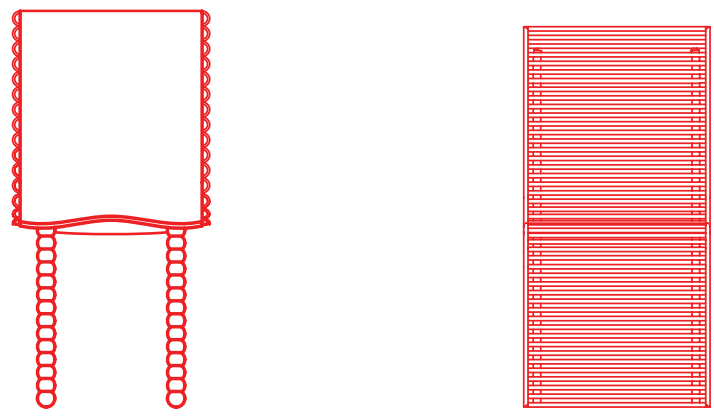

111
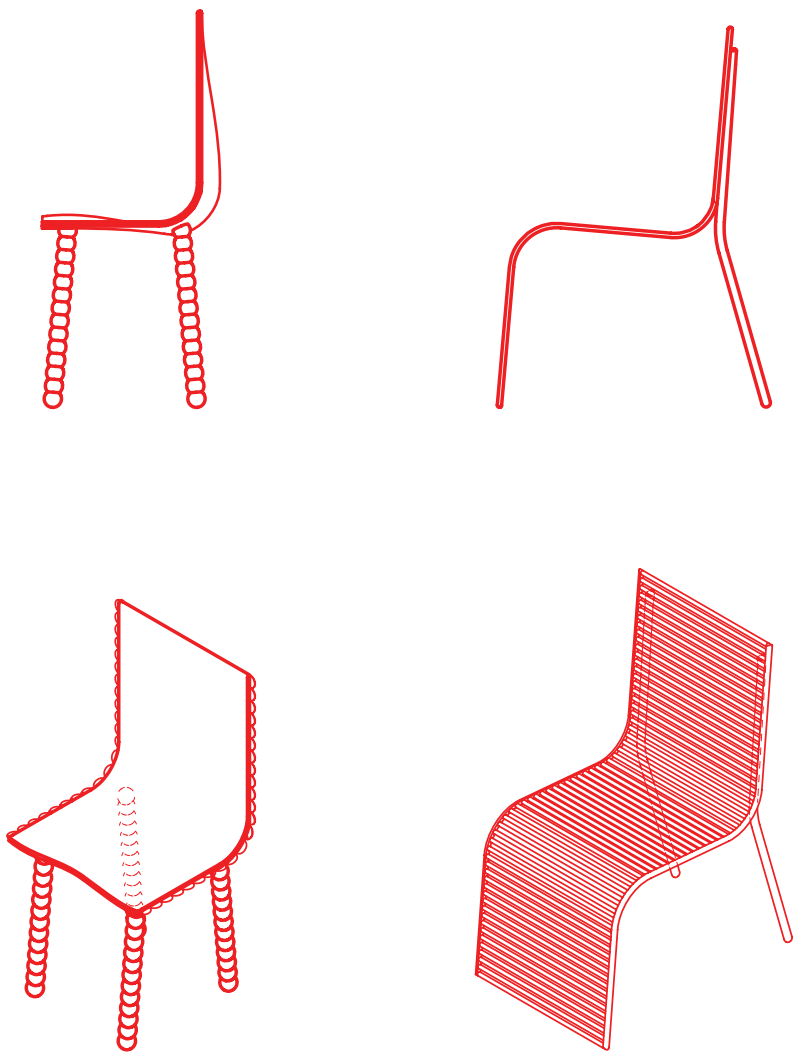

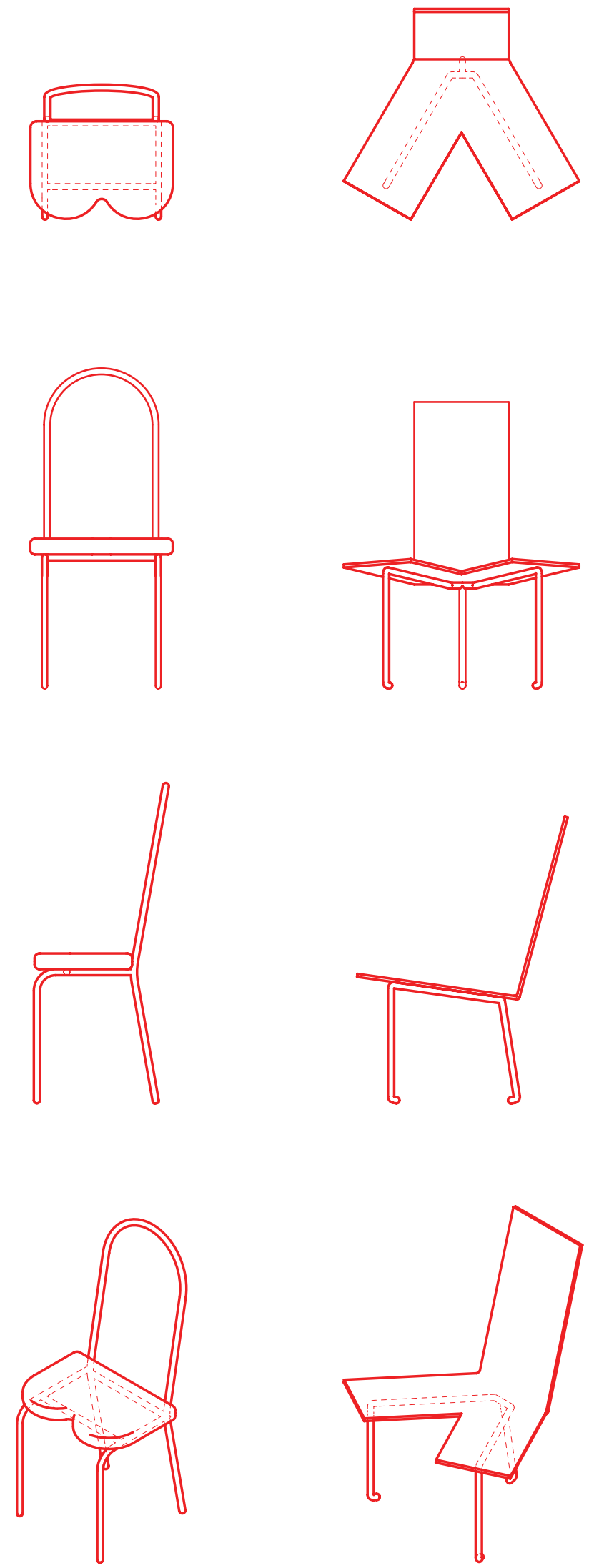

columns from left to right

fig. 141: bubble chair (top to bottom) plan, front elevation, side elevation, isometric, 1:20

fig. 142: split chair chair (top to bottom) plan, front elevation, side elevation, isometric, 1:20 
chairs

fig. 143: spank chair (top to

bottom): plan,

front elevation,

side elevation,

isometric, 1:20

fig. 144: spank chair seat
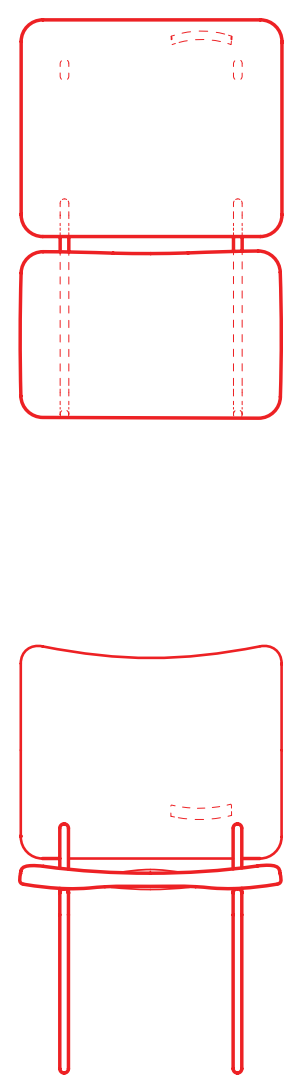

113
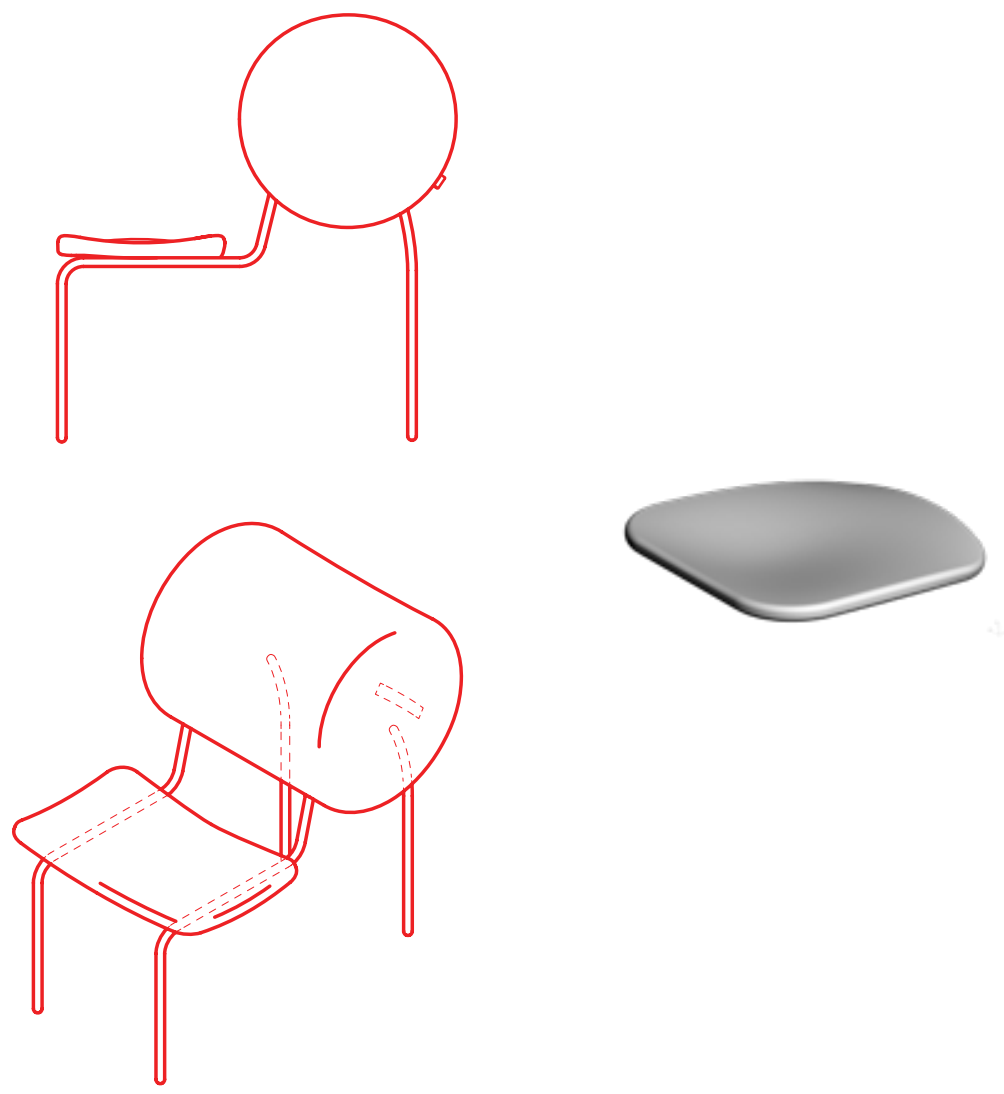

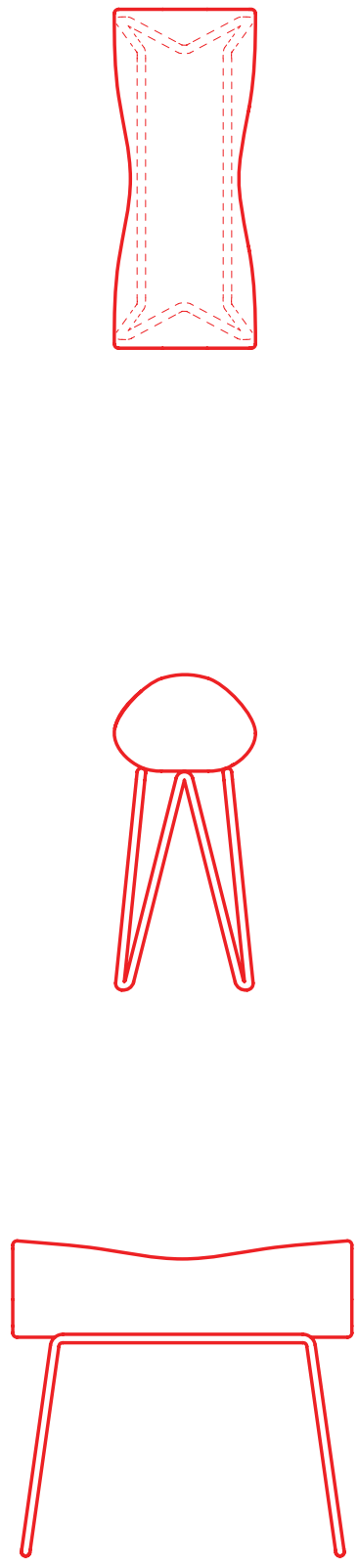

fig. 145: saddle chair (top to bottom) plan, front elevation, side elevation, isometric, 1:20

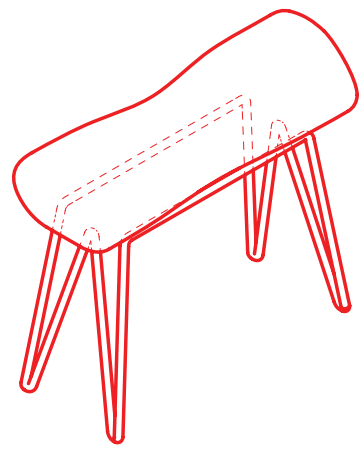






\section{elements}

The following drawings on pages 115 to 122 depict a queering of elements, the breaking down of architecture to parts, to "support proximity between those who are supposed to live on parallel lines," (Ahmed, 2012, xx). These instances do not necessarily depict a single element, but accepts a fluid exchange between categories to host fluidity of performance in space, and explores the possibilities of breaking the normative patterns in the built world.

\section{The five \\ figures on this page depict a manipulation of depth and porosity of vertical planes for the purpose of storage, display, exchange, demarcation and access 117 fig. 146: wall as cabinet and doors as tiles}

fig. 147: wall as closets and closets as door and corridor

fig. 148: wall as bookcase

fig. 149: window as shelf

fig. 150: door as window/ window as door

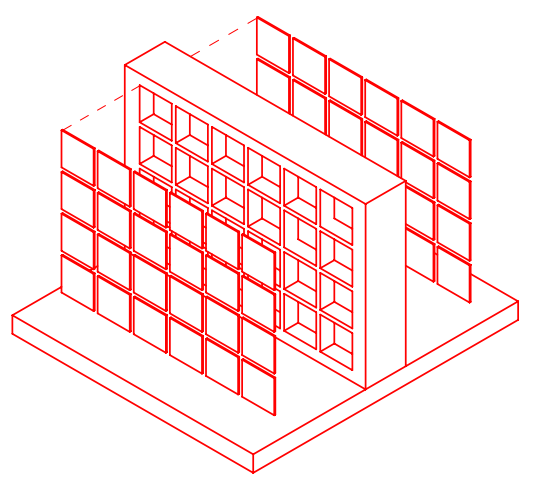

wall as cabinets and doors as tiles / a void within walls that can be accessed through a disruption of the wall's surface, and a multiplication of hinged doors that tile the plane 


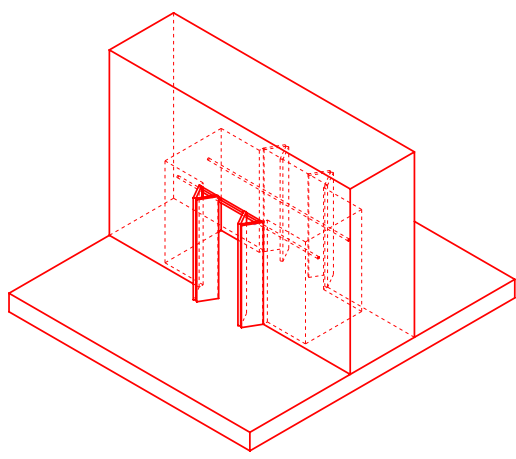

wall as closets and closets as door and corridor / closets are typically neighboring each other without any relation to each other, doors typically have the only job of allowing bodies to pass through walls, and walls are shared by rooms so why can closets not be shared?

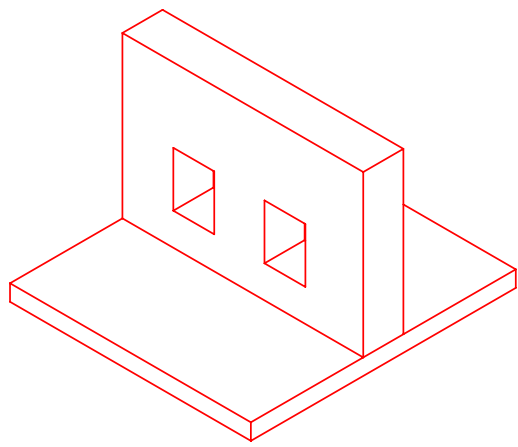

window as shelf / the depth of the wall makes itself known in the apertures, and the windows form a shelf plane

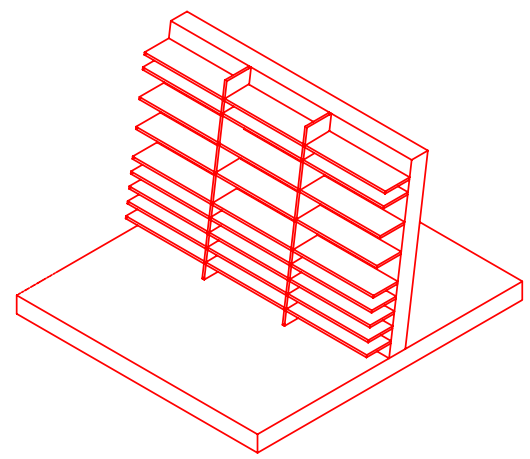

wall as bookcase / the wall is slanted towards an outside, keeping the books that line the shelves in place during any seismic activity, and giving the library a presence from the outside, and references Bookshelf House by Shinsuke Fujii Architects (2014) door as window/window as door / the window has the appropriate dimensions for a human sized door 


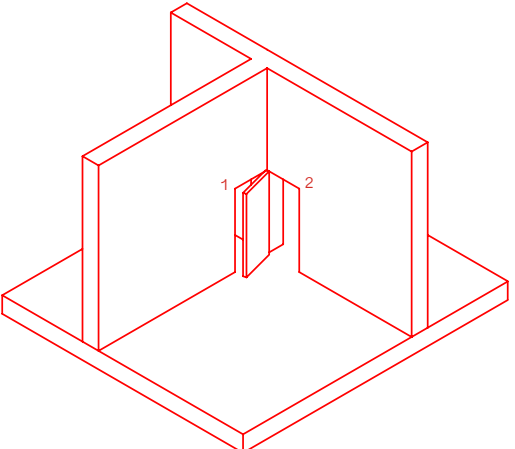

door as negotiator / a door hinged to service the closure of one room at a time out of two, and references Door 11, Rue Larrey by Marcel Duchamp (1927)

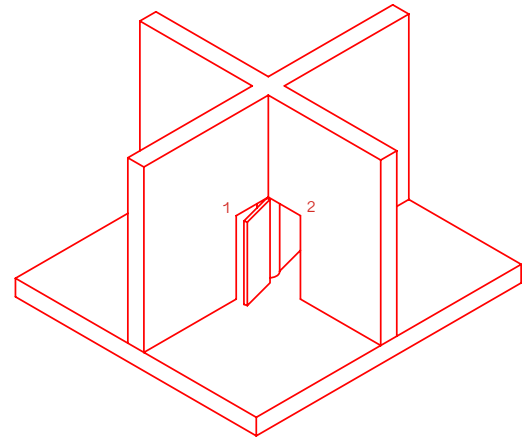

door as [pseudo-]negotiator I a door hinged at its centre to service the closure of two rooms at a time out of four, flipping the relations of rooms

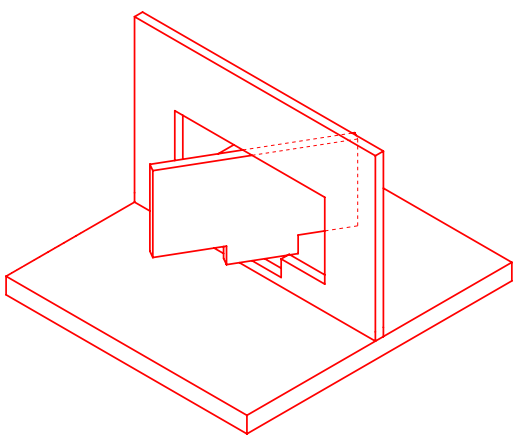

wall as door and display / the aperture of the wall rotates at a point somewhere in the middle like a revolving door, so expansive that when it's perpendicular to its original plane, it becomes a wall of its own, and references Storefront for Art and Architecture by Vito Acconci and Steven Holl (1993)

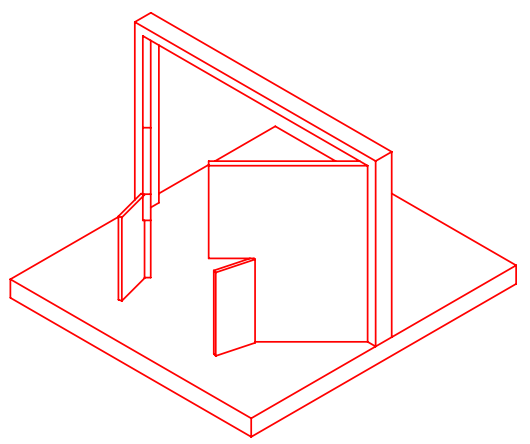

wall as door and door in door / a wall is composed of two scales of door, for regular humans and for giants (or for spirits or aliens), and references HerzJesu-Kirche by Allmann Sattler Wappner (2000) 
The four figures on this page depict a manipulation of the door to change relations of space

fig. 151: door as negotiator fig. 152: door as [psuedo]negotiator

fig. 153: wall as door and display

fig. 154: wall as door and door in door 


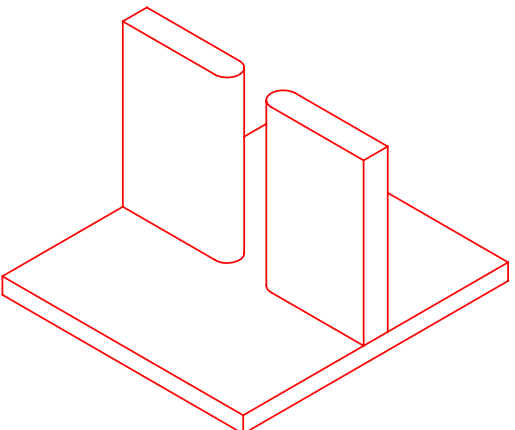

wall as continuous surface / breaks in a wall do not give the effect of being sliced into, rather carved out of, to allow for the hand to glide along without disruption

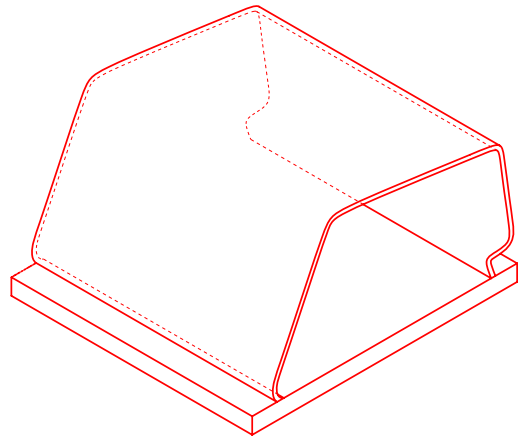

wall and ceiling as room and bench / the solid form rises and wraps around space to form a room, creasing to provide a platform for sitting, and references Brasserie by Diller + Scofidio (1999)

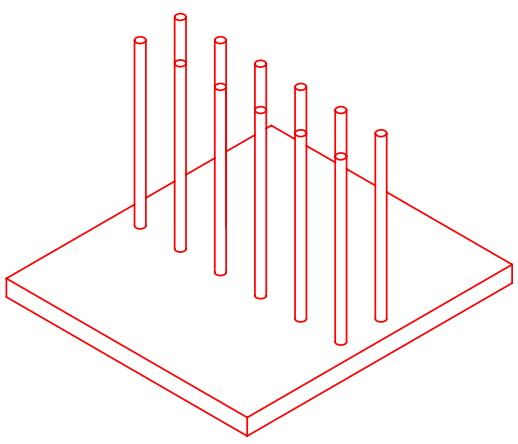

columns as corridor / a series of slender columns spaced about a door's width apart suggest a corridor without separating space into two disconnected volumes

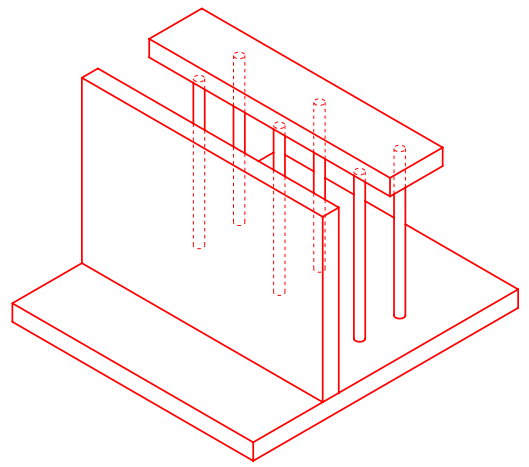

wall as barrier versus ceiling and column as boundary / the wall depicts one a separation of space through forming a barrier, while the roofed structure depicts another separation of space through forming a boundary, something can be occupied as well (Montiel, 2018) 


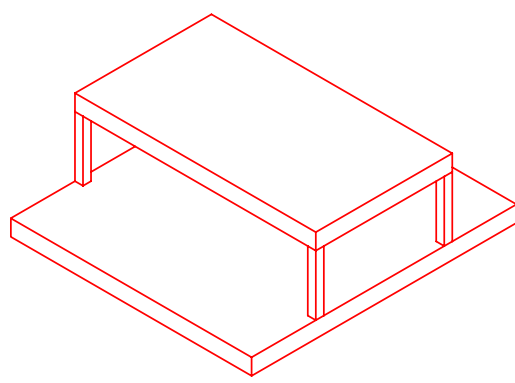

ceiling as mediator / the Toguna house, a meeting space of individuals of indigenous groups with a low ceiling force individuals to sit down and speak at eye level, a democratic representation of a room of equals (Studio Gang, 2018)

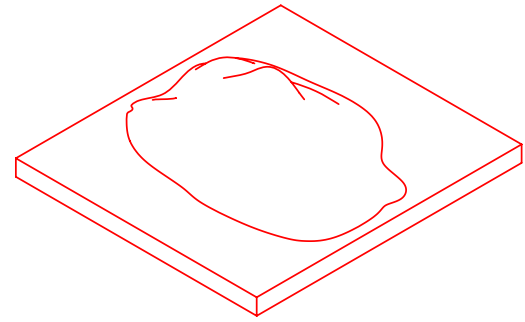

mound as wall and floor / the height of the mound surpasses what you can see over, and combined with the depth of the mound, it can be walked on, sat on, lay on
The six figures on this page depict a study of boundaries and borders through various elements and planes 122

fig. 155: wall as continuous surface

fig. 156: wall and ceiling as room and bench

fig.157: columns as corridor

fig. 158 wall as barrier versus ceiling and column as boundary

fig. 159: ceiling as mediator

fig. 160: mound as wall and floor 


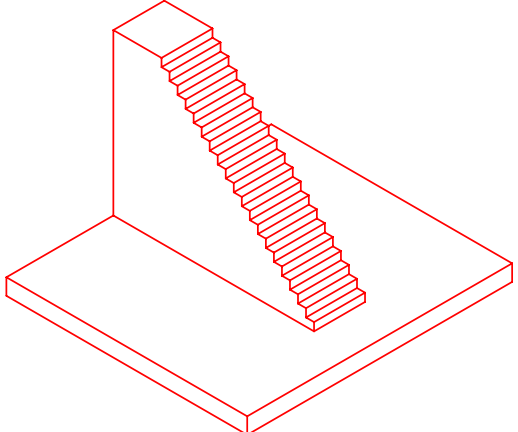

stair as wall / a run of stairs that forms a thick vertical barrier

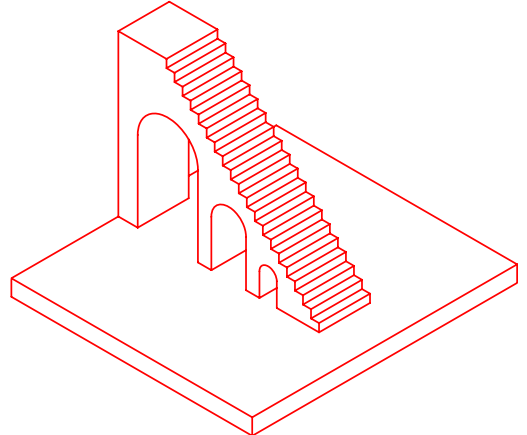

stair as wall and corridor / a run of stairs that are cut into to delineate a path or a corridor (contingent on the width of the stair), and references an early external stair typology that serviced residences in Venice (Foscari, 2014)

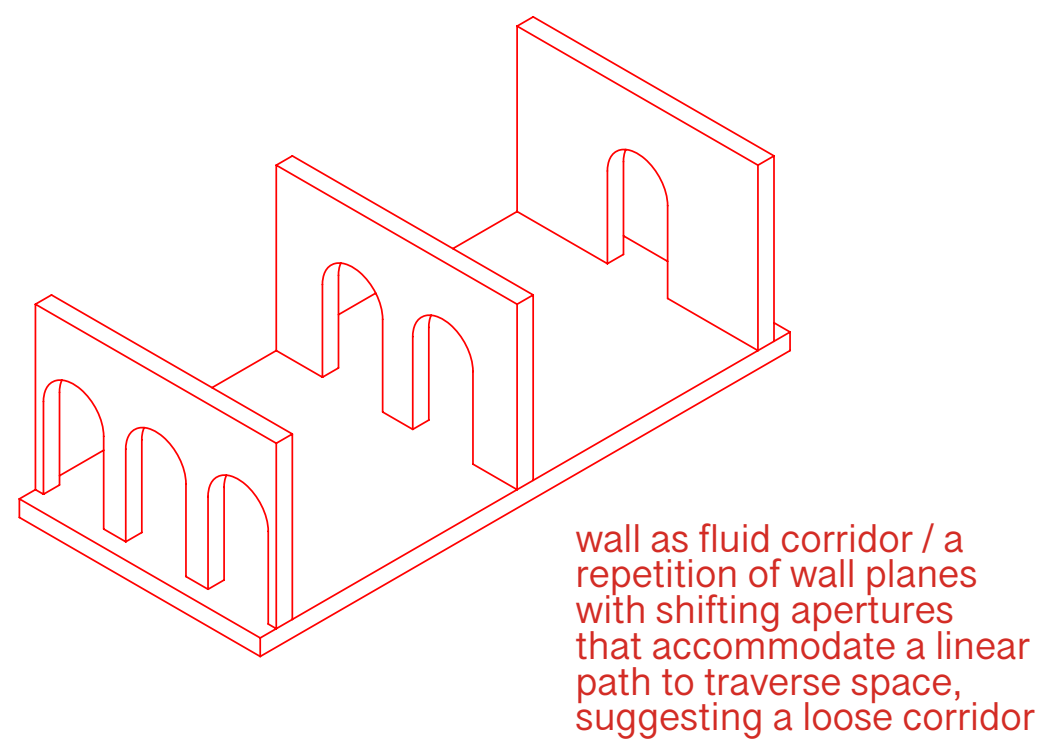




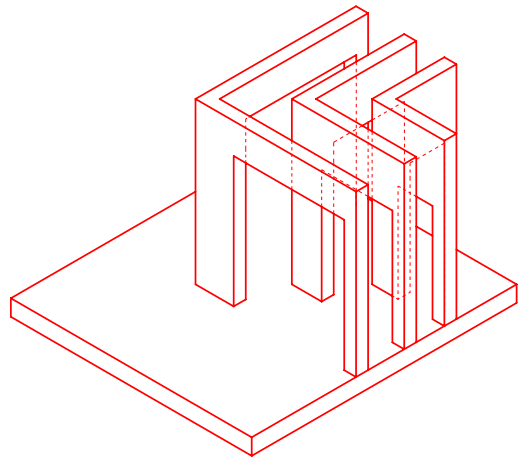

wall and aperture as scalable object and signifier of space / the three nesting walls form a corner that faces an outside, and can signify an spatial ordering logic, and references Todoroki Residence by Hiromi Fujii (1976)
The five figures

on this page depict a study of division and transparency

fig. 161: stair as wall

fig. 162: stair as wall and corridor

fig. 163: wall as fluid corridor

fig. 164: wall and aperture as scalable object and signifier of space

fig. 165: wall as fluid corridor 2

124

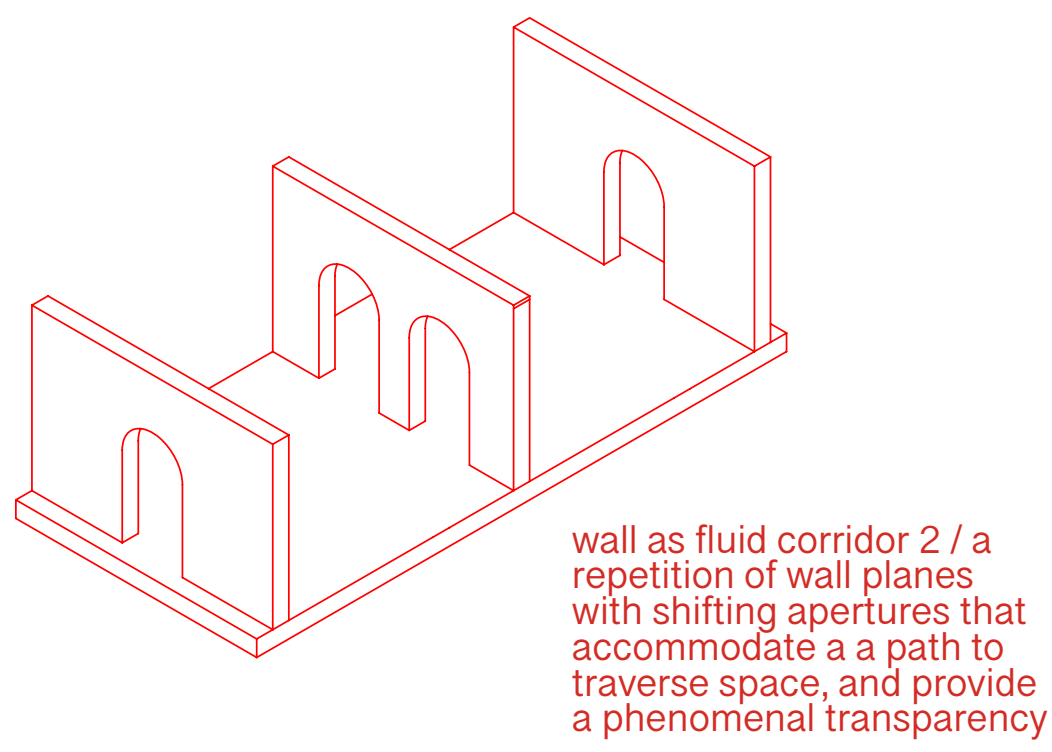






\section{stored in house}

While architects of the nineteenth century produced and extended their manifestos into a production of public buildings, operas, museums, and parliaments, the type of the twentieth century was the house. "The twentieth century monument is a private house, but a house that is not simply a building on the street, not simply lived in. Rather, the house is constructed in a new form of public space: the space of publications, photographs, exhibitions, congresses, fairs, magazines, museums, art galleries, international competitions, advertising, computers, etc. The twentieth century house is constructed in the ephemeral space of the media. The media is what allows the private to be the site of public memory," (Colomina, 1999, 337).

For the architect, it makes sense for the house to be a captive of manifestoes. Consider the recurrence of the table in philosophical discourse. The table is something the philosopher uses to speculate through, something familiar and ubiquitous that provides a place for the writing of philosophy to be done (a writing table), or a place for writing to be organized (a table of contents) (A hmed, 2006). There is an intimacy to the table. The houses' scale, specificity, familiarity, and intimacy in relation to the individual allows for a full range of speculations of life and habitance to be translated into 'built form'. It is a site that demonstrates and forms social, political and cultural ideologies.

"The twentieth century house is exhibitionistic in character. It is not just that it is designed for publication, designed to photograph well. Rather, it is concerned with new forms of exposure, new forms of display, new forms of transparency. The modern house has been deeply affected by the fact that it is both constructed in the media and infiltrated by the media. Always on exhibition, it has become thoroughly exhibitionist," (Colomina, 1999, 358). The twenty-first century house inherits a relationship to media, but must reconcile the expansive forms and forces of media. Consider the normative logics of house space that guide placements of 
objects in furniture showrooms, or the established language of rooms in real estate listings - repeated terms like master bedroom, den, living room, specified and implied use within space in the domestic realm - or depictions of the house in reality TV shows like Trading Spaces and various spin offs, where sets of two couples trade homes to hastily redecorate rooms in two days. The creations of interior designer Hildi Santo-Tomas, loathed or ridiculed by many viewers of the show, also displayed a production of queered spaces (Ward, 2018). In the great tradition of camp, her room makeovers were drag caricatures of rooms and themes, comically a rebellious act as many heteronormative coupled house owners seemed to be unhappy with her creations within their pristine homes. The relationship between media and house is delicate and ripe in opportunity for queer imaginations of space to reach tangibility, considering how the house can be fitted and occupied in alternative ways.

In Towards a New Architecture, Le Corbusier wrote "A house is a machine for living in," (4). I would insist that the house is an assemblage for living in. An assemblage can be defined within many fields. In composition, it refers to a text that is composed solely of existing texts in order to communicate problems and arguments within a new context (JohnsonEilola and Selber, 2007). In art, it refers to the collage of three-dimensional elements, typically of found objects but

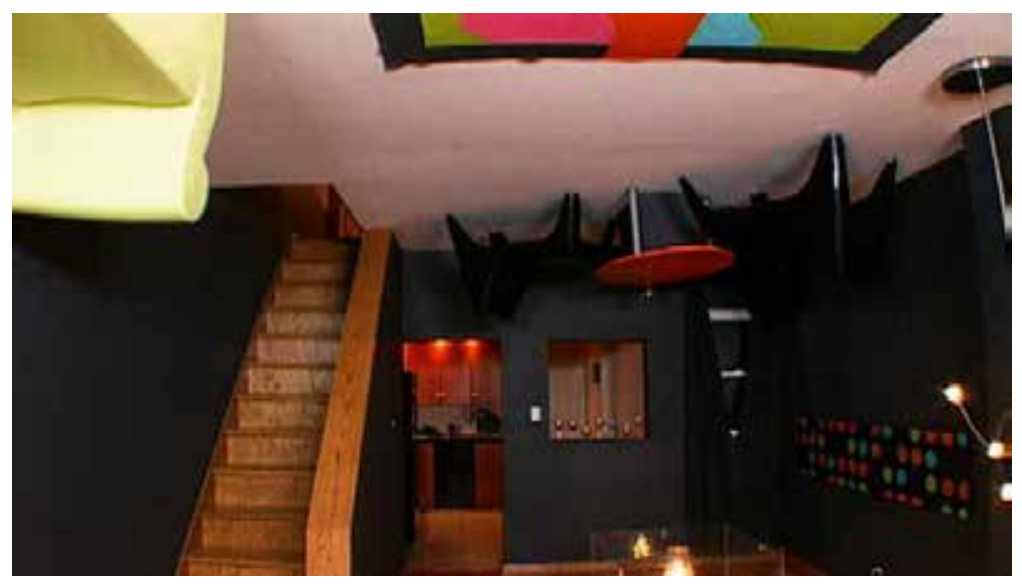

fig. 166: The upside-down room designed by Hildi SantoTomas, Trading Spaces 
fig. 167: house

1 plan, 1:200

(a) entry, (b) circulation space, (c) small bedroom, (d) large bedroom, (e) washroom, (f) office, (g) living room, (h) library, (i) kitchen, (j) dining room, (k) garden, (I) patio can also be composed of new ones. In archaeology, it refers to a group of artifacts that recur within a frame of time and place, and are used to define a history of human activity (Bahn and Renfrew, 2016). In philosophy, assemblage theory refers to an analysis that, "emphasizes fluidity, exchangeability, and multiple functionalities. Assemblages appear to be functioning as a whole, but are actually coherent bits of a system whose components can be "yanked" out of one system, "plugged" into another, and still work. As such, assemblages characteristically have functional capacities but do not have a function - that is, they are not designed to only do one thing," ("Assemblage Theory", n.d.). In all accounts, the formation of an assemblage involves a shifting or displacement of things, material or immaterial, recontextualized to create something. These things bring meanings together through reference and arrangement, and transmit or construct something else. Assemblages surpass the sum of their parts. The house is not simply 


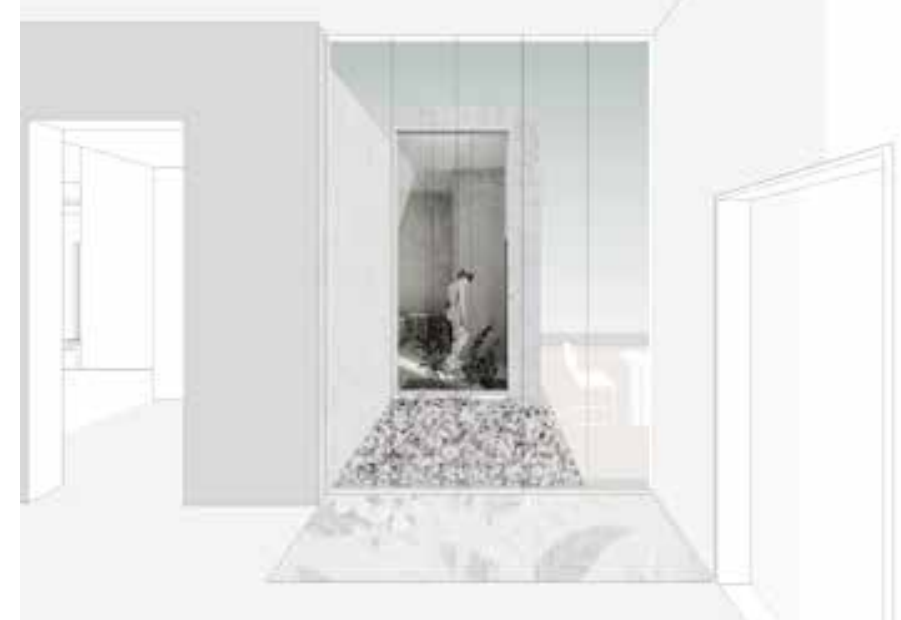

an instrument for performing a task, for production. It is an assemblage of histories, cultures, ideologies, politics, economies, languages, achieved through material means. And the emphasis in Corbusier's parlance on machine, by extension (re)productive and presumably well-oiled, limits the possibilities of housing. The machine has a controlled set of parts difficult to substitute that work together to formulate a kind of production. This stresses every part of a machine to pull its weight, eliminating redundancy. When machine is swapped out for assemblage, things desired can be brought to the foreground, no longer undermined by efficiency as the objective. Matrices of an assemblage's constituents have a looseness with respect to what can come in and what can fall away, granting a flexibility.

In 2016, I designed House 1 (see fig. 167), which engaged with two ideas: (1) configuring contemporary elements of domestic space without the use of corridors, and (2) configuring privacy between interior and exterior, and interior and interior. While I did not consciously design 
(from left to right, top to bottom)

131

fig. 169:

One Room

Apartment

by Cornelius

Meijer, 1969,

Elevation 1

fig. 170:

One Room

Apartment

by Cornelius

Meijer, 1969,

Elevation 2

fig. 171:

One Room

Apartment

by Cornelius

Meijer, 1969,

Elevation 3

fig. 172:

One Room

Apartment

by Cornelius

Meijer, 1969,

Elevation 4 this house queerly, what resulted was a building that was not queer through aesthetics or references, but through its performance. While still maintaining perimeters of programmed space in a traditional binary walled condition of here and there, the flow of space was disturbed through a lack of doors and a strategic configuration of rooms and apertures that maximized sight lines from room to room.

Surfaces that met with the exterior were arranged through patterns of solid and transparent that ensured the interiors were always facing inwards, even when an individual looked outwardly, to the world outside, to a public realm. Although transparent segments in exterior walls existed, they are placed to point toward other transparent segments in other rooms that share no sight lines through the formal interior of the house (rather than the perceived interior, altered through senses and orientations). The rooms located at the four corners of the overall form push out their exterior facing perimeters, resulting in exterior pockets, or visual corridors. For example, the rendering pictured is taken from one bedroom and looks into the other through this visual corridor (see fig. 186). Slivers of the public realm also come into view if one's orientation to space shifts. This organization maximizes an ability to effortlessly peer into other spaces that would typically offer a higher level of privacy, situated in opposing corners for example. Through varying roof levels, each room is expressed volumetrically from the outside, but its contents are prudishly tucked away. Simultaneously, occupation of the house is severed from a physical publicity but is forced into an arcane intimacy. Normalized room types of the single detached house exist but their relations to one another are tampered with, blurring any gendered notions through a raw connectivity.

In order to seamlessly flow through space without the use of corridors, rooms must provide passageways into the next. Each (suggestively) programmed room shares a portion of their perimeter adjacent to the core of the house, 

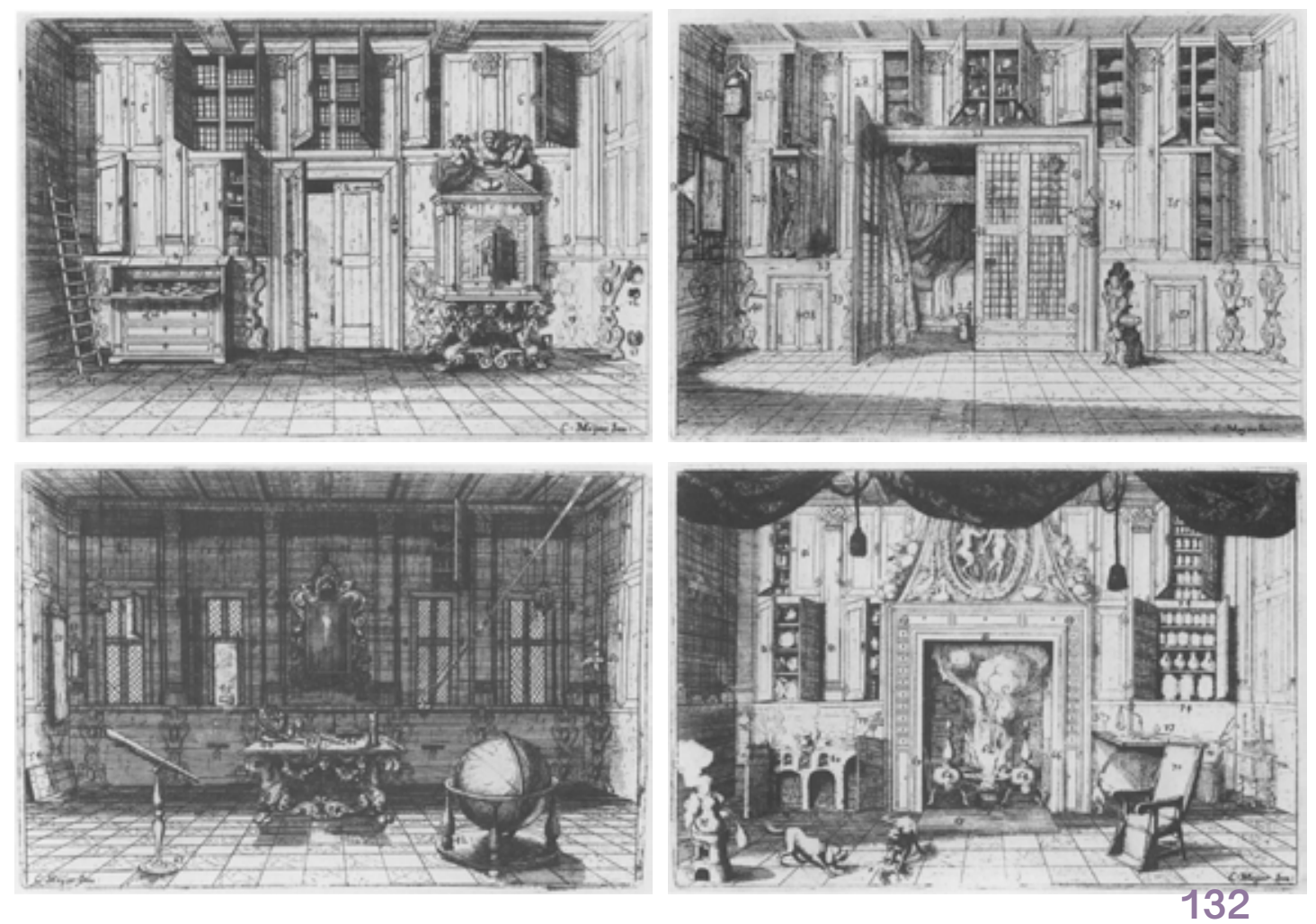

a blank 'room' that provide glimpses into every space, not much different from the arrangements of Roman houses or Parisian hotels prior to the eighteenth century. To stand here in the centre rids all views to the outside except for an upward gaze through a single roof aperture. I would argue now that not only is this house queer, but specifically this central space allows bodies to perform queerly due to its intimacy with all interiors.

The intent behind the patchwork spatial configuration lies in the desire to maximize sight lines from all points of the house, excluding the patches of space located in front of the toilets. The six doors within the entire house connect the inhabitant from interior to exterior rooms, delineated through platforms that sit a step above grade, or grant access to water closets. In other words, the potential for exposure of inhabitants amongst each other is constant providing a voyeuristic lens through domestic space. 


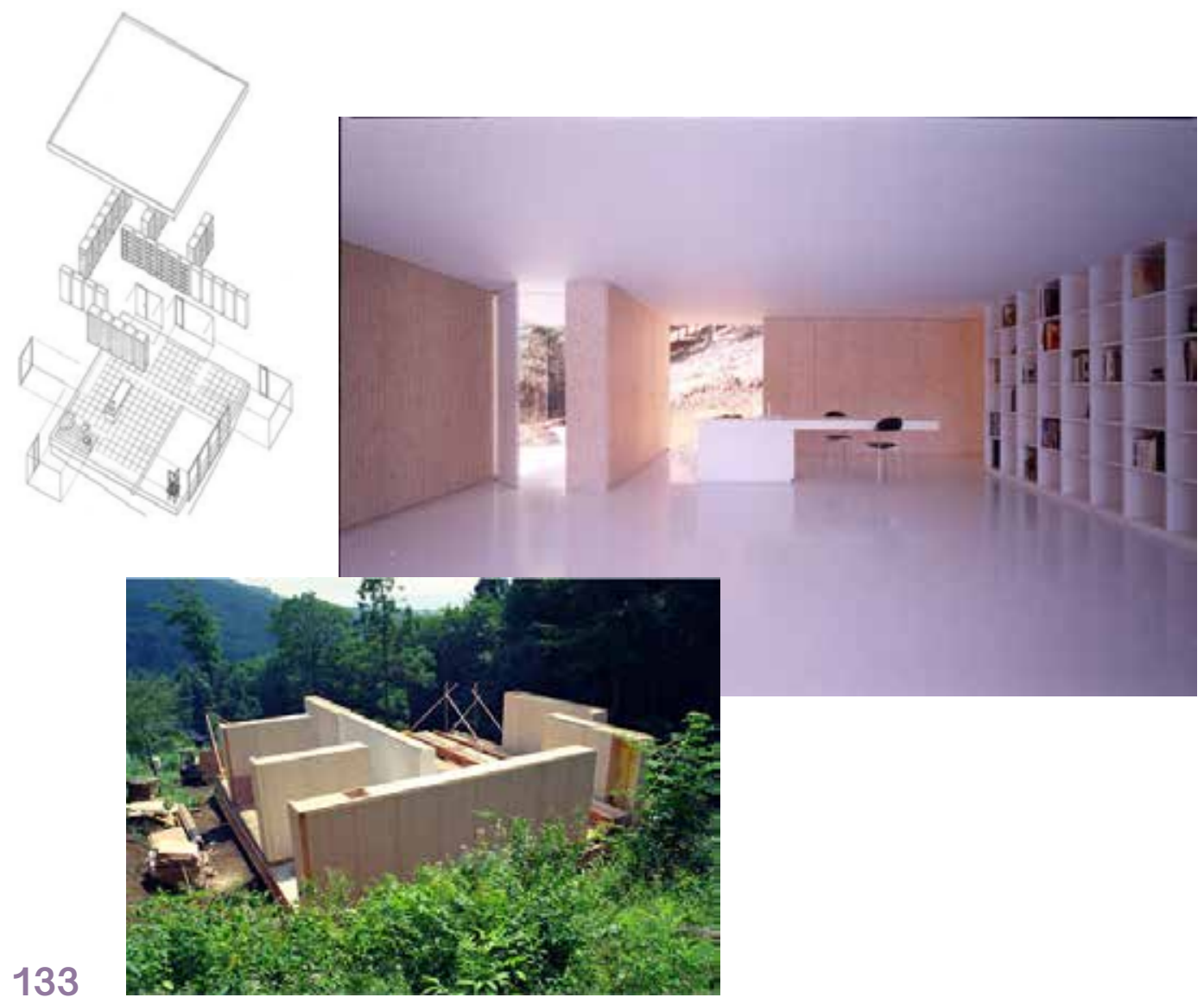

(from left to right, top to bottom)

fig. 173:

Furniture House 1 by Shigeru Ban Architects, isometric

fig. 174:

Furniture House 1 by Shigeru Ban Architects, interior

fig 175: Furniture House 1 by Shigeru Ban Architects, construction
The One Room Apartment, designed by Cornelius Meyer in 1689 , acted as a critique of the multiplication of specialized space in contemporary palaces of that period, which consequently scattered the possessions of the individual through an expansive network of rooms. It was designed for the bachelor virtuoso, and the four walls depicted in the four interior elevations of the room consolidate objects within them by way of a patchwork of closets and cabinets (see fig. 169-172). Objects that belonged outside the perimeters of the room included various built-in elements; such as listening tubes (to spy on neighbours), a dog kennel, fold-away furniture, and secret passageways to other apartments; accommodating the storage of objects, such as letters, books, tools, chickens, linens, and beds. A periscope with a concave mirror allowed the individual to observe street life without being seen (Lucarelli, 2017). The 
architecture of storage, secrecy, and convenience begins to perform queerly.

The architecture of storage becomes more threedimensional in Shigeru Ban's series of Furniture Houses, the first of which was completed in 1996. The vertical elements in Furniture House 1 (see fig. 173-175) were composed of multiple prefabricated units, wardrobes and bookshelves, that not only store objects and organize space into rooms or nooks, but structurally support and insulate the house. Every inch of the interior wall planes hold a secret behind its surfaces, or doors, with modest handles and gaps between to minimize their assertion as traditional door. Conceptually, the units and objects that are held within the 'walls' are bestowed with a status of prominence, a promise of shelter through structural and organizational performance, but are rendered invisible through opaque parts that assemble to imitate walls, effectively becoming a series of storage walls.

It is not by chance that parallel to the growth of the middle class following World War II, which marked an increase in time for leisure and disposable income, do-it-yourself culture (relying on will, time, and capital) rose in popularity, and in turn the storage wall became a revered design object in midcentury America. Providing volume for the storage of growing accumulations of objects, it is "an object of aggressive consumption," (Obniski, 2018, 24). The storage wall was first acknowledged in the field of architecture in the November 1944 issue of Architectural Forum, and introduced to a wider audience in the January 1945 issue of Life magazine (Obniski, 2018).

For George Nelson, who wrote on storage design and designed the Storagewall, storage was about disappearing into the wall, effectively becoming a part of the architecture, which in turn reimagined the home as a container for things that support life and leisure through an ostensibly user-friendly reshuffling of spatial dividers (Obniski, 2018). 
fig. 176:

Housewife overcome by

her things,

Tomorrow's

House, George

Nelson and

Henry Wright, 1945

135

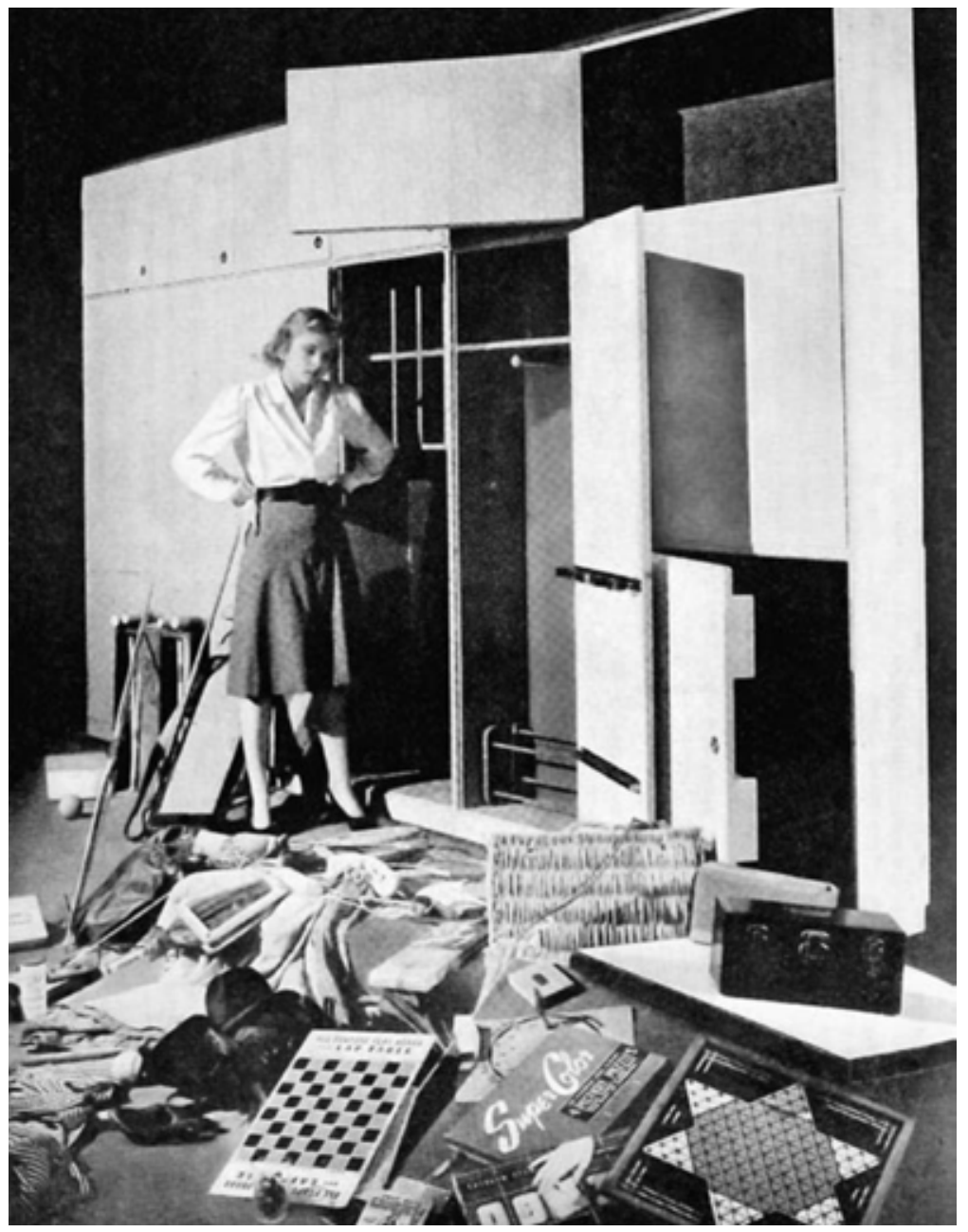

This was a dilution of the qualities of the built-in closet, its anonymity and disguise, through its newfound mobility as something with up to two fronts, something that can be pushed away from the wall to become a wall itself. These objects challenged the constructedness and inflexibility of existing home storage and of the home itself.

Nelson's Storagewall was initially presented as a reaction to the reduction in modern home sizes, a decrease in servant labour, and a growth in domestic objects following the rise in leisure and wealth. He projected that it aided the housewife, who was no longer supported by servants in the conduct of domestic labour, with space to solve the problem of clutter, keeping objects out of sight. Tomorrow's House, a publication by George Nelson and Henry Wright, 
promoted modernism while criticizing other conceptions of "homes of tomorrow" featured in media and exhibitions that were filled with electrical servants and other devices that reflected futures imagined in science fiction. Nelson and Wright's vision presented a visual elimination of electronic and media devices (radios, television sets, projectors), tools (typewriters, pens and pads) and other household appliances, consolidated with print media, items of leisure, and decorative objects. Emphasized in these texts is the concept of "active storage", which forces the housewife to critically analyze all domestic objects, identify which are used daily or weekly, and store those in the Storagewalls, while all other objects are to be rid of. "In return for her efforts, she would no longer spend hours searching for things because the Storagewall - with its superior patterns of organization - promised instant retrieval. Like push-button appliances and remote controls, which also proliferated in the postwar period, the Storagewall was a means of redefining the resident's relation to domestic time and space... Nelson's wall was a programmatic built-in, mainframe, invisible solution" (Spigel, 2012, 558). This embeds the "logic of information society" into the structure of domestic life, and

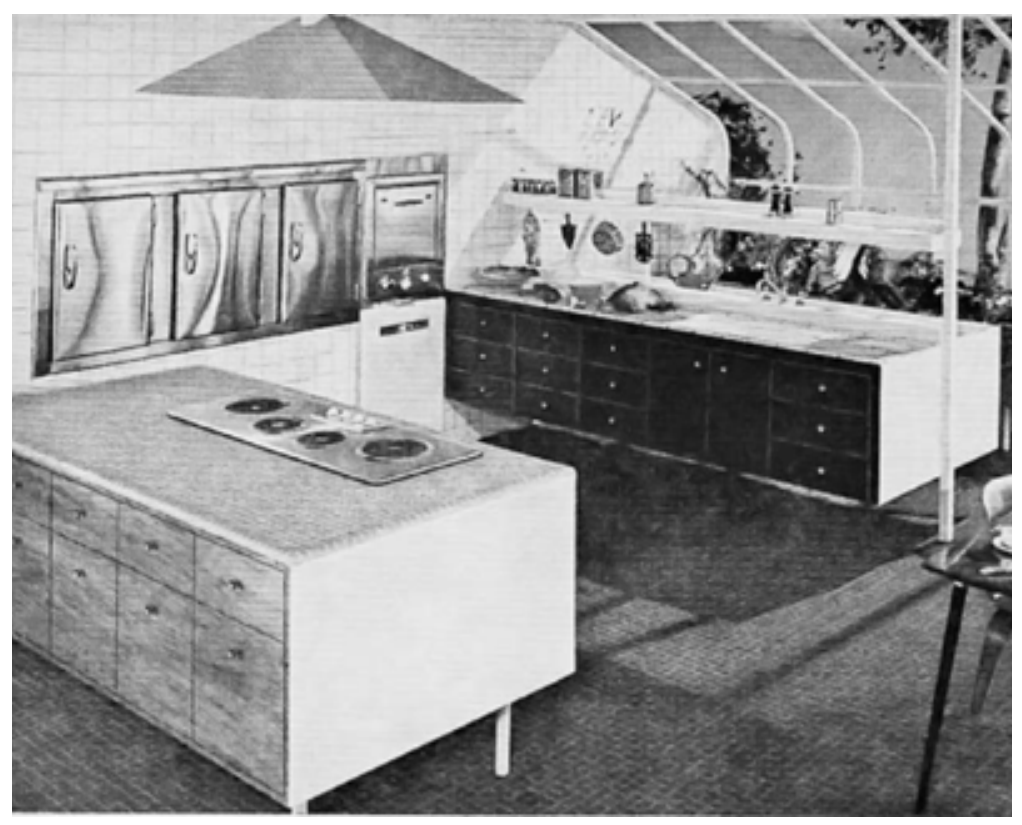

fig. 177: The Nelson kitchen has cupboard units that resemble office storage and reduce the visibility of kitchen appliances and plumbing. Advertisement, 1952 
ultimately supported a transition in the types of labour that took place in the home (Spigel, 2012, 559).

The Storagewall was a part of a promotion of lifestyle, blurring the lines between office and house through its organization of a network of machines and its modular furniture counterparts, which rearranged activities of the home into an open plan multipurpose space. In Tomorrow's House, the chapter titled "The Work Center" specifically focused on kitchens, a term vague enough to represent multiple forms of labour in a "work center-social center" (Spigel, 2012, 562). "Decorating manuals displayed configurations that suggested women's ambiguous status as homemaker-secretary in bedroom, kitchen, or living room units that contained an incongruous mix of sewing machines, blenders, encyclopedias, letter and bill storage, TV sets, mixing bowls, desk supplies, and typewrites, and in bedrooms built-in desks sometimes doubled as vanities," (Spigel, 2012, 562). With the shift in economies, women not only were tasked with domestic duties of cooking, maintenance and child rearing, but also with the managerial and secretarial role over family finances.

The invisibilization of any signs of labour, like communication technologies or cleaning appliances, was intrinsically tied to the larger transition of power dynamics and social relations. Tomorrow's House was filled with fictional narratives that indicate an objectification of the servant or maid, implied to be a person of colour and of a lower social class, and their "disappearance" and replacement by storage cabinets that "solved the 'housewife's problem"' (Spigel, 2012, 565). The Storagewall was promoted to turn the middle-class white woman into an "organization woman", managing a network of technology, rather than a maid, a woman who formerly worked for her (see fig. 178). In relation to configuration, the family room was presented as a casual living room or multipurpose space, unifying the "different gender and generational roles" of the family through activity zones. 
Maintained by the housewife, she becomes simultaneously: on display, visible from every point of family space as she participates in the performance of domestic labour; and rendered invisible, with the traces of domestic labour she performs to be kept out of sight when not in use. "The most successful housewife makes it look as if housekeeping is easy, as if housework is not work at all. In this regard, the Storagewall doesn't only hide objects; it also hides the gendered relations of work and leisure at home," (Spigel, 2012, 569).

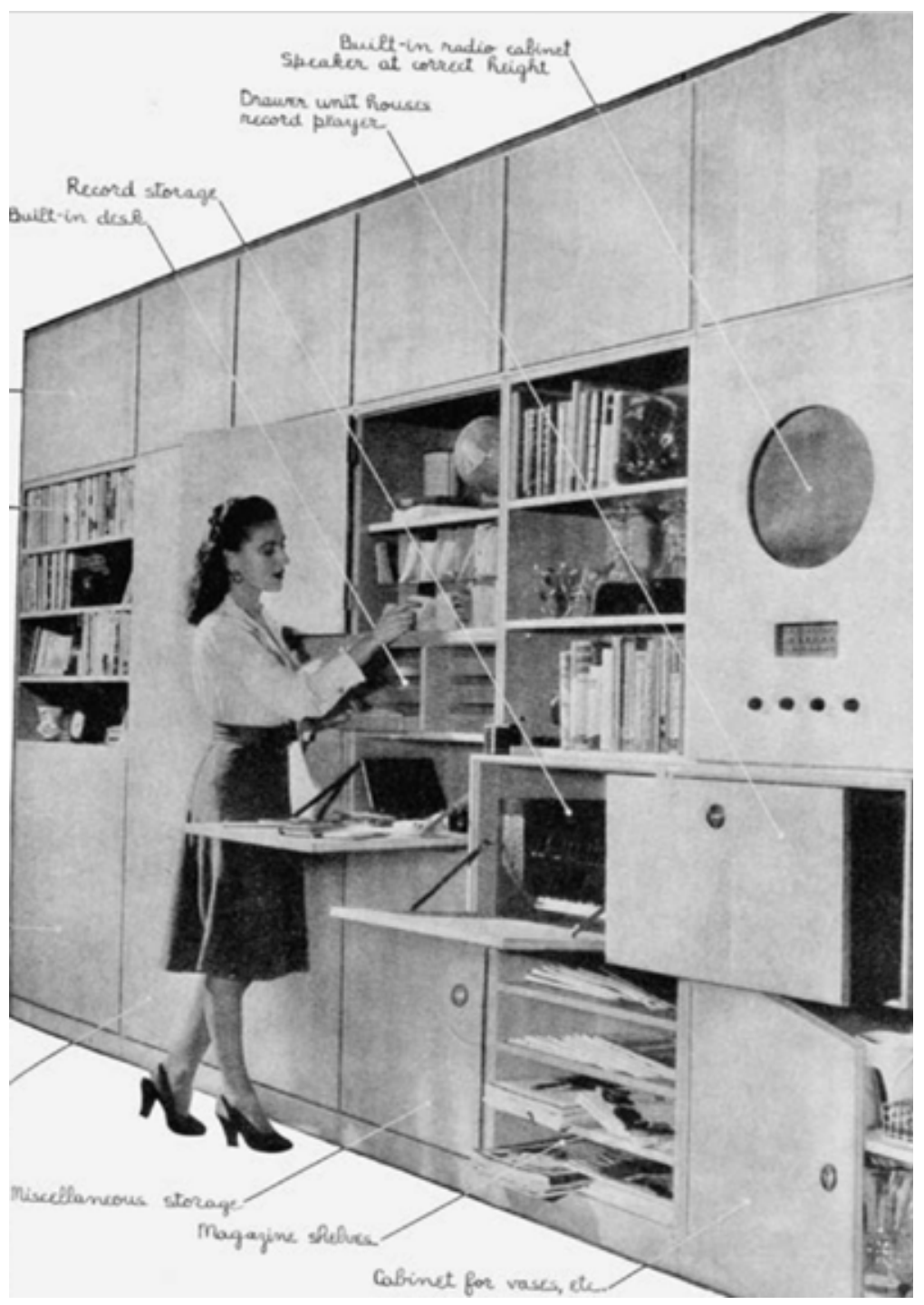

fig. 178: Storagewall, Tomorrow's House, George Nelson and Henry Wright, 1945 
The Storagewall presented a sanitation of domesticity not only in this regard, but also of memory, subjecting the house "as a space of bureaucratic storage," (Spigel, 2012, 570). Optimization is key, and domesticity is represented within a flux of labour and leisure, input and output. "The Storagewall inscribes this shift from memory to storage, from Victorian sentiment to rational modernism," (Spigel, 2012, 571). Decor, considered to be feminine, was eliminated. And productivity, idealized in this conception of house as a well oiled machine, situates queerness aside by default.

The work of Mierle Laderman Ukeles explicitly states the status of maintenance work that takes place in private and public realms. In her "Manifesto for Maintenance Art", Ukeles points a cultural accordance on the status of maintenance work - jobs that pay minimum wage and domestic labour that grants no compensation:

"clean your desk, wash the dishes, clean the floor, wash your clothes, wash your toes, change the baby's diaper, finish the report, correct the typos, mend the fence, keep the customer happy, throw out the stinking garbage, watch out don't put things in your nose, what shall I wear, I have no sox, pay your bills, don't litter, save string, wash your hair, change the sheets, go to the store, I'm out of perfume, say it again - he doesn't understand, seal it again - it leaks, go to work, this art is dusty, clear the table, call him again, flush the toilet, stay young," (Ukeles, 1969).

This manifesto was a proposal for her exhibition "CARE", where exhibition space would be tended to through a constant domestic performance by Ukeles herself: "Now, I will simply do these maintenance everyday things, and flush them up to consciousness, exhibit them, as Art. I will live in the museum [as] I customarily do at home with my husband and my baby, for the duration of the exhibition. (Right? or if you don't want me around at night I would come in every day) and do all these things as public Art activities: 
I will sweep and wax the floors, dust everything, wash the walls (i.e. "floor paintings, dust works, soap-sculpture, wallpaintings") cook, invite people to eat, make agglomerations and dispositions of all functional," (Ukeles, 1969). Material exhibitions would include interviews with various individuals of different classes and occupations on their understanding and relationship to maintenance. The third part of the exhibition would take form in varying materials that indicate an exploitation of resources (polluted water, air and land) brought in single truck loads on a daily basis. This matter would be rehabilitated, purified, damages undone by Ukeles and other maintenance workers. This recontextualization of maintenance work amongst perceptions of maintenance work excavates gender and class relations, publicly exposing realities of invisibilized labour. Karl Marx explains that the objectification of labour as a process where "the product of labour is labour which has been congealed in an object, which has become material," (Mangold, 2011, 74) and estranged from the producer. The object is a material demonstration of labour unseen, "[producing] itself and the worker as a commodity," (Mangold, 2011, 74). The alienation of the worker takes place through the transformation of labour power into an object, but this only applies when there is a object to be seen or experienced. Maintenance is invisible - is it because it is shown subtly through state rather than production of a thing? The divergence of exchange-value (subjective) from use-value (objective) further obscures the value of labour (Mangold, 2011). In a similar manner, the invisibilization of labour through the use of such things escalates such a division, except now values bear no representation, pushing the worker into further abstraction. Nelson's Storagewall reciprocated and convoluted labour through use, additional to the formation of itself and objects contained. "Rendering artifacts invisible has a problematic underside that creates occult trajectories for technology that hide not only ugly forms but also the entire social and political apparatus that supports the technology," (Spigel, 2012, 573). 
stored in house

fig 179: Eames

Storage

Unit (ESU)

Bookcase,

Charles Eames

and Ray

Eames, 1949

141

fig. 180: Eames-

designed

room, Detroit

Institute of Arts,

An Exhibition

for Modern

Living. 1949

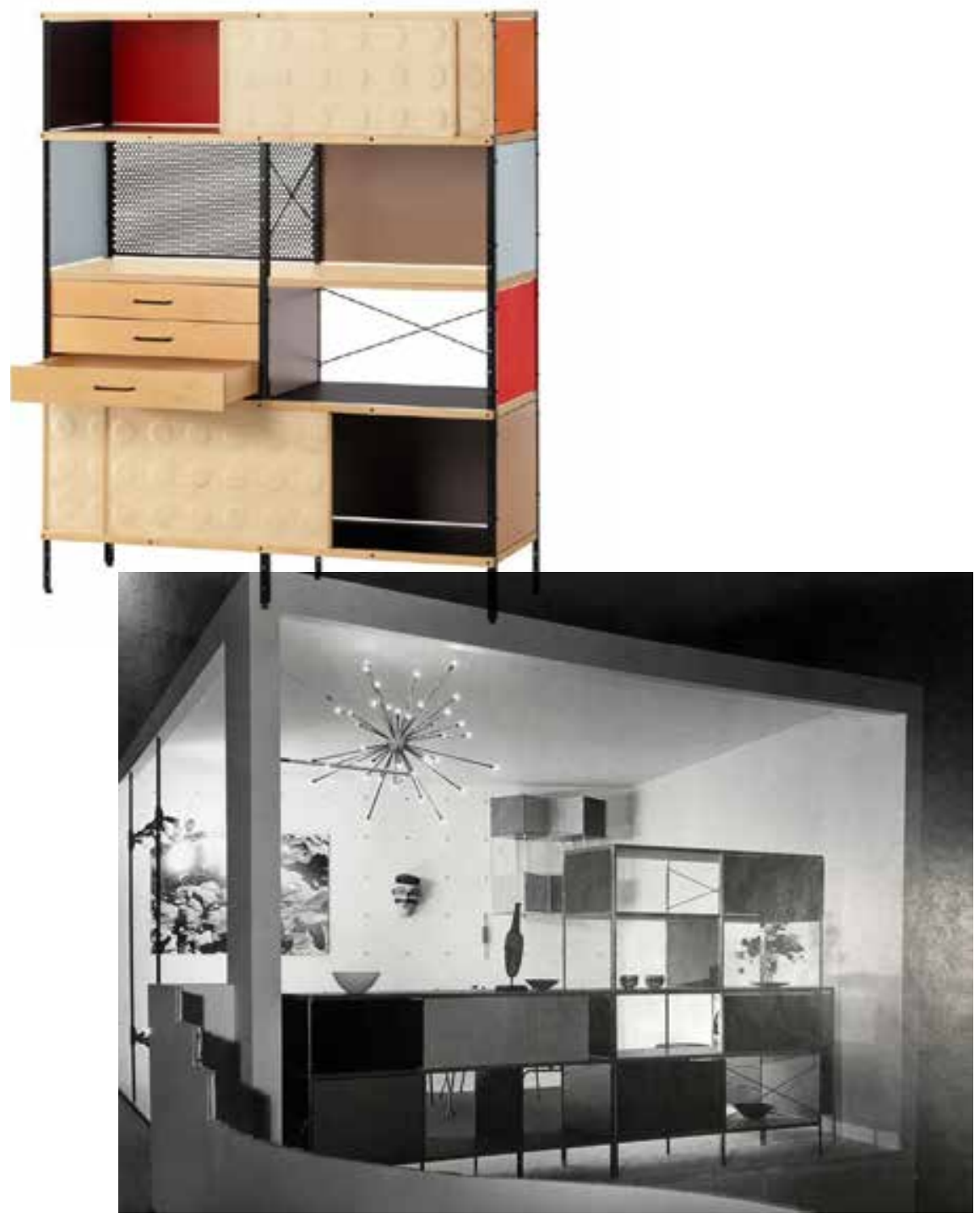

Charles and Ray Eames looked to the storage wall or storage unit as an architectural form for expression, to inspire creativity through careful curation and an offer of a kit of parts that transformed how units were populated and used. They wrote of their storage wall design productions as modular systems that allowed for play, allowing for a multitude of arrangements of collected objects as signifiers of culture and wealth, and opaque cabinets and drawers to transform space through "an antiminimal approach," 
(Obniski, 2018, 30). Amongst the slew of objects displayed in imagery of their storage walls are cultural works, some of which collected by the Eameses, which paralleled the suggested acquisition of cultural objects while on vacation in home and lifestyle (!) magazines from that period, not unlike design-related media published in the present day. An article in Life magazine reads, "to feed an insatiable interest in the looks of things, [Charles Eames] and his wife take frequent sleeping-bag trips into the surrounding seaside and desert areas collecting weeds, rocks and driftwood whose appearance they want to study. They decorate their home with Chinese fans, Indian blankets and golden eggs for the same reason," (Obniski, 2018, 30). The extraction that takes place in the aesthetic study of cultural objects, stripped of contextual use or history, depicts a narrative of designadministered colonisation. This project of modernism, the Eames storage walls, perpetuated the Orientalist gaze,

fig. 181:

Shelving system designed by

Alexander Girard for the

Alcoa Forecast

campaign,

Charles

Eames, 1957

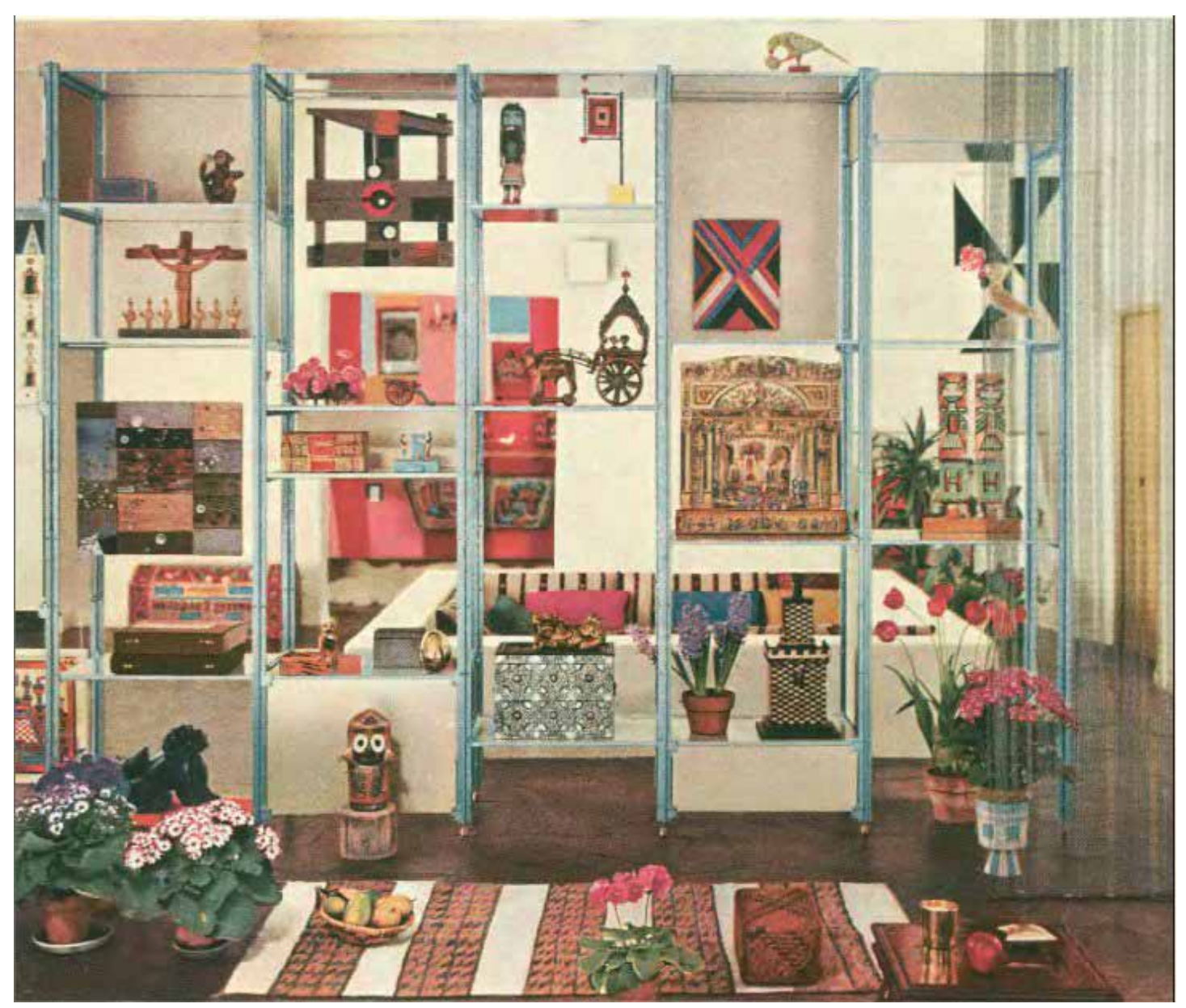


fig. 182: house 2 plan, 1:200 situating the East, or the non-Western world, as places of white consumption, and directing the use of cultural objects as ornamentation, as exotic keepsakes that let visitors of the home know how well-travelled and cultured the hosts are. The resulting network of cultural objects in privileged Western homes decontextualized their origins and blurred distinctions of culture.

Alexander Girard, who worked alongside the Eameses, also had interests in the display of objects, prioritizing the decorative possibilities over the function of storage. "He acknowledged his interest in the idea of souvenirs and the construction of memory through these objects, writing that 'in most of us there is a tendency to try to halt time, to relive the past through the accumulation of souvenirs,"' (Obniski, 2018, 35). The combination of display within storage walls that concealed some of its volume intentionally forced a discrimination of objects, a filter that

143

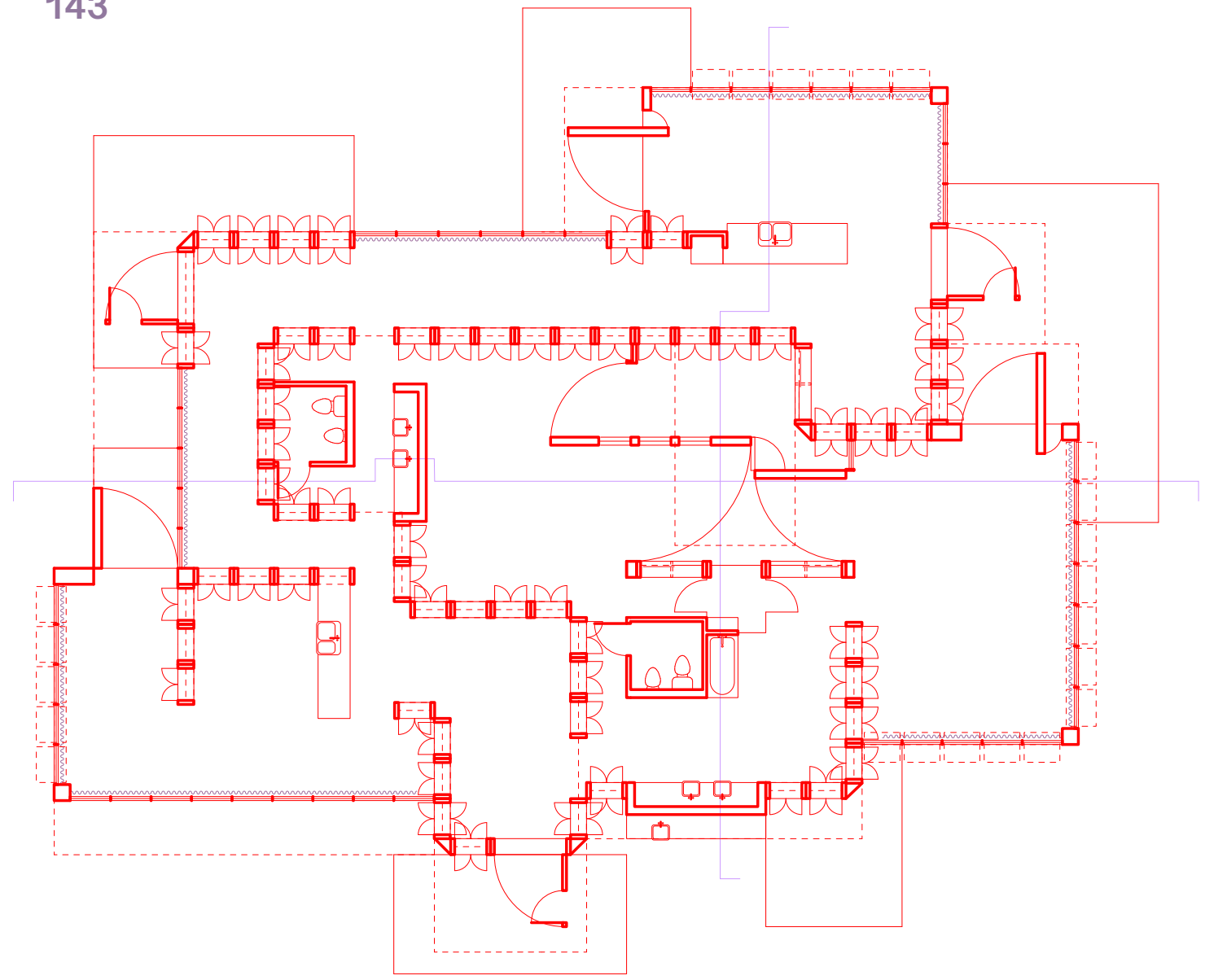


forced consideration of what is in and what is out. He stated, "what folly to gather objects because the sight of them pleases us, because the contemplation of them enriches us, or because they stimulate recollection of good times and places - and then to conceal them," (Obniski, 2018, 38). Through words published in magazines like House \& Garden, he encouraged homemakers (women to be specific, as they were viewed to be the only homemakers) to test arrangements within the wall, in turn learning about and playing with scale, proportions, colour and material. It is interesting to note that despite the prevalence of storage walls with nooks for display, "non-functional decoration was marginalized as whimsical and unnecessary in much of the elite design discourse of the period," (Obniski, 2018, 38).

I turn to the back of house to compose a queer assemblage for living. The prominence of objects in the present day and their inherited wealth becomes a spatial driver. Objects have an ability to form networks of exchange, and their arrangements can convey an infinite number of intelligibilities. The architectural means by which the storage, display and use of objects are facilitated requires a reimagining of existing norms and conventions. Spaces or functions pushed to the depths of home are pulled back into the foreground to subvert the normative procession of space. The culmination of ideas presented up to this point are invested in the design of House 2.

In simplest terms, the house plays out a scenario: what if instead of entering homes through living rooms, dining halls, offices, even bedrooms (studio apartments), hybrids - rooms that are flaunted more publicly when we physically move through space - we are confronted with what are and have been considered to be the depths of a home - the closets, the washrooms or water closets, the laundry rooms, the kitchens? This move is much in line with projections 
of space in the digital realm and entertainment: hoarders, closet tours and makeovers, hair dyeing tutorials in the shower, bath product hauls, skincare routines, lingerie tryons, solo eating shows, laundry hacks, 24 hour live streams. No inch of the home is left undisturbed or unrepresented in the internet of things when access to the internet is nearly ubiquitous. The online has been transformed through its provision of an open forum for practically anything, and what was deemed personal and furtive is not so much in this growing ease with respect to online communication and our distinctions of what composes domestic life.

Upon official entry of the house, through three possible formal doorways, there is a confrontation of things that have come to the foreground, spaces that historically and presently have been condemned to monogamously (see page 68) serve everything else in a veiled state. They have also been associated with the occupation of women, servants, and the anonymous, shameful acts or something behind-the-scenes. These auxiliary spaces or back of house - washrooms, closets, kitchens, laundry rooms, most of which happen to require plumbing - form the spaces of transition, that must be traversed to penetrate deeper into the home. The doorway itself is nestled into a stretched out

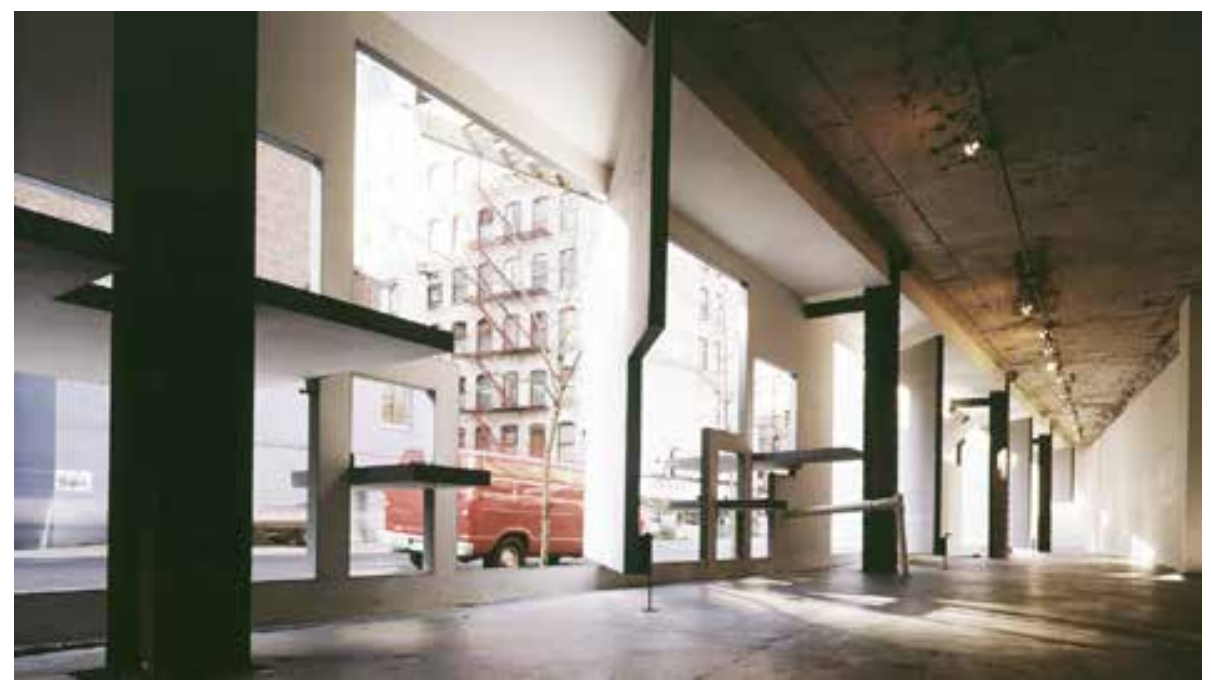



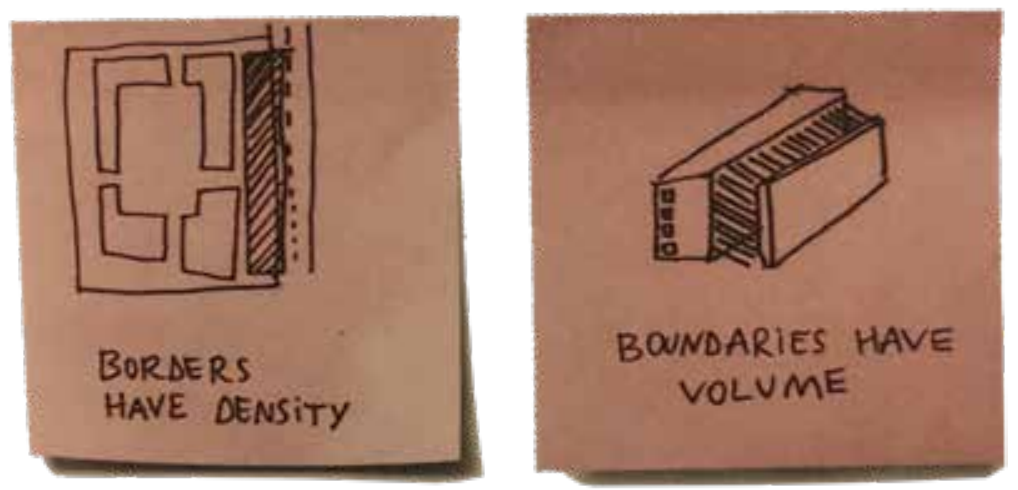

closet unit, a door in a door to support the flow of things large and small. Orientation considered within the house is queered through entry. The straight lines registered in a conventional procession of space of the home cannot be followed.

Locations where cleansing, sanitation, disclosure of physical bodies, objects, and sexuality take place become the key points of entry to other spaces, and flow into one another. All other space contained in the precinct of the home, where other activities of living take place, flow between indoor and outdoor, and are able to change in character and volume through doors disguised as walls. These walls, the most opaque and obtrusive vertical markers of space, dance/swing from their origin points into other oblique arrangements that are sheltered and formally acknowledged through extensions of the roof that terminate beyond implied perimeters of the formal interior. Here, solid walls allow the sizes of rooms to swell or contract.

In Common Spaces in Housing Units, barriers and boundaries are both defined as markers of spaces between a here and a there (Montiel, 2018). A barrier is defined as a border, something with density, while a boundary as a sheltered or roofed space, something with volume (see fig. 184). While these definitions are in relation to the separation of public and private ownerships of space, the distinction of density versus volume can be applied to something more fig. 184: sticky note sketches on page 33, Untitled, Rozana Montiel, Common Spaces in Housing Units, 2018

\section{6}

facing page

fig. 183: when segments of vertical planes dance, their obliqueness and absence from their origin point blur the distinction between border and boundary, Storefront for Art and Architecture by Steven Holl Architects and Vito Acconci, , Paul Warchol, 1993 

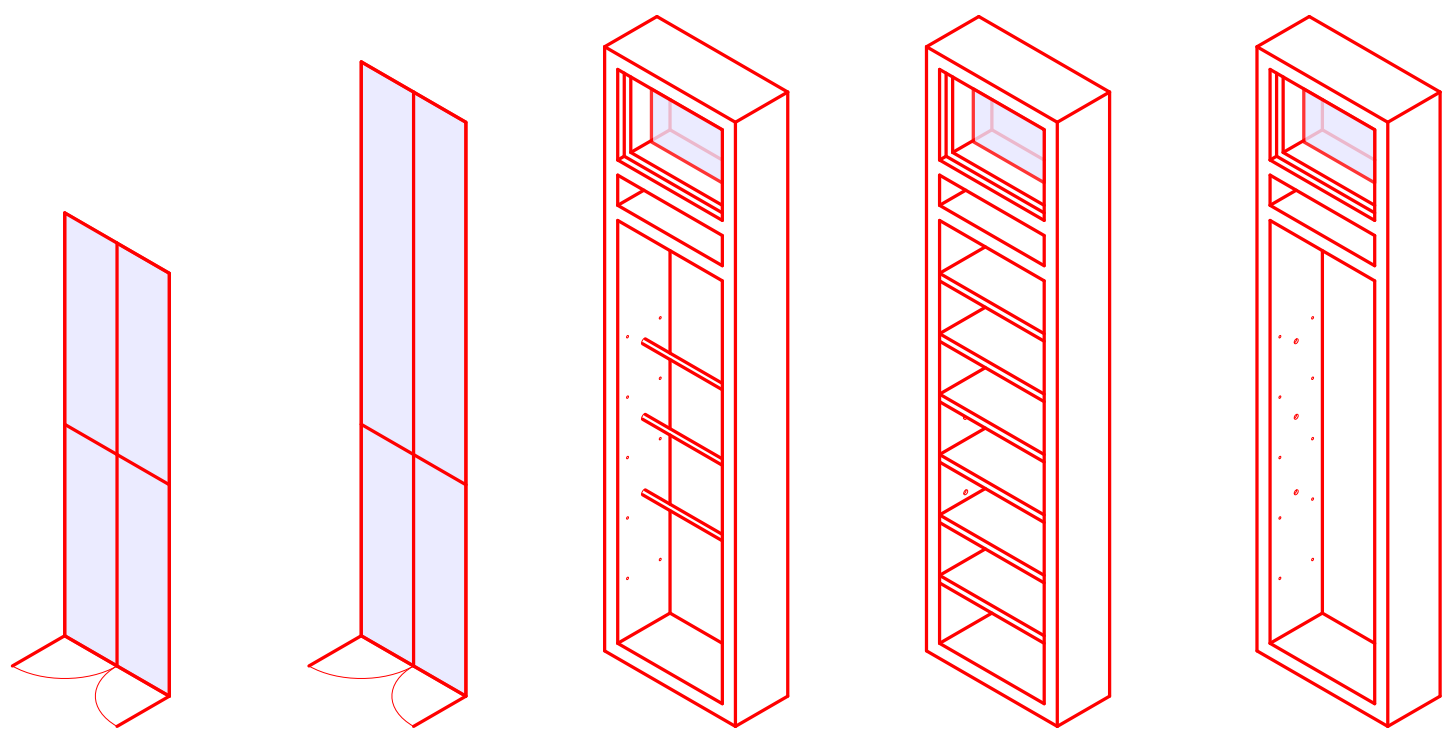

or less specific. When vertical planes that mark edges of a space become habitable, they offer a possibly shared volume between here and there that blurs the definedness of a space's edge. The closet unit, unlike the typical built-in closet, is not simply a dead end auxiliary space that serves

(from left

to right)

fig. 185: set of closet doors for rooms with low roof

fig. 186: set of closet doors with higher roof

fig. 187: closet unit with possible rod positions

fig.188: closet unit with possible shelf positions

fig. 189: bare closet unit monofunctionally. Used in place of walls, it acknowledges each space it sections off as it is backless. The closet space, where the depth of the units are unobstructed from reach by doors, serve as a suggestive passageway, so to walk into the house means to be plunged into the closet. Doors, glazed and transparent, are located in the 'rooms'. These boundaries between space suggest a rejection of modesty and consistent publicity of things through the open display of possessions. Passageways snake around other 'rooms' (see fig. 200-202), architecturally read as separate through a repetition of parts, but ultimately their respective footprints ease into one another if that is what is asked of the house. The same could be said about the relationship between interior and exterior. When opaque walls assume oblique arrangements, they blend adjacencies previously quarantined from one another through shared surfaces.

Objects and building surfaces combine to serve as filtration devices. The planes of glass that enclose objects are not really the wall, nor are the vertical supports of each closet 

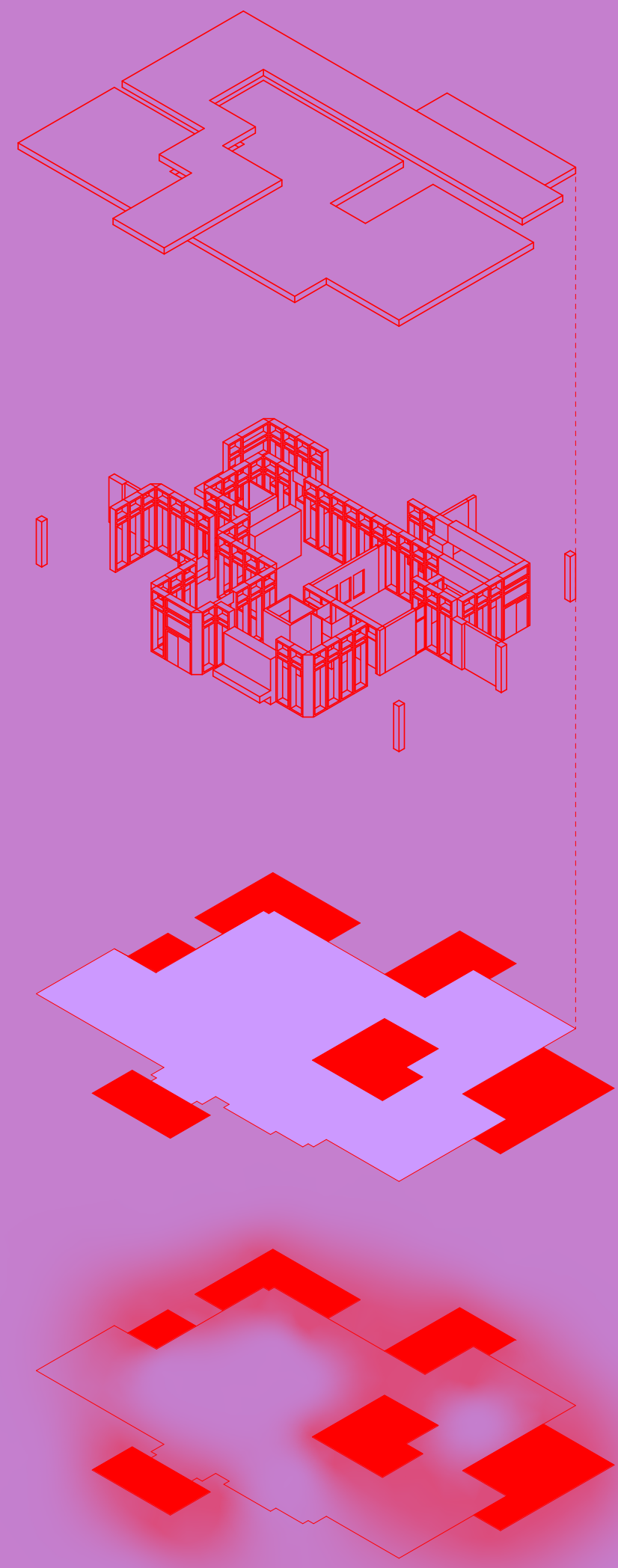
stored in house

fig. 191: layers of inflection, from top to bottom:

mediation

between ground and sky

border that

support a

mobility in

occupation

entries and

exits that form

the house as a

porous structure

architectural

precint of the

house, ground

and fence
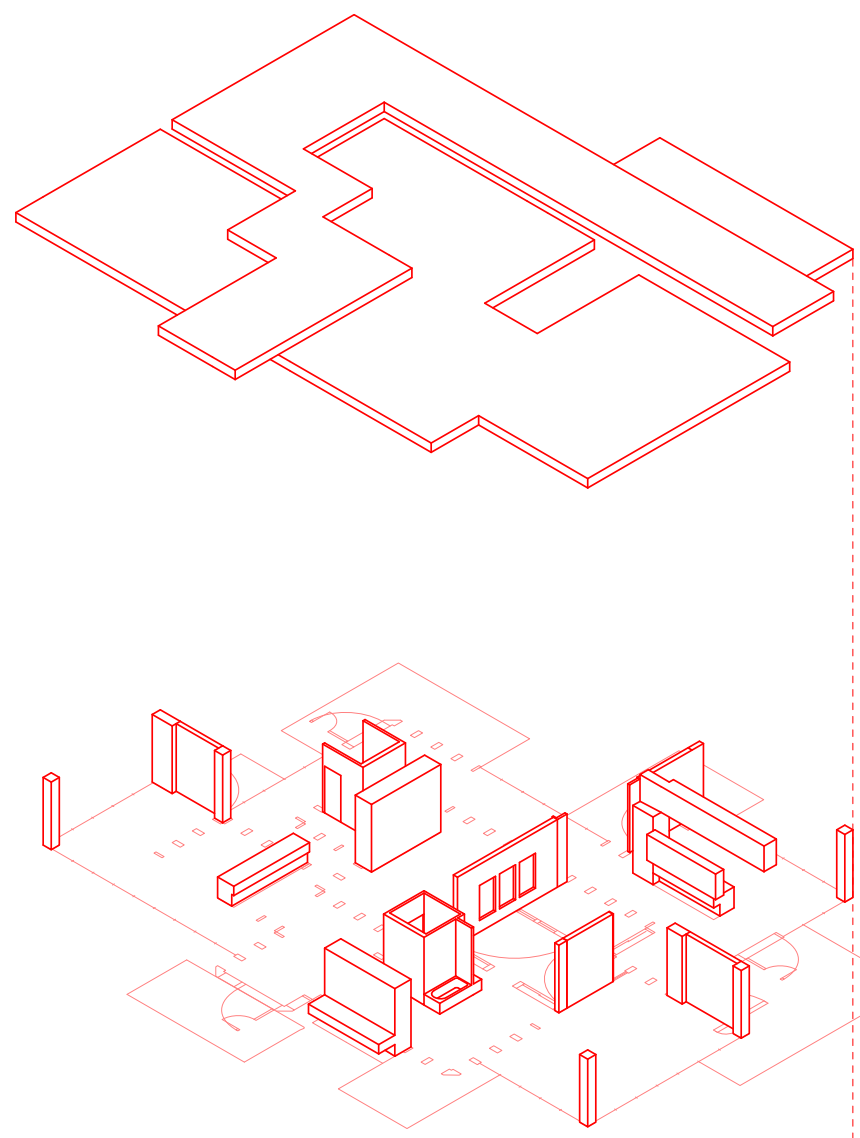

149
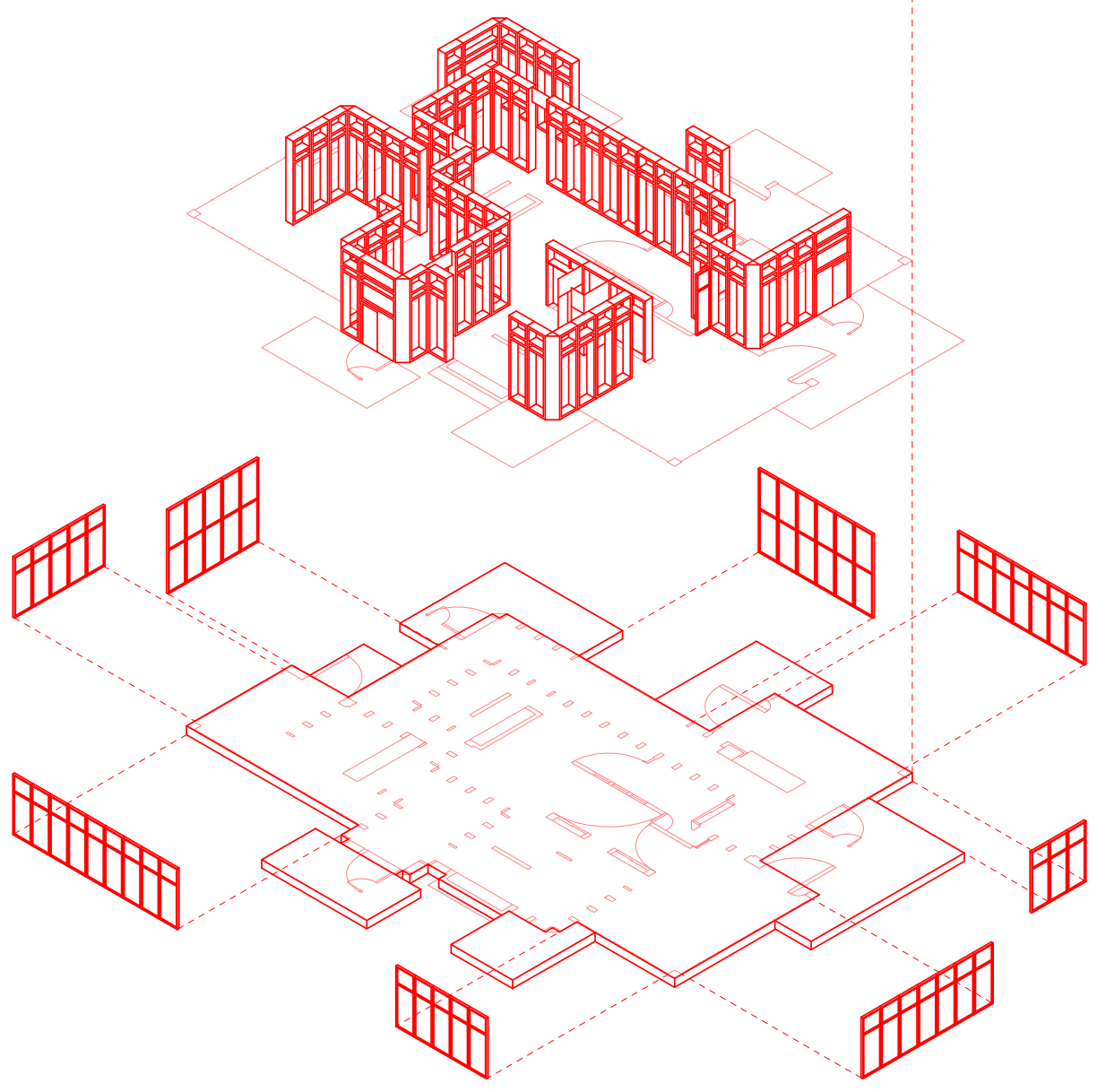
unit. Separation is made through possessions and their placement, through the mobility of closet doors in swing. Filters are defined, negotiated by the individuals who reside here, legible in sight, displayed and accounted for.

Without the presence of stuff, shelves, rods, and objects, the closet unit presents itself throughout the house either in repetition as a series of slender deep columns/mullions or independently as a frame for a door/window. When doors are open and units are populated, intimate nooks appear. When doors are open or removed and units are cleared, new passageways are formed. The boundaries of rooms are highly flexible despite their status as load-bearing elements, as they allow for things of different scales to permeate. The management of objects and placements of horizontal components amongst the units enables individuals to construct and adjust solid and void through objects, through accumulations of material things that have the added purpose to them of controlling levels of intimacy and privacy is at the individual's discretion. However, while accumulations of objects can provide a visual barrier, they betray and give indication to the occupation that takes place in one or both spatial adjacencies. Things stored are not just objects but signifiers of the inner workings of domesticity - the labours, leisures, relations - and they are explicitly displayed from inside and out, establishing an accountability, contrary to invisible design solutions like the ones proposed in Nelson's Storagewall.

They give agency to those who occupy these spaces through the choice of population. Ultimately, the constructedness of the house and its inflictions and arrangements can be tested and dissolved. Closet units can hold shelves and rods that hold objects to transform into something much more porous than an opaque wall, but they can also be cleared, with doors left on or taken away, to extend and newly define space that traverses vertical barriers. While suggesting ways in which to move through the site, House 2 restricts very 
little, supporting desire lines (or deviations from determined paths) and challenges the necessity of constructedness of the house altogether. The location of closet space at the perimeters of the house undermine the function of the formality of the three large doors as the units cluster around them - conflusion at the edges of architecturally defined space. The concept of entry is blurred through the disruption in typical formalities of traversing space. The flatness of the house's floors are framed as near seamless blends of horizontal planes, permitting a very fluid surface for every body to occupy, rather than the more common shift from an outer 'ground' level to the elevated precincts of the house (see fig. 194-195). Hierarchy formed through changes in level are minimized. Figure 191 organizes the constituents of the house based on how they inflect, bringing to question how roofs and walls and closets and counters and windows and floors come together to form something highly fluid.

The perspectives are collages of objects cut out from the works listed on the following pages (see fig. 203-205), some of which participate in queer narratives, overlaid onto a simplified illustration of spaces within the home. The contrast between the richness in detail, texture, colour, and form of the cutouts on the minimally accentuated planes of the home give weight to objects and occupations of space rather than the parts that come together to form the edges of space. The architecture is focused on performance, the framing of spaces through repetition. Once submerged into the depths of the house, every line of vision presents scenes of life through frames - closet frame, door frames, window frames. Larger obstructions (opaque stretches of wall) can be manipulated to move in and out of the way. Through a filter of objects that populate crevices of the closet, scenes of life populate the open pores, and the layering of objects, bodies and acts bring these visual planes of stuff to life. The background comes to the foreground through its animation in between stillness. 
The occupation of the room is defined by the habitants. Spaces are intentionally left open to one another so that alternate modes of cohabitation can take place. "Instead of being organized as an autonomous unit, housing must be conceived as a composition of equal private spaces organized in relation to shared collective spaces. Instead of being the quintessential symbol of private property, the house can be rethought as a system of collective property," (Aureli and Tattara, 2015).

Queerness lies in the composition of spaces, distorted elements of architecture, transparency of planes, the ability to live beyond the constructedness of building parts, sparse placement of doors in formal doorways, and solid expansive planes that dance. The house exemplifies an aversion to binaries, of inside or outside, of something that is or is not, of here and there. The house is a site of display, using all housed objects in the construction of the home. Objects become explicit, less buried - signs, symbols, tools, details, decors, habits The stripped version of the house (fig. 193), a reduction that rids of elements that neither structurally support the house nor provide utilities, presents a rather porous structure - a monstrosity of sprawling display cabinets that flaunt all things contained. House 2 blurs privacy and publicity, serving and served, through material means that interrogate cultural constructions that practice inextricable marginalization and burden some bodies but not others. House 2 is an imposition of traditional domestic hierarchies through the overlay of other hierarchies in order to neutralize distributions of power.

The following pages contain images of House 2. 
stored in house

fig. 192: plan, 1:100

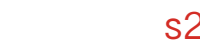

153

s2
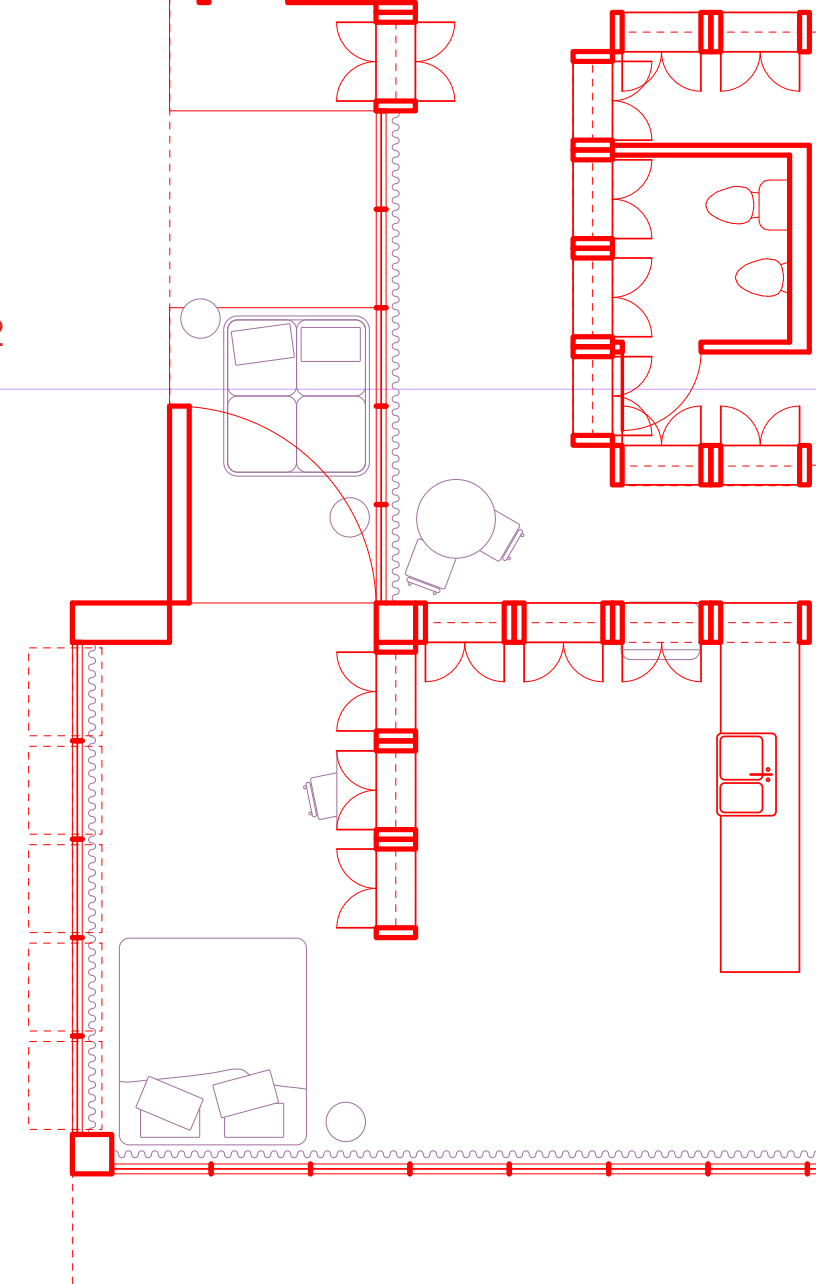

$\mathbb{m}, \mathbb{m}, \mathbb{m}, \mathbb{m}$
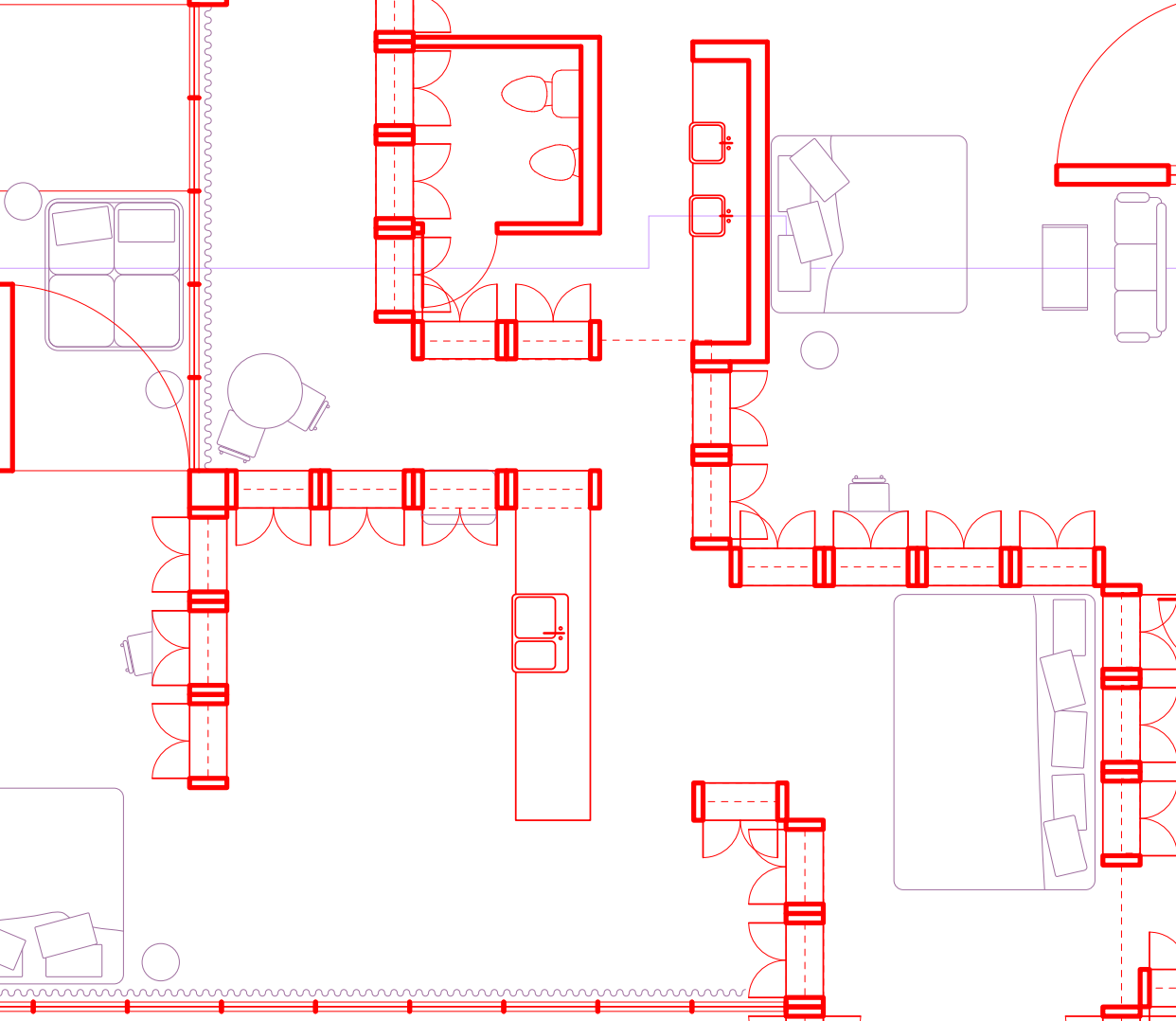

$\longrightarrow$

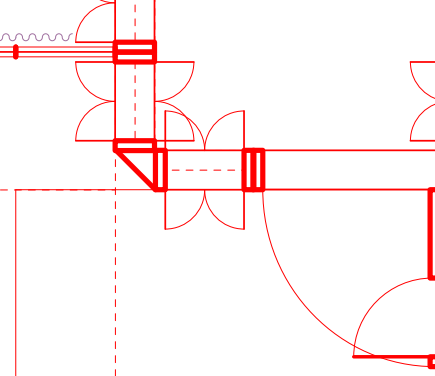




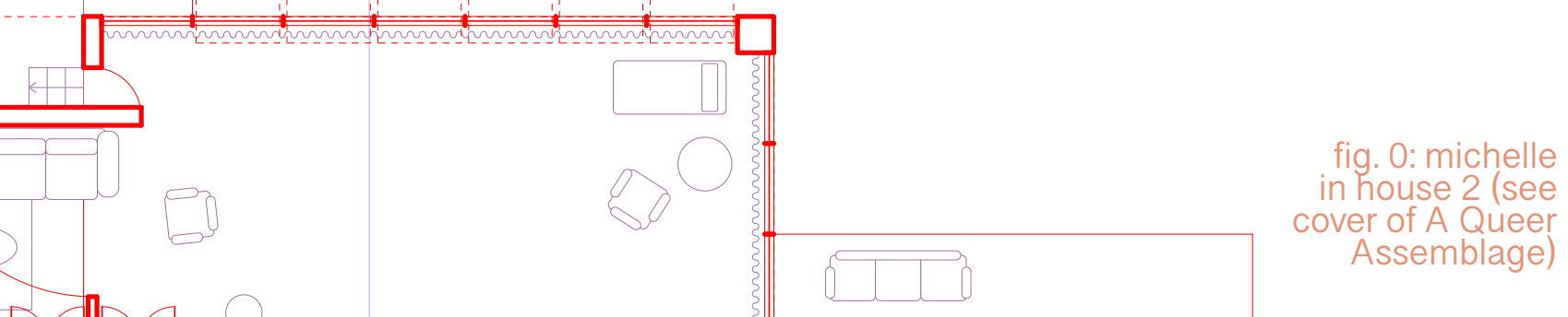

$\frac{000}{4 n_{0}}$

III) mand
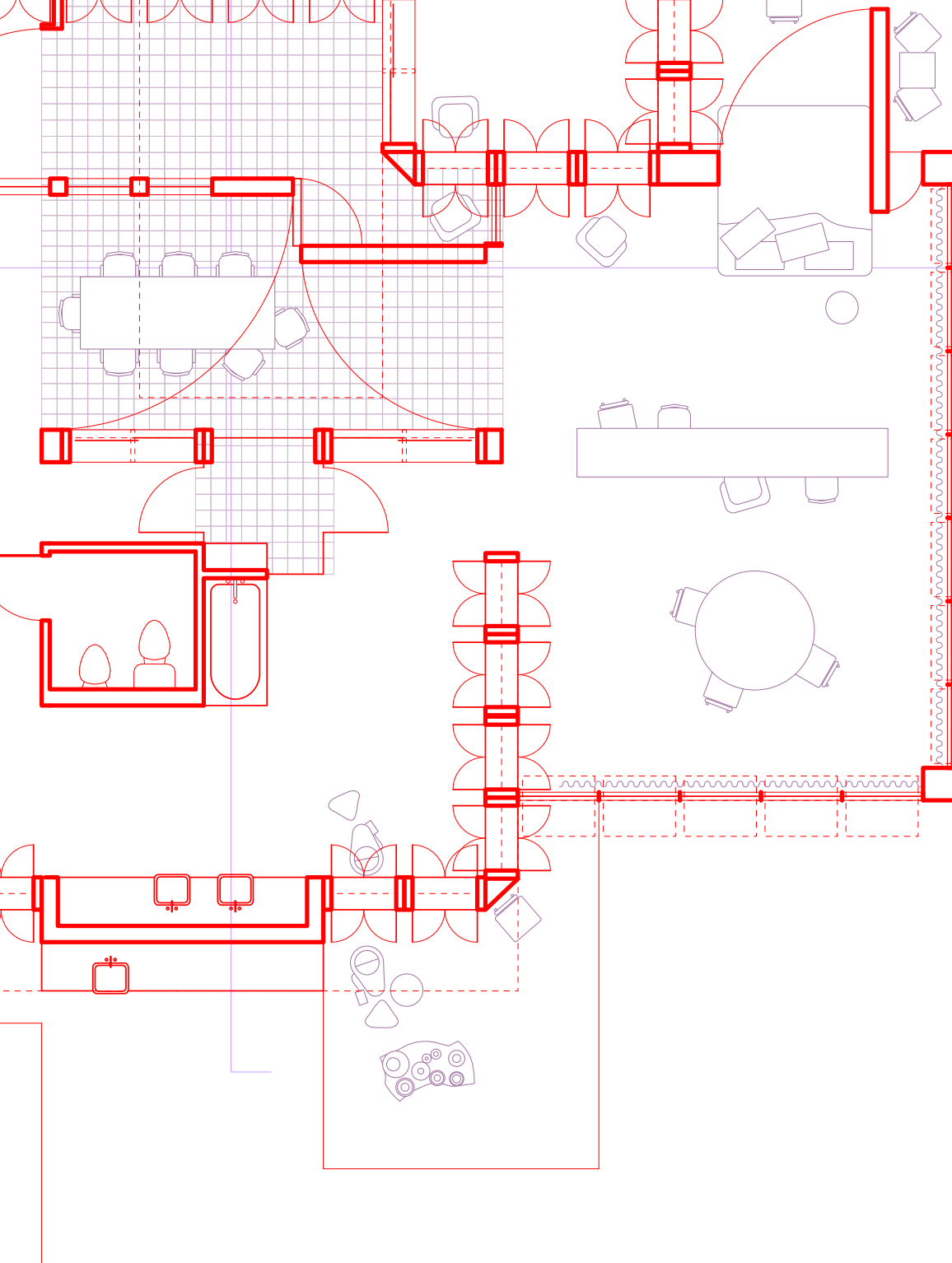

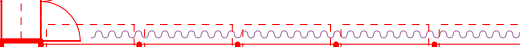
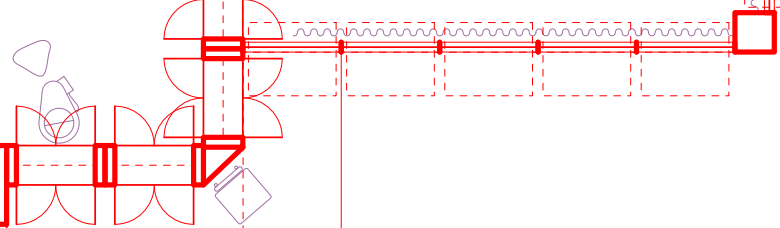

凹

\%๐ 
stored in house

fig. 193: stripped

plan, 1:100

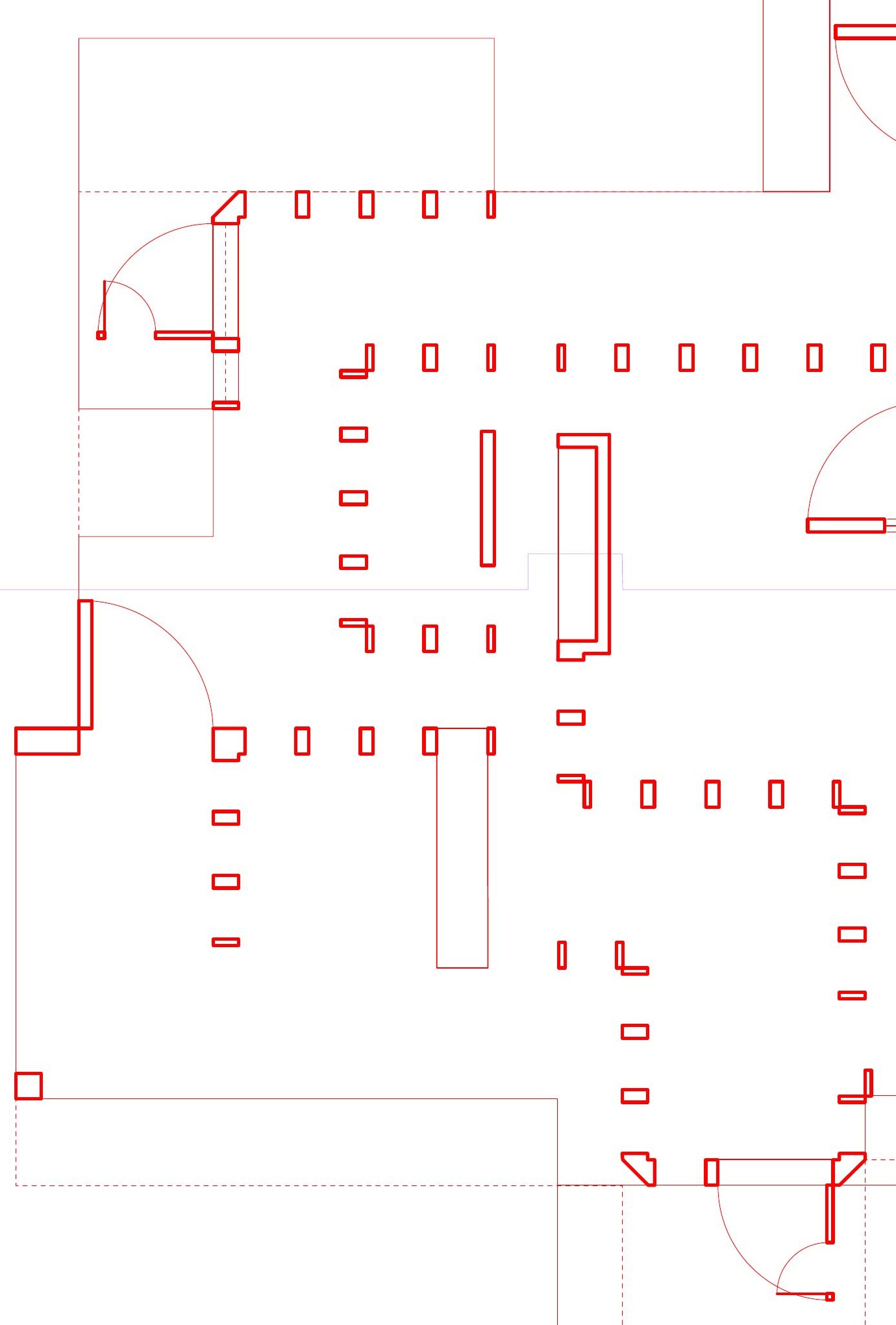

155 


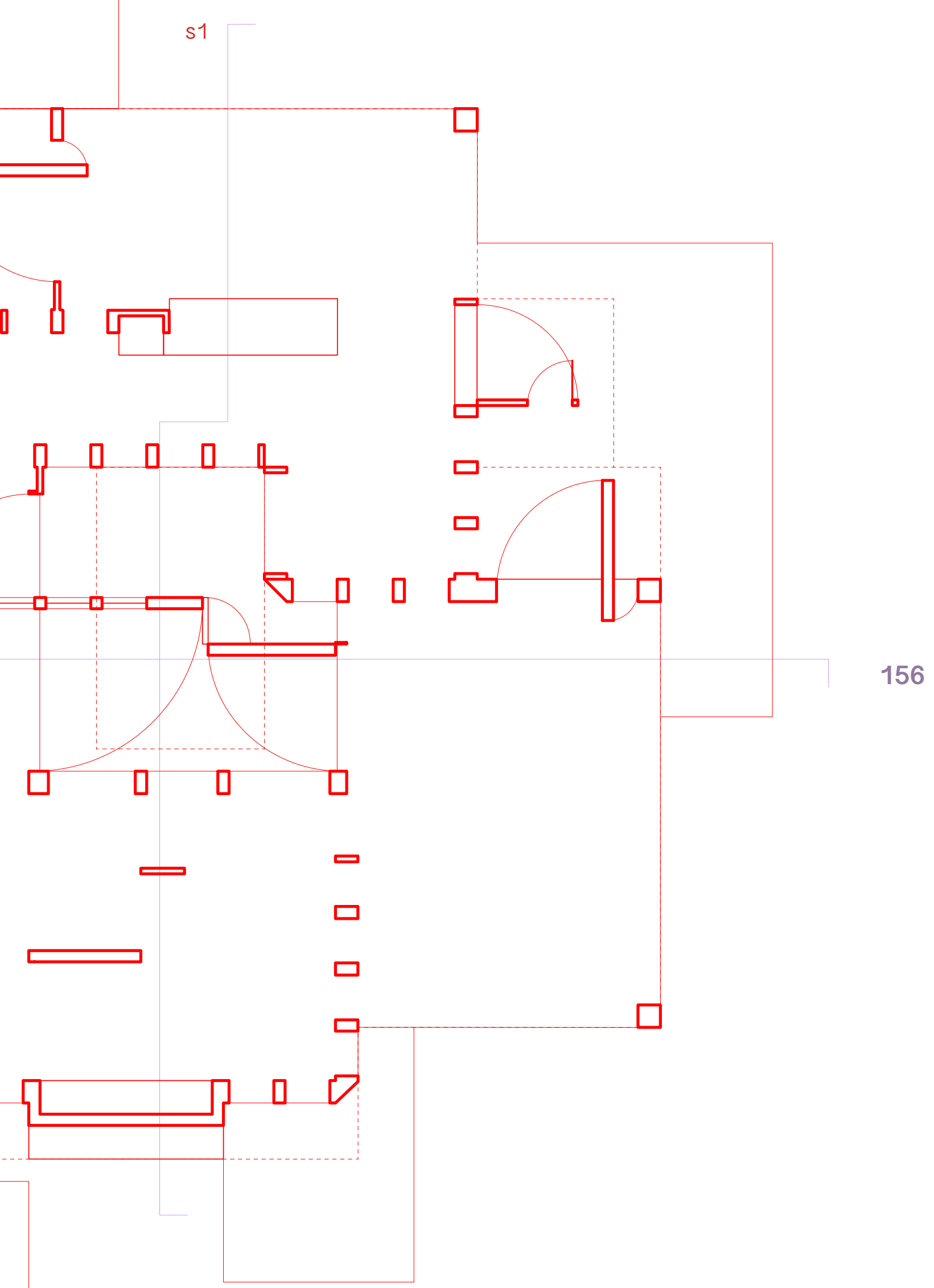


stored in house

fig. 194: section

1, $1: 100$

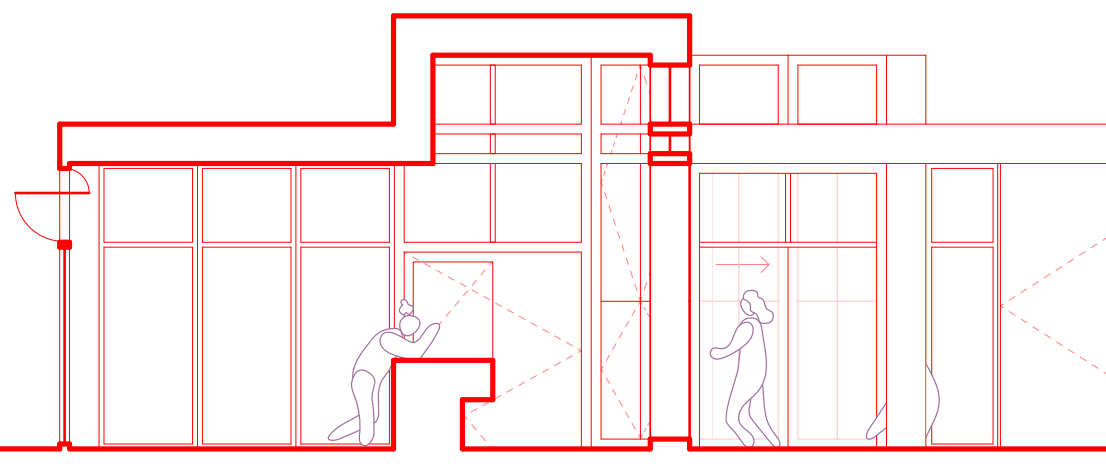

157

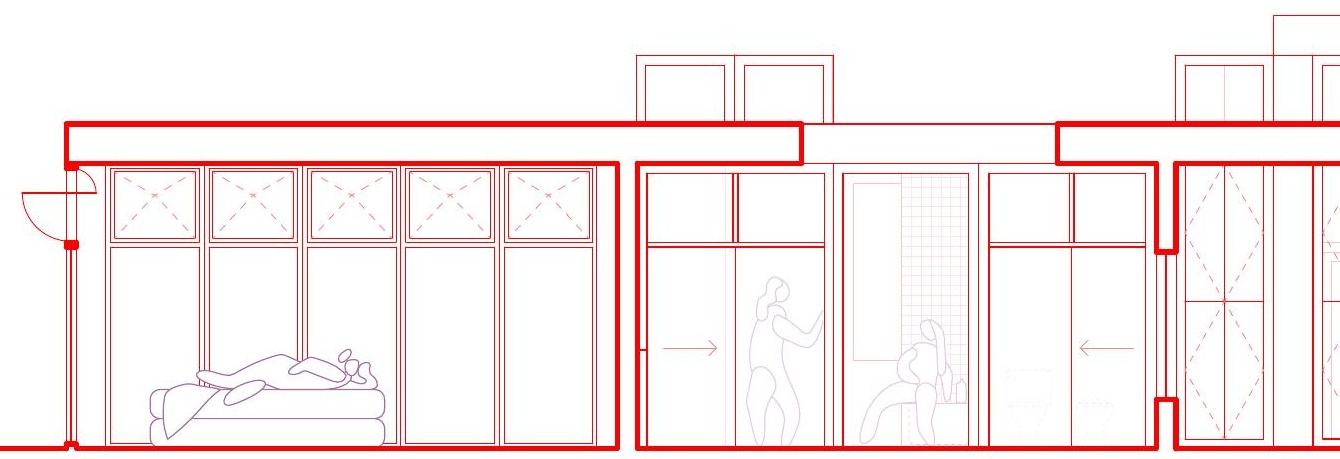



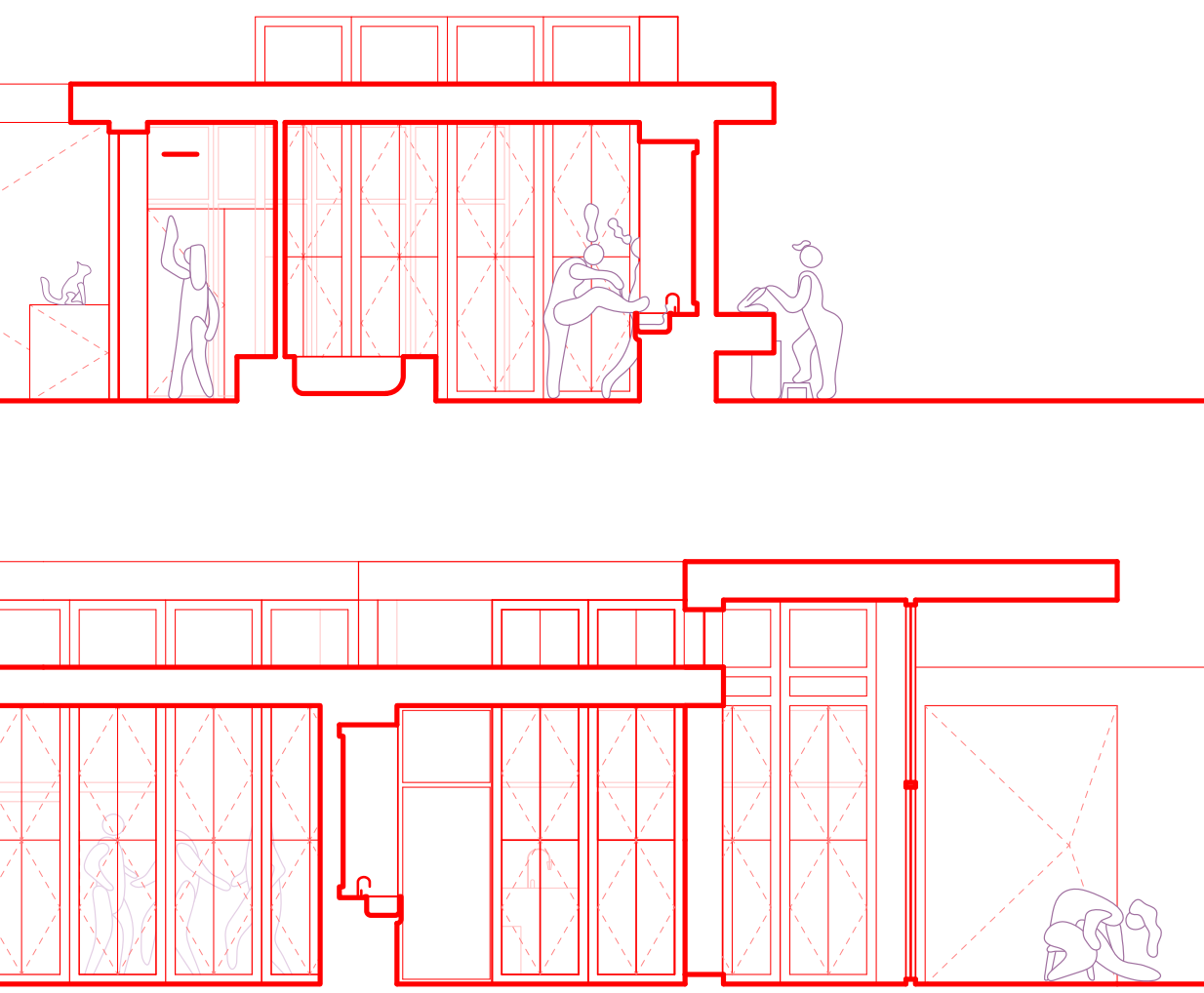

fig. 195: section
$2,1: 100$ 
stored in house
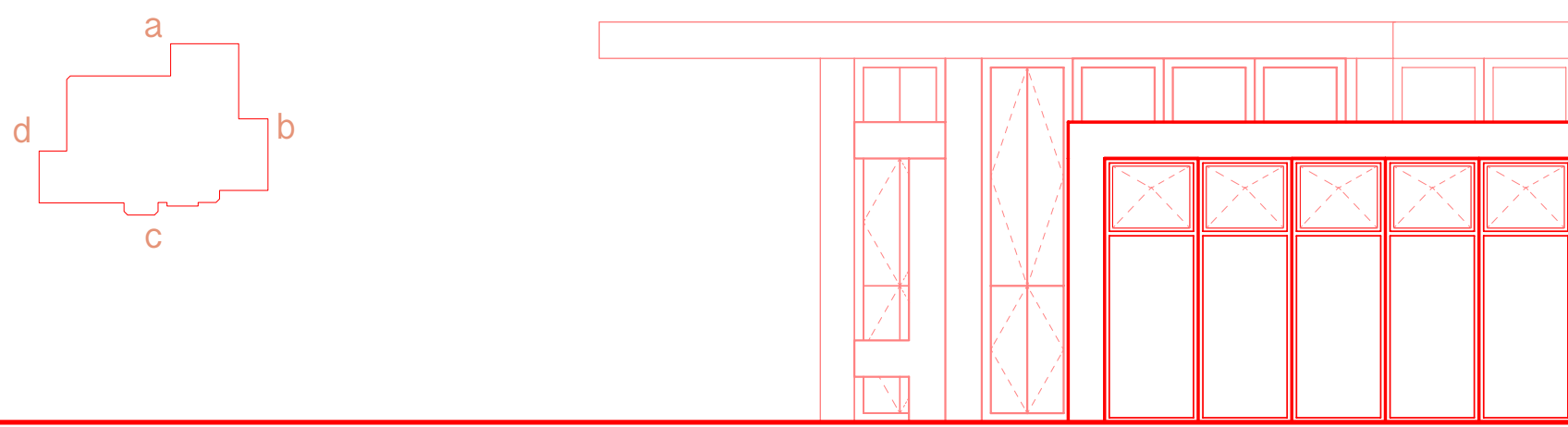

fig. 197 elevation

c, 1:100

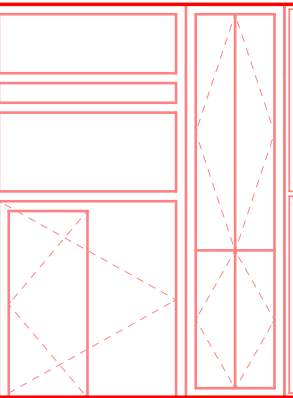

159

fig. 199: elevation d, 1:100

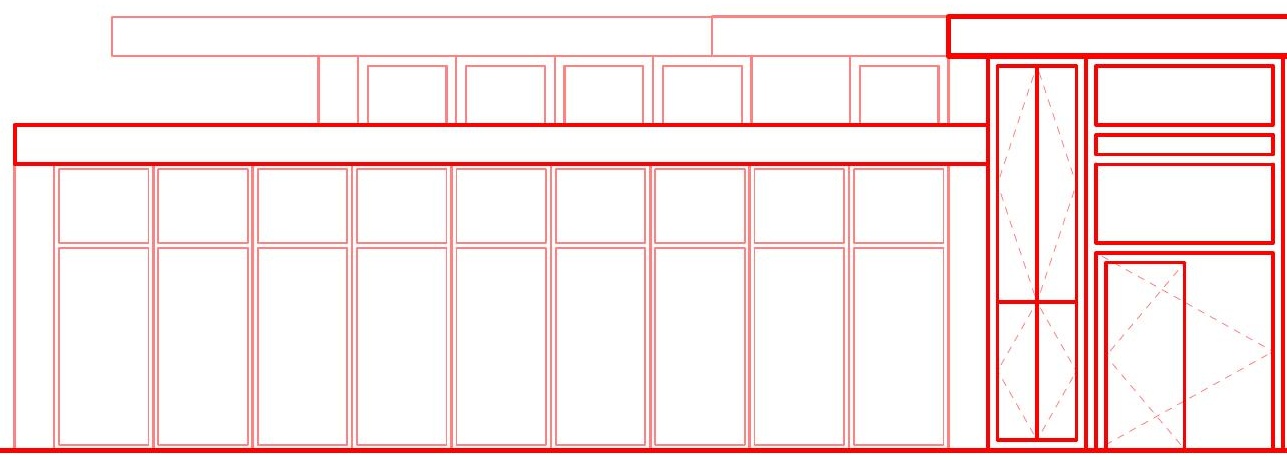




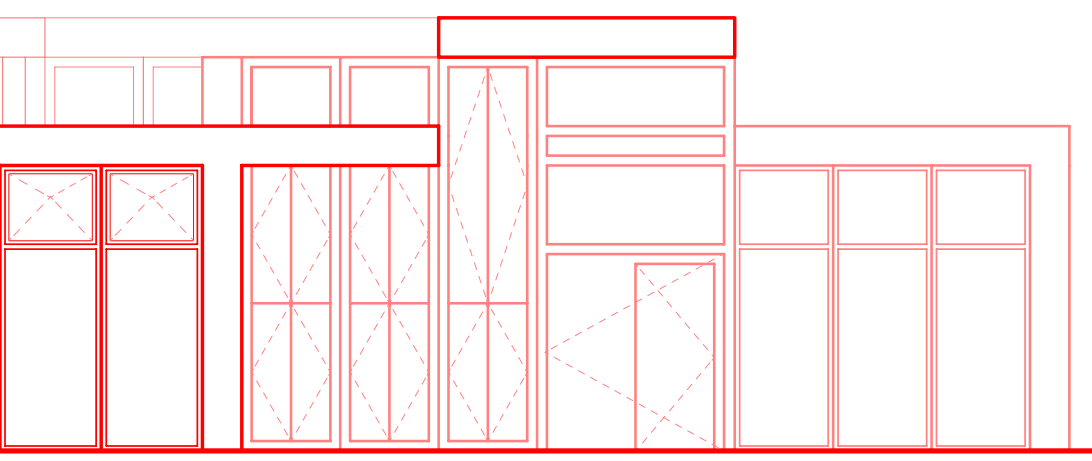

fig. 196: elevation

a, 1:100

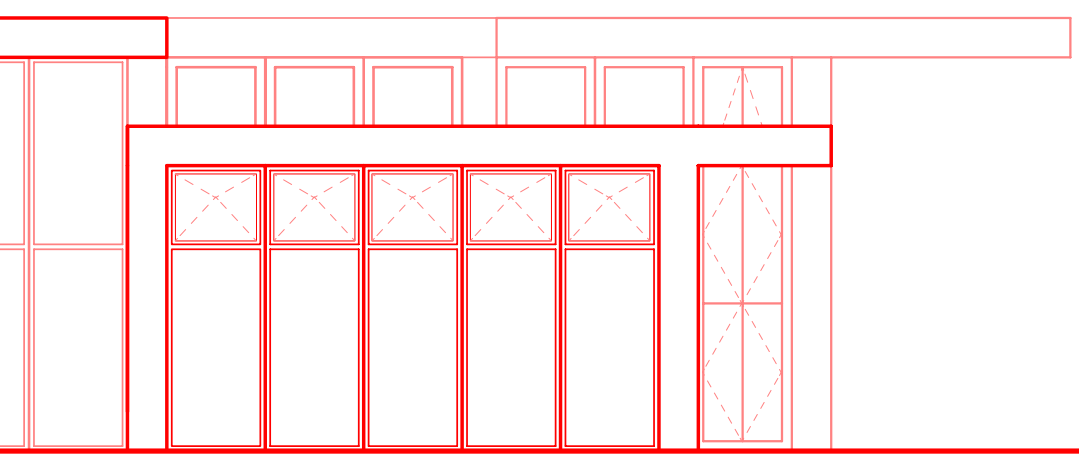

160

fig. 198: elevation

b, 1:100

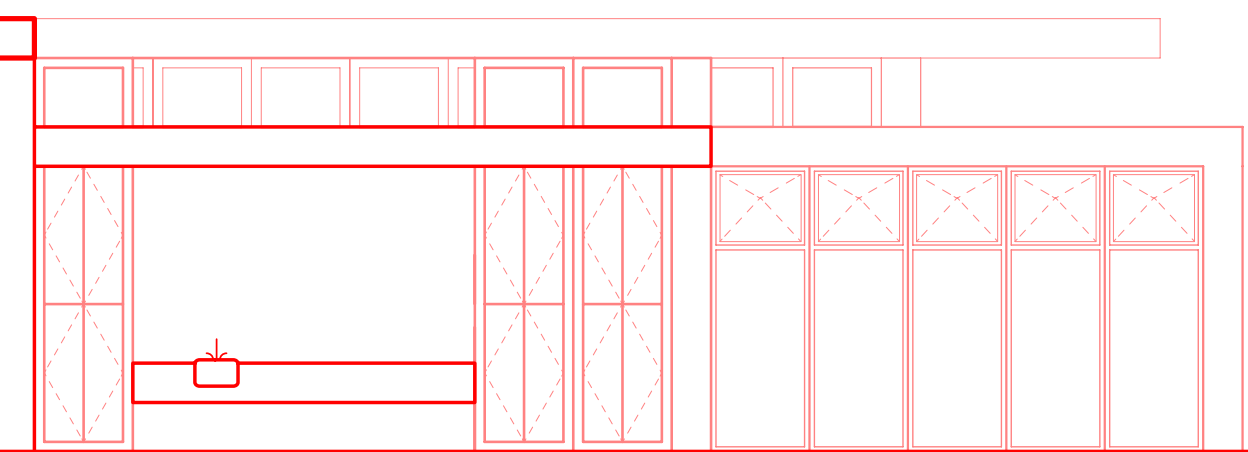


stored in house

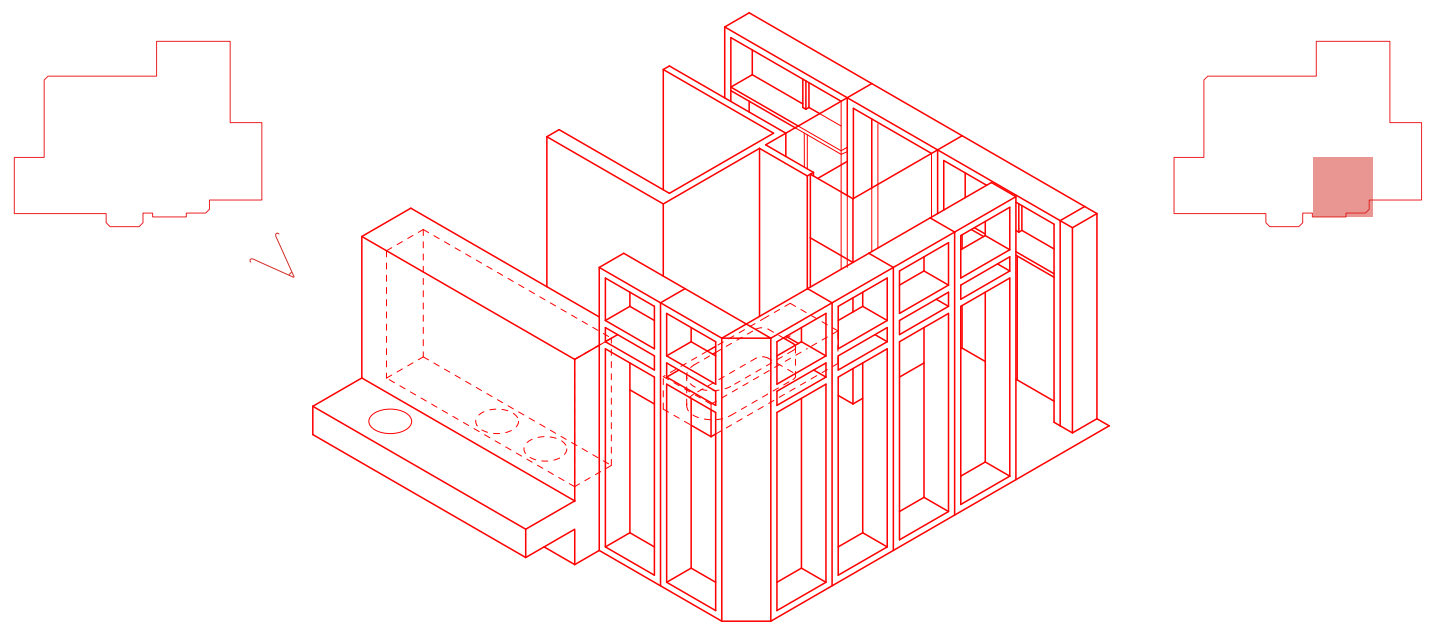

161
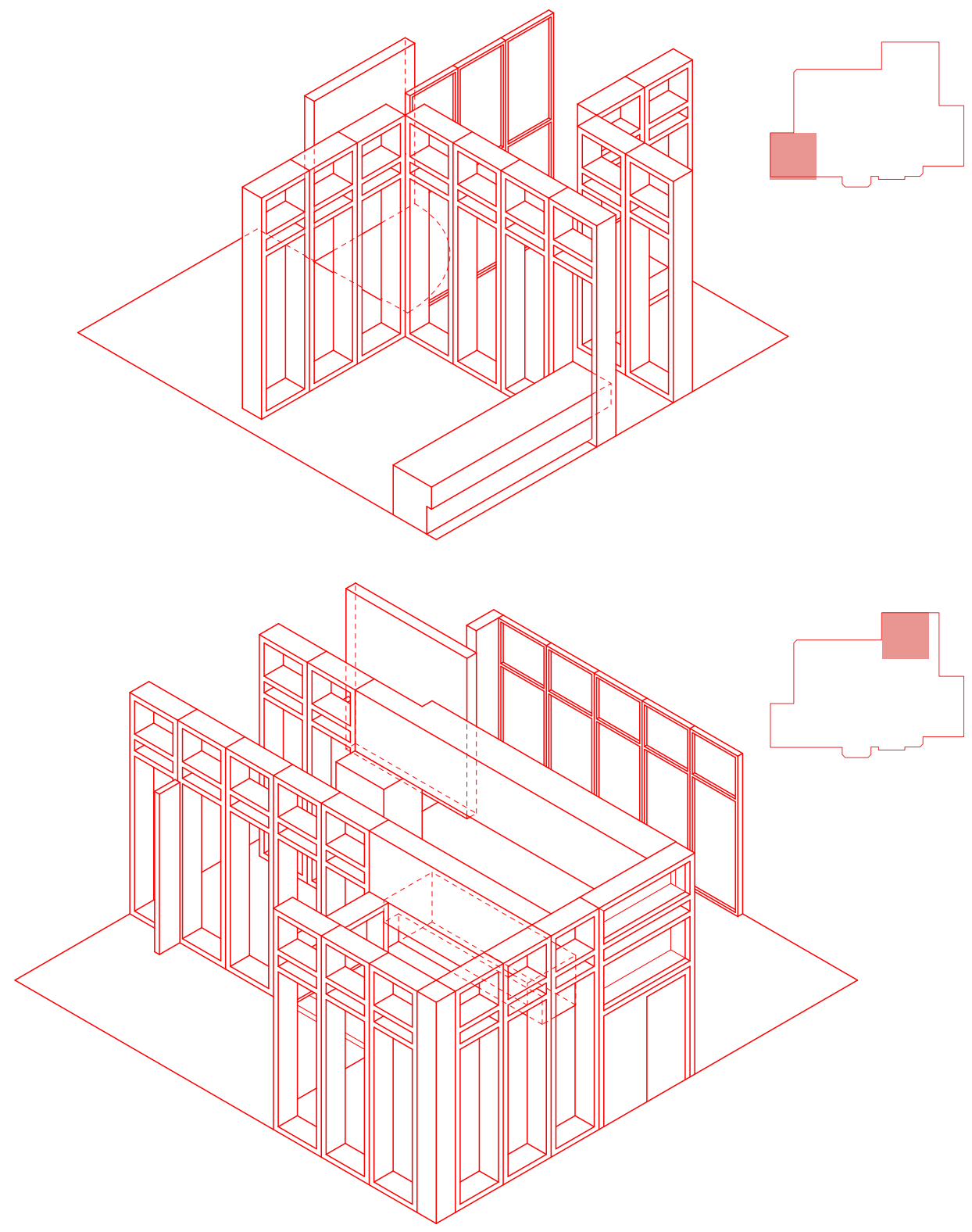
fig. 200, 201, 202: segment of house 2 layers of vertical markers of space from an outer exterior to the inner precincts of the house

162 
stored in house

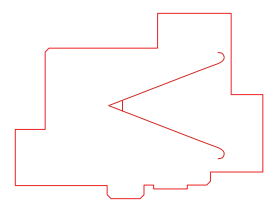

fig. 203: things

through the

courtyard,

perspective

of house 2,

looking through

courtyard

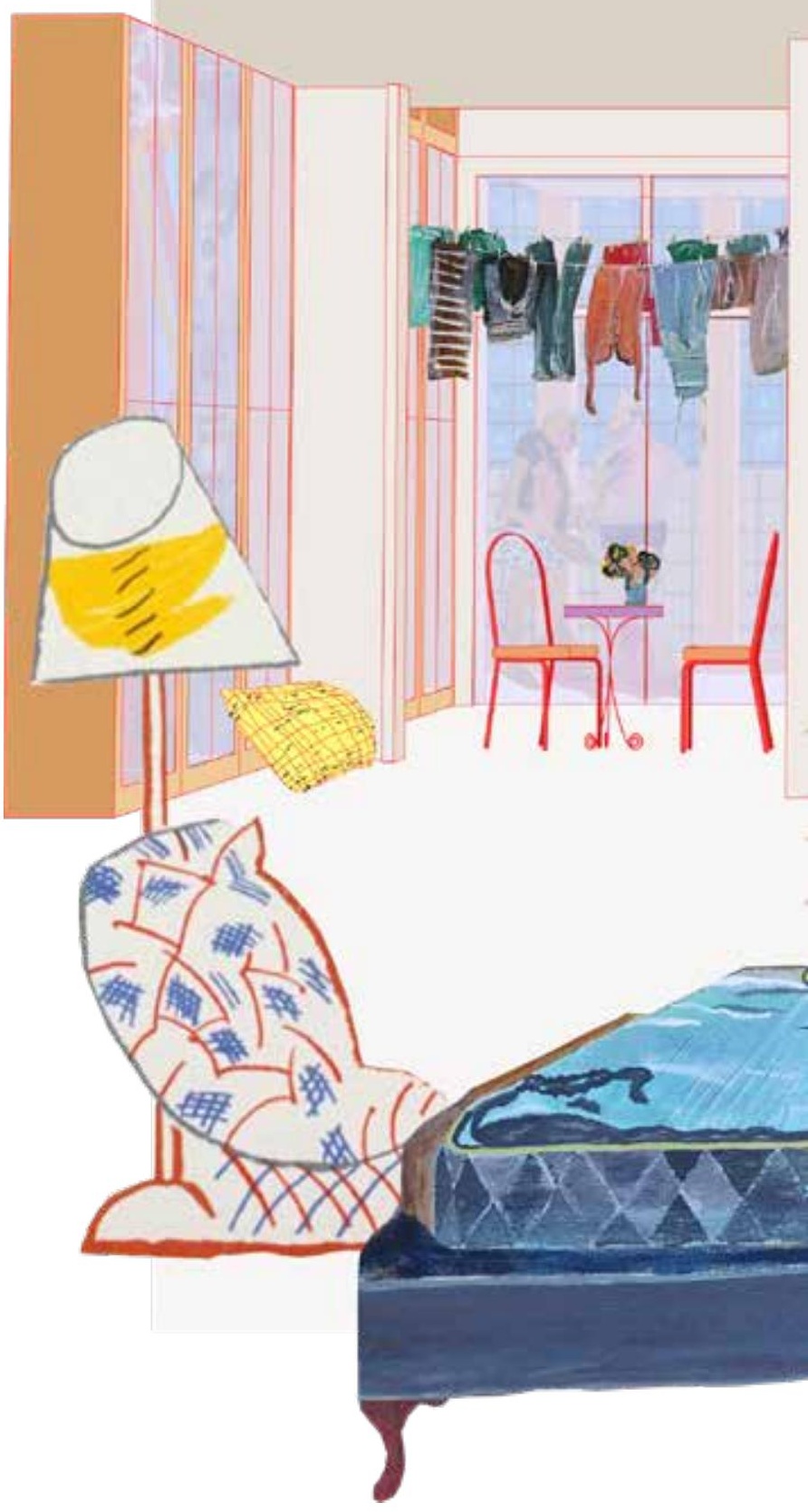




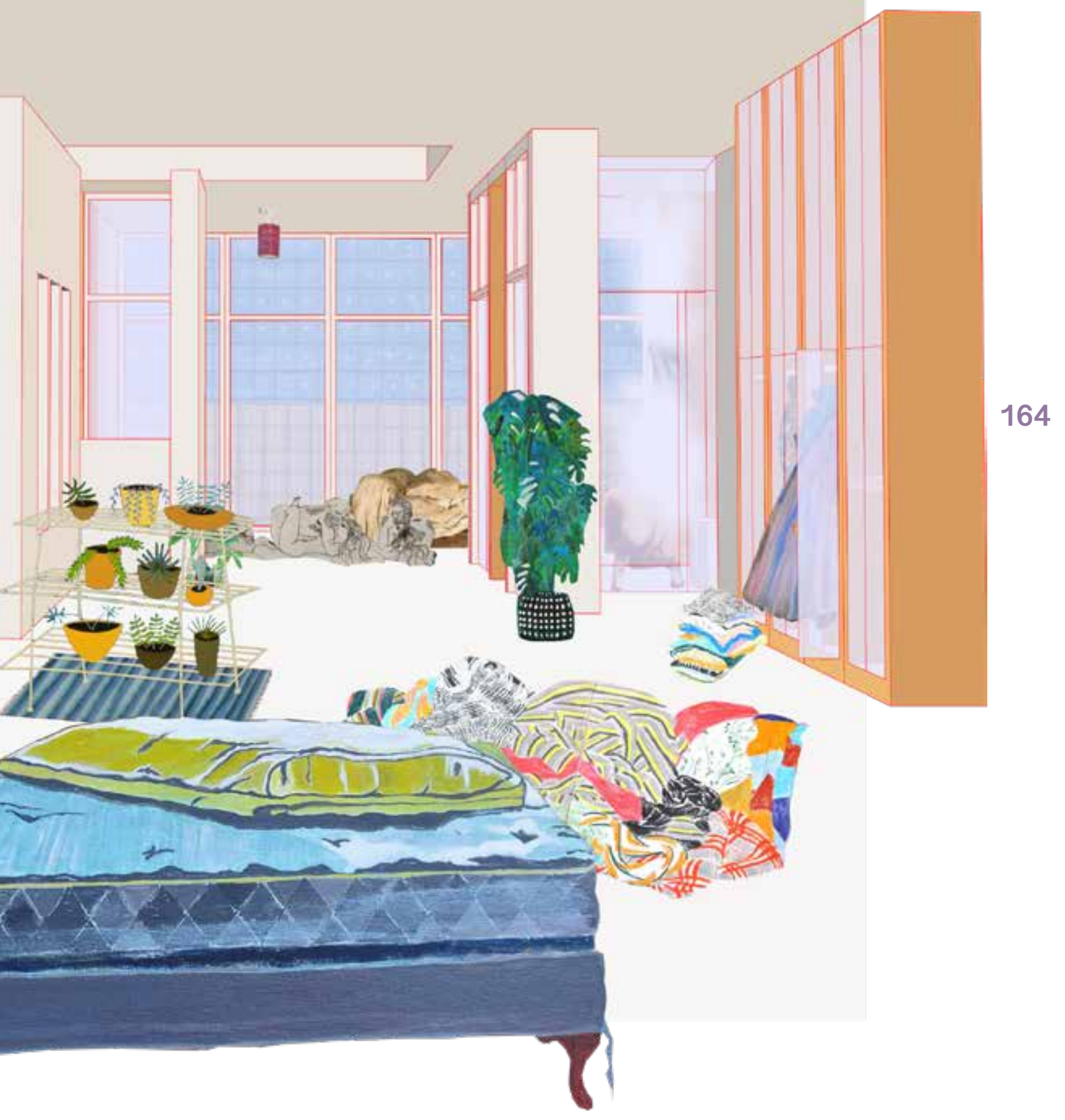


stored in house

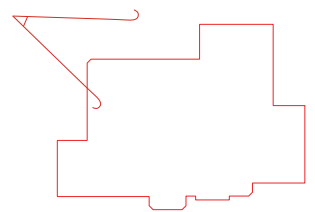

165
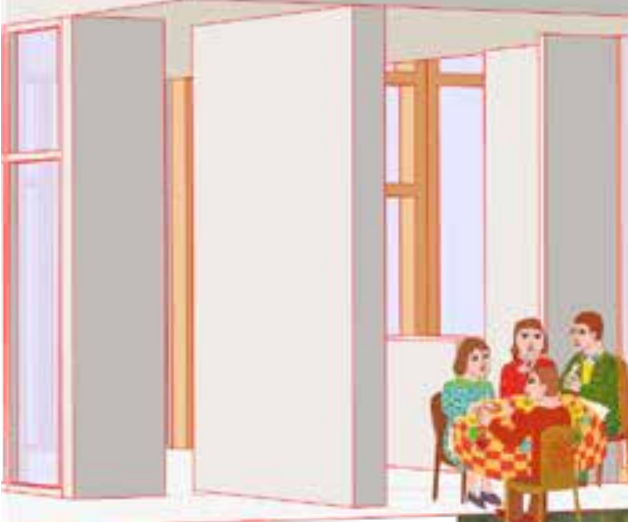
fig. 204:

curb alert, perspective of house 2, from corner b-c 
stored in house
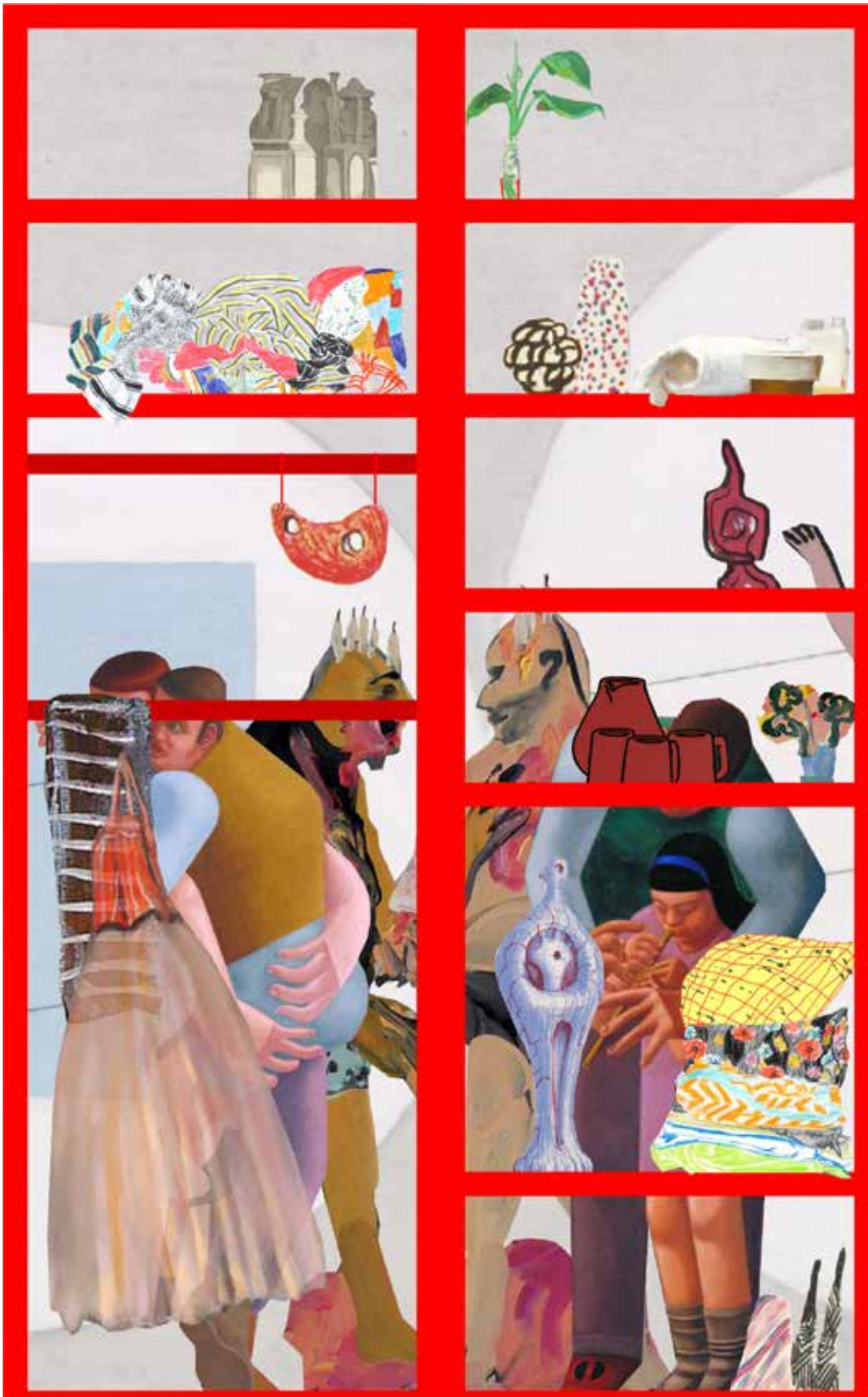


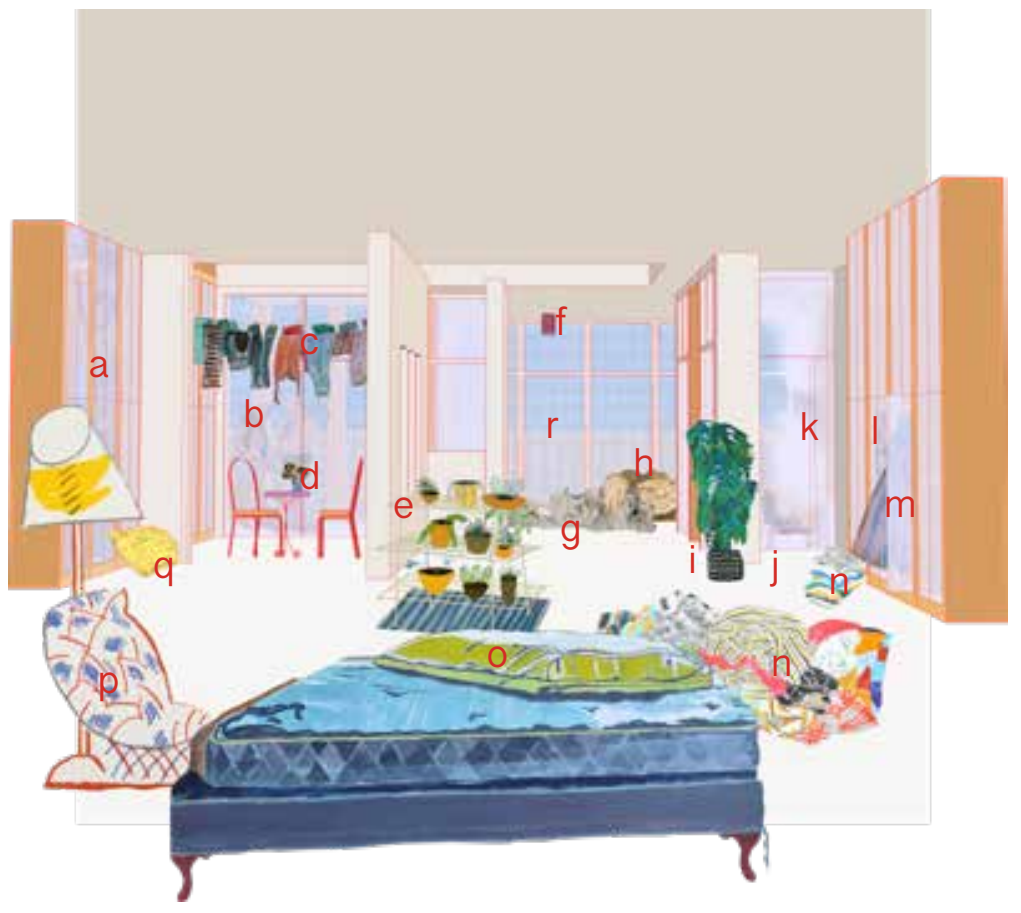

a St Germain by Albert Irvin, 1995

Storage by Laura Vahlberg

b Pink Cake by Tala Madani, 2008

c City Life Laundry Day by Gerald Rader, 2013

d Funky Floral by Brent Baker

e Plant Stand 3 Retro Interior Life Still by Michael Pfleghaar

f Shadows on the ceiling by Johanna Mcweeney

g title not known by Dame Elisabeth Frink, 1970

h An Unmade Bed by Eugene Delacroix, 1828

i Plant by Ksenia Datsiuk

j Shower by Klaas Koster

k Blue Waters by Maria Puzanova

I Wardrobe 16 by Colin Smith, 1995-97

$\mathrm{m}$ Closet of Ballerina Irina Baranova by Zinaida Serebriakova, 1933

n Pile of Clothes by Sophie Kitching, 2009

- A Room with a View without a Painting by John McDonald

p Pembroke Studio Interior by David Hockney, 1984

q Pen on Post-Its by Maike Hemmers, 2017-18

r Summer by Agnes Martin, 1964

Wood 1 by Agnes Martin, 1965 
a Marilyn 11 by katsu, 2014

b Sea and Sky, English Coast by Joseph

Mallord William Turner, 1832

c The Restaurant by John Swanson, 1974

d Study for the Seaside by William Roberts, 1965-66

e Pembroke Studio Interior by David Hockney, 1984

f Breakfast for Alice by Mariia Korotkova

g Earthenware by Patrick Caulfield, 1967

h June in the Austrian Tyrol by John Macwhirter, 1892

i Two Girls Picking Flowers by Cathrine Zernichow

j Parade, Metropolitan Opera by David Hockney, 1981
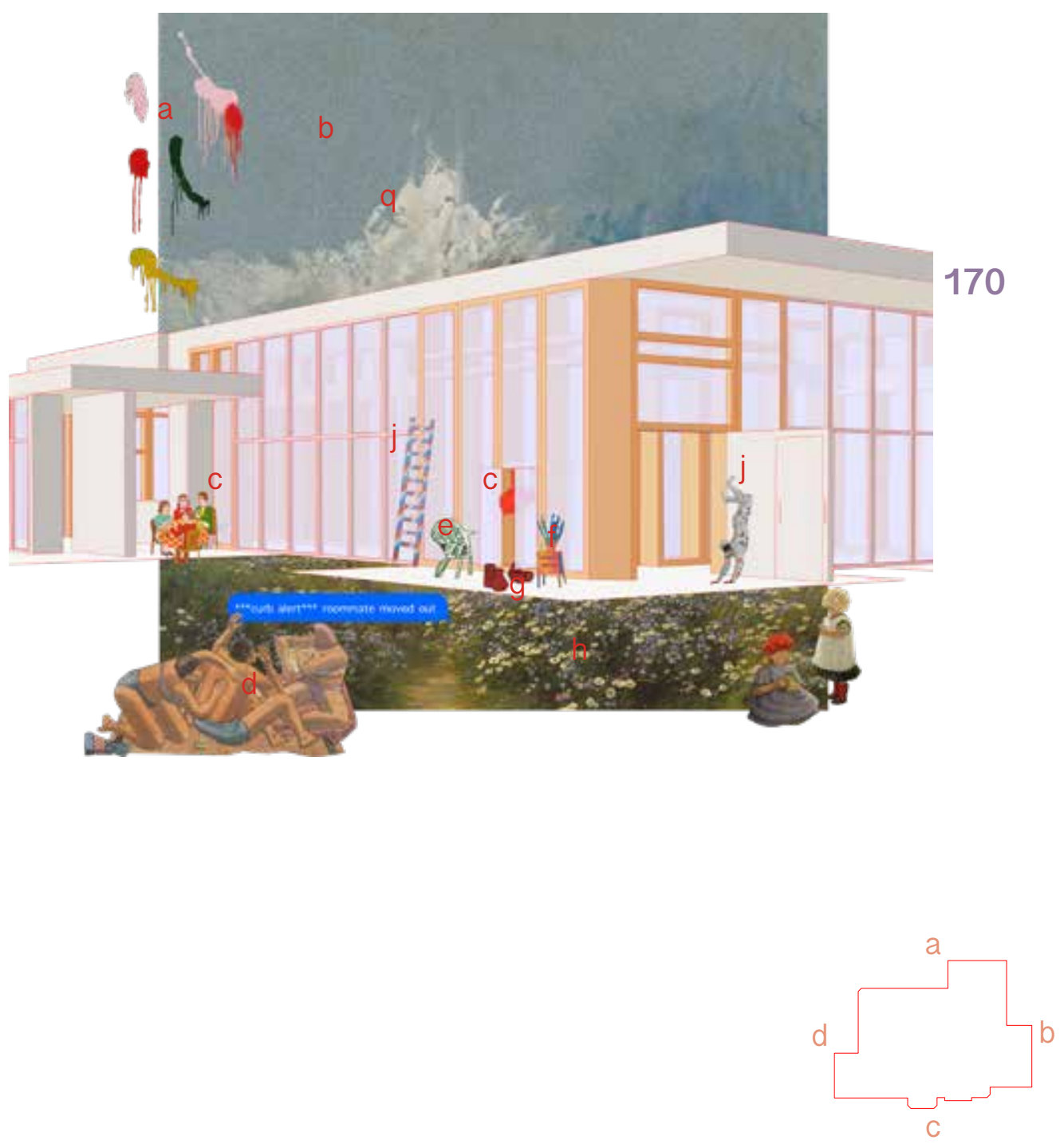
stored in house

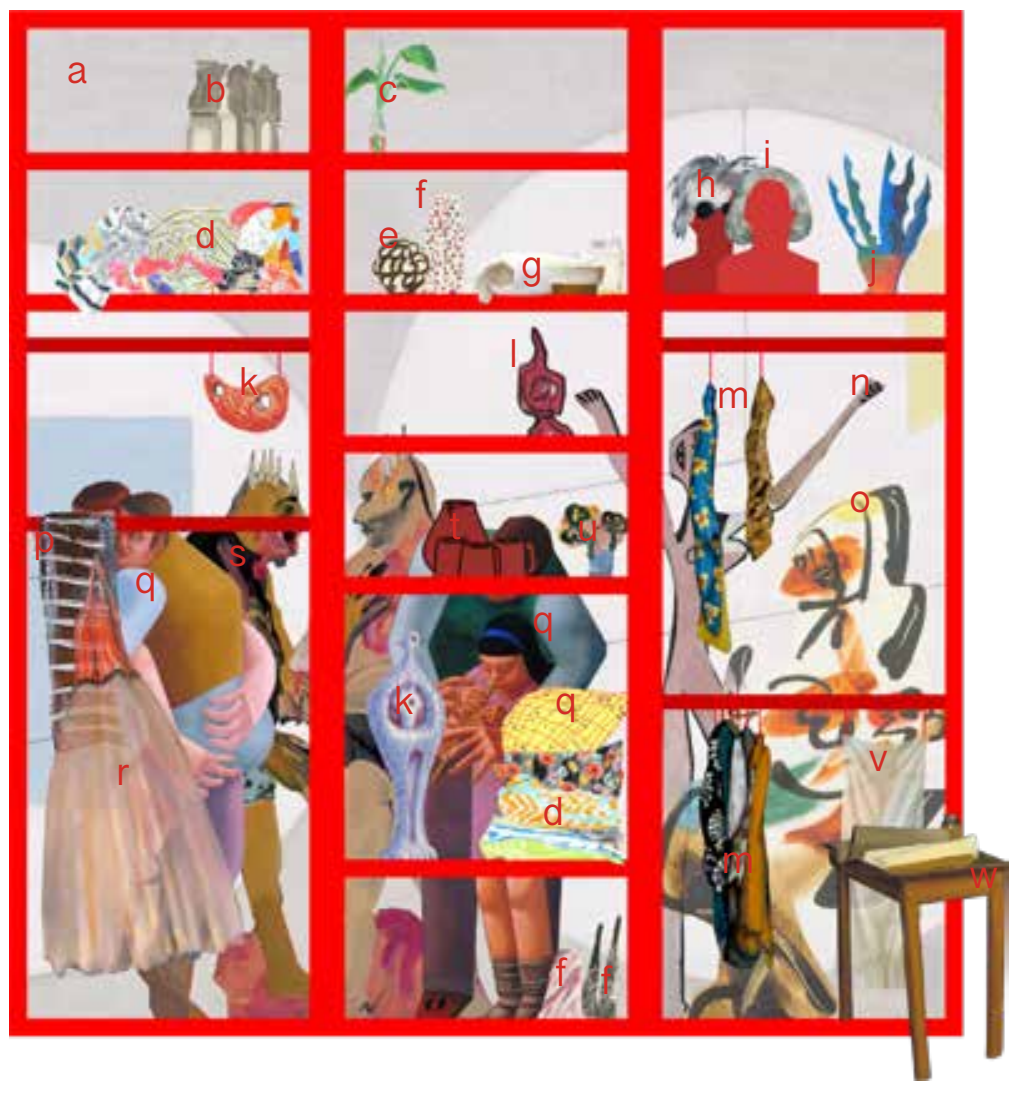


a Quarante Huit Quai d'Auteuil by Winifred Nicholson, 1935

b Still Life with Very Fine Hatching by Giorgio Morandi, 1933

C Growing plants in jars standing on a custom made black locust furniture with a drawer by Kris Barta

d Pile of Clothes by Sophie Kitching, 2009

e Pembroke Studio Interior by David Hockney, 1984

f Drawing for 'Glass Table with Objects' by David Hockney, 1969

$g$ The Shelf: Objects and Shadow - front view by Rodrigo Moynihan, 1982-83

h Self Portrait with Fright Wig by Andy Warhol, 1986

i Self Portrait with Platinum Pageboy

Wig by Andy Warhol, 1986

j Breakfast for Alice by Mariia Korotkova

k Sculptural Objects by Henry Moore, 1949

I Ritual Objects by Kenneth Rowell, 1965

m Wardrobe 16 by Colin Smith, 1995-97

n The Three Dancers by Pablo Picasso, 1925

o Kitchen-maids by Andre Masson, 1962

p City Life Laundry Day by Gerald Rader, 2013

q Playground (The Gutter) by William Roberts, 1934-35

$r$ Closet of Ballerina Irina Baranova by Zinaida Serebriakova, 1933

s Pink Cake by Tala Madani, 2008

t Earthenware by Patrick Caulfield, 1967

u Funky Floral by Brent Baker

v The Penelope by Jose Leonilson Bezerra Dias, 1993

w Studio Interior, Hampstead by Richard Carline, 1918 




\section{towards}

In a sense, the very formation and recording of points toward a queered architecture is antithetical to the dynamism of queerness through the communication of some thing or idea as fixed, and in turn, ruptures in architecture begin to be normalized through this act. However, the points are not to prescribe an architecture that replies to a static state of affairs, but rather specify a lens to look through when considering and moulding the contours of space. Queering architecture is a production of phantasmagoria sensitive to the dominator model of culture that situates all relationships within a struggle of power (hooks, 2004).

The first set of inquiries in this thesis involved interrogating how heteronormativity is nurtured or perpetuated in the context, site, type, program, organization, tradition of architecture, but also in everything else. This requires practice until it is subconsciously processed, because the dynamic oppression of queerness in any sense of the word is embedded in the depths of structures and hierarchies that inform or constrain the ways we can live. These interrogations are to habitually take place even if they have been posed before, as the passage of time sets up a complex assemblage of reality that has never existed in the same state before.

\section{Disruption}

Queered architecture is disruptive. It reacts to what is norm and convention, in architecture, in orientation, in culture. It overturns binaries, turning things inside out, imposing new systems of organization. It reacts to cis-heterosexist constructions that form and sabotage all aspects of social life. Investigations of language and metaphor, of cyberspace, of law - these all hold meaning that queerness can interpret, develop and dismantle. Much like in queer culture, everything is a point of reference, eradicating a hierarchy - architecture is to borrow from everything. This is demonstrated through the references in House 2, like 
toilets and sinks and shelves, that are reformulated from historical placements to challenge the norms of spatial scattering of bodies.

\section{Transience}

Queered architecture accepts ephemerality, or the transient state of occupations of space. It relinquishes the constructedness of private property and reimagines a fluidity amongst distributions of space. The outer edges of built form are not the endings of one architecture and the start of another. "[This] entails a dawning sense of total publicity - that the interiors of buildings are just the deepest reaches of a perpetual exterior that could still be implicated in some future exchange," (Holder, 2017, 160).

In House 2, closet units with doors located on both faces form segments of the perimeter, forming a possibility of exchange beyond between habitants of the house. These units do not visually differentiate themselves in any way from units that live in the interior, dislocating any hierarchy of partitions. Expanses of floor and roof are pulled out of the formal interior to obscure a delineation between inside and outside, and what is house and what is not. Closet space becomes the most penetrable accessible space. They support all the roofs and where they intersect with one another, and are therefore the last standing unit before there is nothing left of the house. In a possible future, an acceptance of the reuse of building, the closet is that central point when facades are stripped back.

Different scales of perceived space vary, from the occupiable space of room boundaries, to a flow through shower room, to the sink counters found inside but also outside, to the ways in which rooms open up to one another and blend. Doors vary in size to facilitate the passage of things and events, large and small. 


\section{Fluidity}

Established forms and elements lose their place as absolute and defined, exercising a fluidity amongst other constituents of an assemblage. A queered architecture plays with known parts to construct new networks of meaning, plays on words, senses, forms, arrangements. Intangible processes are made discernible to then be abstracted again as a method of subversion to form non-normative narratives. Queering breaks the definitive nature of things and the binary conditions that are seemingly inescapable.

\section{Orientation}

Queerness is derived from its concern with orientations, and queer is the catchall of non-normative sexuality and gender. A queered architecture intimately considers how the body moves through space, how it orients itself to

*consider monuments and public buildings, state finances, and overall distributions of wealth and power that enables only a small percentage of people to be truly involved in architectural processes, In this sense, architecture can not be seen as accessible. objects, forms, organizations, and other bodies in order to house something conventionally unintended. How does it restrict motion through space, and is that restriction in situ for a good reason? Considering orientation enables us to contextualize the sites in which we operate.

Architecture is often about power*, and a queered architecture disorients the directions of power in favour of marginalized groups. Queering architecture is a process that begins with the identification and declaration of power imbalances at the intersection of one or more social locations. This is a promotion of intersectionality, of acknowledging that some bodies are acted on alternatively due to their social locations coalescing. Through recognition and consideration of how this imbalance spatially manifests presents the true context of architecture, and subversion and diversion from such practice is how we queer. This involves gestures large and small - a loop of definition and 
abstraction that unveils messes, the undersides of ubiquity, the need to stray from universality. The destabilization of oppressive structures not only emphasizes the engendering of heteronormativity in all facets of life, but promises to delineate space for a proper queer occupation. 




\section{references}

Adler, S., \& J. Brenner. (1992). Gender and space: Lesbians and gay men in the city. International Journal of Urban and Regional Research 16. 24-34.

Age of Consent to Sexual Activity. (2017). Department of Justice. Retrieved from www.justice.gc.ca/eng/rp-pr/otherautre/clp/faq.html

Agrest, D. I. (1996). Architecture from Without: Body, Logic, and Sex. In K. Nesbitt (Ed.), Theorizing a New Agenda for Architecture: An Anthology of Architectural Theory. New York: Princeton Architectural Press. 541-553

Ahmed, S. (2006). Queer Phenomenology: Orientations, Objects, Others. Durham (NC): Duke University Press.

Aitchison, C., \& Jordan, F. (1998). Gender, space and identity: leisure, culture and commerce. Eastbourne: Leisure Studies Assocation.

Assemblage Theory (n.d.) The University of Texas at Austin. Retrieved from www.web.archive.org/ web/20160314011817/http:/wikis.la.utexas.edu/theory/ page/assemblage-theory

Aureli, P. V., \& Tattara, M. (2015). Production/Reproduction: Housingbeyond theFamily.Harvard DesignMagazine:Family Planning, 41. Retrieved from www.harvarddesignmagazine. org/issues/41/production-reproduction-housing-beyondthe-family.

Baghoolizadeh, B. (2018). White Fantasies, Colourful Interiors. Medium. Retrieved from: www.medium.com/s/offbeat/white-fantasies-colorful-interiors-1aeb9439c3f1

Bahn, P., Renfrew, C. (2016). Archaeology: Theories, Methods, and Practice. London: Thames \& Hudson. 
Bailey, F., Barbato, R., Campbell, T., RuPaul, Corfe, S., Post, P., Salangsang, M., McKim, C. (Producer). (2018 January 25). Rupaul's Drag Race: All Stars [Television series]. LA: World of Wonder.

Bell, D., \& Binnie, J. (2004). Authenticating Queer Space: Citizenship, Urbanism and Governance. Urban Studies, 41(9), 1807-1820.

Benson, D. (2014) Then \& Now: Boom Boom Room. Then and Now Toronto. Retrieved from

www.thenandnowtoronto.com/2014/09/then-now-boomboom-room.

Berlant, L., \& Warner, M. (1998). Sex in Public. Critical Inquiry, 24(2), 547-566.

Betsky, A. (1997). Queer Space: Architecture and SameSex Desire. New York: William Morrow and Company.

Betsky, A., \& Kolb, J. (2017). The End of Queer Space? Log 41,13(3), 85-88.

Bill C-75. (2019). Retrieved from www.openparliament.ca/ bills/42-1/C-75/

Blanchfield, C., \& Lotfi-Jam, F. (2017). The Bedroom of Things. Log 41, 12(3), 129-134.

Booher, P. W. (2009) Louis I. Kahn's Fisher House: A Case Study on the Architectural Detail and Design Intent. (Master's thesis). Retrieved from www.repository.upenn. edu/hp_theses/132.

Box Truck Sex. (2017). BOXTRUCKSEX - SHY HOT CHICK FUCKS IN A ONE-WAY MIRRORED TRUCK IN THE PUBLIC [Video]. Pornhub. Retrieved from www.pornhub. com/view_video.php?viewkey=ph58ad87e589b07 
Butler, J. (1990) Gender Trouble. New York: Routledge.

Castricum, S. (2017). When Program is the Enemy of Function... Gender-Nonconforming Experiences of Architectural Space. Architect and Culture, 5(3), 371-381.

Cavanagh, S. L. (2014). Queering Bathrooms Gender, Sexuality, and the Hygienic Imagination. Toronto: University of Toronto Press.

Chambers, S. (2003). Pierre Elliot Trudeau and Bill C-150: A Rational Approach to Homoesexual Acts, 1967-69. (Master's thesis). Retrieved from www.ruor.uottawa.ca/ bitstream/10393/26362/1/MQ79331.PDF

Chauncey, G. (1995). Gay New York: Gender, Urban Culture, and the Making of the Gay Male World, 1890-1940. NY: Basic Books.

Criminal Code (R.S.C., 1985, c. C-46). (2018). Justice Laws Website. Retrieved from www.laws-lois.justice.gc.ca/eng/ acts/c-46/section-159.html

Cole, S. (2018). Trump just signed SESTA/FOSTA, a law sex workers say will literally kill them. Motherboard. Retrieved from www.motherboard.vice.com/en_us/article/ qvxeyq/trump-signed-fosta-sesta-into-law-sex-work.

Colomina, B., \& Bloomer, J. (1992). Sexuality \& space. New York: Princeton Architectural Press.

Colomina, B. (1994). Privacy and publicity: modern architecture as mass media. Cambridge (Mass.): The MIT Press.

Colomina, B. (1999) The private site of public memory. The Journal of Architecture, 4(4), 337-360. 
Colomina, B. (2013). Radical Interiority: Playboy Architecture 1953-1979. Volume, 33. Retrieved from www. volumeproject.org/volume-33-beatriz-colomina-radicalinteriority-playboy-architecture-1953-1979.

Colomina, B. (2014). The Century of the Bed. In Vienna Business Agency (Ed.), The Century of the Bed. Austria: Verlag fur moderne Kunst. 19 - 23.

Cotter, H. (2016). An Artist Redefines Power. With Sanitation Equipment. The New York Times. Retrieved from www. nytimes.com/2016/09/16/arts/design/an-artist-redefinespower-with-sanitation-equipment.htmlutt

Cottrill, J. (2006). Queering Architecture: Possibilities of Space(s). Cheng, R., Tripeny, P. J., \& Association of Collegiate Schools of Architecture. Getting real: Design ethos now. Proceedings of the 2004 Annual Meeting. Washington, DC: Association of Collegiate Schools of Architecture. 359-370.

Crawford, L. (2015). Transgender Architectonics: The Shape of Change in Modernist Space. Farnham, Surrey: Ashgate.

Drury, H., \& Fopp, D. (2019). Pictures, Porn and Fantasy. Real Review, (8), 82-89.

Ellin, N. (Ed.). (1997). Architecture of Fear. New York: Princeton Architectural Press.

For the People Theatres of N.Y. Inc. v. City of New York. (2017). Justia. Retrieved from https://law.justia.com/cases/ new-york/court-of-appeals/2017/59.html

Foscari, G. (2014). Elements of Venice. Lars Mueller. 
Garcia, L. M. (2014). An alternate history of sexuality in club culture. Resident Advisor. Retrieved from www. residentadvisor.net/features/1927.

Gavroche, J. (2016). Queering straight space: Thinking Towards a queer architecture. Autonomies. Web. Retrieved from: www.autonomies.org/2016/10/struggles-for-spacequeering-straight-space-thinking-towards-a-queerarchitecture-4/

Hall-Duncan, N. (2006). Bodyspace: destabilizing geographies of gender and sexuality. London: Routledge.

Hayden, D. (1981). The Grand Domestic Revolution. Cambridge: The MIT Press.

Hayden, D. (1995). The Power of Place: Urban Landscapes as Public History. Cambridge: The MIT Press.

Hayden, D. (1980). What Would a Non-Sexist City Be Like? Speculations on Housing, Urban Design, and Human Work. Signs, 5(3), S170-S187. Retrieved from www.jstor.org/ stable/3173814.

Hemmers, M. (2018). Supporting Intentions of a Sofa Cushion. Site Magazine. Retrieved from www. thesitemagazine.com/read/supporting-intentions-of-asofa-cushion.

Holder, A. (2017). Five Points Toward a Queer Architecture; Or, Notes on Mario Banana No. 1. Log 41, 13(3), 155-160.

hooks, b. (2004). The Will to Change: Men, Masculinity, and Love. New York: Atria Books.

Howarth, S. (2000). Fountain. Tate Modern. Retreived from www.tate.org.uk/art/artworks/duchamp-fountain-t07573 
Jacobson, S.R. (2013). Notes on Sexuality and Space. (Master's thesis). Retrieved from www.dspace.mit.edu/ handle/1721.1/81660.

Jarzombek, M. (2010.) Corridor Spaces. Critical Inquiry, 36, $728-770$.

Johnson-Eilola, J., Selber, S. A. (2007) Plagiarism, originality, assemblage. Computers and Composition, 24(4), 375 - 403.

Kennicott, P. (2018). An art critic explains what the Guggenheim was really saying when it offered Trump a golden toilet. The Washington Post. Retrieved from www.washingtonpost.com/entertainment/museums/ an-art-critic-explains-what-the-guggenheim-wasreally-saying-when-it-offered-trump-a-goldentoilet/2018/01/26/953b49c4-021c-11e8-bb03722769454f82_story.html?utm_term=.bc88a366cc45

Kent, S. (1990). Domestic Architecture and the Use of Space: An Interdisciplinary Cross-Cultural Study. Cambridge: Cambridge University Press.

King, E. (2016). Cupboard Love. Harvard Design Magazine: Shelf Life, 43. Retrieved from www.harvarddesignmagazine. org/issues/43/cupboard-love.

Kogan, T. S. (2007). Sex-Separation in Public Restrooms: Law, Architecture, and Gender. Michigan Journal of Gender \& Law, 14(1), 1-57.

Kolb, J. (2017). Working Queer. Log 41,13(3), 63-66.

Kristiansson, T., Maze, R. \& Schalk, M. (2017). Feminist Futures of Spatial Practice: Materialisms, Activisms, Dialogues, Pedagogies, Projections. Spurbuchverlag. 
Lally, S. (2014). The air from other planets: a brief history of architecture to come. Baden: Lars Mueller.

Lawrence, R. J. (1996). Housing layout reconsidered in societal context: a case study in Switzerland. META JFA, 16 (1-2), 31 - 44.

Le Corbusier. (1986). Towards a new architecture. New York, Dover Publications.

Lico, G. R. (2001). Architecture and Sexuality: The Politics of Gendered Space. Humanities Diliman, 3044. Retrieved from www.journals.upd.edu.ph/index.php/ humanitiesdiliman/article/download/74/56.

Lipsitz, G. (2007). The Racialization of Space and the Spatialization of Race: Theorizing the Hidden Architecture of Landscape. Landscape Journal, 26(1), 10-23.

Liu, C. (2011). The Wall, the Window, and the Alcove: Visualizing Privacy. Surveillance and Society, 9. Retrieved from www.ojs.library.queensu.ca/index.php/surveillanceand-society/issue/view/gss.

Lucarelli, F. (2017). The One-Room Apartment by Cornelius Meyer (1689). Socks Studio. Retrieved from www.socksstudio.com/2017/11/12/the-one-room-apartment-bycornelius-meyer-1689/.

Mangold, W. (2011). Money-Tecture...or How Architecture is Exploited by Capitalism. 99th ACSA Annual Meeting Proceedings: Where Do You Stand. Retrieved from www. apps.acsa-arch.org/resources/proceedings/uploads/ streamfile.aspx? path=ACSA.AM.99\&name=ACSA. AM.99.10.pdf 
Mattern, S. (2016). Before BILLY: A Brief History of the Bookcase. Harvard Design Magazine: Shelf Life, 43. Retrieved from www.harvarddesignmagazine.org/ issues/43/before-billy-a-brief-history-of-the-bookcase.

Middleton, R. (1983). THE ONE-ROOM APARTMENT. AA Files, (4), 60-64. Retrieved from www.jstor.org/ stable/29543363.

Montiel, R. (2018). Common Spaces in Housing Units. Mexico City: Instituo del Fondo Nacional de la Vivienda para los Trabajadores.

Munuera, I. L. (2017). An Organism of Hedonistic Pleasures: The Palladium. Log 41, 13(3), 103-112.

Muschamp, H. (1999). ART/ARCHITECTURE; Updating a Brasserie with Pizazz. The New York Times. Retrieved from www.nytimes.com/1999/08/29/arts/art-architectureupdating-a-brasserie-with-pizazz.html.

Nixon, R. (2013). Slow violence and the environmentalism of the poor. Cambridge, MA: Harvard University Press.

Obniski, M. (2018). Playful Domesticity. In D. Alfred \& M. Obniski (Ed.), Serious Play: Design in Midcentury America, Exhibition Catalogue. Yale University Press, Milwaukee Art Museum, and Denver Art Museum. 23-49.

O. Reg. 332/12: BUILDING CODE. (2018). Ontario. Retrieved from www.ontario.ca/laws/regulation/120332

Pereira, M. (2003). What's in the Archives? Police Raids. The Arquives. Retrieved from: www.clga.ca/newsfeed/ whats-archives-police-raids/ 
Razack, S. H. (2000). Gendered Racial Violence and Spatialized Justice: The Murder Pamela George. Canadian journal of law and society, 15 (02), 91-130.

Ripley, C. (1993a). Safe as Houses. Unpub. manuscript.

Ripley, C. (2017). Strategies for Living in Houses. Unpub. manuscript.

Rendell, J. (2000). Gender Space Architecture: An Interdisciplinary Introduction (B. Penner \& I. Borden, Eds.). London: E \& FN Spon.

Sanders, J. (2017). From Stud to Stalled! Architecture in Transition. Log 41, 13(3), 145-154.

Sanders, J., \& Stryker, S. (2016). Stalled: Gender-Neutral Public Bathrooms. South Atlantic Quarterly, 115(4), 779788.

Sartre, J. P. (1949). Nausea. France: Editions Gallimard. Shi, D. E. (1996). Facing facts: realism in American thought and culture, 1850-1920. New York: Oxford University Press.

Shi, D. (1995). Facing Facts: Realism in American Thought and Culture, 1850-1920. New York: Oxford University Press.

Sigler, J. (2016). Socks and Stocks. Harvard Design Magazine: Shelf Life, 43. Retrieved from www. harvarddesignmagazine.org/issues/43/socks-and-stocks.

Spade, D. (n.d.) About Purportedly Gendered Body Parts. Dean Spade. Retrieved from www.deanspade.net/wpcontent/uploads/2011/02/Purportedly-Gendered-BodyParts.pdf

Spartan Villa. (n.d.) Bernard Tschumi Architects. Retrieved from www.tschumi.com/projects/46/\# 
Spigel, L. (2012). Object Lessons for the Media Home: From Storagewall to Invisible Design. Public Culture. 24, (3 68). 535-576.

Studio Gang. (2018). Arcus Center for Social Justice Leadership Kalamazoo, USA. Biennale Architettura, Venice.

Teitel, E. (2017). As the queer community spreads out, can the gay village remain vital? The Star. Retrieved from www.thestar.com/news/canada/2017/06/25/as-the-queercommunity-spreads-out-can-the-gay-village-remain-vital. html

Trudeau: 'There's no place for the state in the bedrooms of the nation. (n.d.) CBC Digital Archives. Retrieved from www.cbc.ca/archives/entry/omnibus-bill-theres-no-placefor-the-state-in-the-bedrooms-of-the-nation

Ukeles, M. L. (1969). Manifesto for Maintenance Art, 1969. Retrieved from www.arnolfini.org.uk/blog/manifesto-formaintenance-art-1969

The Un-Private House. (1999). Musuem of Modern Art. Retrieved from www.moma.org/interactives/ exhibitions/1999/un-privatehouse/essay.html

Urbach, H. (1996). Closets, Clothes, disclosure. In D. McCorquodale, K. Ruedi and S. Wigglesworth (Ed.), Desiring Practices: Architecture, Gender and the Interdisciplinary. London: Black Dog Publishing.

Ward, M. (2018). 'Trading Spaces' and finding an unlikely queer icon in Hildi Santo-Tomas. Curbed. Retrieved from www.curbed.com/2018/4/5/17200170/trading-spacesdesigners-hildi-santo-tomas.

Ward, R. B. (1992). Women in Roman Baths. The Harvard Theological Review, 85(2), 123-147. 
Wilson, M. (1940). Closets and Storage Spaces. Washington, DC: US Department of Agriculture Farmer's Bulletin no.1865.

Vallerand, Olivier (2014). Making homes, building identities: queer subversions of domestic space, 1994-2014. (Doctoral dissertation). Retrieved from www.digitool.library.mcgill. $\mathrm{ca} / \mathrm{R} /$ - ?func $=$ dbin-jump-full\&object_id=127113\&silo_ library=GEN01.

van den Heuvel, D. \& Gorny, R. (2017). Trans-Bodies / Queering Spaces [Special Issue]. Footprint, 21. Rotterdam: NAI.

Verman, A. (2019). It's about time we ask why men aren't funny. A.Side. Retrieved from www.ontheaside.com/culture/ its-about-time-we-ask-why-men-arent-funny/

Verzier. M. O. (2018). Work, Body, Leisure. Netherlands: Het Nieuwe Instituut \& Hatje Cantz Verlag GmbH.

Vidler, A. (2000). Warped Space: Art, Architecture, and Anxiety in Modern Culture. Cambridge, MA: MIT Press.

Yuko, E. (2018). The Glamorous, Sexist History of the Women's Restroom Lounge. CityLab. Retrieved from www. citylab.com/design/2018/12/history-womens-bathroomdesign-lounge/576742. 
192 


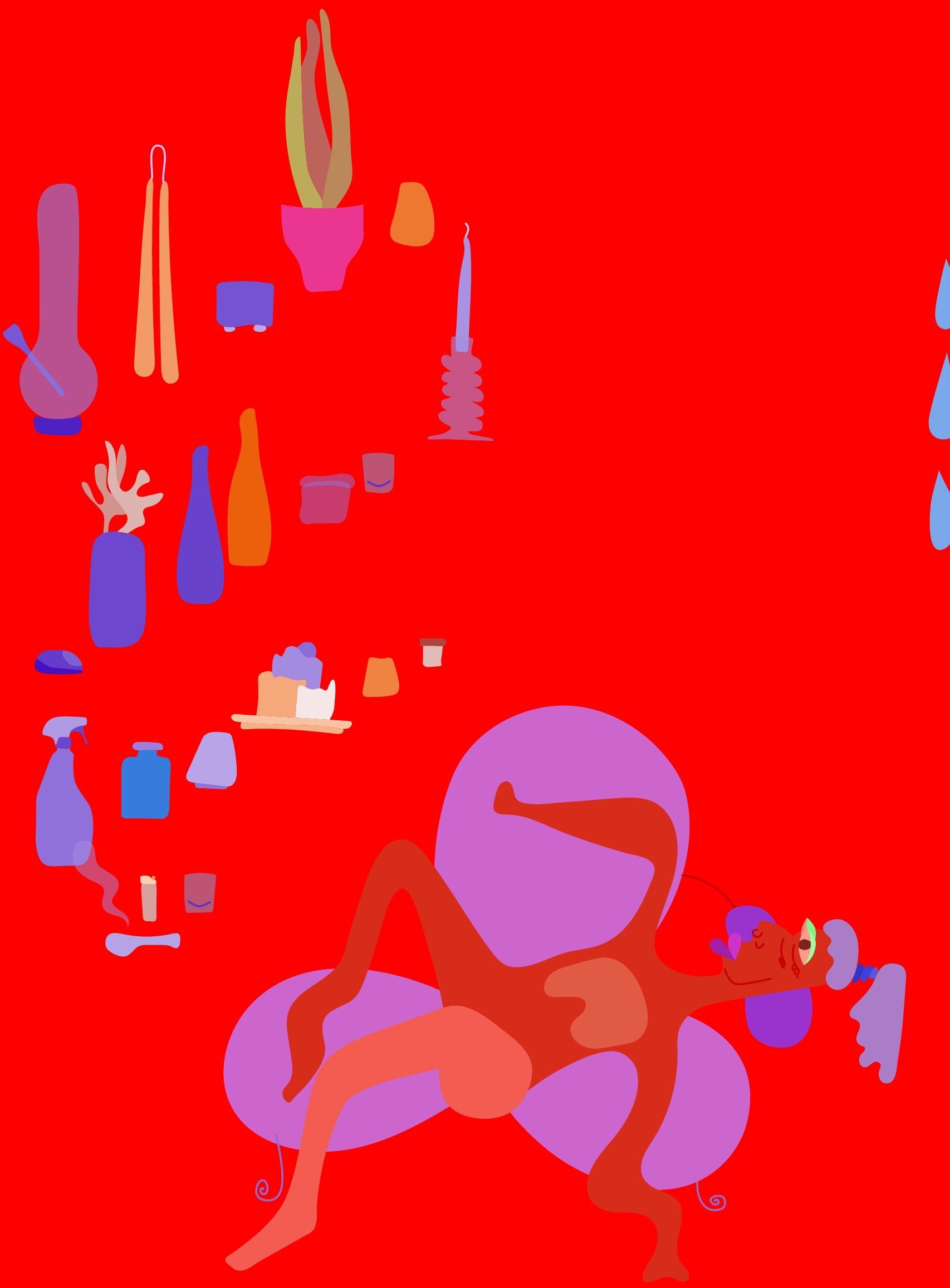

